\title{
Skizzen und Fragmente für eine dekoloniale politische Bildung
}

\subsection{Verortung einer dekolonialen politischen Bildung}

Der hier vorliegende Text zielt darauf ab, Impulse für die Konzeption einer dekolonial ausgerichteten politischen Bildung zu entwickeln, die aus meiner Perspektive als eigenständiges Feld notwendig erscheint und als fundamentaler Bestandteil einer sich als kritisch verstehenden politischen Bildung (Lösch/Thimmel 2010) anerkannt werden sollte. Gleichzeitig kann sie auch als eine Dekolonisierung der gegenwärtig hegemonialen politischen Bildung gelesen werden. Um die Implikationen meiner empirischen Ergebnisse für die politische Bildung zu kontextualisieren, beziehe ich mich im gesamten Kapitel auf bestehende Ansätze dekolonialer - wenngleich natürlich hochpolitisch, nicht explizit der Fachdisziplin der Didaktik der politischen Bildung zugeordneten - Bildungsperspektiven, im deutschsprachigen Raum vertreten beispielsweise durch María do Mar Castro Varela oder Patricia Baquero Torres. Dafür werde ich auch zwei Felder skizzieren, die nicht explizit als dekoloniale Bildungsperspektiven benannt werden, die allerdings große Überschneidungen aufweisen und daher auch zu berücksichtigen sind. Zum einen das Feld der Global Citizenship Education sowie zum anderen rassismuskritische und migrationspolitische Bildung. Im Anschluss an dieses Kapitel zur Verortung einer dekolonialen politischen Bildung werde ich die sich aus den von mir ko-konstruierten Lernendenvorstellungen ergebenden didaktischen Momente darstellen und theoretisch einbetten. 


\subsubsection{Global Citizenship Education}

Der Ansatz von Global Citizenship ist inzwischen in Regierungs-, Zivilgesellschafts- und Bildungsdiskursen prominent geworden (Andreotti/de Souza 2012: 1). Das aus dem englischsprachigen Raum stammende, dazugehörige Bildungskonzept Global Citizenship Education hat auch im deutschsprachigen Raum große Verbreitung gefunden. Der Ansatz vom Globalen Lernen wird hier manchmal als ein Vorläufer, als ein Teilbereich oder als Synonym verstanden. Zwei einschlägige Publikationen für das insgesamt sehr heterogene Feld sind beispielsweise Global Citizenship Education. Politische Bildung für die Weltgesellschaft (Wintersteiner et al. 2014) und für das Globale Lernen Bildung in der Weltgesellschaft: Gesellschaftstheoretische Grundlagen Globalen Lernens (Seitz 2002) oder als Überblick über den Diskurs Globales Lernen in Deutschland (Overwien/Rathenow 2009). Global Citizenship Education kann als Antwort auf eine sich globalisierende Welt und die damit verbundenen Herausforderungen verstanden werden. Der Ansatz zielt darauf ab, in der Schule, Jugendarbeit und Erwachsenenbildung Global Citizenship zu stärken, globale Perspektiven in die Bildungspraxis zu integrieren und Bildung von global citizens zu ermöglichen (Wintersteiner et al. 2014: 37 f.). Wintersteiner et al. zufolge kombiniert Global Citizenship Education dabei „Themen aus der historisch-politischen Bildung, der Friedenserziehung, dem Globalen Lernen, Menschenrechts- und Demokratiebildung, Bildung für Nachhaltigkeit und anderen politischen Pädagogiken“ (ebd.: 38). Dabei seien Fragen ,der Friedenssicherung, der demokratischen Partizipation, der ökonomischen Beziehungen zwischen globalem Süden und Norden, Fragen der Gerechtigkeit“ sowie das „Herausarbeiten von globalen Machstrukturen, welche sich letztlich in allen Themenbereichen widerspiegeln“ (ebd.), zentral. Ziel sei es, Lernende - global citizens - durch Sachkenntnis und die Fähigkeit zu kritischer Analyse in die Lage zu versetzen, ,(Macht-) Strukturen und Zusammenhänge [zu] erkennen und [zu] kritisieren, was der erste Schritt zum bewussten, auf Veränderung zielenden Handeln ist" (ebd.: 39). Dabei sei es eine „wichtige Lernerfahrung“, zu begreifen, „dass es keine ,einheitliche“ Interpretation oder Sichtweise auf ein Thema gibt, sondern dass der eigene Standpunkt die Analyse beeinflusst“ (ebd.). Aus Sicht der Global Citizenship Education sollten mündige global citizens in der Lage sein, ,sich aktiv für ihre Überzeugungen und Werte einzusetzen“ (ebd.: 40). Diese Werte - „Frieden, Menschenrechte, Demokratie, soziale Gerechtigkeit und Gleichheit“" (ebd.) - seien die „Eckpfeiler eines allgemein anerkannten Wertekanons, der sich aus der Arbeit der UN und ihrer Teilorganisationen sowie aus der Erklärung 
der Menschenrechte ableiten lässt“ (ebd.) Dieser Wertekanon sei „weltweit anerkannt“, jedoch gäbe es in ,,verschiedenen Staaten verschiedene Interpretationen“. Ein wichtiger Bestandteil von Global Citizenship Education sei deshalb ,das dialogische Aushandeln und die Verständigung über die Bedeutung von Werten“ (ebd.).

In der englischsprachigen Diskussion wird aus dekolonialer Sicht stark gemacht, dass im sehr heterogenen Feld der Global Citizenship Education oft koloniale Machtstrukturen zugunsten einer vermeintlich neutral-universalistischen Position ausgeblendet werden, was zur Folge hat, dass das proklamierte kritischreflektierte Verhältnis zu Prozessen und Verhältnissen der Globalisierung sich in ihr Gegenteil verkehrt und unkritisch und affirmativ wird:

\begin{abstract}
"In spite of the complexity of contemporary globalization, many of these initiatives seem to echo simplistic us/them, here/there binarisms that have denounced and addressed by postcolonial critique. [...] Thus, despite of claims of globality and inclusion, the lack of analyses of power relations and knowledge construction in this area often results in educational practices that unintentionally reproduce ethnocentric, ahistorical, depoliticized, paternalistic, salvationist and triumphalist approaches that tend to deficit theorize, pathologize or trivialize difference." (Andreotti/de Souza 2012: 1)
\end{abstract}

Dabei zielen diese dekolonialen Kritiken auf eine dekoloniale Reartikulation der Global Citizenship Education, in der Potenziale für die Entwicklung dekolonialer Perspektiven gesehen werden. Dafür muss der Ansatz aber zunächst selbst dekolonisiert werden: "Indeed, much critical work needs to be done to investigate how an agenda for GCE, while it could be identified as a postcolonial move, is still very much implicated in the colonial legacy of education." (Pashby 2012: 9) Ich werde auf diese Perspektiven im Rahmen meiner didaktischen Auswertung in den folgenden Abschnitten zurückkommen.

Auch im deutschsprachigen Raum wurden ähnliche Kritiken formuliert. Zugespitzt hat sich die Auseinandersetzung insbesondere im Zuge der Diskussion um den Orientierungsrahmen für den Lernbereich globale Entwicklung (KMK/BMZ 2015, 2007). 2007 hat eine gemeinsame Arbeitsgruppe aus dem Bundesministerium für wirtschaftliche Zusammenarbeit und Entwicklung (BMZ) und der Kultusministerkonferenz (KMK) den Orientierungsrahmen veröffentlicht, der zum zentralen Referenzrahmen für schulische und außerschulische Bildungspraxis im Feld des Globalen Lernens und der Bildung für Nachhaltige Entwicklung werden sollte. Spätestens im Zuge seiner Überarbeitung im Jahr 2014 war der Orientierungsrahmen der Ausgangspunkt einer dekolonialen Intervention in das Feld. 
Vor der Fertigstellung der überarbeiteten Fassung des Orientierungsrahmens wurde ein von zahlreichen Organisationen, Initiativen, Verbände und Wissenschaftler_innen unterzeichneter offener Brief - Decolonize Orientierungsrahmen! - veröffentlicht (Berlin Postkolonial et al. 2014). Der Vorwurf war, dass die im Vorfeld vielfach eingereichte Kritik - insbesondere ,aus postkolonialen und migrantisch-diasporischen Perspektiven“ (ebd.) - nicht oder nur unzureichend aufgegriffen wurde. Anhand von fünf Punkten wird im offenen Brief die Kritik zusammengefasst. (1) Autor_innen: Die Entstehung des Orientierungsrahmens wird als undemokratisch kritisiert, wobei insbesondere darauf hingewiesen wird, dass kaum Stimmen der Diaspora oder aus dem Globalen Süden aktiv oder passiv einbezogen wurden. (2) Zielgruppe: Implizit und häufig auch explizit wird eine „weiße deutsche Zielgruppe“ (ebd.) angenommen und angesprochen. Dabei würden klare Grenzen von ,,Wir‘ und ,die Anderen“, von ,Eigenem“ und ,Fremdem ““ (ebd.) hergestellt. Die so konstruierten Anderen werden so zum objektivierten Gegenstand von Bildungspraxis der essenzialisierten, hegemonial gemachten weißen deutschen Zielgruppe.

(3) Theoretischer Rahmen: Es werden eurozentrische Wertmaßstäbe universalisiert und kritische Stimmen beispielsweise zum dominanten Verständnis von Nachhaltigkeit ausgeschlossen. Es wird, so die Kritik weiter, eine „homogene deutsche Gesellschaft" imaginiert, die lernen müsse durch „Toleranz, Akzeptanz und Respekt mit Vielfalt" (ebd.) umzugehen. Im Zuge dessen wird das höchst problematische Integrationsparadigma reproduziert und Ausschlussmechanismen individualisiert statt Rassismus als strukturelles Herrschaftsverhältnis einzubeziehen oder zumindest zu benennen. Analysekategorien für das „Verständnis von globalen Verhältnissen wie Gender und Klasse“, „Zusammenhänge zwischen Armut und Reichtum“ oder Konzepte wie Kapitalismus oder Neoliberalismus fehlen zugunsten der unkritischen Reproduktion von Konzepten wie modernisierungstheoretischer „Entwicklung“ und statischer „Kultur“ (ebd.).

(4) Inhalte: Kritisiert wird, dass in der Neuauflage zwar Themen wie „globalisierte Freizeit“ Einzug erhalten haben, die „Themen Machtverhältnisse, Rassismus, Diskriminierung, Ausbeutung, Reichtum und Privilegien“ (ebd.) aber weiterhin fehlen. Der Einbezug vom Thema Kolonialismus wird als absolut unzureichend und ,ahistorisch“ (ebd.) bewertet. Statt koloniale und postkoloniale Aspekte zu thematisieren wird eine ,afrikanische Stimme bemüht, um auch auf die angeblich positiven Seiten des Kolonialismus hinzuweisen“ (ebd.). Antikoloniale Perspektiven von „Kolonisierten“ kommen nur an einer Stelle vor, in Michael Kayoyas sarkastischem Gedicht über die vermeintlichen „Errungenschaften" der Kolonialrassist_innen in Afrika. Dies wird allerdings durch die darauf folgende Aufgabenstellung konterkariert, in der die Schüler_innen darüber 
diskutieren sollen, ,was ein Vertreter der Kolonialmächte Kayoyas Darstellung der Kolonialherrschaft möglicherweise entgegengehalten hätte“ (KMK/BMZ 2015: 215). Statt an der einzigen Benennung antikolonialer Kritik von Kolonisierten darauf hinzuarbeiten, Schüler_innen dazu anzuregen, zuzuhören und sich in diese Position hineinzudenken, wird Kolonialismus ,als akzeptable Perspektive auf die Welt verharmlost" (Berlin Postkolonial et al. 2014). Gefordert wird, die „Geschichten von Versklavung, kolonialer Gewalt, Rassismus und wirtschaftlicher Ausbeutung, aber auch von Selbstbehauptung und Widerstand“ (ebd.) aufzugreifen und die ,,500-jährige - auch deutsche - koloniale Geschichte als unmittelbar die Gegenwart betreffend zu verstehen" (ebd.).

(5) Handlungsoptionen: Begrüßt wird die Ausrichtung an der Handlungskompetenz. Allerdings wird kritisiert, dass der Orientierungsrahmen „offenbar nicht alle Menschen gleichermaßen zum Handeln“ anregen soll. Während diejenigen im Globalen Süden „Probleme haben und entwickelt werden müssen“, sollen ,diejenigen im globalen Norden, die Lösungs- und Konfliktkompetenzen und die Fähigkeit zur Mitgestaltung von Entwicklungsprozessen“ erlangen. Die Handlungsoptionen, die den Schüler_innen aufgezeigt werden, würden sich dabei neben allgemeiner Sensibilisierung auf ,apolitische Handlungsoptionen“ wie „Hilfsprojekte, fairen Konsum und interkulturellen Kontakt“ (ebd.) beschränken, statt beispielsweise Veränderung von Machtverhältnissen, machtkritische Selbstreflexion oder - um auf der ,individuellen Ebene“ zu bleiben - „Zivilcourage“ oder die „Herausbildung einer solidarischen Haltung“ (ebd.) anzustreben.

Die hier dargestellten Einwände und Argumente zeigen, dass Global Citizenship Education, deren hegemoniale Formen auch als Antwort auf dekoloniale Stimmen $\mathrm{zu}$ verstehen sind, bereits durch dekoloniale Interventionen $\mathrm{zu}$ einem Politikum wurden. Außerdem dienen sie der Veranschaulichung der weit über die Diskussion um den Orientierungsrahmen hinausgehenden dekolonialen Kritiken. Bereits vor der Veröffentlichung des Orientierungsrahmens hatte sich beispielsweise an Ansätzen des Globalen Lernens vielfältige Kritik geregt, die sich auch in zahlreichen wissenschaftlichen Artikeln wiederfindet. ${ }^{1}$ Wichtige Impulse für

\footnotetext{
${ }^{1}$ Beispielsweise Der blinde Fleck des Globalen Lernens? Eine rassismuskritische Betrachtung von Konzepten und Arbeitsmaterialien (Geißler-Jagodzinski 2007), Wer mit Zweitens anfängt. Bildung für nachhaltige Entwicklung kann Machtwissen tradieren (Danielzik 2012), Lernziel universale Weiß-heit? - Ein Plädoyer für die Integration einer rassismuskritischen Perspektive in das Globale Lernen (Geißler 2013), Überlegenheitsdenken fällt nicht vom Himmel. Postkoloniale Perspektiven auf Globales Lernen und Bildung für nachhaltige Entwicklung (Danielzik 2013), Eine postkoloniale Analyse von Materialien der entwicklungspolitischen Bildung (Danielzik/Kiesel/Bendix 2013) oder ,Eine Ziege für Afrika! “ Globales Lernen unter postkolonialer Perspektive (Castro Varela/Heinemann 2017a).
} 
eine Veränderung Globalen Lernens geht zudem kontinuierlich vom Verein Glokal aus, der in zahlreichen Broschüren Material für die Bildungspraxis zur Verfügung stellt (Glokal e. V. 2017a, 2017b, 2017c, 2016, 2013a, 2013b). Hingegen plädiert beispielsweise Bernd Overwien dafür, das Feld des Globalen Lernens als heterogen zu begreifen und kritisiert, dass die postkolonialen Einwänden zu pauschal formuliert sind - wobei er nicht die Relevanz der Argumente selbst infrage stellt (Overwien 2019: 2013).

\subsubsection{Rassismuskritische und migrationspolitische Bildung}

Rassismuskritische Perspektiven wurden sowohl als Lerngegenstand als auch als reflexive Strukturkategorie der Lernsituation als notwendig für politische Bildung im Allgemeinen herausgearbeitet (Linnemann/Mecheril/Nikolenko 2013). Migrationspolitische Bildung geht davon aus, dass alle in der Migrationsgesellschaft lebenden Menschen, sich in dieser verorten; dass sie über Vorstellungen verfügen, sich in dieser $\mathrm{zu}$ bewegen, $\mathrm{zu}$ orientieren und $\mathrm{zu}$ positionieren (Lange 2009). Rassismuskritische politische Bildung und migrationspolitische Bildung zielen darauf ab, mit Lernenden die migrationsgesellschaftlichen (inklusive der bildungsinstitutionellen) Machtverhältnisse - die ihnen immanenten Zuschreibungen, Unterscheidungspraxen, Ordnungen natio-ethno-kultureller (Nicht-)Zugehörigkeiten, Normalisierungsweisen, Subjektivierungsformen, etc. problematisierbar zu machen. Rassismuskritische Bildung hat sich in Abgrenzung von bzw. der Auseinandersetzung mit der interkulturellen Bildung und der antirassistischen Bewegung entwickelt. Rassismuskritische Bildung lässt sich aus meiner Sicht nicht zuletzt dadurch charakterisieren, dass sie Rassismus als gesellschaftliche Strukturkategorie thematisiert, die alle Subjekte umfasst. Da es aufgrund der Involviertheit aller keine Außenperspektive auf Rassismus geben kann, geht rassismuskritische Bildung davon aus, dass selbstreflexive Prozesse zentraler Bestandteil von einer Bildung sein müssen, die sich gegen Rassismus richten will.

Das Verhältnis zu einer dekolonialen politischen Bildung erscheint dabei als ineinander verschachtelt, sich überschneidend und ergänzend. Rassismuskritische Perspektiven sind - ebenso wie der systematische Bezug zu Dimensionen der Globalität - fundamentaler Bestandteil einer dekolonialen politischen Bildung. Dekoloniale politische Bildung kann an die vielfältigen Perspektiven rassismuskritischer Theoriebildung und Forschung anknüpfen, welche letztlich auch selbst als dekoloniale Perspektiven angesehen werden können. Umso erstaunlicher ist es, dass es in rassismuskritischen Diskursen zahlreiche Ansätze gibt, 
die meinen, ohne einen expliziten Bezug zu dekolonialen Perspektiven auszukommen. Ausgehend von den von mir empirisch ko-konstruierten Vorstellungen der Lernenden wird deutlich, wie eng im Alltagsverständnis Fragen der Globalität und der internationalen Arbeitsteilung mit Fragen von Migration und migrationsgesellschaftlichen Zugehörigkeitsordnungen verwoben sind. Eine Ausweitung dekolonialer Perspektiven in rassismuskritischen Ansätzen - in der beide Dimensionen zusammengedacht werden - erscheint vor diesem Hintergrund als anstrebenswert und perspektivenerweiternd (Castro Varela 2016; Foroutan 2019: 53; Mecheril 2020).

In aktuellen Diskursen wird allerdings oftmals der Bezug zur Kolonialität des Rassismus als ein (diskursives) Nachwirken der vergangenen Epoche des historischen Kolonialismus konzeptionalisiert. Die implizite Annahme scheint hier zu sein, dass eine fehlende historische Aufarbeitung einen Mangel an Aufklärung verursacht, der wiederum zu diesem Status des immer-noch-da führe. Nach meinem Verständnis des ,post' von postkolonial ist Kolonialität aber als ein Herrschaftsverhältnis zu verstehen, das die Gegenwart strukturiert und sich dementsprechend aktualisiert und transformiert; also eher eine Gegenwärtigkeit der Kolonialität als Nachwehen einer vergangenen Gegenwart. Beispielhaft ließe sich das an den Beiträgen zur den kolonialen Mustern deutscher Arbeitsmigrationspolitik (Ha 2003) oder den kolonialisierenden Effekten des deutschen Integrationsregimes (Ha/Schmitz 2006) aufzeigen. Als theoretische Bezugspunkte sehe ich hier nicht nur die rassismuskritische Bildung im engeren Sinne, sondern auch damit verwandte disziplinäre Perspektiven, wie etwa die Grenzregimeforschung (Hess/Kasparek 2010).

Eine dekoloniale politische Bildung rekonstituiert sich im gegenwärtigen deutschen Kontext also mindestens in Bezug auf die zwei Felder der politischen Bildung, die ich als Global Citizenship Education und rassismuskritische Bildung bzw. migrationspolitische Bildung bezeichne. Dieser Bezug ist vielfältig; so stellen die beiden Diskussionsfelder zum einen Ausgangspunkte und Ideengeberinnen dar. Zum anderen kann eine Perspektive dekolonialer politischer Bildung diese wiederum bereichern und Perspektiven erweitern. Eine dekoloniale politische Bildung als eigenständig akzeptierte Perspektive steht so also nicht in einem Verhältnis der Konkurrenz oder der Vereinnahmung zu diesen beiden Bereichen, sondern viel eher in einem Verhältnis der Allianz, in dem aber der Wert einer eigenständigen Perspektive dekolonialer politischer Bildung sehr wohl hervorgehoben wird.

Wie sich in der empirischen Untersuchung herausgestellt hat, setzen die Lernenden Fragen der Migrationsgesellschaft und der globalen Ungleichheitsverhältnisse in ein enges Verhältnis. Zentrale Aspekte, die sonst oft in ganz 
unterschiedlichen Diskursfelder auftauchen, wie etwa in Bezug auf migrationsgesellschaftliche Verhältnisse, Migrationsbewegungen und Fragen des Grenzregimes sowie die internationale Arbeitsteilung, sind beide Dimensionen stark aufeinander bezogen. Vor diesem Hintergrund sollte migrationspolitische Bildung ihr Spektrum erweitern bzw. mit für eine Stärkung einer Perspektive dekolonialer politischer Bildung eintreten, um ihrem eigenen Anspruch gerechter zu werden, Lernendenvorstellungen eher als Ausgangspunkt zu nehmen, als fachdisziplinäre Trennungen. Ansätze hierzu finden sich zum Teil schon in dem auch auf die migrationspolitische Bildung referierenden Ansatz von Inclusive Citizenship Education. Im Rahmen dieses Ansatzes wurden unter anderem die Frage der (Nicht-)Zugehörigkeit, die Frage des Politischen im Sinne der Infragestellung des Zugehörigkeitsregimes und die Verwobenheit zu anderen - wie zum Beispiel der globalen - Dimension herausgearbeitet (2.3.2). Inclusive Citizenship Education stellt für eine dekoloniale politische Bildung, wie ich sie verstehe, einen wichtigen Bezugspunkt dar. Dabei überschneiden sich migrationspolitische Bildung und Inclusive Citizenship Education insbesondere in Bezug auf die Perspektive auf die lernenden Subjekten. Die Subjekte - und die von ihnen praktizierten Weisen, sich in gesellschaftlichen Verhältnissen zu orientieren, zu bewegen und zu positionieren - werden als Start- und Zielpunkt und dabei auch als Stärke gesehen, von der politische Bildungsprozesse profitieren und lernen können. Das normatives Ziel liegt dabei darin, Bildungsräume zu erschaffen, die es lernenden Subjekten ermöglicht, sich selbst zu mündigen Subjekten zu formen, also an ihrem Vermögen $\mathrm{zu}$ arbeiten, sich selbstbestimmt, reflexiv und handlungsfähig in und zu gesellschaftlichen Verhältnissen verhalten zu können. Wenn die Prämisse dekolonialer politischer Bildung geteilt wird, nämlich dass wir in einer post- und neokolonialen Welt leben, die die Lebenswelten der Subjekte mitstrukturiert, erfolgt hieraus die Aufgabe, dekoloniale Perspektiven in der politischen Bildung zu stärken.

\subsection{Didaktische Impulse für eine dekoloniale politische Bildung vor dem Hintergrund der Schüler_innenvorstellungen}

Im Folgenden werde ich ausgehend von der Analyse der Lernendenvorstellungen Impulse für eine dekoloniale politische Bildung entwickeln. Eine dekoloniale politische Bildung zielt dabei normativ darauf ab, das postkoloniale Erbe in der historischen Selbsterzählung zu einem schwierigen Erbe werden zu lassen (2.3.3.2) und Lernenden Instrumente an die Hand $\mathrm{zu}$ geben, Denkweisen und Identifikationsmuster zu dekolonisieren. Es geht dabei durchaus auch um 
den Umgang einer dekolonialen historisch-politischen Bildung mit dem Lerngegenstand des historischen Kolonialismus, wie ich im ersten Abschnitt (4.2.1) diskutieren werde. Über eine Veränderung des historischen Blicks hinaus geht es zudem in allen folgenden Abschnitten darum, dass eine dekoloniale politische Bildung darauf zielt, die Postkolonialität der Gegenwart anzuerkennen, den Blick auf das Gewordensein der Gegenwart zu verändern, andere Zukunftsvisionen zu ermöglichen und das Erbe für eine Veränderung des Denkens selbst - für die Dekolonisierung des Denkens - nutzbar zu machen. Lara (Gym18) fasst dies in etwas schönere Worte:

\begin{abstract}
„Weil alle denken: ,Heute ist alles wieder gut. Es gibt keine Sklaven. Es gibt keine Kolonien mehr. Es ist alles in Ordnung. ' Aber eigentlich stimmt das ja nicht. [...] Die meisten merken vielleicht nicht, dass Geschichte wirklich passiert ist. [...] Im Bereich Geschichte zum Beispiel die Geschichte mit den Sklaven und so was in der Art halt. Die dunklen Seiten der Geschichte, sag' ich mal. Also natürlich möchte man nicht an das Schlechte aus der Vergangenheit irgendwie erinnert werden. Aber ich finde, man sollte vielleicht ein bisschen was lernen dazu, um vielleicht ein bisschen anders zu denken.“(Lara, Gym18)
\end{abstract}

Mit diesem Vorhaben im Kopf werde ich in den folgenden Abschnitten eine durch die Lernendenvorstellungen inspirierte Skizze einer dekolonialen politischen Bildung entwerfen. Dabei werde ich kursorisch, fragmentarisch, unzulänglich und programmatisch bleiben. Ich werde mich fragen, an welche Momente der Lernendenvorstellungen eine dekoloniale Bildung anschließen könnte, wie didaktische Antworten auf koloniale Lernendenvorstellungen aussehen könnten und inwiefern bisherige Bildungsansätze vor diesem Hintergrund als problematisch erscheinen. Die hier entwickelten Impulse verstehe ich dabei als Diskussionsbeitrag und nicht als einen Vorschlag für ein neues Curriculum, wenngleich es als Forderung für ein solches durchaus herhalten könnte. Dieser Diskussionsbeitrag präsentiert auch keine neue Wahrheit, die an die Stelle der alten tritt. Sie ist, wie Dhawan und Castro Varela die postkoloniale Theorie beschrieben haben, vielmehr ein Werkzeugkasten, aus dem sich eine kritische politische Bildung bedienen kann. Dieser Negation eines universellen Anspruchs liegt neben einer grundlegenden erkenntnistheoretischen Überzeugung in die Begrenztheit jeder Perspektive und Forschung auch die Überzeugung zugrunde, dass die Partialität der Perspektive nicht abstrakt für alle gleich ist, sondern, dass sich innerhalb der Kolonialität die Partialitäten der Perspektive auf spezifische und mit Macht verbundene Weise konstituieren. 
Ich strukturiere dieses Kapitel in vier Abschnitte, die vier verschiedene Dimensionen bezeichnen. Geteilte Geschichte (4.2.1), globale Ungleichheit (4.2.2), migrationsgesellschaftliche Zugehörigkeiten (4.2.3) und Episteme (4.2.4) verstehe ich in der Doppelbedeutung von geteilt als shared und divided (Conrad/Randeria 2002). Diese beiden Bedeutungsdimensionen stehen dabei nicht getrennt nebeneinander. Kolonialität erzeugt Trennungen in einer gemeinsam bewohnten Welt. Dieses Spannungsverhältnis gibt mir die Struktur für dieses Kapitel.

\title{
4.2.1 Geteilte Geschichte( $(n)$ in einer postkolonialen Welt
}

\begin{abstract}
„Weil Afrika war ja mal kolonialbesetzt, [...] die wurden ja von den Europäern, gerade von den Engländern, extrem ausgeraubt. Und ich glaube die wirtschaftliche Lage und auch die Lage von der afrikanischen Bevölkerung wäre um einiges besser, wären die Bodenschätze noch erhalten.“ (Pascal, Gym12)
\end{abstract}

Pascal gehört mit seiner Benennung des Kolonialismus, insbesondere mit seiner Sicht der Relevanz des Kolonialismus für die Gegenwart, zu einer Minderheit unter den Schüler_innen. Er stellt einen Zusammenhang her zwischen dem kolonialen Raub von Bodenschätzen und der aktuellen Situation der ,afrikanischen Bevölkerung". Daran anknüpfend diskutiert er Fragen von Schuld und Gerechtigkeit kontrovers - sowohl in Bezug zu aktueller Reichtumsverteilung als auch zu Migration (3.2.3). Pascal stellt so auf eine spezifische Weise einen geschichtlichen Raum dar, in dem europäische und nicht-europäische Akteure in ein Verhältnis gesetzt werden, das für beide Folgen nach sich zieht. Wobei diese Folgen unterschiedlicher nicht sein könnten, finden sie doch in ein und derselben Geschichte statt.

Sebastian Conrad und Shalini Randeria (2002) haben den Ansatz der geteilten Geschichten als Ansatz für die Geschichtswissenschaft vorgeschlagen. Dieser erscheint für eine dekoloniale historisch-politische Bildung als sinnvoller Ausgangspunkt. Statt Geschichte als in ,in nationalen Teleologien verdichtet“ (ebd.: 10) zu sehen, wird Geschichte hier vielmehr in einer transnationalen bzw. globalen Perspektive als entanglement verstanden. Diese Art globalgeschichtliche Perspektive darf keineswegs mit einer neuen Universalgeschichte verwechselt werden. Geschichte als entanglement nimmt die ,zahlreichen Abhängigkeiten und Interferenzen, die Verflechtungen und Interdependenzen" (ebd.: 17) auf, ohne an die Stelle eine neue, beispielsweise eine universale Kolonialgeschichte zu stellen. Die beiden Autor_innen zielen darauf ab, ,,aus postkolonialer Sicht den Blick 
auf die Verwobenheit der europäischen mit der außereuropäischen Welt“ zu lenken und den „Imperialismus als den gemeinsamen Rahmen der wechselseitigen Konstitution von Metropole und Kolonien“ (ebd.: 10) zu begreifen. Dabei kann es durchaus Aspekte des gesellschaftlichen Lebens geben, die sich besser innerhalb regionaler, nationaler oder internationaler Rahmen verstehen lassen; ,der Grad der Verwobenheit variiert“ (ebd.: 18). Grundlegend infrage stellen Sebastian Conrad und Shalini Randeria aber die vielen geschichtswissenschaftlichen Paradigmen zugrundeliegenden Annahmen, wie etwa die Vorstellung, ,die europäische/westliche Entwicklung sei abgekoppelt vom ,Rest ' der Welt verlaufen und könne daher aus abendländischen Besonderheiten heraus verstanden werden“ (ebd.: 10). Dem Blick auf die Geschichte als die Entwicklung des ,modernen“ Europas sui generis bezeichnen sie als „Tunnelblick“ (ebd.: 16). Vielmehr gehen sie von einem gemeinsamen Entstehungsrahmen der sogenannten Moderne beziehungsweise des Kapitalismus aus; Kolonialität war (und ist) konstitutiv für die Entwicklung sogenannter moderner Gesellschaften. Dies stellt die bis heute auch in antikolonialen oder marxistischen Diskursen virulente Vorstellung des Diffusionsmodells infrage, in dem das Subjekt des Kolonialismus, Europa, und das aufzuoktroyierende Gesellschaftsmodell des Kapitalismus bereits unabhängig von dem Kolonialismus bestanden.

Die These der Verwobenheit ist keineswegs neu und wurde beispielsweise wie Conrad und Randeria anführen - bereits 1944 von Williams vorgetragen, der aufzeigte, dass der europäische Kapitalismus keineswegs in Europa entwickelt wurde, sondern ,,vielmehr auf den wirtschaftlichen Austausch europäischer Kolonialmächte mit den großen Plantagen in der karibischen Welt zurückgeführt werden muss“ (ebd.: 28). Die konsequente Ausbeutung von Rohstoffen und Arbeitskraft in den Kolonien sei die Bedingung der Möglichkeit für die enorme Kapitalakkumulation gewesen, die für die industrielle Fertigung von Textilwaren nötig wurde (ebd.). Der Begriff der geteilten Geschichten bezieht sich dabei auf die Doppelbedeutung von geteilt im Sinne von (a) shared und (b) divided.

(a) Wenn Geschichten unter Einbezug der Globalität als shared angesehen werden, wurden die Gesellschaften der Kolonialmächte ebenso grundlegend durch koloniale Verhältnisse geprägt, wie die Gesellschaften der Kolonisierten. Dies sei Hall zufolge eine der grundlegenden Einsichten postkolonialer Theorien:

„Indeed, one of the principal values of the term 'post-colonial' has been to direct our attention to the many ways in which colonization was never simply external to the societies of the imperial metropolis. It was always inscribed deeply within them - as it became indelibly inscribed in the cultures of the colonized." (Hall 1996: 246) 
Postkoloniale Studien haben diese Einschreibung des Kolonialismus in die Gesellschaften der imperialen Metropolen anhand von zahlreichen Studien in unzähligen Bereichen wie beispielsweise Kunst, Wissenschaft, Politik, Wirtschaft und Alltag nachgewiesen (bspw. Said 1994; Spivak 2012b). Wiederum Stuart Hall veranschaulicht diesen Zusammenhang im folgenden Zitat mit Bezug auf England:

„For centuries, its [British Empire's] wealth was underpinned, its urban development driven, its agriculture and industry revolutionized, its fortunes as a nation settled, its maritime and commercial hegemony secured, its thirst quenched, its teeth sweetened, its cloth spun, its food spiced, its carriages rubber-wheeled, its bodies adorned, through the imperial connection. [...] how deeply intertwined were the facts of colonization, slavery and empire with the everyday daily life of all classes and conditions of English men and women." (Hall 1999: 76)

Als shared werden die geteilten Geschichten insofern gesehen, als dass die kolonialen und imperialen Verhältnisse Menschen kolonialisierender und kolonisierter Gesellschaften in ein Verhältnis zueinander gesetzt haben, sie Teil gemeinsamer Geschichten wurden.

(b) Als divided erscheinen Geschichten, insofern als zum einen das Gemeinsame in der Regel von fundamental unterschiedlichen Standpunkten erfahren wurde und zum anderen insofern diese Verhältnisse konstitutiv auf Abgrenzungen beruhten, die sie hervorbrachten: „Die Verbundenheit der Welt impliziert keineswegs die Abwesenheit von Ungleichheit, Macht und Gewalt [...].“ (Conrad/Randeria 2002: 18) Mit der Entstehung des globalen, kolonialen Raums geteilter Geschichten korrespondiert die Konstruktion von Grenzlinien und Partikularitäten- von dichotomischen Strukturen von , unzivilisiert' und ,zivilisiert' über die Imagination von essenzialisierten Kulturen bis zur Konstruktion und Durchsetzung von Nationalstaaten. Dabei sind die zwei auf den ersten Blick widersprüchlichen Prozesse der kolonialen Globalisierung und der Nationalstaatlichkeit als zwei Seiten ein und derselben Medaille anzusehen. „Die modernen Nationalstaaten erscheinen daher nicht nur als Grundlage und Ausgangspunkt der kapitalistischen und kolonialen Austauschbeziehung, sondern zugleich auch als ihr Produkt." (ebd.: 19).

Das Konzept der geteilten Geschichten oder entangled histories ist in den Geschichtswissenschaften noch immer als Randphänomen zu bezeichnen. Dies geht mit der gesellschaftlichen Nicht-Anerkennung der postkolonialen Situiertheit einher. 
"However, in general, 'Empire' is increasingly subject to a widespread selective amnesia and disavowal. And when it does appear, it is largely narrated from the viewpoint of the colonizers. Its master narrative is sustained in the scenes, images and the artefacts which testify to Britain's success in imposing its will, culture and institutions, and inscribing its civilizing mission across the world." (Hall 1999: 76)

In den Lernendenvorstellungen verweisen zwar einige auf die Geschichte des Kolonialismus, aber nur sehr wenige - drei von 44 - nehmen eine Überblicksperspektive über Teile der Kolonialgeschichte ein und verfügen punktuell auch über Detailwissen (3.4.3). Wie die Nicht-Nennung von Kolonialismus zu verstehen ist, bleibt unklar. Zum einen kann sie als Nicht-Thematisierung gelesen werden, die zum Ausdruck bringt, dass die Schüler_innen nicht viel darüber wissen, ihr Wissen darüber nicht für relevant halten - im Kontext des Sprechens über Globalisierung oder im Allgemeinen - oder es nicht zu ihrem unmittelbar abrufbaren Repertoire gehört.

Die Nicht-Nennung kann aber auch als De-Thematisierung interpretiert werden, also als aktive Auslassung dieses Teils der Geschichte. Die Markierung als De-Thematisierung ist hier nicht als individueller Vorwurf zu verstehen, sondern eher als Kontextualisierung in gesellschaftliche Diskurse. Im Gegensatz zu anderen ehemaligen Kolonialländern spielt der Kolonialismus in hegemonialen Geschichtserzählungen in Deutschland nahezu keine Rolle. Es gibt in Deutschland nicht nur eine massive Abwehr der Auseinandersetzung mit diesem Thema, sondern vor allem auch Ignoranz (Ziai 2016). Die Marginalisierung der Geschichte des Kolonialismus führen Conrad und Randeria auf drei Ursachen zurück. (a) Da das deutsche Kolonialreich von „verhältnismäßig geringer Dauer“ war und die ,oft schmerzlichen Auseinandersetzungen im Zuge der Dekolonisierung nach 1945, die häufig zur Verankerung des kolonialen Erbes im nationalen Gedächtnis beigetragen haben“, in Deutschland nicht stattfanden, wurden „nicht in demselben Maße wie in anderen Gesellschaften Affinitäten und Konflikte, Sehnsüchte und Ängste“ (Conrad/Randeria 2002: 40) ausgelöst. (b) Anders als in anderen Ländern gibt in der Bundesrepublik keine ,größeren Immigrationsgemeinschaften aus den ehemaligen Kolonien“ (ebd.), welche die Erinnerung an die Zeit des Kolonialreiches auf die politische Tagesordnung setzen. (c) Das ,zentrales Ereignis des Holocaust" beanspruchte die Aufmerksamkeit von Wissenschaftler_innen, was „andere Fluchtlinien der deutschen Geschichte als marginal erscheinen“ (ebd.) ließ.

Diese drei Argumente werde ich weiter unten in diesem Abschnitt kritisch diskutieren. Zunächst ist jedoch festzustellen, dass diese drei Argumente nicht mit dem reaktionären Argument verwechselt werden sollten, dass deswegen der 
Kolonialismus weniger oder gar überhaupt keinen Einfluss auf die postkoloniale Situation in Deutschland hinterlassen hat, so wie dies in vielen dominanten Diskursen als „Mittel der Verharmlosung und Relativierung“ (Ha 2010a: 272) eingesetzt wird. Es geht hier vielmehr um eine Erklärung dafür, warum eine Anerkennung des Kolonialismus als fundamentaler Teil deutscher Geschichte und damit verbunden die Anerkennung von Deutschland als einem postkolonialen Raum vor spezifische Probleme gestellt ist. Ebenfalls von entscheidender Bedeutung für eine solche Erklärung ist aus meiner Sicht eine Art nationaler Abwehrreflex; eine Anerkennung des Kolonialismus als fundamentaler Teil der deutschen Geschichte geht auch mit einer Anerkennung der Kolonialität der Verhältnisse einher. Analog dazu und damit verbunden ist vielfach auf die spezifisch in Deutschland auftretende Schwierigkeit verwiesen worden, über Rassismus zu sprechen (Broden 2016: 819; Messerschmidt 2008).

Eine dekoloniale politische Bildung zielt in jedem Fall darauf ab, den historischen Kolonialismus als Lerngegenstand zentral auf die Agenda zu setzen. Sie interveniert damit in einen Streit und positioniert sich darin, indem sie dafür plädiert, das postkoloniale Erbe Deutschlands anzuerkennen (4.2.1.1). Die zweite Forderung an historisch-politische Bildung besteht darin, die Auseinandersetzung mit Erinnerungspolitik und der postkolonialen Situation in Deutschland zum zentralen Lerngegenstand zu machen (4.2.1.2).

\subsubsection{Historischer Kolonialismus als zentraler Lerngegenstand historisch-politischer Bildung}

Der historische Kolonialismus als europäisches Projekt und natürlich insbesondere der deutsche Kolonialismus müssen aus meiner Sicht zu einem zentralen Lerngegenstand politischer Bildung werden. Ich werde an dieser Stelle gar nicht erst versuchen, das Ausmaß der Gewalt, der Zerstörung, des Tötens, der Ausbeutung, der Ausplünderung und der Entwürdigung, die vom von Europa ausgehenden historischen Kolonialismus, dem Sklavenhandel und dem Imperialismus verursacht wurden, in Worte zu fassen. Meine Sprache erscheint mir dem Gegenstand der Geschichte des Kolonialismus allgemein - nicht angemessen. Darüber hinaus sehe ich mich nicht im Stande und auch nicht in der Rolle Überblick darüber zu geben, ohne dabei eine totalisierende Perspektive oder Sprechposition einzunehmen. Eine solche Perspektive - insbesondere wenn sie von einer Position der ehemals Kolonisierenden vorgetragen wird - birgt die Gefahr, über Auslassungen, Unsichtbarmachung oder Vereinnahmung die koloniale Gewalt auf epistemischer Ebene zu reproduzieren. Deutschsprachige, lesenswerte und einfach zugängliche - im Sinne von ohne große Vorkenntnisse verständliche - Überblicke oder Systematisierungen der (deutschen) Kolonialgeschichte gibt es aus einer weißen, 
deutschen Perspektive einige, beispielsweise zu Kolonialismus (2012) allgemein von Jürgen Osterhammel und Jan Jansen oder die Deutsche Kolonialgeschichte (2016) von Sebastian Conrad. Meine Aufgabe sehe ich hingegen darin, konzeptionelle Überlegungen einer historisch-politischen Bildung für eine angemesseneren didaktischen Umgang mit dem Lerngegenstand und seiner Rolle im Bildungsverhältnis zu diskutieren, die im Zusammenhang mit meinen Ergebnissen der empirischen Untersuchung der Gespräche mit den Schüler_innen stehen.

In den letzten Jahren lassen sich erste Anzeichen eines (möglichen) Beginns eines Paradigmenwechsels im Umgang mit dem historischen Kolonialismus in der historisch-politischen Bildung verzeichnen. Die relativierenden und letztlich eher koloniale Annahmen bestätigenden als diese durch historische Auseinandersetzung infrage stellenden Perspektiven beginnen sich teilweise zu verschieben, wie sich beispielsweise anhand von Schulbüchern erkennen lässt (Grindel 2008). Diese Andeutung eines Paradigmenwechsels soll hier keineswegs ein Problem klein reden; ausführlich hat Josephine Apraku (2017) gezeigt, wie die koloniale und rassistische Kontinuität sich auch in Schulbüchern - in dieser Untersuchung in Geschichtsschulbüchern für die Sekundarstufe II zwischen 1970 bis in die Gegenwart - niederschlägt. Doch trotzdem können diese ersten Anzeichen eines Brüchigwerdens als ein Anknüpfungspunkt für einen möglichen, in der Zukunft liegenden Paradigmenwechsel gesehen werden.

Dieser Paradigmenwechsel, für den eine dekoloniale Perspektive eintritt, besteht aus meiner Sicht mindestens darin, dass (i) der deutsche Kolonialismus nicht mehr als irrelevantes Randphänomen abgetan wird, sondern zu einem zentralen Teil deutscher Geschichte bzw. einer entangled history wird; (ii) dass der deutsche Kolonialismus nicht auf die formellen Kolonien beschränkt bleibt, sondern ebenso die vielfältigen kolonialen Eingriffe in nahezu allen Erdteilen zu allen Zeiten der Geschichte des europäischen Kolonialismus seit dem 16. Jahrhundert einbezogen werden, er also als Teil des europäischen Projekts des Kolonialismus konzipiert wird; (iii) dass der Kolonialismus und Imperialismus konstitutiver und irreduzibler Teil der Entwicklung der deutschen Gesellschaft war und diese maßgeblich prägte; (iv) dass der Kolonialismus nicht durch die Übernahme kolonialer Ideologien verharmlost oder sogar verteidigt wird, was eine Auseinandersetzung mit konstitutiven Elementen der Geschichtswissenschaft und ihrer Kolonialität und Eurozentrismus voraussetzt; und (v) dass der Kolonialismus nicht als eine einseitige Aktion der Kolonisierenden als einzigen Akteuren, sondern vielmehr als eine widersprüchliche Herrschaftsstruktur mit vielen, auch ambivalenten Akteurspositionen gesehen wird, ohne dabei die Gewalttätigkeit dieser Struktur und die von ihr Privilegierten aus dem Blick zu verlieren. 
(i) Die Geschichte des Kolonialismus als konstitutives Element historischpolitischer Bildung

Eine dekoloniale politische Bildung setzt sich dafür ein, dass der Kolonialismus zu einem zentralen Lerngenstand wird, nicht zuletzt, da seine Auswirkungen die globalisierten Lebenswelten der Schüler_innen zutiefst prägen. Dafür stellt eine Revision der national fokussierten Perspektive in den Geschichtswissenschaften und der historisch-politischen Bildung eine Voraussetzung dar, zumal auch die Ausbildung der Nationalstaatlichkeit selbst als Teil des Prozesses von Globalisierung, Kolonialismus und Imperialismus - „die Globalisierung des Nationalstaats“ (Conrad 2010: 316) - verstanden werden kann. Kenntnisse über die Geschichte des Kolonialismus erscheinen so als Voraussetzung, um auch die gegenwärtigen Verhältnisse und Konflikte zu verstehen, sich zu orientieren und die eigenen Vorstellungen zu Geschichte und Gegenwart in einer globalen Welt reflektieren zu lernen. Auch in der Ausbildung von zukünftigen Lehrkräften des Feldes der historisch-politischen Bildung muss der historische Kolonialismus einen größeren Stellenwert einnehmen. Dabei geht es aber nicht nur um die Frage des quantitativen Wissens, sondern insbesondere auch um konzeptionelles Wissen, das für eine historische Auseinandersetzung mit dem Kolonialismus und seiner Auswirkungen auf die Gegenwart ebenso entscheidend ist.

\section{(ii) Den Blick der Geschichte des Kolonialismus über den Tellerrand der formalen Kolonien}

Die Reduktion des deutschen Kolonialismus auf Afrika durch die Schüler_innen korrespondiert mit der zentralen Rolle, die die vier deutschen afrikanischen Kolonien im Vergleich zu den asiatischen und ozeanischen Kolonien im Deutschen Kolonialreich einnahm. Dieser Aussage liegt jedoch eine Begrenzung des Begriffs des Kolonialismus auf die formalen Kolonien zugrunde. Für einen (didaktischen) Blick auf die differenzierten und vielfältigen Geschichten historischer Kolonialismen ist es wichtig, den Blick nicht auf die formalen Kolonien des deutschen Reiches zu beschränken. Doch schon die Auseinandersetzung mit den formalen Kolonien ist voller Widersprüche, Ambivalenzen und vielfältigen Formen der Rückwirkung auf die kolonisierende Gesellschaft. Schon innerhalb dieses Rahmens muss von „Kolonialismen im Plural“ (Conrad 2016: 15) gesprochen werden. Sebastian Conrad schlägt hier eine mögliche Systematik zur Analyse vor, obgleich diese ihrem Gegenstand nicht gerecht wird, und er auf die Grenzen der eigenen Perspektive verweist: Beispielsweise Togo kann so als Beherrschungskolonie, Kiatschou als Stützpunktkolonie und Deutsch-Südwestafrika teilweise als Siedlerkolonie charakterisiert und so unterschiedliche Kolonialpraktiken sichtbar gemacht werden (ebd.: 14). 
Conrad plädiert aber für ein breiteres, die formale Definition übersteigendes Verständnis von Kolonialismus, das allerdings ,seine Spezifik“ nicht verlieren dürfe, um nicht „unklar und unscharf“ (ebd.: 15) zu werden. Unter differenzierter Einbeziehung historischer Forschungen schlägt er vor, ,territoriale Herrschaft, die geographische Distanz und die rechtliche Fixierung des kolonialen Status“ (ebd.) nicht zur Voraussetzung zu machen, Interaktionen als kolonial zu klassifizieren. Der koloniale Charakter von Interaktionen müsse nach ihm - in Abgrenzung zu einem allgemeinen Begriff von Herrschaft - hingegen die Voraussetzungen erfüllen, dass ,1. imperiale und kolonisierte Gesellschaften unterschiedliche sozio-politische Ordnungen aufweisen, 2. [sie] auf eine unterschiedliche Geschichte zurückblicken und 3. [sie] seitens der Kolonisatoren auch durch die Vorstellung eines unterschiedlichen Entwicklungsstandes voneinander getrennt" (ebd.: 15 f.) imaginiert werden. Vor diesem Hintergrund erscheinen zahlreiche Aspekte als relevant, wie etwa die deutsche Beteiligung am transatlantischen Sklavenhandel und der Aufbau kolonialer Handelsbeziehungen seit dem 17. Jahrhundert im Kontext der kurbrandenburgischen Kolonie Groß Friedrichsburg auf dem heutigen Gebiet Ghanas (van der Heyden 2001); die Beteiligung der deutschen Hansestädte am transatlantischen und globalen kolonialen Handel $^{2}$ (Weber 2004); der Aufbau des Reichtums großer deutscher Unternehmen, wie etwa der Nordwolle, auf der Grundlage großer kolonialer Ländereien in diesem Fall in Argentinien; die Auswanderung von Deutschen nach Süd- und Nordamerika, wie etwa nach Brasilien im 19. Jahrhundert (Conrad 2010: 229 ff.), ihre massive Beteiligung an dortigen Kolonisierungsprozessen sowie die Wirkung dessen für die kolonial beeinflusste Etablierung vom deutschnationalistischen Arbeitsethos - um die in meinem Imaginationshorizont zuerst auftretenden Aspekte zu nennen. Die Kontingenz der Beispielauswahl dieser Liste kann daran aufgezeigt werden, dass ich als Kind mit meinen Großeltern am Emder Delft auf denjenigen Kanonen herumgeklettert bin, die im 17. Jahrhundert die Festung Großfriedrichsburg verteidigen sollte und die dort bis heute an die vermeintlich ruhmreiche Kolonialgeschichte erinnern. Die Liste ließe sich sehr lange fortsetzen und die unstrukturierte Darstellung verweist dabei auf ein Forschungsdesiderat der Verstrickung Deutschlands in die Geschichte der Kolonisierungsprozesse außereuropäischer Gesellschaften jenseits der formalen Kolonien. Klar ist dabei, dass

\footnotetext{
${ }^{2}$ Besonders hervorzuheben sind hier die bestehenden Bildungsprojekte, die gemeinsam mit Schüler_innen oder Studierenden in Prozessen des forschenden Lernens, die lokale Verbindung zur Geschichte von Versklavung und kolonialen Handelsbeziehungen bearbeiten. Beispielsweise im Projekt ,Gewebe der Sklaverei` gingen Schüler_innen gemeinsam mit Wissenschaftler_innen auf die lokale Spurensuche nach kolonialen Verstrickungen und Widerstandsgeschichten in Bezug auf die Eingebundenheit ihres lokalen Kontextes Bremen in den globalen Sklavenhandel.
} 
Deutschland auch jenseits seiner formalen Kolonien in vielfältigen Formen am europäischen Kolonialismus beteiligt war und dieser nicht als in national getrennte Entitäten, sondern vielmehr als „ein europäisches Projekt“ (Conrad 2016: 16) verstanden werden sollte. Eine solche Perspektive hebelt die vielfach vorgetragenen Argumente aus, die die Geschichte des deutschen Kolonialismus mit Bezug auf die verhältnismäßig geringe Dauer relativieren; obwohl bereits die „,neuere kulturgeschichtliche Forschung gezeigt hat, dass die Rolle des überseeischen Kolonialismus“ der formalen Kolonien ,nicht so marginal war, wie die ältere Literatur“ (Conrad 2010: 50) vermuten ließ.

Um die deutsche Verstrickung in das europäische Projekt des Kolonialismus und zwar seit seines Beginns - zu veranschaulichen, sei hier ein weiteres Beispiel angefügt. Vom Geschichtsunterricht über Darstellungen in Publikationen für die Didaktik einschlägiger Verlage wie etwa Klett bis hin zu wirtschaftshistorischer Forschung und musealer Ausstellungspraxis werden die Augsburger Familien Fugger und Welser als erfolgreiche, mutige und nachahmenswerte Kaufleute und Finanziers dargestellt, die auch den ,Mut' gehabt hätten, sich am überseeischen Handel in der ,neuen Welt' ${ }^{`}$ zu beteiligen (Terkessidis 2019: 19 ff.). Tatsächlich beteiligten sie sich an einer ,portugiesischen Plündertour“ an den heutigen Küsten von Kenia und Tansania, beteiligten sich am Handel mit versklavten Menschen, wie etwa 1528 mit 4000 Versklavten, führten deutsche Besiedelungsprojekte in Venezuela durch, insbesondere um die dort ansässigen Menschen zu versklaven, und schlugen mehrere Aufstände einheimischer Menschen brutal nieder (ebd.). Bartholomé de Las Casas, Dominikanermönch und spätere Bischof von Chiapas kommentierte die Kolonialpraktiken der Welser in seinem berühmten Bericht von der Verwüstung der westlichen Länder von 1542 so:

\footnotetext{
„Sie [er nennt die Deutschen hier nur ,eingefleischt Teufel“, MK] wüteten weit grausamer unter ihnen [den Ureinwohner_innen, MK], als alle bereits erwähnten Barbaren; ja noch viehischer und rasender, als die blutgierigsten Tiger und wütigsten Wölfe und Löwen. Vor Geiz und Habsucht handelten sie weit toller und verblendeter, als alle ihre Vorgänger, ersannen noch abscheulichere Mittel und Wege, Gold und Silber zu erpressen, setzten alle Furcht vor Gott und dem Könige, und alle Scham vor Menschen hintenan; und da sie so große Freiheiten genossen, und die Jurisdiktion des ganzen Landes in Händen hatten, so vergaßen sie beinahe, daß sie Sterbliche waren." (Las Casas 1542, zitiert nach Terkessidis 2019: 20)
}

Grundlegend erweitert wird der Horizont einer dekolonialen Geschichtsperspektive auf die deutsche Beteiligung am historischen Kolonialismus nochmals, wenn die Kritik des - vom kanadischen Historiker Robert L. Nelson (2009) so bezeichneten Salzwasser-Modells kolonialer Geschichtsschreibung ernst genommen wird. Diese 
Kritik zielt darauf ab, dass auch innereuropäische Prozesse als Kolonialisierung verstanden werden sollten. Für eine Geschichtsschreibung im deutschen Kontext würde dies bedeuten, die zentrale Rolle, die der ost- und südosteuropäische Raum gespielt hat, herauszuarbeiten und vor diesem Hintergrund sowohl die National- als auch die Kolonialgeschichte Deutschlands überdenken zu müssen. Dieser komplexen Fragestellung werde ich mich skizzenhaft im kommenden Abschnitt (4.2.1.4) zuwenden.

\section{(iii) Der Kolonialismus prägt(e) maßgeblich die deutsche Gesellschaft}

Effekte des Kolonialismus auf die deutsche Gesellschaft werden von den Schüler_innen - außer bei durch die ökonomische Frage des durch den Kolonialismus entstandenen Profits und durch die in Beziehung zur Geschichte des Kolonialismus gesetzte Existenz von Rassismus - nicht direkt angesprochen; die beiden Aspekte werde ich an späterer Stelle diskutieren (4.2.2; 4.2.3). Die Möglichkeit, die Geschichte der deutschen Gesellschaft über diese Aspekte hinaus, als vom Kolonialismus maßgeblich beeinflusst zu sehen, erscheint aber aus einer dekolonialen Perspektive als höchst relevant. Die deutsche Gesellschaft muss ebenso als postkolonialer Raum verstanden werden, wie die ehemals kolonisierten Gesellschaften - wenn auch von einer grundlegend anderen Perspektive aus. Sebastian Conrad spricht davon, dass kulturgeschichtliche Ansätze - deren Sichtbarkeit aus meiner Perspektive auf die jahrzehntelangen Interventionen selbstorganisierter Gruppen zurückgehen - verdeutlicht haben, dass der Kolonialismus „keine Einbahnstraße“ (Conrad 2010: 43) gewesen ist. Die Effekte des Kolonialismus auf die deutsche Gesellschaft sind dabei weniger als „Rückwirkungen“ als vielmehr als „gemeinsame Konstituierung der modernen Welt innerhalb des kolonialen Kontextes“(ebd.) zu verstehen.

Ganz allgemein kann beispielsweise aus Sicht der Weltsystemtheorie von Immanuel Wallerstein der Kolonialismus als konstitutiv für kapitalistische Entwicklungen gesehen werden. Sebastian Conrad zufolge erscheint auch die - vordergründig als das Gegenteil von Globalisierung oder kolonialer Globalität erscheinende Form der Nationalstaatlichkeit und die Entstehung und Konstitution nationaler Gesellschaftsordnungen als Effekt der „,kolonialen Moderne“(Conrad 2010: 65 ff.). Diesen allgemeinen Thesen ist aus meiner Sicht zuzustimmen, was aber keinesfalls eine detailliertere, konkretisierende Sicht auf die Verwobenheiten der Geschichten der deutschen Gesellschaft mit dem Kolonialen ersetzt. Der Kolonialismus prägte selbstverständlich die deutsche Gesellschaft maßgeblich auf ökonomischen und nationalpolitischen Ebenen. Doch prägte er ebenso kulturelle und symbolische Prozesse nahezu aller Lebensbereiche auf eine grundlegende Weise. Trotz der zahlreichen Studien, die die Verwobenheit lokaler oder nationaler Prozesse mit der 
Geschichte des Kolonialismus herausarbeiten, bestehen hier nach wie vor riesige Forschungslücken. In den Blick geraten sind beispielsweise Kolonialwarenläden (EDEKA stand übrigens für ,Einkaufsgenossenschaft deutscher Kolonialwarenhändler'), Völkerschauen von Hagenbeck über die Oldenburger Dobbenwiese bis zum Oktoberfest, Kolonialliteratur vom, edlen Wilden “ Winnetou bei Karl May über Pippi Langstrumpfs Taka-Tuka-Land über die Rezeption des kolonialen, modernekritischen Romans Papalagi von 1920 im Alternativmilieu der 1970 und 80er Jahre bis zu Fontanes Effi Briest, lokale und nationale Denkmäler, Museumsgüter und -ausstellungen usw. (für weitere Beispiele vergleiche beispielsweise den Band Kolonialismus hierzulande, herausgegeben von van der Heyden und Zeller (2007)). Diese Beispiele sind als Ausdrücke der konstitutiven Rolle zu verstehen, die der historische Kolonialismus für die Konstruktion von Individualisierungsweisen, Vergemeinschaftungsweisen und Denkweisen in kolonisierenden Ländern, und auch der deutschen Gesellschaft, hatte und hat (Kleinschmidt 2013). Dies betrifft neben Alltag, Kunst und nationaler Symbolik ebenso die Geschichte der Wissenschaft und ihrer Episteme selbst (Mignolo 2018).

Der oben ausgehend von Conrad und Randeria skizzierte Ansatz der geteilten, verwobenen oder verflochtenen Geschichten - oder auch entangled histories oder histoire croisée - erscheint hier ein sinnvoller Ausgangspunkt für eine dekoloniale historisch-politische Bildung. Oft wurden in postkolonialen Theorien die Kolonien als Laboratorien der Moderne bezeichnet (Stoler/Cooper 1997; Conrad 2016: 90 f.; 2010: 43). Da im kolonialen Imaginären die Kolonien oft als tabula rasa imaginiert wurden und einige Kolonialregime radikale Umgestaltungen von oben , einfacher" erscheinen ließen, da Widerstand brutaler niedergeschlagen werden konnte, dienten zahlreiche Kolonien als „Experimentierfeld“ (Conrad 2016: 43) für die biopolitischen Allmachtsfantasien der westeuropäischen Elite. Conrad nennt hier als herausragende Bereiche Stadtplanung, Geschlechterordnung und Eugenik. Diese gewaltvollen ,Experimente“ umfassten die Umstrukturierungen ganzer Städte, Bevölkerungen und gesellschaftlichen Arbeitsteilungen und dienten als Blaupause und wissenschaftliche Legitimation für Umstrukturierungen in Westeuropa. Als ein Beispiel verwobener Geschichten arbeitet Conrad die „Erziehung zur Arbeit in Ostafrika und Ostwestfalen“ (2010: 74 ff.) heraus. Er stellt differenziert dar, wie staatliche und kirchliche Akteure das Problem der ,Arbeitsscheu" der Arbeiter_innen in Deutschland und in Deutsch-Ostafrika ähnlich - nicht gleich - konzeptionalisierten und welche Wechselwirkungen diese sozialanthropologischpädagogischen Diskurse und institutionalisierten Praktiken der Disziplinierung in Ostafrika und Ostwestfalen hatten, wie sich in der Namensgebung von Arbeiter_innensiedlungen bzw. sogenannten Arbeiterkolonien versinnbildlicht, die häufig 
nach Kolonien benannt wurden. Dieser Zusammenhang war zum einen strukturell - also implizite, nicht explizit intendierte Überschreibungen der Diskurse und Praktiken in beiden Kontexten - bedingt, war aber durchaus auch explizites Ziel bevölkerungspolitischer Planung, wie an folgendem Zitat des Sozialanthropologen Fagus deutlich wird: „Es ist zu hoffen, daß der Besitz von Kolonien mit einer Bevölkerung, die weit unter unserer Rasse steht, einen erzieherischen Einfluss auf uns ausüben wird." (Fagus, zitiert nach El-Tayeb 2001: 120 f.)

Das Beispiel der Wechselwirkung der Erziehung zur Arbeit in der kolonisierten und kolonisierenden Gesellschaft habe ich hier aus unzähligen Beispielen verwobener Geschichten ausgewählt, weil es die Genealogie des ,deutschen“ Arbeitsethos, die normalerweise sogar von den Kritiker_innen als eine nationale Genealogie als Geschichte innerhalb des nationalen Containers - erzählt wird, infrage stellt und erweitert. Die Perspektive der verwobenen Geschichte plädiert nicht dafür, die spezifischen historischen Konstellationen aus dem Blick zu verlieren, sondern verweist auf die Beschränkung des Blicks durch eine nationalisierte Perspektive. Das Konzept kann ein Ausgangspunkt sein, um alltägliche Phänomene, diskursive Elemente, institutionelle Strukturen in der deutschen Gesellschaft im Kontext ihrer postkolonialen Verstrickung in den Blick zu bekommen. Eine dekoloniale historisch-politische Bildung hat hier Gelegenheit, die diskursiven oder räumlichen Lebenswelten von Lernenden als Ausgangspunkt dekolonialer Reflexionsoder Aufarbeitungsprozesse zu entwickeln.

\section{(iv): Keine Apologetik der Kolonialgeschichtsschreibung durch die unreflek- tierte Übernahme eurozentrischer und kolonialer Episteme}

Die Verurteilung des Kolonialismus als gewaltvolles Unrecht in der Geschichte ist dabei in öffentlichen Diskursen keineswegs so eindeutig, wie es zu erwarten wäre. Häufig wird der Kolonialismus durch die Übernahme kolonialer Ideologien verharmlost, verteidigt oder glorifiziert. In Frankreich beispielsweise verfügte das Parlament 2005, dass im Schulunterricht die ,positiven Aspekte' kolonialer Herrschaft betont werden müssten (Conrad 2016: 7). Die Apologetik des deutschen Kolonialismus wird in Schulbüchern ebenso deutlich, wie in den Lernendenvorstellungen. Beispielsweise Mark (Gym09), der durch auffällig fundiertes Wissen über die Kolonialgeschichte heraussticht, betont mehrfach, dass es dem Kolonialismus anzurechnen sei, dass die kolonisierten Gesellschaften überhaupt eine gesellschaftliche Ordnung hätten entwickeln können, was aus seiner Sicht die Bedingung für den Eintritt in die ,Entwicklung ' bzw. die Geschichte überhaupt darstellt (3.2.7). Die Kolonisierung der Amerikas bezeichnet er ebenfalls als ,eine ganz gute Idee“ bzw. „gute Sache“, da sie so Teil einer Religion werden konnten (3.4.3). Diese Beispiele sollen illustrieren, wie die Übernahme bzw. Nicht-Reflexion kolonialer Episteme 
ein koloniales und den Kolonialismus verteidigendes Geschichtsbild hervorbringen. Diese Ideen sind keineswegs als Irrwege oder Uninformiertheit zu interpretieren. Vielmehr sind sie fundamentaler Teil des kolonialen Erbes, wie Geschichte gedacht wird. Sie knüpfen direkt an Ideen an, wie sie beispielsweise Hegel, Marx (Kleinschmidt 2013) oder Weber (Kleinschmidt 2017) formuliert haben.

Eine dekoloniale historisch-politische Bildung muss die Episteme von Geschichte - die Verwobenheit zentraler Elemente der Geschichtswissenschaft mit Kolonialität und Eurozentrismus - dekolonisieren. Ohne die reflexive Aufarbeitung der Kolonialität läuft historisch-politische Bildung Gefahr, die kolonialen Annahmen zu reproduzieren. Der Historiker Dipesh Chakrabarty (1992) bezeichnete diese Unterfangen als die Aufgabe, Europa zu provinzialisieren. Ihm zufolge ist der Geschichtswissenschaft und der hegemonialen Geschichtsschreibung das „hyperreale Europa“ (ebd.: 292) als impliziter Agent eingeschrieben. Hyperreal ist es, weil es nicht um das wirkliche ,Europa ' geht, das als solches ja gar nicht existiert, sondern um dasjenige, das Maßstab und Norm der Wissenschaften, Grundlage der Epistemologie selbst darstellt und in den akademischen Wissenskomplexen als hyperreales anwesend ist.

\begin{abstract}
„Den Versuch zu unternehmen, dieses ,Europa“ zu provinzialisieren, heißt, das Moderne als Feld von Auseinandersetzungen zu begreifen. Es bedeutet, die bislang privilegierten Erzählungen der Staatsbürgerschaft mit Erzählungen anderer menschlicher Bindungen $\mathrm{zu}$ überschreiben, die sich von erträumten Vergangenheiten und Zukunftsentwürfen nähren, in denen Kollektivitäten weder durch die Rituale der Staatsbürgerschaft noch durch den Alptraum der durch die ,Moderne“ geschaffenen ,Tradition“ definiert sind.“ (ebd.: 309)
\end{abstract}

Jede Geschichte von Gesellschaften außerhalb Westeuropas muss als defizitäre, als Mangel, als ein noch-nicht oder noch-nicht-soweit erscheinen, da der implizite Maßstab, das Telos das des hyperrealen Europas darstellt. Eine vermeintlich neutrale Geschichtsschreibung ist also alles andere als das; oder um es mit Fanon zu sagen: „Für den Kolonisierten ist Objektivität immer etwas, das sich gegen ihn richtet.“ (Fanon 1961: 65).

\title{
(v) Agency von Kolonisierten als wichtiger Ausgangspunkt einer dekolonialen historisch-politischen Bildung
}

In den Lernendenvorstellungen erscheinen die Kolonisierten oft nur als Spielball der mit Agency ausgestatteten Kolonisierenden. Eine Minderheit thematisiert diese Agency aber durchaus, zu der auch Mark (Gym09) gehört, der in seinen Ausführungen die Agency von Kolonisierten als Flucht vor Versklavung und schlechten 
Lebensbedingungen, gewalttätige Aufstände gegen die East India Company und nationale Unabhängigkeitsbewegungen thematisiert (3.4.3). Demgegenüber stehen die zahlreichen Denkweisen, in denen die Schüler_innen entweder die Kolonisierten gar nicht als Handelnde thematisiert haben, oder in denen die Darstellungen der kolonialen Begegnungen auf eine dermaßen stereotype Weise vorgestellt werden, dass hier jede Agency der Kolonisierten ausgeschlossen ist, wie etwa bei Finn (HS04). Er stellt sich die koloniale Begegnung so vor, dass die Kolonisierten aufgrund zu gering ,entwickelter“ Intelligenz ,,veräppelt“ wurden, indem sie Gold gegen ,wertlose Gegenstände“" getauscht hätten (3.4.3). Solche Stereotype finden sich auch in Schulbuchdarstellungen wieder (Apraku 2015). Solche Stereotype gilt es bei der Thematisierung von Kolonialismus als Lerngegenstand unbedingt zu reflektieren und zu problematisieren.

Eine historisch-politische Bildung muss einen Schwerpunkt auf die Agency von Kolonisierten legen. Dies ist zum einen die Grundlage dafür, den Kolonialismus als komplexe und widersprüchliche Herrschaftsstruktur mit ambivalenten Akteurspositionen sowohl innerhalb der kolonisierenden als auch der kolonisierten Gesellschaft zu verstehen, wobei die Hervorhebung der Ambivalenz nicht zu einer Apologetik der europäischen Täterschaft in Bezug auf Versklavung und Kolonialismus führen darf. Am Beispiel der Aussagen des emeritierten Professors für Geschichte Jörn Rüsen, angesehener Geschichtswissenschaftler und -didaktiker, der beispielsweise das Konzept des Geschichtsbewusstseins maßgeblich mitprägte, zeigt sich, wie der vordergründige Einbezug von Agency von Kolonisierten zur Geschichtsklitterung führen kann. In einem im Nachhinein abgedruckten Streitgespräch verstieg er sich zur folgenden Aussage:

\footnotetext{
„Nehmen wir zum Beispiel Sklaverei. [...] Das ist ein wunderbares Beispiel für die nicht-westlichen Intellektuellen, uns ein schlechtes Gewissen zu machen. [...] Jetzt frage ich, wer denn die Sklaven gemacht hat? Die sind doch nicht vom Himmel gefallen. Das waren nicht die westlichen Händler, das waren die Schwarzen selber. Und wer hat die Sklaverei abgeschafft? Der Westen!“ (Rüsen/Völkel 2017: 228, zitiert nach Mecheril 2020: 104)
}

Dies kann zum einen so gedeutet werden, dass es in der ,bürgerlichen, national geprägten Wissenschaft“ immer noch nicht so einfach ist, über die „Gewalttätigkeiten der europäischen Moderne in Europa“ (Mecheril 2020: 104) - oder wie die Schülerin Lara oder Walter Mignolo es ausdrücken würden, die „dunkle Seite“ (Lara, Gym18) der Moderne - zu sprechen. Vertreter_innen nationaler Geschichtsschreibung scheinen ein starkes Bedürfnis nach Schuldabwehr zu haben, das ihnen weiterhin die unilineare Geschichtsschreibung der eigenen nationalen Teleologie 
ermöglicht. Doch in dem Zitat steckt noch ein weiteres Element, das ich hervorheben möchte. Während das ,Böse “ hier als Teil der Agency der „Schwarzen selber“ erscheint, erscheint die auf Emanzipation und Fortschritt zielende Agency im festen Besitz der ,Weißen“ respektive des ,Westens“ zu sein. Dieses koloniale Bild von Geschichte ist durchaus weit verbreitet, wie ich im Abschnitt zur kolonialen Raum-Zeit-Matrix (4.2.2.2) weiter ausführen werde.

Eine dekoloniale historisch-politische Bildung muss die Agency von kolonisierten Akteuren als wichtigen Bezugspunkt nehmen, um den genannten problematischen Konstellationen entgegenzuwirken. Hier gibt es zahlreiche Anknüpfungspunkte in postkolonialen Forschungen, von bekannten historischen Ereignissen, wie dem Maji-Maji-Aufstand in Deutsch-Ostafrika als ein Beispiel von Aufständen in nahezu allen deutschen Kolonien (Terkessidis 2019: 94) über gut dokumentierte, komplexe biographische Perspektiven auf wie beispielsweise von Samuel Maharero in Deutsch-Südwestafrika (Förster 2010) bis zu alltägliche Herrschaftsformen unterlaufenden Praktiken wie beispielsweise in den Auseinandersetzungen um das ,Mischehen'-Verbot in den deutschen Kolonien (Kundrus 2003: 219 ff.). In der postkolonialen Forschung gibt es vielfältige Auseinandersetzungen über die Schwierigkeiten und Möglichkeiten der, Rekonstruktion ' der Perspektive von Kolonisierten angesichts der archivalischen Dominanz der kolonialen Perspektive, auf die beispielsweise die methodologischen Ansätze des kontrapunktischen Lesens von Edward Said oder die Polyphonie in L'Amour, la Fantasia von Assia Djebar in der postkolonialen Theorie prominente Antworten darstellen (Kleinschmidt 2013). Dieser dekoloniale Anspruch verbleibt an dieser Stelle aber ein Forschungsdesiderat und kann hier nicht ausführlich besprochen werden.

\subsubsection{Erinnerungspolitische Auseinandersetzungen um den deutschen Kolonialismus als zentraler Lerngegenstand}

\footnotetext{
S: [...] Weil Afrika war ja mal kolonialbesetzt, da gab es ja ganz viele Kolonien. Und die wurden ja von den Europäern, gerade von den Engländern, extrem ausgeraubt. Und ich glaube die wirtschaftliche Lage und auch die Lage von der afrikanischen Bevölkerung wäre um einiges besser, wären die Bodenschätze noch erhalten. Weil wenn man jetzt hört wie viel Gold, Öl und diese ganzen fossilen Brennstoffe Wert sind - oder allgemein die endlichen Stoffe - dann würde die Wirtschaft da ja boomen. Und auch der Bevölkerung würde es in dem Punkt besser gehen. Deswegen wäre es von der EU auch nur gerecht, oder von Europa auch nur gerecht, diese Leute aufzunehmen. Aber an der jetzigen Situation kann unsere Generation ja zum Beispiel nichts. Ich kann ja nichts dafür, dass damals meine, ähm, Vorfahren die afrikanischen Kolonien ausgeraubt haben. (Gym12, Pascal)
} 
Pascal setzt hier, wie eingangs erwähnt, die Geschichte des Kolonialismus in eine Zusammenhang mit der ungleichen Reichtumsverteilung der Gegenwart. Damit erkennt er erinnerungspolitisch die koloniale Vergangenheit als Teil der europäischen Geschichte an. Dabei bleibt sein Gedanke der Anerkennung nicht rein ideell. Aus der kolonialen Ungerechtigkeit der Vergangenheit leitet er die Forderung einer aufnehmenden Migrationspolitik für die Gegenwart ab. In an die erinnerungspolitischen Diskussionen in Bezug auf den NS erinnernder Weise diskutiert er dann das intergenerationelle Erbe der Verantwortung für die Verbrechen der Vergangenheit. Unabhängig davon, zu welchem Schluss er in Bezug auf die ethische Verpflichtung der Annahme oder Nicht-Annahme des Erbes letztlich käme, bietet die Art und Weise dieser Frage Anknüpfungspotenzial für eine dekoloniale historisch-politische Bildung.

Für eine dekoloniale historisch-politische Bildung geht es hier darum, dafür zu sensibilisieren, dass wir in einer postkolonialen Gesellschaft leben, die grundlegend von der Geschichte des Kolonialismus geprägt worden ist, deren Spuren omnipräsent sind und sich nicht nur als Artefakte, sondern in sich transformierten Formen immer wieder neu aktualisiert. Dekoloniale Perspektiven zielen darauf, die Kolonialität von Vergangenheit und Gegenwart sichtbar und problematisierbar zu machen. Darüber hinaus geht es aber auch darum, die Frage der Erinnerungskultur als einen Ort des Streits sichtbar zu machen - wer schreibt hier für wen und wofür Geschichte fest - sowie den Schüler_innen im Sinne einer Handlungsfähigkeit mögliche Positionierungen und Interventionsmöglichkeiten zugänglich zu machen. Normativ zielt eine dekoloniale politische Bildung darauf, für eine Anerkennung der aus den kolonialen Verbrechen erwachsende Verantwortung zu streiten. An die Frage der symbolischen Anerkennung von Verantwortung knüpft sich die Frage der materiellen Reparation an - der Terminus ,Wiedergutmachung' erscheint mir hier unangemessen. Jenseits einer migrationspolitischen Reparation im Sinne Pascals, deren Zusammenhang aber durchaus auch Teil der Diskussion sein kann, ginge es hier wohl eher um angemessene Reparationszahlungen, kompletten Schuldenerlass für ehemals kolonisierte Länder und Strukturveränderungen ökonomischer, sozialer und politischer Prozesse, wie sie vor wenigen Jahrzehnten im Zusammenhang trikontinentaler Süd-SüdOrganisationen und teilweise heute auch gefordert werden (Kaleck/Theurer 2018). Postkoloniale Erinnerungspolitik ist ein Ort des Streits, ein politischer Ort; und genau diesen Ort gilt es sich aus Sicht einer dekolonialen historisch-politischen Bildung mit den Lernenden zu erschließen. Dafür bedarf es der Kenntnis von Akteur_innen und Streitthemen. Auch Ansätze des forschenden Lernens würden sich hier - insbesondere zur Erschließung des lokalen Raums der Lernenden - anbieten, wie nicht nur im universitären Kontext inzwischen oft erprobt. 
Dabei kann eine dekoloniale politische Bildung an die Arbeit zahlreicher dekolonialer Initiativen anknüpfen, die diese Fragen zum öffentlichen Streitthema gemacht haben. So gibt es eine Reihe von Wissenschaftler_innen und Initiativen, die postkoloniale Stadtrundgänge, Ausstellungen oder Aktionen und Kampagnen zur Straßenumbenennung durchgeführt haben. Sie haben aufgezeigt, wie Sprache, Namen, Museen, Institutionen, Denkmäler und kulturelle Symboliken lokal direkt durch den Kolonialismus geprägt wurden und das koloniale Erbe still und bisher meist unhinterfragt im Stadtraum repräsentiert war (BpB 2019). In diesen Rahmen gehören auch die zahlreichen Decolonize-Gruppen, die sich gegen die De-Thematisierung wehren. Wichtige Inspirationsquellen können hier ebenso die Auseinandersetzungen um das Humboldtforum darstellen, in denen verschiedenste Akteur_innen die fehlende Aufarbeitung von Deutschlands postkolonialem Erbe oder die Ausblendung der kolonialen ,Beschaffung ' der Ausstellungsstücke thematisiert sowie die Reproduktion kolonialer Muster in der Ausstellungspraxis problematisiert haben, wie etwa die Logik der ,Entdeckung' oder der Ausblendung des kolonialen Hintergrunds von Humboldt selber (zu den postkolonialen Kritiken vgl. bspw. Terkessidis 2019: 47 ff.). Insbesondere zu nennen sind hier Akteur_innen, wie ISD, Berlin postkolonial, das Bündnis „Völkermord verjährt nicht!" und andere, die die immer noch ausstehende Anerkennung des Völkermords an den Herero und Nama einfordern und beispielsweise die an koloniale Haltungen erinnernde Rückgabepraxen der zu kolonialwissenschaftlichen Zwecken geraubten Schädel kritisieren (Melter 2014). Als letztes Beispiel einer potenziell langen Liste soll hier noch die Klage durch namibische Akteur_innen nicht unerwähnt bleiben, die die Bundesregierung, die jegliche Reparationszahlungen kategorisch ablehnt, auf der Basis des Völkerrechtsverstoßes an einem New Yorker Gericht auf Reparationszahlungen verklagen. Diese Interventionen wurden auch schon - wenn auch nur punktuell und vereinzelt - in Bildungsprogramme umgesetzt. Verwiesen sei hier beispielsweise auf die Erfahrungen mit den Lehrer_innenfortbildungsprogrammen „Hier und jetzt! Kolonialismus und Kolonialrassismus im Schulunterricht" oder Projekten zum forschenden Lernen mit Jugendlichen zur lokalen Verankerung der Sklaverei im Bremer Stadtraum (AriC 2018). Diese - und andere, hier nicht benannte - vielfältigen Interventionen haben schon viel erreicht - und stehen gleichwohl noch am Anfang, gemessen an dem Ziel einer erinnerungspolitischen Anerkennung, gesellschaftspolitischen Aufarbeitung und der Zahlung von Reparationen. Zumindest haben sie erreicht, dass der Anfang eines solchen Prozesses denkbar wird und das Thema des deutschen Kolonialismus nicht mehr ganz verschwiegen werden kann. Als Symptom dieses Wandels kann die erstmalige Aufnahme des Themas in den Koalitionsvertrag der CDU-SPD-Regierung von 2018 gelten. Neben der „Aufarbeitung 
der NS-Terrorherrschaft und der SED-Diktatur gehöre eine Beschäftigung mit der ,deutschen Kolonialgeschichte“ zum „demokratischen Grundkonsens“ (zitiert nach Terkessidis 2019: 10).

Im Folgenden werde ich die Forderungen der Erklärung des bundesweiten Netzwerks zur Dekolonisierung der Erinnerungskultur von 2018 darstellen, an der zahlreiche der bereits kursorisch aufgeführten dekolonialen Initiativen beteiligt $^{3}$ waren, um ein mögliches - sich aus wichtigen Basisgruppen entwickeltes - Spektrum dekolonial inspirierter Transformationsprozesse der deutschen Erinnerungskultur aufzuzeigen. Das Bündnis kritisiert bereits die Form der Aufnahme des Themas in den genannten Koalitionsvertrag, denn hier wird der Kolonialismus nicht explizit - im Gegensatz zur NS-Terrorherrschaft und der SED-Diktatur - als Unrechtsherrschaft benannt. Ebenfalls kritisiert wird die Beschränkung auf die deutsche Kolonialgeschichte, denn Kolonialgeschichte sei „eben keine nationale, sondern eine verwobene Geschichte Kolonisierender und Kolonisierter, welche nicht länger einseitig von Deutschland aus interpretiert werden darf“" (Bundestreffen der Initiativen zur Dekolonisierung der Erinnerungskultur 2018). Gefordert wird, dass die Bundesregierung im Sinne der unterzeichneten UNErklärung gegen Rassismus von 2001 Kolonialismus als „Unrecht“ benennt und „unmissverständlich verurteilt“ (ebd.). Weiter wird gefordert, ,jegliche Forschung an menschlichen Überresten aus kolonialen Kontexten, die nicht der Rückführung dieser Gebeine dient, sofort zu stoppen sowie ausreichend finanzielle Mittel zur Verfügung zu stellen, um die Rückführung der Gebeine in Zusammenarbeit mit den Herkunftsgesellschaften zu organisieren. Weiterhin wird gefordert, dass die Bundesregierung dem Beispiel der Bundesländer Berlin und Hamburg folgt und die „Nachfahr*innen der Opfer des deutschen Genozids (1904-08) an den Herero und Nama [...] um Entschuldigung“ (ebd.) bittet. In diesem Kontext soll auch über die ,zu zahlende Entschädigung für den von der deutschen Regierung im Rahmen des Genozids vollzogenen Land- und Viehraub verhandelt“" (ebd.) werden. Des Weiteren sollen ausreichende Mittel für die Provenienzforschung zu

\footnotetext{
${ }^{3}$ Konkret beteiligt waren hier die folgenden Gruppen: AfricAvenir International, AFROTAK TV cyberNomads, Arbeitskreis Hamburg Postkolonial, Arbeitskreis Koloniales Vergessen. Quo Vadis, Hamburg? Arbeitskreis Panafrikanismus München, Arca - Afrikanisches Bildungszentrum e. V., Augsburg postkolonial, Berlin Postkolonial, Berliner Entwicklungspolitischer Ratschlag - BER, Cottbus postkolonial und postsozialistisch, decolonize Jena, Decolonise Academia; Tübingen, Düsseldorf postkolonial, Dresden Postkolonial, FuturAfrik - Forum für Globale Gerechtigkeit Halle Postkolonial, Initiative Schwarze Menschen in Deutschland, ISD - kassel postkolonial, Kirchliche Arbeitsstelle Südliches Afrika - KASA Leipzig Postkolonial, [muc] münchen postkolonial, Potsdam postcolonial, Schwarze Diaspora Hochschulgruppe Potsdam Tanzania-Network.de.
} 
Kulturobjekten aus kolonialen Kontexten in deutschen Museen und Sammlungen zur Verfügung gestellt werden und die betroffenen Gesellschaften ,über den Verbleib der in kolonialen Gewaltkontexten angeeigneten Kulturschätze“ (ebd.) informiert werden. Die betroffenen Gesellschaften sollen die Möglichkeit erhalten, die geraubten Kulturgüter zurückzuerhalten. Darüber hinaus müssten die öffentlichen Museen dekolonisiert werden, da die Repräsentation in der Regel „,noch heute auf den eurozentrischen und nationalistischen Ideen des 19. Jahrhunderts [basieren], die zu einer rassistischen Konstruktion des außereuropäischen ,Anderen' geführt haben“ (ebd.). Die gewaltvolle Kolonialgeschichte wird zudem „oft verharmlost oder verschwiegen“ (ebd.). Dabei müssten die Nachkommen der Kolonisierten als „maßgebliche Expert*innen“ eingeladen und in die „Museumsteam“ (ebd.) eingebunden werden. In Bezug auf Bildung und Geschichtsunterricht fordert das Bündnis

\begin{abstract}
„den schulischen und universitären Geschichtsunterricht zu globalisieren und zu diversifizieren. Der kritischen Auseinandersetzung mit dem europäischen Kolonialismus und Rassismus sowie der Erinnerung und Würdigung des antikolonialen Widerstands muss ein zentraler Platz in den Lehrplänen von Schulen, Universitäten und Fortbildungseinrichtungen für Lehrkräfte eingeräumt werden. Die Zusammenarbeit von Bildungsinstitutionen mit externen Bildungsexpert*innen aus Initiativen zur Dekolonisierung und gegen Rassismus ist stärker zu fördern. [...] Zudem soll eine namibisch-deutsche Schulbuchkommission einberufen werden." (ebd.)
\end{abstract}

Dieser Forderungskatalog ist keineswegs abschließend zu verstehen; allein die Fokussierung auf den namibischen Kontext macht die Begrenztheit der Forderungen deutlich. Und trotz seiner Begrenztheit greift er weit über das hinaus, was im erinnerungspolitischen Alltagsgeschäft zur Zeit als durchsetzbar erscheint. Jeder der darin benannten Punkte kann einer dekolonialen politischen Bildung als möglicher Startpunkt dienen, sich die erinnerungspolitischen Auseinandersetzungen um den Kolonialismus als Ort des Streits zu erarbeiten.

In den folgenden zwei Abschnitten werde ich zwei Fragen nachgehen: Die Beziehung zwischen der Erinnerung an die Shoah und dem Kolonialismus und der Frage der Bestimmung des Begriffs des Kolonialismus, insbesondere für den deutschen Kontext. Mir ist bewusst, dass diese aus meiner Sicht heiklen Fragen auch Dissens hervorrufen werden. Da ich aber die Verhandlung von Dissens für eine produktive Art der Auseinandersetzung halte und sie wichtig für die Kontextualisierung und Bestimmung einer dekolonialen politischen Bildung sind, habe ich sie trotzdem geschrieben. 


\subsubsection{Kolonialismus und Shoah als zwei kompetitive Paradigmen von Geschichte und historisch-politischer Bildung?}

Der mehrfach von den Schüler_innen aufgegriffene Bezug zum Nationalsozialismus ist der Ausgangspunkt dieses Abschnitts, in dem das Verhältnis von Kolonialismus und Shoah innerhalb einer dekolonialen historisch-politischen Bildung kursorisch diskutiert wird.

\subsection{Die Shoah als Legitimationsfigur im neuen deutschen Nationalismus}

Merle (Gym21) argumentiert in ihren Überlegungen zu der Frage nach den Ursachen der ,Unterentwicklung' Afrikas, dass die Regierungsform der Alleinherrschaft in Afrika sehr verbreitet sei (3.2.4). Einen Grund dafür sieht sie in der Erfahrung des Nationalsozialismus. Diese habe es in Europa ermöglicht, daraus zu lernen und demokratische Regierungsformen zu entwickeln. Die Erfahrung des Nationalsozialismus wird so in ein Überlegenheitsnarrativ integriert, indem die ,Entwicklung ' und ,Unterentwicklung ' begründet wird. Dies wirft die Frage danach auf, welche Rolle der Nationalsozialismus im Geschichtsverständnis hat und wie sein Verhältnis zum Kolonialismus aus Sicht einer dekolonialen historisch-politischen Bildung verstanden werden kann. Aus meiner Sicht ist die Rolle, die der Nationalsozialismus im hegemonialen Diskurs einnimmt, als ambivalent zu betrachten. Zum einen stellt er ein schwieriges Erbe (2.3.3.2) dar, das mit Sharon Macdonald als eine Vergangenheit betrachtet wird, die als bedeutsam für die Gegenwart angesehen wird und die insofern schwierig ist, als dass sie eine positive, selbstbestätigende Identitätskonstruktion in der Gegenwart herausfordert (Macdonald 2009: 1). Auch wenn Deutschland sich als ,Erinnerungsweltmeister' inszeniert und der Mythos genährt wird, Staat und Gesellschaft hätten die NS-Vergangenheit hervorragend und umfassend aufgearbeitet, stellt sich bei kritischer Betrachtung heraus, dass die tiefer gehende Anerkennung von der BRD als eine postnationalsozialistische Gesellschaft alles andere als abgeschlossen ist. Allerdings haben sich die Abwehrreflexe im hegemonialen Diskurs grundlegend verschoben. Zwar gibt es immer noch zahlreiche Stimmen, die diesen Teil der Geschichte lieber ausblenden wollen, doch erscheint spätestens mit der rotgrünen Regierung in den 1990er Jahren eine erinnerungspolitische Transformation eingeleitet worden zu sein.

Konkurrierend zu Schuldabwehr und Relativierung wurde der Einbezug des Nationalsozialismus in das nationale Narrativ bzw. seine vorgeblich umfassende gesellschaftliche Aufarbeitung zur Staatsräson. 1999 wurde in Serbien und im Kosovo beispielweise nicht trotz, sondern wegen ,Auschwitz das erste Mal wieder ein Angriffskrieg mit deutscher Beteiligung durchgeführt 
(El-Tayeb 2016: 169 ff.). ,Auschwitz' wurde so zu einer nationalen Legitimationskonstruktion, die aus der deutschen Täter_innenschaft bzw. der vermeintlich gelungenen Aufarbeitung eine besondere, deutsche ,Verantwortung ' ableitet, die sich auf den zweiten Blick als eine deutsche Überlegenheitskonstruktion herausstellt. Die Einzigartigkeit der nationalsozialistischen Verbrechen - die Singularitätsthese - begründete sich insbesondere im sogenannten Historikerstreit Ende der 1980er Jahre als Replik von Jürgen Habermas gegen nationalistische Relativierungsversuche des reaktionären Historikers Ernst Nolte. Die Singularitätsthese wurde im Zuge der Auseinandersetzungen in den 1990er Jahren zum einen auf eurozentrische Weise globalisiert und zum anderen paradoxerweise dafür verwendet, eine deutsche Überlegenheit und damit das Recht auf militärische Intervention aufgrund der aufgearbeiteten Täter_innenschaft zu beanspruchen. Die nach wie vor mit rechten Relativierungsversuchen des Nationalsozialismus konkurrierende relative Hegemonie dieser neuen erinnerungspolitischen Staatsräson kann auch als eine Transformation des deutschen Nationalismus interpretiert werden, in der Deutschland als zentraler Teil des ,Westens“ oder der ,westlichen Moderne“ imaginiert wird. Dieser transformierte Nationalismus, in dem die Shoah als Ressource fungiert, bringt dabei veränderte, aber ebenso problematische Formen des Othering und Selfing hervor.

\subsection{Zivilisationsbruch?}

Die Shoah bzw. das als Symbol dafür fungierende Auschwitz wurden und werden häufig als „Zivilisationsbruch“ (Diner 1988; Salzborn 2015) interpretiert. Zwar stellt auch Diner fest, dass es nicht die Gewaltförmigkeit oder massenhaftes, genozidales Töten ist, dass den Unterschied zu anderen historischen Gewaltformen ausmacht. Das den Bruch ausmachende Spezifikum der Shoah ist nach Diner das Töten ohne Zweck der Selbsterhaltung im eliminatorischen Antisemitismus. Dies wird auch als „Erlösungsantisemitismus“ (Klävers 2019: 202) verstanden. Damit einher geht auch die Abwehr gegen das Konzept, Antisemitismus als eine Form von Rassismus zu verstehen. Das qualitative Unterscheidungsmerkmal sei neben dem eliminatorischen Element, dass der Antisemitismus Angebote zur ,Welterklärung" (ebd.: 207) liefere, was ihn so attraktiv mache. Diese Annahmen erscheinen aus einer dekolonialen Perspektive als diskussionswürdig. Im Sprechen über die Unterscheidung zwischen Rassismus und Antisemitismus findet häufig eine Art Relativierung von Rassismus und Kolonialismus statt. Rassismus erscheint hier als zweckgerichtet und rational, während Antisemitismus dies eben nicht sei. Neben dieser problematischen Hierarchisierung von Rassismus und Antisemitismus erscheint auch die kategorische Differenzierung und die kategorialen 
Unterscheidungsmerkmale als wenig überzeugend. Absolut nicht nachvollziehbar ist die Vorstellung, Rassismus böte keine „Welterklärungen“, da doch genau dies eine zentrale Funktion dieser Herrschaftsform ist. Auch die eliminatorische Form - das Ziel des Tötens als Selbstzweck - findet sich in verschiedenen Formen des Rassismus, wie etwa im Genozid an den Herero und Nama 1907 in Deutsch-Südwestafrika oder in der jüngeren Geschichte im Völkermord 1994 in Ruanda.

Meine Argumentation zielt hier nicht darauf ab, die spezifischen Elemente des Antisemitismus verkennen und nivellieren zu wollen. Ganz im Gegenteil erscheint aus einer dekolonialen Perspektive diese Form der Sakralisierung oder Fetischisierung als problematisch,, die schon im Begriff des „Zivilisationsbruch“ aufscheint; nicht nur, weil so eine eurozentrische Perspektive eingenommen würde, mit der das Leid und die Gewalt kolonialer Herrschaft relativiert wird, sondern insbesondere auch, weil so die Perspektive der Kritik des Antisemitismus verengt und stumpf wird. Für den Bildungskontext hat Theodor W. Adorno durch seine Radioansprache Erziehung nach Auschwitz den berühmt gewordenen Imperativ geprägt, dass die ,allererste“ Forderung an Erziehung sei, dass „Auschwitz nicht noch einmal sei, [...] daß Auschwitz sich nicht wiederhole“" (Adorno 1966: 88). Auschwitz als einen Bruch darzustellen, fällt weit hinter die Gedankenfigur einer Dialektik der Aufklärung zurück. Für Adorno bestand eine Erziehung nach Auschwitz keineswegs in einer sakralen Singularisierung der Shoah, sondern vielmehr darin, ein „allgemeines Bewusstsein jener Mechanismen“ zu wecken, „die die Menschen so machen, dass sie solcher Taten fähig werden“ (ebd.: 90), und ihre tiefe Verankerung in der bürgerlichen Gesellschaft zu erforschen und erkennen zu lernen. Gerade weil auch die sprachlichen und denkerischen Mittel, die uns für Analyse und Reflexion zur Verfügung stehen, selbst mit Herrschaft verstrickt sind, braucht es zur Erreichung dieses Ziels eine Reflexion jenseits von starren, festgefahrenen Strukturen.

$\mathrm{Zu}$ jeder Reflexion über die erinnerungspolitischen Konstellationen in Bezug auf die Shoah gehört immer auch die Frage, wer wie und mit welchem Ziel über die Shoah spricht. Besonderes Augenmerk ist beim Sprechen über die Shoah in Deutschland auf deutsche Schuldabwehrreflexe und Formen von sekundärem Antisemitismus zu legen, die ressentimentgeladene Argumentationen in ihrer Infragestellung der Singularität reproduzieren. Astrid Messerschmidt stellt dabei beispielsweise heraus, dass auch der „vielstimmige postkoloniale Diskurs“ dazu genutzt werden könne, eine „Bedürfnis nach Schuldabwehr zu befriedigen“, wenn an die Stelle einer komplexen Aufarbeitung „kolonialer Hybridität“ eine Projektion aller Schuld für „,weltweite Ungerechtigkeit und Gewalt“ auf die „mit dem ,Westen “ identifizierte[n] Verursacher [...] USA oder Israel“ (Messerschmidt 
2019: 154) stattfände. Ebenso gilt es aber, die Instrumentalisierung der Shoah für nationalistische Zwecke oder die neokoloniale Etablierung und Hegemonisierung des ,Westens ' und der Konstruktion und Abwertung seiner ,Anderen` zu legen.

\subsection{Von doppelten Standards}

Die Vorstellung eines Zivilisationsbruchs durch die Shoah wurde schon früh von dekolonialen Theoretiker_innen infrage gestellt, die weniger, überrascht ${ }^{\star}$ von der Qualität der in der Shoah ausgeübten Gewalt waren und weniger ,erschreckt ${ }^{\text {* }}$ davon, wozu Menschen fähig sind. Beispielsweise W.E.B. Dubois (1947: 23) oder James Baldwin (1963: 53) erschienen die Gewalt und Entmenschlichung der nationalsozialistischen Verbrechen vor dem Hintergrund der Kenntnis über die koloniale Gewalt aus der Perspektive von Nachfahren von Kolonisierten und Versklavten keineswegs als unvorhersehbar (Castro Varela 2014: 115). Was allerdings als ,überraschend" erschien, war insbesondere die Tatsache, dass dieser Genozid sich in Europa und nicht in Überseekolonien zutrug (ebd.: 116). Am bekanntesten zum Thema Shoah aus einer antikolonialen Perspektive sind wohl die Äußerungen von Aimé Césaire. In seiner Rede über den Kolonialismus schreibt er dazu folgendes:

„Ja, es wäre schon die Mühe wert, klinisch genau und in allen Einzelheiten die Methoden Hitlers und des Hitlerismus zu untersuchen und dem ach so distinguierten, ach so humanistischen, ach so christlichen Bourgeois des 20. Jahrhunderts begreiflich zu machen, dass er selbst einen Hitler in sich trägt, ohne es zu wissen, dass Hitler ihn bewohnt, dass Hitler sein innerer Dämon ist, dass sein Wettern gegen ihn Mangel an Logik ist und dass im Grunde das, was er Hitler nicht verzeiht, nicht das Verbrechen an sich ist, das Verbrechen gegen den Menschen ist, nicht die Erniedrigung des Menschen an sich, sondern das Verbrechen gegen den weißen Menschen, die Erniedrigung des weißen Menschen und dass er, Hitler, kolonialistische Methoden auf Europa angewendet hat, denen bislang nur die Araber Algeriens, die Kulis Indiens und die Neger Afrikas ausgesetzt waren." (Césaire 1955: 81)

Césaire verweist hier zunächst auf die schon am Beispiel von Adorno aufgezeigte Kritik der Vorstellung eines Zivilisationsbruchs zugunsten einer Perspektive, die die Bedingung der Möglichkeit der nationalsozialistischen Verbrechen in der bürgerlichen Gesellschaft und ihren Strukturen verortet. Im Anschluss an Césaire arbeitet Aram Ziai in Bezug auf den unterschiedlichen öffentlichen Umgang mit Kolonialismus und Nationalsozialismus heraus, dass hier doppelte Standards gelten. Er zeigt an Beispielen aus der Presse, dass weiterhin öffentlich und weitgehend unwidersprochen behauptet werden kann, dass die negativen Aspekte der Dekolonisierung dominieren bzw. sogar als Katastrophe dargestellt werden sowie, 
dass sowohl in Zeitungen als auch in Schulbüchern (Marmer/Ziai 2015) häufig die positiven Seiten des Kolonialismus herausgestellt werden (Ziai 2016b: $14 \mathrm{ff}$.). Dem stellt er die Vorstellung gegenüber, dass in deutschen Schulbüchern den Schüler_innen die Aufgabe gestellt wird, „Pro-und-Kontra Nationalsozialismus“ abzuwägen und Argumente für beides zu sammeln (ebd.: 15). Ziai zielt dabei natürlich nicht darauf, dass die Ungleichwertigkeit der beiden Erinnerungskontexte zu einer Abwertung der Erinnerung an den Nationalsozialismus führen sollte, dass beispielsweise die „Autobahnen und der Wirtschaftsaufschwung“ als die Konzentrationslager aufwiegend erscheinen sollten (ebd.). Er begrüßt den Ausschluss der Relativierung der nationalsozialistischen Verbrechen aus dem „Bereich des Sagbaren in der deutschen Öffentlichkeit“ (ebd.). Allerdings verdeutlicht diese Analogie, welche Gewalt, Ignoranz und Verhöhnung der Opfer in den weit verbreiteten relativierenden Umgängen mit dem Kolonialismus stecken. Ziai stellt also fest, dass die von Césaire 1955 aufgestellte These der „Anwendung unterschiedlicher ethischer Standards für unterschiedliche Menschengruppen“ (ebd.: 16) in den gegenwärtigen Erinnerungsdiskursen zu Nationalsozialismus und Kolonialismus durchaus zutrifft. Die Vorstellung eines Zivilisationsbruch baut dabei aus der Sicht Ziais auf dieser Differenz zwischen Menschengruppen und den damit verbundenen doppelten Standards auf. Zudem setze die Vorstellung eines Bruchs die Annahme einer ungebrochenen, prinzipiell ,intakten Zivilisation vor Auschwitz" (ebd.) voraus, was wiederum eine Ignoranz gegenüber fünf Jahrhunderten kolonialer Eroberung, Herrschaft, Ausbeutung, Massakern und Völkermorden impliziert (ebd.). Gleichzeitig problematisiert Ziai den Zivilisationsbegriff selbst, der bereits eine koloniale Konstruktion darstellt.

\subsection{Zur Verwobenheit von Kolonialrassismus und Antisemitismus}

Ein weiterer Aspekt im Zitat von Césaire ist die Sicht auf die Shoah als die Anwendung kolonialer Methoden in Europa. Er benutzt dafür den Begriff des choc en retour, den Michael Rothberg mit „reverse shock, backlash, boomerang effect" (Rothberg 2017: 70) ins Englische übersetzt und mit dem Begriff des Bumerang-Effekt von Hannah Arendt vergleicht. Arendt hatte diesen verwendet, um die Anwendung imperialer Herrschaftsmechanismen in imperialen Gesellschaften zu beschreiben, die bis dahin ,nur' in kolonisierten Territorien angewendet wurden. Bereits Arendt verwies auf die Erfindung der Konzentrationslager in kolonialen Kontexten; sie benennt hier die spanischen Konzentrationslager auf Cuba im zehnjährigen Krieg (1868-1878), die britischen im zweiten Burenkrieg (1899-1902) und die zu ihrer Zeit gegenwärtigen in Südafrika (Arendt 1951; Castro Varela 2014: 117). Die Bumerang-These von Arendt beinhaltete auch, die 
„Brutalisierung der Verhältnisse in den deutschen Kolonien als eine Voraussetzung dafür [anzusehen], dass der Holocaust möglich wurde" (Hamann 2016: 162). Ulrike Hamann dreht diese These teilweise um. Statt die Rückwirkung der Kolonialpraktiken als ursächlich für die Verwerfungen innerhalb Europas anzusehen - in Analogie zur Sicht auf die Kolonien als Laboratorien der Moderne, diskutiert sie die Verwobenheit beider. Aufbauend auf den Erkenntnissen des Historikers Christian S. Davis in seiner Studie Colonialism, Antisemitism, and Germans of Jewish Descent in Imperial Germany zeigt sie, die Verwobenheit - das ,reziproke Verhältnis“ (ebd.: 159) - von Kolonialrassismus und Antisemitismus in der deutschen Geschichte.

Davis geht in seiner Studie der unter anderem im Vorwärts, dem Parteiorgan der SPD, 1896 aufgestellten These nach, dass im kolonialen Rassismus der Vernichtungswille der Antisemit_innen erstmals praktisch artikuliert werden konnte (ebd.: 159). In der Untersuchung der Verwobenheit der Entwicklung von Antisemitismus und Kolonialrassismus im Kaiserreich stehen nicht nur die Überschneidungen der Akteur_innen - ob Personen oder Institutionen - im Fokus, sondern auch diskursive Verschiebungen innerhalb der politischen Kultur. Hier wird gezeigt, wie die Konjunkturen beider Rassismen in ihrer Wechselwirkung zu einer Hegemonie des Denkens des Rassenkampfes ${ }^{4}$ in rechten Diskursformationen führt. In Hinblick auf Literatur des 18. und des frühen 19. Jahrhunderts hatte bereits Claudia Bruns (2011) in ihrem Artikel Antisemtism and Colonial Racism. Transnational and Interdiscursive Intersectionality die Interdependenz und Verwobenheit von Antisemitismus und Kolonialrassismus herausgearbeitet, die bereits weit vor Beginn des deutschen Kolonialreichs 1884 sehr eng aufeinander bezogen waren. Ulrike Hamann untersucht die anschließenden verwobenen Dynamiken - beispielsweise von politischen Bewegungen bis zu medizinischen Diskursen. Insbesondere die Entwicklung des - von Foucault (1976a; siehe dazu auch der Exkurs in 4.2.3.3) wegweisend analysierten - biopolitischen Denkrahmens, in dem aus dem ,Volk ',Bevölkerung ' und aus ,Politik' und ,Krieg' ein sozialer ,Organismus` wurde (Hamann 2016: 163). Damit zusammenhängend diskutiert sie die interdependente Entwicklung anhand von biopolitischen Konzepten, wie ,Lebensraum', ,Rassenreinheit', ,Mischrassen“, Parasitentum', ,Faulheit". Hamann zufolge ist es dieser Denkrahmen, der die Bedingung der Möglichkeit der Entwicklung des eliminatorischen Elements - den Willen zur Vernichtung - hervorbringt, das sich im Genozid an den Herero und Nama manifestiert und später in Auschwitz weiter realisiert.

\footnotetext{
${ }^{4}$ Vergleiche dazu die wegweisende Studie von Michel Foucault (1976a), die ich auch im Exkurs in 4.2.3.3 diskutiere.
} 


\subsection{Multidirektionales Erinnern}

Ohne diese Frage der kolonialgeschichtlichen Vorgeschichte der Shoah hier diskutieren zu wollen (vgl. dazu bspw. Zimmerer 2011a, b, c), erscheint es mit offensichtlich, dass ein Blick auf die Verwobenheiten der Geschichten einen analytischen Mehrwert für beide Forschungsbereiche hat. Ausgehend von Césaire und Arendt haben zahlreiche Theoretiker_innen ihre Thesen weiterverfolgt und Kontinuitäten und Parallelen von Kolonialismus und Antisemitismus herausgearbeitet, die dazu beitragen können, das Verständnis für beide Phänomene zu vertiefen. Von dieser Perspektive erscheinen die Abwehrreflexe einiger Antisemitismusforscher_innen gegen die Möglichkeit Kolonialrassismus und Antisemitismus als verwoben anzusehen oder beides ohne Ausblendung der spezifischen Elemente in eine analytische Klammer der Rassismuskritik zu integrieren als problematisch; so etwa die Studie von Klävers, deren zentraler Punkt ist, dass das In-BeziehungSetzen der beiden Phänomene letztlich „relativierend“, ,inadäquat“ und „,nicht wissenschaftlich" (Klävers 2019: 223) sei. Diese Ansätze, die sich durch ihr Beharren auf dem Modell des ,Zivilisationsbruchs“ und der fetischisierten ,Singularität' auszeichnen, erweisen aus Sicht einer dekolonialen historisch-politischen Bildung auch der Antisemitismuskritik letztlich einen Bärendienst. Ein fetischisiertes Erinnern der Shoah kann das Gegenteil dessen Bewirken, worauf Adornos Imperativ zielte, nämlich Bildung darauf auszurichten, die Wiederholung zu verunmöglichen. Es kann die Sicht auf die überdeterminierte Entwicklung der vielfältigen Formen des Antisemitismus verengen, auf neue Formen rassialisierter Differenz vernebeln sowie Blind machen für erinnerungspolitische Instrumentalisierungen der Shoah für nationale oder kontinentale Interessenspolitik und Überlegenheitsdenken.

Eine dekoloniale historisch-politische Bildung sollte die Verwobenheit von den zwei für den deutschen Kontext konstitutive Kolonialismus und Antisemitismus in Vergangenheit und Gegenwart als zentralen Ausgangspunkt nehmen. Der afro-amerikanische, jüdische Philosoph Laurence Mordekhai Thomas kritisiert Theorien, die das Leid von Jüdinnen und Juden über das der US-amerikanischen Sklaven stellen und anders herum. "He states that both historical experiences are deeply evil, albeit in radically different ways." (Castro Varela 2014: 115) Auch vor dem Hintergrund der globalisierten und migrationsgesellschaftlichen Realitäten sollte an die Stelle kompetitiven erinnerungspolitischen Wettstreits eine Perspektive des multidirektionalen Erinnerns (Rothberg 2009) treten, um die offene Artikulation und wechselseitige Anerkennung unterschiedlicher historischer Gewalterfahrungen und seine Nachwirkungen in der Gegenwart zu ermöglichen. 


\subsubsection{Das Salzwassermodell der Kolonialgeschichte}

Das vom kanadischen Historiker Robert L. Nelson (2009) so bezeichnete Salzwassermodell kritisiert ein Modell, kolonialer Geschichtsschreibung, in dem innerer oder angrenzender Kolonialismus ausgeblendet bleibt, es also der Überwindung von Ozeanen bedarf, um ein Verhältnis als kolonial zu denken. Demgegenüber stehen - auch in dekolonial ausgerichteten Diskussionszusammenhägen sehr kontrovers diskutieren - Ansätze, die die koloniale und imperiale Dimension der Beziehung Deutschlands nach Osten herausarbeitete (Ha 2003; Conrad 2010; Terkessidis 2019).

In den Schüler_innenvorstellungen wird in den Beziehungen kein expliziter Bezug zu einer postkolonialen Perspektive auf ost- oder südosteuropäische Staaten hergestellt. Implizit finden sich aber zahlreiche Verweise darauf. So wird beispielsweise das Thema der Korruption, das eng mit der Herstellung kolonialer Überlegenheit verbunden ist (3.2.6), sehr häufig in Bezug Griechenland und die vermeintliche griechische Mentalität aufgebracht. Ein anderes Beispiel wäre Jan (Gym20), der im Nachdenken über den Charakter und die vermeintliche ,Zurückgebliebenheit' , afrikanischer Stämme“ ins Stocken gerät und aus einem Unbehagen dieser Kategorien heraus, die Herkunft seiner Eltern aus Jugoslawien bzw. Mazedonien einbringt (3.2.6). Es erscheint ihm als in einer deutschen Metropole aufgewachsen als eine Möglichkeit, seine Vorstellungen des Lebens in einem ,Stamm' gedanklich zu nähern. Gleichzeitig bringt diese Verwobenheit des Sprechens über die kolonialen Anderen mit der eigenen, familiären Geschichte eine Verunsicherung hervor, die zu einer Relativierung und teilweise Infragestellung der kolonialen Vorstellungen führt.

\subsection{Innereuropäischer Kolonialismus?}

Es gibt viele gute Argumente, die Beziehung Deutschlands zu ost- und südosteuropäischen Ländern als kolonial zu denken. Zunächst kann es merkwürdig erscheinen, ein innereuropäisches Verhältnis als kolonial zu denken, ist doch der Eurozentrismus ein zentrales Element des Kolonialismus und dieser wird oft als die Unterwerfung nicht-europäischer Weltteile durch Europa verstanden. Hier stellt sich die Frage, was dieses Europa überhaupt ist, dass hier beschworen wird oder hier möglicherweise als Akteur der inneren Kolonisierung in Erscheinung tritt? Wenn von Europa die Rede ist, muss zwischen einem geopolitischen und einem geographischen Verständnis Unterschieden werden. Selbst die EUZugehörigkeit dient hier - spätestens seit der EU-Osterweiterung - nicht mehr als Trennungsmarker dieser beiden Verständnisse. Maria Todorova untersucht in Anknüpfung an Edward Saids Orientalismus die Rolle des Balkan im Kontext Europa und kommt zu dem Schluss, dass dieser - im Sinne eines Balkanismus, 
also die diskursive Erfindung des Balkans als der diskursive Gegenpart vom als Europa bezeichneten Westeuropas - ebenfalls als Europas Anderes anzusehen ist (Todorova 1997). In den Diskussionen um diese Frage werden auch Unterschiede benannt, die beispielsweise durch die Form eines „,detached empire“ in Übersee und einem innereuropäischen „contiguous empire“ (Böröcz 2001: 25) entstehen. Es gibt auch Modelle einer Gradualität der Orientalisierung, die Ländern auf dem Balkan in der kolonialen Weltsicht den Status des Dazwischenseins (in betweenness) - eine Art Puffer zwischen dem ,Orient" und dem ,Westen “ - zuschreibt: „semideveloped, semico-lonial, semicivilized, semi-Oriental $[\ldots]$ always in the process of ,catching up with the West"“" (Boatcă 2006: 92) Nichtsdestotrotz erscheint der Balkan als Europas kolonialer Anderer im Innern oder als interner Orient:

\footnotetext{
"Wie im Falle des Orients fungierte der Balkan als Deponie negativer Eigenschaften gegen die ein positives und selbstgefälliges Bild ,Europas“ und des ,Westens“ konstruiert wurde. Mit dem Wiedererstarken von Osten und Orientalismus als unabhängigen semantischen Kategorien bleibt der Balkan abhängig von Europa, seine Anti-Zivilisation, alter ego, Schattenseite im Innern." (Todorova 1997: 189)
}

Für eine differenzierte Kartographierung der Konstruktion der inneren Machtverhältnisse - ,the imperial map of multiple Europes“ - hat Manuela Boatcă den Begriff der multiplen Europas geprägt (Boatcă 2013a). Dabei stellt sie heraus, dass es nicht nur die konstruierte Nähe zur ,islamischen Welt' ist, sondern auch das orthodoxe Christentum als diskursives Anderes imaginiert wird. Samuel Huntington, der neokoloniale Prediger, westlicher' Überlegenheit, zog in seinem bekannten Text von 1993 über den Kampf der Kulturen (Clash of Civilisations) die innereuropäische Grenze entlang alter Grenzen des Christentums. Er stellt die protestantischen und katholischen Teile Europas - den Westen - den orthodoxen und islamischen Teilen kategorisch gegenüber. Von der Geschichte des ,Westen' und der Entstehung der ,Moderne" wurden die in Europa liegenden christlich-orthodoxen und islamischen Gesellschaften nur "lightly touched“ (Huntington 1993: 30). Er konstruiert den ,Osten“ Europas als ,kulturell rückständig' im Gegensatz zum freiheitlichen, zivilisierten und modernen ,Westen“ (Boatcă 2006: 97).

\subsection{Polen als die wichtigste Kolonie Deutschlands?}

Die These, dass das deutsche Verhältnis nach Osten als kolonial anzusehen ist, wurde vielfach diskutiert. Sebastian Conrad stellt dazu fest, dass der Austausch 
mit den „offiziellen Kolonien“ in vielerlei Hinsicht, insbesondere wirtschaftlich, „marginal im Vergleich zu den quasi-kolonialen Beziehungen“ (Conrad 2010: 141) im Osten einzuschätzen ist. Diese Beziehungen zu nicht-offiziellen Kolonien konnten „weiter (nach Bagdad oder Venezuela) ausgreifen oder sich eben auf angrenzende Gebiete richten“ (ebd.). David Blackbourn bringt diese Sichtweise in folgendem Zitat auf den Punkt: „Das eigentliche deutsche Gegenstück zu Indien oder Algerien war nicht Kamerun, es war Mitteleuropa.“ (Blackbourn 2004: 322) Diese Sicht wurde aus vielen Spielarten postkolonialer Theorie und der Definition von Kolonialismus der UN ausgeschlossen, weil es aus Sicht vieler postkoloniale Perspektiven eine unüberbrückbare, rassialisierte Differenz bedarf und weil nach der UN-Definition eine räumliche Distanz bestehen muss, um ein Verhältnis als kolonial anzusehen (Conrad 2010: 141). Diesen Setzungen hält Sebastian Conrad seine Analyse entgegen, in der er auf zahlreichen Ebenen die Kolonialität des Verhältnisses aufzeigt. Ich werde im Folgenden einige Punkte skizzieren, die die These der Kolonialität des Verhältnisses als sehr überzeugend erscheinen lassen. Hier spielen unter anderem die Aspekte der deutschen Expansionsbestrebungen nach Osten, die rassialisierte Konstruktion der Pol_innen und anderer als ,östlich` imaginierten Bevölkerungsgruppen als die kolonialen Anderen Deutschlands und die Verortung der polnischen ,Kultur' und Bevölkerung als rückständig und unzivilisiert bzw. zu zivilisieren innerhalb der kolonialen Raum-Zeit-Matrix eine Rolle. ${ }^{5}$

\subsection{Koloniale Expansion nach Osten}

Nicht zuletzt unter Rückgriff auf die seit dem Mittelalter stattfindende Kolonisation ,östlicher' Gebiete durch deutsche Akteure beginnt die Geschichte der staatlichen Expansion in Richtung Osten spätestens im 18. Jahrhundert. Nach den sogenannten Schlesischen Kriegen und der Zerstörung Polens durch die Aufteilung der Territorien zwischen Preußen, Russland und Österreich erstreckte sich das preußische Territorium an der Ostsee bis weit hinter Königsberg (Kaliningrad) und nach Süden bis Schlesien. Damit bestand über die Hälfte des preußischen Staatsterritoriums aus ehemaligen polnischen Ländereien. Von insgesamt etwa acht Millionen Preußen sprachen um 1800 etwa drei Millionen

\footnotetext{
${ }^{5}$ Meine Perspektive fokussiert auf die Rolle Polens für das deutsche nation-building und die Geschichte und Gegenwart kolonialer und rassistischer Denkstrukturen im deutschen Kontext nachzuspüren. Für eine Perspektive, die eine postkoloniale Perspektive für das Verständnis der heutigen polnischen Gesellschaft einnimmt, vergleich beispielsweise den Artikel 'Other' Posts in 'Other' Places: Poland through a Postcolonial Lens? (Mayblin/Piekut/Valentine 2016).
} 
Polnisch. Die Annektierungen wurden mit der kolonial imaginierten ,Zurückgebliebenheit" der polnischen Bevölkerung und der polnischen ,Kultur' nicht nur gerechtfertigt, sondern im Sinne einer Zivilisierungsmission sogar zur moralischen und geschichtlichen Notwendigkeit erklärt (Terkessidis 2019: 128). In der Regel wird in der postkolonialen Analyse von Hegels Geschichtsmodell auf seinen Begriff der Geschichtslosigkeit des afrikanischen Kontinents verwiesen, nach dem Afrika „kein geschichtlicher Weltteil“, ,noch ganz im natürlichen Geiste befangen“ und an der „Schwelle der Weltgeschichte“ (Hegel 1831: 163) zu verorten sei. Ähnliches, nicht gleiches schreibt er aber auch über die „slawische Nation“ im Osten, die er ebenfalls von Geschichtlichkeit ausklammert, wenn auch nicht so absolut, da ein „Teil der Slawen“ von der ,westlichen Vernunft erobert“ (ebd.: 478) worden sei: „Dennoch aber bleibt diese ganze Masse aus unserer Betrachtung ausgeschlossen, weil sie bisher nicht als ein selbstständiges Moment in der Reihe der Gestaltungen der Vernunft in der Welt aufgetreten ist.“ (ebd.) Sebastian Conrad sieht in den Diskursen des 19. Jahrhunderts eine deutlich koloniale Differenz durch die Einordnung bzw. Entgegensetzung Polens und Deutschlands in der kolonialen Raum-Zeit-Matrix: „Wenn Deutschland und Polen so als zwei Welten in unterschiedlichen Zeiten erschienen, dann deutet dies auf die koloniale Dimension, die das Verhältnis zwischen beiden Nationen im 19. Jahrhundert annahm.“ (Conrad 2010: 142).

Die Expansion wurde diskursiv - von der Literatur über politische Reden bis zu wissenschaftlichen Untersuchungen - ebenfalls als eine Kolonisation des , wilden Ostens' gerahmt, womit zwei koloniale Denkmodelle zusammenfielen. Neben die Annahme der ,Rückständigkeit‘ erlaubte die Annahme der terra nullius die Planung der ,Peuplierung' des Ostens durch gezielte Ansiedlungen deutschsprachiger Bevölkerungen (Terkessidis 2019: 128). Ihre Zuspitzung erfuhren diese Politik später in der in der Weimarer Republik erstarkende Vorstellung des ,Lebensraums '. Dieser Begriff wurde unter anderem vom Geograph Friedrich Ratzel geprägt, der „eine Art sozialdarwinistische Geographie von Raumaneignungen, -verwurzelungen und -kämpfen erstellte" (ebd.: 124). Er wurde jedoch in zahlreichen Kontexten geprägt und umrahmt, wie etwa in der Literatur durch den sehr erfolgreichen Roman Volk ohne Raum von 1926 von Hans Grimm. Die Lebensraum-Ideologie spielte auch für Deutsch-Südwestafrika, jedoch insbesondere für den ,Osten' eine zentrale Rolle. In der Vernichtungs- und Vertreibungssowie der Ansiedlungspolitik im nationalsozialistischen ,Generalplan Ost‘ erfuhr es eine kaum vorstellbare Zuspitzung. In seinen Tischgesprächen stellte Hitler seine Vorstellung der Rolle des „Ostraums“ folgendermaßen dar: „Was für England Indien war, wird für uns der Ostraum sein." (Hitler, zitiert nach Terkessidis 2019: 125) Bereits in mein Kampf visierte Hitler die „Kolonisation der 
Ostmark“ als die „Bodenpolitik der Zukunft“ an und warb für eine „Ostpolitik im Sinne der Erwerbung der notwendigen Scholle für unser deutsches Volk“ (ebd.). Das Programm für die kaum vorstellbare Ausmaße annehmende Politik der Vertreibung - beispielsweise aus Posen bis Ende 1941630000 Menschen bei 4 Mio. Gesamtbevölkerung -, Umsiedelung, Massaker, Segregation in ,völkisch rein deutsche' und ,Lebensreservate" für die verbliebene polnische Bevölkerung, Politik der , verbrannten Erde" wie im früheren Deutsch-Ostafrika als Antwort auf Wiederstand und die Ansiedelung deutscher Bevölkerungsgruppen wurde vom Leiter der Verwaltung des Generalgouvernements Hans Frank folgendermaßen zusammengefasst: „Maßgebend für die Regierungstätigkeit im Generalgouvernement sei der Wille des Führers, dass dieses gebiet das erste Kolonialgebiet der deutschen Nation sei.“ (zitiert nach Terkessidis 2019: 149) Anders als häufig in der Geschichtswissenschaft diskutiert, kann diese Fokussierung auf den ,Ostraum " aber nicht nur als ein Ersatz für die verlorenen Kolonien in Übersee interpretiert werden, sondern erscheint vielmehr als Fortführung einer langen Tradition der kolonialen Beziehung nach, Osten'.

Die innerdeutschen Debatten über die Kolonisierung Polens zeichneten sich durch koloniale Ideologie aus. In den Debatten um den Umgang mit polnischem Widerstand und möglicher Unabhängigkeit polnischer Gebiete, wie etwa im Anschluss an die deutsche Revolution 1848, war eine unangefochtene Diskursgrundlage aller Beteiligten die zivilisatorische Überlegenheit der Deutschen. Die große Mehrheit der Beteiligten leitete daraus die Legitimation und Notwendigkeit ab, dass die Deutschen die Pol_innen durch Eroberung und Unterwerfung erziehen und zivilisieren dürften und sollten. Besondere Resonanz bekam beispielsweise die Rede des Schriftstellers Wilhelm Jordan, stellte die Eroberung als ein „Recht der Geschichte“ dar, da die „Übermacht des deutschen Stammes gegen die meisten slawischen Stämme“ eine „naturhistorische Thatsache“ (Jordan 1848, zitiert nach Terkessidis 2019: 131) sei: „Ein Volk, das aus Edelleuten, Juden und Leibeigenen bestand, war, nachdem eine langjährige Anarchie es verwildert, einer vernünftigen Freiheit unfähig.“ (ebd.) Den kindlichen, dem „Hang zu den Freuden rauschender Geselligkeit" fröhnenden Pol_innen stellte Jordan das Bild der Deutschen gegenüber, die sich durch ,harte Arbeit, Fleiß, einfaches Familienleben, Überlegung und Zielgerichtetheit" (Terkessidis 2019: 132) auszeichneten.

\subsection{Interne Kolonisierung - die Angst vor der Polonisierung}

Diesem Zusammenhang, also die Rolle, die die Pol_innen bzw. das imaginierte Polnische als negativ für die Konstitution der Erfindung der deutschen Nation spielte, geht auch Sebastian Conrad (2010: 124-167) nach. Beispielsweise für 
die Konstruktion von Arbeitsdisziplin und Strebsamkeit in der nationalen Ideologie waren die Pol_innen als Negativ - im Sinne Saids als diskursive Figur - zentral. Spätestens seit der Mitte des 19. Jahrhunderts waren die Diskurse in Deutschland vor der Angst der Polonisierung geprägt, die den deutschen Volkskörper gefährdeten. Der berühmte Soziologe Max Weber formulierte das 1895 so: „In Australien wird [...] die Einwanderung der Chinesen verboten, die Polen sind aber durch die Möglichkeit der Vermischung und Herunterdrücken der deutschen Kultur noch gefährlicher.“ (Weber 1895, zitiert nach Conrad 2010: 167) Zentral war hier also die Angst vor einer, Vermischung', die angeblich von den anwesenden Pol_innen und den migrantischen Arbeiter_innen ausgeht. Damit korrespondiert auch die „Gefahr“, die im nationaldeutschen, antipolnischen Diskurs den Polinnen zugeschrieben wurde, welche aus der Perspektive der Hakatisten - dem einflussreichen Kolonialverband des Ostmarkentums - als ,unsere wirksamsten und gefährlichsten Gegner" (nach Conrad 2010: 146) imaginiert wurden, die aufgrund ihrer vermeintlich sexuellen Reize und ihrer vorgeblich hohen Fertilität das ,deutsche Volk zu majorisieren“ und „durch Einheiraten rechtschaffene deutsche [...] Männer“ (ebd.) zu ,polonisieren“ drohten. Die Konstruktion der kolonialen Differenz zwischen Pol_innen und Deutschen war jedoch nicht nur ein „diskursives Ereignis, sondern gleichermaßen Element der rechtlichen und sozialen Praxis in den preußischen Ostgebieten“ (ebd.: 143). Auf zahlreichen Ebenen wurde ein staatliches Sonderrecht geschaffen, das die formal deutschen Staatsangehörigen „entlang ethnisch-kultureller Kriterien in zwei Klassen unterteilte“ (ebd.) Zahlreiche Interessensgruppen - von den Junkern bis zu den Kolonialverbänden - forderten diese existierende gesetzliche Ungleichbehandlung explizit ein, die zu den „Charakteristika kolonialer Rechtsordnungen“ (ebd.) zählt. So plädierte beispielsweise der Mitbegründer des Alldeutschen Verbandes Alfred Hugenberg 1902 dafür, in Osteuropa die „deutsche Kolonialbevölkerung wie im Mittelalter unter eigenes Recht zu stellen" und damit die bestehende gesetzliche Ungleichheit strukturell zu vertiefen. Sowohl Schulbildung als auch politische Recht sollten ihm zufolge ausschließlich den ,Deutschen` zukommen.

In der Frage der Einwanderungs- bzw. Abschottungspolitik gegenüber Pol_innen war die deutsche Politik alles andere als einheitlich. Interessenskonflikte entstanden nicht zuletzt dadurch, dass die (oft polnischen) migrantischen Arbeiter_innen unabdingbar für den Agrar- und Industriesektor waren; der Profit dieser Sektoren basierte auf der Ausbeutung der migrantischen Arbeitskraft (Nicolae-Vladu 2021). In dem Schreiben Die polnische Gefahr von 1901, die dem preußischen Staatsminister Miquel gewidmet war, heißt es, dass die Einwanderung eine Bedrohung des „Volkskörpers“ darstellen würde und sie das 
„hochentwickelte Germanenvolk“ zu einem „Kulturdünger für slawische Völkerschaften" (nach Conrad 2010: 156) degenerieren ließe. Als Ausweg wurde die Anwerbung von „Arbeiter blutsverwandter Völker“ vorgeschlagen, wie etwa Holländer, Dänen, Schweden oder Norweger, die dazu beitragen würde, so der rassistische Tenor weiter, das schon mit "Slawenblut“ durchsetzte „Volk“ mit „Germanenblut“ (ebd.: 157) aufzufrischen. Die Anwerbungsversuche dieser „Völkerschaften" (ebd.) waren zahlreich, können jedoch im Großen und Ganzen als gescheitert angesehen werden. Stattdessen wurde im Sinne des divide et impera eine neue rassistische Differenz erfunden, die zwischen Ruthenen und Polen unterschied und erstere in dieser rassistischen Imago als weniger, volksschädlich ${ }^{*}$ konstruierte (ebd.: 159 ff.).

Die rassistische Angst vor der Polonisierung wurde dabei von einer Überschneidung mit dem Antisemitismus bestärkt. Das „Ostjudentum“ wurde im nationalistischen Diskurs mit „politischem Radikalismus, mit Armut, mit dem Mädchenhandel aus Osteuropa“ verknüpft und rief „Assoziationen mit unhygienischen Zuständen und der Einschleppung von Krankheiten“ (ebd.: 147). Dabei wurde zum einen die Diskussion um die drohende ,Polonisierung " antisemitisch aufgeladen und andersherum aber auch antisemitische Stereotype durch ,die Furcht vor dem ,Osten““ und ,,,asiatischen“ Einflüssen“ (ebd.) und antislawischen Rassismus geprägt. Diese Überschneidung drückte sich auch auf verwaltungsbürokratischer Ebene aus, auf der lange ,Polen“ und ,Juden` als eine Gruppe behandelt wurden (ebd.: 146).

Dabei changierte die rassistische ,Polenpolitik' in Deutschland zwischen zwei Umgangsweisen. Unter Otto von Bismarck beispielsweise, zunächst in seiner Funktion als preußischer Ministerpräsident sowie ab 1871 als Kanzler des deutschen Reiches, wurden Assimilation und Verdrängung als zwei grundsätzliche Strategien etabliert (Terkessidis 2019: 134). Die Anpassungsversuche fokussierten beispielsweise in Posen auf die Durchsetzung von Deutsch als allgemeiner Unterrichtssprache sowie die staatliche Kontrolle über die Religion zur Verminderung katholischen Glaubens. Demgegenüber stand eine Politik der Abschottung und Verdrängung; so wurden beispielsweise in den mittleren 1880er Jahren Massenausweisungen von etwa 32000 Personen aus Posen durchgeführt, um die ,Germanisierung' in dieser Region voranzubringen (ebd.: 135).

Die Möglichkeit der Integration wird in Diskussionen um die Frage der Kolonialität der deutsch-polnischen Beziehungen häufig als Gegenargument angeführt. Es gab in der Tat qualitative Unterschiede zwischen den deutschen Kolonien in Afrika und im Osten. Während beispielsweise die Furcht vor ,Mischehen “ in den polnischen Ostgebieten des Reiches keine rechtliche Umsetzung erfuhr, 
wurde seit 1905 die Eheschließung deutscher Staatsangehöriger mit ,Einheimischen' in den deutschen Kolonien in Afrika rechtlich unmöglich gemacht (Conrad 2010: 146). Aus einer kolonialismustheoretischen Perspektive ist dieser qualitative Unterschied der kategorischen Segregation bzw. Nicht-Integration jedoch keineswegs als Voraussetzung dafür anzusehen, das Verhältnis als kolonial zu begreifen. Beispielsweise bestand die Politik des französischen Kolonialismus, vor allem in den nordafrikanischen Gebieten, aus einer Politik der Assimilation, die es bei Aufgabe des Islam beispielsweise Algerier_innen ermöglichte, die französische Staatsbürgerschaft zu erhalten. „Der Kolonialismus beinhaltete mithin eine Spannbreite unterschiedlicher Assimilationsverhältnisse, die von der (häufig erzwungenen) Integration bis zu Regimes der Apartheid reichen konnte." (Conrad 2010: 145).

\subsection{Vampire als koloniale Projektion}

Auch wenn Polen und die Pol_innen zweifelsohne die zentralste Projektionsfläche deutscher Kolonialfantasien im Osten war, finden sich solche auch für zahlreiche andere, östlich" markierten Gebiete. Ich will im Folgenden nur zwei kontingent gewählte und möglicherweise marginale Aspekte behandelnde Beispiele darstellen, an denen sich die Spannweite und Gegenwartsrelevanz einer Perspektive möglicherweise plausibilisiert, die deutsche - reale oder imaginäre - Zugriffe auf ost- und südosteuropäische Territorien als koloniale in den Blick nimmt. Im kolonialen Imaginären entstand im 19. Jahrhundert die Figur des Vampir, die sich bis heute großer Beliebtheit erfreut. Sowohl der Hauptreferenzpunkt gegenwärtiger Formen des Vampirischen - Bram Stoker's Dracula (1897) - als auch weniger populäre literarische Elemente des Vampirischen - wie etwa für den deutschen Kontext die Geschichte Der Fremde (1847) - entstanden in einem kolonialen Kontext und können als Ausdruck der Auseinandersetzung damit verstanden werden (Meyen 2012). In beiden Texten wird die Vampirfigur im Südosten Europas verortet, konkret in Transsilvanien bzw. den Karpaten. In beiden Texten wird die einheimische Bevölkerung als ,primitiv' und ,zurückgeblieben' dargestellt, während im Gegensatz dazu die ,Engländer' bzw. ,Deutschen' als fortschrittlich und rational dargestellt werden. In Der Fremde wird dabei das Land Schlesiens als offen für eine Kolonisierung und die Deutschen als moderne Landwirte und als koloniale Heilsbringer verherrlicht.

Die Figur des Vampirischen entsteht im Kontext dieser geopolitisch-kolonialen Interessenspolitik als Antwort auf damit verbundene koloniale Ängste sowie gleichzeitig als Festschreibung der ,Rückschrittlichkeit‘ und damit Legitimationsfigur der Kolonialisierung. Stephen Arata (1990) interpretiert in diesem 
Zusammenhang Dracula als die Angst vor der - in dieser Zeit viel diskutierten - umgekehrten Zivilisierung durch Migration. In Der Fremde wandert eine deutsche Familie nach Schlesien aus, um dort das Land zu kolonisieren. Der aus dem ,Türkenkrieg ' zurückkehrende Ritter verhindert den Tod der Gutsherrentochter Franziskas, da er aufgrund seiner umfangreichen Reiseerfahrung in den südosteuropäischen und osmanischen Gebieten den Vampir als solchen erkennt (Meyen 2012). Die als lohnenswertes Abenteuer dargestellte Besiedelung zwecks germanisierender Kolonialisierung östlicher Gebiete wird hier mit der Herausforderung konfrontiert, sich dabei den Gefahren des aus dem Südosten andrängenden ,Unbekannten` zu stellen. Das hier zur Disposition - also zur kolonialen Besetzung bereit - stehende Land ist vor dem unizivilisierten Anderen zu retten. Das koloniale Andere ist hier zwiegespalten. Die ansässige Bevölkerung wird im kolonialen Imaginären als ,rückschrittlich' und ,unterwürfig' konstruiert, während die Figur des Vampirs den Anspruch der gefährlichen, aus dem Südosten andrängenden Seite des kolonialen Anderen personifiziert.

\subsection{Kryptokoloniales Griechenland}

Mark Terkessidis plädiert im Anschluss an Ranabir Sammaddar und Michael Herzfeld dafür, die innereuropäischen Beziehungen, wie etwa die von Deutschland zu den südosteuropäischen Ländern als ,kryptokolonial“ oder ,postimperial“ (Terkessidis 2019: 170) zu bezeichnen. Sammaddar (2016), Politikwissenschaftler und Direktor der Calcutta Research Group untersuchte aus postkolonialer Perspektive die europäische Schuldenkrise und kommt zu dem Ergebnis, dass die europäische Peripherie einem den Postkolonien schon lange bekannten Skript folgt, nach dem wirtschaftliche Abhängigkeit und die Verschuldung ,immer wieder zu einem Verlust der politischen Souveränität" (Terkessidis 2019: 171) führten. Michael Herzfeld hat sowohl bereits lange vor (Herzfeld 1987) als auch während der sogenannten Finanzkrise (Herzfeld 2019) die „kryptokolonial[e]“ (ebd.: 210) Position Griechenlands innerhalb Europas herausgearbeitet. Kryptokolonial bezeichnet, ähnlich wie semikolonial, den Zustand von Staaten, die zwar nominell politisch unabhängig sind, aber aufgrund der wirtschaftlichen Abhängigkeit effektiv auf eine oftmals erniedrigende Weise abhängig bleiben (Terkessidis 2019: 158). Dies trifft auf alle Staaten des Balkan zu, die auch nach der Unabhängigkeit vom Osmanischen Reich direkten und indirekten Herrschaftsformen europäischer Mächte unterworfen wurden. Griechenland wurde seit dem 19. Jahrhundert systematisch auf politischer und ökonomischer Ebene in imperiale Abhängigkeitsverhältnisse gebracht. Die deutsche imperiale Politik begann schon lange vor und zieht sich auch nach der nationalsozialistischen Invasion bis in die Gegenwart. Die nationalsozialistische Invasion führte zur systematische 
Zerstörung von Infrastruktur, der Plünderung von Ressourcen und Kulturgütern, Zwangsarbeit, Massakern und Auslöschungsaktionen, durch die insgesamt über $7 \%$ der griechischen Bevölkerung getötet wurden (ebd.).

Griechenland ist aus deutscher Perspektive auch deswegen besonders interessant, weil im nation-building seit dem 19. Jahrhundert ein Philhellenismus - also eine als Vorgeschichte des Deutschen imaginierte, affirmative Projektion auf das antike Griechenland - als konstitutives Element der diskursiven Erfindung des Deutschen anzusehen ist. Diese nationalhistorischen Projektionen zielten dabei auf das antike Griechenland, das als Vorbild für Kunst, Literatur, Schulreformen, die Organisation von Universitäten etc. herangezogen wurde (ebd.: 161). Die Projektion des antiken Griechenlands wurde dabei in einem Gegensatz zum antiken Rom konstruiert, das mit Frankreich assoziiert wurde. Prominentes Beispiel für die philhellenische Konstruktion einer deutschen Tradition und Überlegenheit stellt der deutsche Philosoph Martin Heidegger dar (ebd.: 166). Die „Neugriechen“ wurden dabei gleichzeitig als ,unzuverlässige, barbarische Kinder“ (ebd.: 163) imaginiert und wurden entweder rassisch oder kulturell als enthellenisiert dargestellt. Diese lange kolonial gefärbte Vorgeschichte der Beziehung zwischen Deutschland und Griechenland, die sich in der gegenwärtigen Imperialität der „ökonomischen Verhältnisse und der Wissensstrukturen“ (ebd.: 172) wiederfindet, fand dann in den Diskursen rund um die sogenannte Finanzkrise ihren Ausdruck, in denen die Griech_innen in der deutschen Presse erniedrigt und beleidigt und politisch dem griechischen Staat der letzte Rest Souveränität entzogen wurde (Sammaddar 2016; Terkessidis 2019: 170).

\subsection{Und heute?}

Sowohl auf ökonomischer - ungleiche Handelsbeziehungen, Schulden und aufoktroyierte Privatisierungsprogramme - als auch auf der Ebene der Wissensbestände sind die anhaltenden Kontinuitäten mit der beschriebenen Kolonialvergangenheit Deutschlands augenscheinlich. Im Folgenden führe ich drei beispielhafte Aspekte aus der wissenschaftlichen Auseinandersetzung an, für die eine Erweiterung der Perspektive auf die deutsche Kolonialgeschichte für eine differenziertere Sicht auf die Gegenwart als fruchtbar erscheint. In der von Antiziganismus überlagerten Diskussion um die ,Armutsmigration“ aus Südosteuropa, in der Behauptung der Überlegenheit des politischen Systems Deutschland im Gegensatz zu den ,östlichen' Ländern als auch in den deutschen Zugehörigkeitskonstruktionen der Gegenwart finden sich zahlreiche Spuren dieser Kolonialvergangenheit.

Mark Terkessidis schreibt beispielsweise im Kontext des deutschen Kolonialverhältnisses zu Polen: „Noch heute existieren in Deutschland ganz erhebliche rassistische Wissensbestände über Menschen polnischer Herkunft, Klischees 
über ,Polenmärkte', informelle Wirtschaft, Autoschieberei oder Alkoholkonsum.“ (Terkessidis 2019: 155) Er referiert beispielsweise die Journalistin Emilia Smechowski. In Wir Strebermigranten beschreibt sie, wie ihre Eltern sich als polnische Einwanderer in Deutschland für ihr , unterentwickeltes Land" förmlich geschämt haben. Daraus entwickelte sich für sie selbst ein ,verordnetes Deutschsein “, ,in dem sie als Person aber niemals aufging“ (ebd.) Sie bezieht sich dabei auf den postkolonialen Theoretiker Homi K. Bhabha, der im Kontext der postkolonialen Diaspora davon gesprochen hat, dass die Nachahmung (mimikry) ein Dazwischensein erzeuge, dessen Differenzkonstruktion doch niemals ganz aufgehoben werde. Diese Ambivalenz der Mimikry, die oft mit dem Ausdruck ,,beinahe dasselbe, aber nicht ganz" (Bhabha 1994: 127) zusammengefasst wird, bringt bei Smechowski ein Gefühl hervor, ,anderen etwas vorzuspielen und dennoch unvollständig zu sein, diese Angst, bald durchschaut und dann nicht mehr gemocht zu werden“ (Terkessidis 2019: 155-156).

Fatima El-Tayeb beschreibt die Parallelen und Kontinuitäten vom Diskurs um Geflüchtete ,Ostjuden “ in der Weimarer Republik und dem Diskurs um die ,Flüchtlingskrise“ nach 2015. Damit wackelt sie an dem die „Mehrheitsmeinung prägenden“ Bild eines ,traditionell kulturell vielfältigen, aber ethnisch und religiös einheitlichen Deutschlands (und Europas)“ (El-Tayeb 2016: 94), das erst durch die als ,fundamental (religiös, kulturell, ,rassisch')“ anders konstruierten Einwanderer_innen ab den 1950er Jahren aus dem „Gleichgewicht gebracht“ wurde, wobei deren „Integrationsfähigkeit“ (ebd.) in Frage steht. Dieses ,,Vorhernachher-Modell“" ist nicht nur eine inadäquate Beschreibung der Realität, es konstruiert eine Perspektive, ,die es unmöglich macht, die vorausgesetzte klare Trennung in deutsch und undeutsch" (ebd.) zu überwinden.

Kien Nghi Ha hat bereits 2003 Die kolonialen Muster deutscher Arbeitsmigrationspolitik in den Blick genommen. Er analysiert die Kontinuitäten deutscher Arbeitsmigrationspolitik und vergleicht Politiken der Gegenwart mit denen im Kaiserreich und der Weimarer Republik. Anfang des 20. Jahrhunderts waren 1,26 Millionen Ausländer_innen im Deutschen Reich beschäftigt, von denen etwa zwei Drittel aus den polnischen Gebieten Österreich-Ungarns und Russlands kamen (Ha 2003: 67). Neben den diskursiven Tropen der ,Überfremdung', den imaginierten Gefahren der Migrationsanderen, der naturalistisch-kolonialen Vorstellung des ,Ansturms“ etc. fallen in diese Zeit auch die Entwicklung zentraler Sozialtechniken der institutionalisierten Diskriminierung, die damals wie heute als Kontrollmechanismen eingesetzt werden, wie etwa die Lagerunterbringung, der Legitimationszwang, der Rückkehrzwang in der Karenzzeit. Im Kaiserreich wurden die polnischen Arbeiter_innen diskursiv als „kriecherisch“, „unterwürfig“, 
„,billig“ und „willig“ (Ha 2016: 173, 176) sowie als ,rassisch“ für schwere Arbeiten auf dem Feld oder unter Tage disponiert konstruiert. Dies findet sich auch in heutigen Diskursen. Ha analysiert diese Kontinuitäten als eine „Internalisierung kolonialer Verhältnisse“ (Ha 2003: 63). Eine solche Perspektive auf die rassistische Stratifikation des Arbeitsmarktes und ihrer staatlichen Instrumentarien bekommt bei einem Blick auf die gegenwärtigen Strukturen umso mehr Gewicht; ganze Branchen, wie etwa Bauwirtschaft, Fleischproduktion, Landwirtschaft, Sexarbeit, Pflege und Putzkolonnen bauen auf dieser Stratifikation auf und verdanken ihr ihren Profit. Ein Großteil der Arbeiter_innen kommt, wie im Kaiserreich, aus Polen sowie Südosteuropa. Zudem finden sich in den gegenwärtigen Ausbeutungsstrukturen, Differenzkonstruktionen und Lebensverhältnissen koloniale Muster wieder, die an die Internalisierung kolonialer Verhältnisse aus dem Kaiserreich anknüpfen.

\subsection{Zu den Gründen für eine Vernachlässigung einer dekolonialen Sicht}

Angesichts der - wenn auch nur lückenhaft und kursorisch - angeführten Argumente stellt sich die Frage, warum dekoloniale Perspektiven auf die Kolonialgeschichte des deutschen ,Drangs nach Osten“ und seine Effekte für die Gegenwart weiterhin als marginal zu bezeichnen sind. Mark Terkessidis führt als zentralen Grund für die Vernachlässigung der ,kolonialen Erfahrungen im europäischen Osten und Südosten“ an, dass diese nicht ,in die beiden global gewordenen Schemata von Erinnerung passen“ (Terkessidis 2019: 126). Diese seien zum einen die Erinnerung an die Shoah - zu den Potenzialen einer Erweiterung der Perspektiven sei hier auf das vorherige Kapitel verwiesen - und zum anderen seit noch nicht allzu langer Zeit die Erinnerung an Versklavung und Kolonialismus, von denen Schwarze und Personen of Color betroffen waren. Geschichten, die nicht in dieses Schema passen, könnten „kaum artikuliert“ (ebd.) werden. In zentralen Werken postkolonialer Theoriebildung, auch solchen, die einen umfassenden Anspruch haben, wie etwa im Lexikon Wie Rassismus aus Wörtern spricht - (K)Erben des Kolonialismus im Wissensarchiv deutsche Sprache (Arndt/Ofuatey-Alazard 2011) findet sich keine Erwähnung eines auf Osteuropa oder Südosteuropa bezogenen Kolonialismus oder Rassismus, trotz der Existenz „ganz erheblicher rassistischer Wissensbestände“ (Terkessidis 2019: 155) über Menschen ost- oder südosteuropäischer Herkunft (ebd.: 155).

Terkessidis problematisiert die Exklusivität postkolonialer Perspektiven, in denen auf die überseeische Erfahrung referiert werden muss, um als koloniale Erfahrung zu gelten. Er führt Irland, Malta und Zypern als Beispiele an, die „ohne Zweifel Kolonien des britischen Weltreiches [waren], obwohl deren 
Bevölkerung überwiegend als weiß gilt“, um die Dominanz der kolonialen Farbenlehre innerhalb postkolonialer Perspektiven infrage zu stellen. Terkessidis plädiert dafür die „deutsche Expansion in den europäischen Osten und Südosten in einer postimperialen/postkolonialen Weise zu untersuchen - als Bestandteil des Dominanzprojekts ,Mitteleuropa ' oder als Teil des Nazi-Plans vom neuen ,germanischen“ Reich“ (ebd.: 127). Eine dekoloniale politische Bildung muss sich dieser Diskussion stellen, die nach einer Erweiterung des Begriffs des Kolonialen auf innereuropäische Kolonialverhältnisse verlangt. Diese Diskussion steht vor der Herausforderung, dass durch eine solche Anerkennung die Erfahrungen der überseeischen Kolonien und ihrer Nachfahren nicht relativiert werden, sondern vielmehr das Potenzial dieser Perspektivenerweiterung zum Tragen kommt. Angesichts der andauernden Relativierungsversuche der kolonialen Erfahrung und ihrer Gegenwärtigkeit muss die Gefahr, dass eine solche Erweiterung des Kolonialismusbegriffs für die Dethematisierung Schwarzer Perspektiven und Erfahrungen instrumentalisiert wird, ernst genommen werden.

\subsubsection{Geteilte Gegenwart(en) in einer neokolonialen Welt}

In diesem Abschnitt und in den folgenden geht es nicht mehr in erster Linie beziehungsweise nicht explizit um den historischen Kolonialismus als Lerngegenstand oder die erinnerungspolitischen Umgänge damit. Vielmehr geht es um andere Dimensionen der Dekolonialität, verstanden als Gegenwärtigkeit kolonialer Machtverhältnisse. Hier geht es also darum, wie sich die Lernenden in ihren globalisierten Lebenswelten orientieren und wie eine dekoloniale politische Bildung damit umgehen kann.

\subsubsection{Von Wertschöpfungsketten, imperialer Lebensweise und Solidarität}

Fast ausnahmslos sehen sich die Schüler_innen in eine Globalität eingebunden. Dabei ist die dominante Weise dies zu tun, die Wertschöpfungsketten zu benennen, an deren Ende sie als Konsumierende stehen. Benannt werden hier insbesondere die Produktion von Kleidung, Lebensmitteln und Technologie im globalen Süden. Als Gründe für die Auslagerung der Produktion werden von der überwiegenden Mehrheit die Lohnungleichheiten genannt, die eine weniger kostenintensive Produktion und so einen größeren Profit oder günstigere Konsumtionsgüter zur Folge haben. Im Imaginären der Schüler_innen sehen sie sich so auf eine bestimmte Art und Weise mit den Arbeiter_innen im Globalen Süden 
verbunden. Dies ist verbunden mit einem humanistischen Diskurs, der die vorgestellten Arbeits- und Lebensbedingungen der Arbeiter_innen im Globalen Süden als zutiefst ungerecht empfindet. Dieser Affekt der Ungerechtigkeit kann ein zentraler Ausgangspunkt einer dekolonialen politischen Bildung darstellen, mit dem über die globale soziale Ungleichheit und die internationale Arbeitsteilung reflektiert werden kann.

\subsection{Imperiale Lebensweise}

Als theoretischer Anknüpfungspunkt bietet sich hier das Konzept der imperialen Lebensweise an, das von Ulrich Brand und Markus Wissen (2017a) geprägt wurde. Die Schüler_innen diskutieren ihre Verwobenheit mit der internationalen Arbeitsteilung in der großen Mehrheit auf eine individualisierende und moralisierende Weise. Oft spitzt sich die Frage darauf zu, ob sie Fair-Trade-Produkte kaufen wollen bzw. können oder nicht. Mit dem Konzept der imperialen Lebensweise kann den Schüler_innen ermöglicht werden, ihre Vorstellungen und das Unrechtsempfinden über die, direkten“ Wertschöpfungsketten hinaus mit der Frage zu verknüpfen, wie wir als Gesellschaft - wer auch immer jetzt damit gemeint ist; regional national, kontinental, global - leben wollen. Damit kann den Schüler_innen ein Instrument an die Hand gegeben werden, ihr moralisches Unwohlsein in eine Frage des Politischen zu transformieren. Mit dem Begriff der imperialen Lebensweise wird darauf verwiesen, dass die Gesellschaften des Globalen Nordens und damit auch die Menschen in ihrem Alltag systematisch auf die Ausbeutung billiger Arbeitskraft und der natürlichen Ressourcen anderer Weltregionen in Europa und des Globalen Südens zurückgreifen, um sich selbst zu reproduzieren. „Die imperiale Lebensweise ermöglicht, sich auf eine bestimmte Art und Weise fortzubewegen, zu kommunizieren, zu essen und sich zu kleiden.“ (Brand 2018: 79) Diese Art erhöht die Reichweite und materiellen Ressourcen zur Handlungsfähigkeit. ,Die relativ besseren materiellen Lebensbedingungen ermöglichen eine höhere Lebensqualität.“ (ebd.) Die imperiale Lebensweise kann als diejenige einer „globalen Minorität“ bezeichnet werden, „die ihren Wohlstand, ihre Mobilitäts- und Konsumptionsbedürfnisse nur auf Kosten der sozialen und ökologischen Ressourcen einer globalen Majorität führen kann“ (Mecheril 2020: 108).

Die Reflexion dieses Zusammenhangs als gesellschaftliches Strukturprinzip ist ein Ziel einer dekolonialen politischen Bildung. Der Agrarsoziologe Philip McMichael spricht von „Food from nowhere“ und meint damit „das Verdunkeln der Herkunft und Produktion von Lebensmitteln, mit der ihre raumzeitlich unbegrenzte Verfügbarkeit normalisiert wird" (Brand/Wissen 2017b). Diese Verdunkelung und Normalisierung findet sich teilweise auch in den Vorstellungen der 
Lernendenvorstellungen, er wird allerdings von der großen Mehrheit selbst wieder reflexiv eingefangen. Zum Beispiel stellt Luka (3.4.2) in Bezug auf die internationale Arbeitsteilung und die Verfügbarkeit der Güter folgendes fest: „Also ich finde das richtig gut. Das ist ja auch produktiv. Also wir haben überall alles. Das finde ich eigentlich perfekt. So sollte es sein." (Luka, Gym02) Wenige Sätze später benennt er aber selber den Ursprung der Güter, problematisiert die Arbeitsbedingungen sowie die Lohnunterschiede und reflektiert über die ethische Rechtfertigung der Ungleichheit: „Ich meine, ähm, das sind ja auch genauso Menschen wie wir und wieso ist es denn bei denen günstiger?" (Luka, Gym02) Die Ausblendung des imperialen Zusammenhangs der Konsumtion in den Lernendenvorstellungen basiert also in erster Linie nicht auf einem Nicht-Wissen, wie eine der Thesen von Brand und Wissen ist, sondern auf der Habitualisierung der imperialen Konsumtionsform, die in den „Alltagspraxen der Menschen tief eingelassen“ ist und „sich zu Routinen verfestigt“ (Brand 2018: 80) hat.

\subsection{Entpolitisierung durch bewussten Konsum?}

Die Schüler_innen sehen in der Reflexion eigener Handlungsoptionen zur Veränderung der in den ungleichen Lebensverhältnissen aufscheinenden Ungerechtigkeit ihren eigenen Konsum als zentrales Handlungsfeld an. Brand und Wissen problematisieren die soziale Ungleichheit in den Gesellschaften des Globalen Nordens: „Während sich die einen“ dem Zwang zur imperialen Lebensweise ,punktuell auch entziehen können, indem sie etwa regionale und saisonale Lebensmittel kaufen“ würden andere nur ,über eine geringe Handlungsfähigkeit“ (Brand/Wissen 2017a: 55) verfügen. „Wer über ein niedriges Einkommen und Vermögen verfügt oder von der Arbeitslosenversicherung oder Sozialtransfers lebt“, könne am ,gesellschaftlichen Wohlstand nur in dem Maße partizipieren, wie er oder sie - etwa beim Kauf eines T-Shirts oder von preiswerten Lebensmitteln - von den schlechten Arbeitsbedingungen und der Ausbeutung von Natur andernorts profitiert" (Brand/Wissen 2017a: 55). Genau dieser Punkt wird auch von zahlreichen Schüler_innen aufgegriffen, die als einziges Handlungsfeld die FairTrade-Konsumtion sehen und gleichzeitig ihre beschränkten Ressourcen dafür anführen, warum sie diesen Weg nicht gehen können. Sie verweisen damit auf die Begrenztheit des Ansatzes des bewussten Konsums zur Transformation globaler Ungleichheitsstrukturen. Hinzu kommt die Problematik, dass der bewusste Konsum auch als Distinktionsmittel der oberen sozialen Schichten zur Abwertung der unteren sowie zur Selbstaufwertung und Glorifizierung - quasi als Feigenblatt - der eigenen Lebensweise verwendet wird.

Slavoy Žižek - der aus dekolonialer (und feministischer) Sicht auch extrem problematische Ansichten vertritt, wie beispielsweise Hamid Dabashi in seinem 
Buch Can Non-Europeans Think? (2015) eindrucksvoll nachgewiesen hat - hat zum Thema des bewussten Konsums einige polemische und dennoch bedenkenswerte Einwände formuliert. Für Žižek hat sich die Konsumtionsweise im Globalen Norden des im Anschluss an die 1968er Bewegung entstehenden ,kulturellen“ Kapitalismus grundlegend gewandelt. Das konsumierte Produkt übersteigt dabei die Befriedigung eines materiellen Bedürfnisses nicht nur durch die Erlangung eines Statussymbols. Vielmehr zielt der Akt des Konsums auf die Erfahrung, die ,unser" Leben als genussvoll (pleasurable) und sinnhaft (meaningful) erscheinen lässt (Žižek 2009: 52). Als Beispiel führt er die Werbekampagne von Starbucks an: "It's not just what you're buying. It's what you're buying into" (Starbucks, zitiert nach Žižek 2009: 53). Es geht zugleich um Authentizität der gemachten Konsumerfahrung sowie um den Glauben damit etwas Gutes, Sinnhaftes für Andere oder den Planeten zu tun. Mit dem Kauf eines Starbucks-Kaffees erwerben die Konsumierenden gleichzeitig das Gefühl auf authentische Weise mit den produzierenden Bauern und Bäuerinnen in Kontakt zu sein und die Welt dadurch besser gemacht zu haben. Das mitgekaufte Karma durch das Fair-Trade-Siegel macht den Kaffee noch leckerer (Žižek 2009: 53). Damit wird eine frühere Kritik der Unsichtbarmachung der Arbeitsverhältnisse von Produkten im Globalen Süden in die kapitalistische Logik inkorporiert. Der Verweis auf die Herkunft verliert so sein kritisches Moment, dient vielmehr der Entpolitisierung des Konsums und der kapitalistischen Subjektivierung.

Diese Problematisierung bewussten Konsums ist dabei nicht als absolut zu verstehen. Es ist immer noch notwendig auf die Herkunft eines Produkts zu verweisen und es kann trotzdem einen Unterschied machen, ob Kaffee von solidarischen Kooperativen oder unter sklavereiähnlichen Umständen hergestellt wurde. Der Aspekt des entpolitisierenden Feigenblatteffekts ist aber durchaus ernst zu nehmen. Die Sichtbarmachung der „Landkarte dieser neuen Imperialität“ (Mecheril 2020: 108) muss also mit einer Einbettung in globalgesellschaftliche Machtstrukturen einhergehen. Ulrich Brand beschreibt das so: „Das Funktionieren der imperialen Lebensweise hat zuvorderst mit kapitalistischen Profitinteressen und Akkumulationsimperativ zu tun, mit geopolitischen und ökonomischen Strategien als Teil eines neo-kolonialen Weltsystems." (Brand 2018: 80) Die imperiale Lebensweise kann nicht einfach individuell durch eine andere ersetzt werden. Sie ist nach Brand auch ein „Zwang“ (ebd.). 


\subsection{Multiplication of labor in innereuropäischen Wertschöpfungsketten}

Eine dekoloniale politische Bildung sollte dabei anknüpfend an die Lernendenvorstellungen über die Verbundenheit mit dem Globalen Süden über Wertschöpfungsketten auch die Dimension der Stratifikation der innereuropäischen Wertschöpfungsketten miteinbeziehen. Die globalen Ungleichheiten der internationalen Arbeitsteilung finden nicht nur zwischen den Territorien des Globalen Südens und Globalen Nordens statt. Die internationale Arbeitsteilung findet ihre Entsprechung in der durch Momente des Grenzregimes hergestellte rassistische Stratifikation des EUropäischen Arbeitsmarktes. Die große Mehrheit der Tomaten wird beispielsweise im sogenannten andalusischen Plastikmeer von Arbeiter_innen aus Rumänien, dem Senegal, Marokko oder anderen Ländern außerhalb des Globalen Nordens angebaut. Die große Mehrheit der Fleischproduktion basiert auf der Ausbeutung beispielsweise polnischer, syrischer oder rumänischer Arbeiter_innen im Oldenburger Speckgürtel. Die von den Schüler_innen beschriebenen Phänomene der ungleichen Löhne und Arbeitsbedingungen wurden durch die die Grenzen internalisierenden Mechanismen in den imperialen Zentren reproduziert. Sandro Mezzadra und Brett Neilson (2013) haben dafür die Perspektive der multiplication of labor entwickelt. Damit kann gezeigt werden, wie ein internalisiertes Grenzregime über Ausländergesetze, Visa-Regime und Otheringprozesse eine rassistische Stratifikation des Arbeitsmarktes hervorbringt. Grenzen werden hier nicht als Linien zwischen Territorien verstanden, sondern als Systeme der Produktion von Differenz und der Wertigkeit von Arbeit. Für eine dekoloniale politische Bildung ist dieses Feld aufgrund der räumlichen Nähe zur Lebenswelt der Schüler_innen möglicherweise ein sinnvoller Anknüpfungspunkt, um Reflexionsprozesse zu neokolonialen Ungleichheitsverhältnissen zu entwickeln.

\subsection{Agency und Kolonialität der Arbeit}

In 3.4.2 habe ich gezeigt, dass Agency von Arbeiter_innen im Globalen Süden fast nicht in den Lernendenvorstellungen vorkommt. In den Reflexionen einiger Schüler_innen über die Agency bzw. ihr Fehlen werden koloniale Muster reproduziert. Die Fokussierung auf die Kinderarbeit beim Aufkommen des Themas erinnert an die koloniale Tradition der Infantilisierung Kolonisierter. Davids (Gym14) führt auf der Suche nach einem Weg der Veränderung der von ihm als ungerecht und unmenschlich wahrgenommenen Arbeits- und Lebensbedingungen in China zwei konfligierende Argumentationen an. Zum einen argumentiert er kulturalistisch, indem er die Nicht-Agency von chinesischen Arbeiter_innen in ihrer kulturellen Disposition begründet sieht, die sich im Vergleich zur europäischen Kultur durch 
das Fehlen von Stolz, Selbstwertgefühl und Mut auszeichne. Demgegenüber steht sein Argument, das die Nicht-Agency chinesischer Arbeiter_innen damit begründet, dass die Arbeits- und Lebensrealität keine Handlungsfähigkeit zulasse. In der Konsequenz führt dies dann zu der Vorstellung, dass Handlungsfähige aus dem Globalen Norden dahinfahren sollten, um ihnen zu helfen, die Ohnmacht zu überwinden.

Diese Argumentation reproduziert - auf der Suche nach einer humanistisch begründeten Verbesserung der Lebensbedingungen koloniale Bilder. Die kolonialen Diskursfiguren, die Sebastian Conrad für den Umgang mit chinesischen Arbeiter_innen im Kaiserreich herausgearbeitet hat, scheinen in dem David zur Verfügung stehenden kolonial-rassistischen Wissensarchiv präsent zu sein. In den Diskursen im Kaiserreich wurde die ,kulturelle' Disposition chinesischer Arbeiter beispielsweise im sozialdemokratischen Organ Vorwärts 1898 durch „Anspruchslosigkeit, eine apathische Genügsamkeit“ (zitiert nach Conrad 2010: 190) charakterisiert. Für diese Spezies von „Arbeitsmaschinen, wie sie in den größeren Städten zusammengepfercht lebt, bringt der kapitalistische Großbetrieb keine Erniedrigung, keine Verletzung ihres Menschen- und Persönlichkeitsbewußtseins“" (zitiert nach ebd.). Einer der wohl einflussreichsten Sinologen seiner Zeit, Ferdinand von Richthofen, belegte im gleichen Jahr wissenschaftlich, dass man den chinesischen Arbeiter ,zum besten Maschinenarbeiter, ja zur besten Maschine selbst heranziehen“ (zitiert nach ebd.) könne. 1906 hieß es beispielsweise im Badener Volksblatt: „Der Kuli arbeitet billig und willig; mit ihm kann man keine anderen Arbeiter, sondern nur ein niedrig stehendes Lasttier vergleichen." (zitiert nach ebd.) Diese Figur der , billigen " und , willigen " migrantischen Arbeiter_innen hat auch Kien Nghi Ha (2016) als eine koloniale Kontinuität vom Kaiserreich bis in die Gegenwart herausgearbeitet, die in dieser Form speziell für chinesische Arbeiter_innen, in anderen Formen jedoch ebenso für andere koloniale Geanderte gilt.

Diese Diskursfiguren verweisen auf das Konzept der Kolonialität der Arbeit (coloniality of labor), wie sie beispielsweise von Aníbal Quijano (2000) entwickelt wurde. Dies stellt eine Facette der Kolonialität der Macht (coloniality of power) dar und beschreibt das globale gesellschaftliche Ausbeutungssystem als konstitutiv verwoben mit ,Rasse" und Wert. In der Zeit der Sklaverei und des Kolonialismus wurde Arbeit rassialisiert (Gutiérrez Rodríguez: 2014: 49). „While the labor extracted from those codified as 'white' was considered productive and 'superior', the labor power extracted from the indigenous and enslaved populations was seen as 'inferior' and, as such, conceived as 'free exploitable' labor." (ebd.) Die Kolonisierten, die Anderen Europas, wurden zum Objekt purer Ausbeutung und auf diese Weise "subsumed, alienated and incorporated into the 
dominating totality like a thing or instrument" (Dussel 1995: 39); die kolonialen Anderen wurden auf eine Dingheit reduziert und als Rohmaterial behandelt. In kolonialen Otheringprozessen kann eine Entwicklung von den kolonialen Anderen als Ding hin zu einer Infantilisierung mit Bezug auf die koloniale Great Chain of Being festgestellt werden (Sprute 2000: 67 ff.). Aus der kolonialen Arbeitsteilung und der dazugehörigen Kolonialität der Arbeit entwickelte sich historisch die bis heute wirksame kulturelle Kodierung der globalen Arbeitsteilung (Gutiérrez Rodríguez: 2014: 49).

\subsection{Agency jenseits der Marktlogik}

Die Schüler_innen konstruieren in ihren Überlegungen zu einer Veränderung der ungleichen Arbeits- und Lebensbedingungen im Globalen Süden insbesondere vier Akteursgruppen: Unternehmer - in den Vorstellungen werden sie durchgehend als Männer vorgestellt -, Politiker_innen, Konsumierende und ,Entwicklungshelfer_innen' (3.4.2). ,Entwicklungshilfe“ werde ich im kommenden Abschnitt (4.2.2.2) diskutieren. Im Fokus stehen hier als mögliche Felder, in denen es eine Veränderung geben könnte und in denen eine Verbindung zu Menschen des Globalen Südens vorgestellt werden, erscheinen so der Markt Unternehmer und Konsumierende - und die ,Politik'. Die ,Politik' ist hier nicht mit dem Politischen bei Rancière zu verwechseln, sondern meint einen engen Politikbegriff, insbesondere das Handeln von Politiker_innen innerhalb der vorgegebenen Strukturen. Bei den Schüler_innen herrscht ein eher pessimistischer, wenig hoffnungsvoller Tenor vor, der strukturelle Veränderungen kaum als denkbar erscheinen lässt - entweder weil sie glauben, dass die ,Politik' wenig Einfluss auf Marktprozesse hat oder weil sie der ,Politik' unterstellen, kein echtes Interesse an einer Veränderung zu haben. In Bezug auf den Markt und Unternehmer gilt ähnliches. Die Gesetze der Profitmaximierung sind hier der vielleicht regulierbare, aber dennoch der normsetzende Rahmen.

Für eine dekoloniale politische Bildung ist es unabdingbar, das Spektrum der Akteur_innen und die Felder möglicher Veränderung und Verwobenheit mit dem Globalen Süden grundlegend zu erweitern. Die Entwicklung einer Erweiterung der Perspektiven auf Agency wären aus meiner Sicht eine zentrale Voraussetzung, um eine Reflexion der „Landkarte dieser neuen Imperialität“ (Mecheril 2020: 108) und Handlungsfähigkeit der Schüler_innen zu ermöglichen. Dabei gilt es auch anzuerkennen, dass ein individuelles Heraustreten aus der imperialen Lebensweise kaum zu bewerkstelligen ist, da sie grundlegend in gesellschaftliche Strukturen eingeschrieben ist. Der „Zwang“ (Brand 2018: 80) zur imperialen 
Lebensweise macht es notwendig, über individuelle Alternativen hinaus, gesellschaftliche Alternativen vorstellbar zu machen. Dieses Unterfangen ist ,nicht einfach“" (ebd.).

Die Ungleichwertigkeit von Arbeit im globalen kapitalistischen Akkumulationsregime ist ebenso wie das damit konstitutiv verbundene Regime selbst historisch gewachsen und dementsprechend auch veränderbar. Eine Globalität jenseits der Kolonialität zu denken kann nur als eine dekoloniale Utopie einen Horizont eröffnen, vor dessen Hintergrund die Gegenwärtigkeit der Kolonialität infrage gestellt werden kann. Dies würde in das Denken der internationalen Arbeitsteilung die Frage des Politischen einschreiben, in der neue (globale) Subjektivitäten denkbar würden, die - anschließend an das humanistische Unbehagen mit der globalen Ungleichheit der Schüler_innen - den Keil der Gleichheit in die - damit erst ihrem Namen gerecht werdende - Weltgesellschaft einführen würden. Dafür ist es unabdingbar, für Schüler_innen Akteur_innen des Globalen Südens sichtbar zu machen, die die Kolonialität sozialer Ungleichheitsstrukturen infrage stellen. Als Beispiel seien hier die Zapatistas im Süden Mexiko angeführt, die neokoloniale Ungleichheitsstrukturen kritisieren und dabei den Spagat zwischen dem Bestehen der Dimension von pluriversen Wissens- und Vergesellschaftungsstrukturen und der Dimension des Planetarischen (4.2.4.3) als globaler Solidarität versucht. Ein Denkhorizont, in dem Akteure des Globalen Südens vorkommen, stellt die Voraussetzung für mindestens zwei Dinge dar. Zum einen erlaubt er es, die problematischen Konstruktionen der Nicht-Agency und der damit verbundenen ,Zivilisierung ' und ,Rettung' durch Akteure des Globalen Nordens kritisch in den Blick zu nehmen. Gleichzeitig kann darüber zum anderen die Möglichkeit eines globalen Imaginären geschaffen werden, in dem globale Solidarität als eine Option überhaupt denkbar wird.

\subsubsection{Koloniale Raum-Zeit-Matrix}

Ich werde in diesem Abschnitt dekoloniale Analysekategorie der kolonialen Raum-Zeit-Matrix darstellen. Zunächst werde ich dafür die koloniale Verräumlichung der Zeit und der Verzeitlichung des Raums anhand der Metapher des Zeitreisens vorstellen. Nach der kolonialen Diskursfigur des Nicht-Eintritts in die Geschichte werde ich mich dem Entwicklungsparadigma und der daraus resultierenden problematischen Logik der ,Entwicklungshilfe' zuwenden. Quer dazu liegt die Frage der historischen Agency, die über das Diffusionsmodell in Europa verortet wird. Ich lege in diesem Abschnitt mein Augenmerk darauf, wo die Schüler_innen diese Dimensionen der Kolonialität implizit oder explizit reproduzieren, 
um notwendige Interventionsfelder aufzeigen zu können. Auf alternative, dekoloniale Perspektiven der Schüler_innen gehe ich in den folgenden Abschnitten ein.

\subsection{Vom Zeitreisen}

Eine Gruppe Journalisten berichtete im Wall Street Journal über die Begegnung mit indischen Managern und kam zu der vollkommen ernst gemeinten Aussage: „Inder sind dazu fähig, in mehreren Jahrhunderten gleichzeitig zu leben.“ (zitiert nach Chakrabarty 2001: 118) Diese Aussage verweist auf die koloniale Raum-Zeit-Matrix. Die koloniale Raum-Zeit-Matrix verräumlicht die Zeit und verzeitlicht den Raum auf eine spezifische Weise. Edgardo Lander sieht in der Folge der spanischen Eroberung ein „großes, universales Narrativ“ entstehen, in dem „die Totalität von Raum und Zeit - alle Kulturen, Völker und Territorien dieses Planeten, gegenwärtige und vergangene“ (Lander 2000: 16) - zusammengefasst werden. ,Europa ' ist in diesem Narrativ immer "gleichzeitig das geographische Zentrum und der Gipfel der zeitlichen Bewegung" (ebd.) gewesen. Die von einer ",partikularen Erfahrung der europäischen Geschichte“ ausgehende Universalität und der damit zusammenhängenden „Totalität von Zeit und Raum“ charakterisiert er als eine „,radikal ausschließende Universalität“6 (ebd.). Die sich so konstituierende "Master Voice" (Mignolo 2007b: 471) klassifiziert, beschreibt und hierarchisiert die Menschen und Weltregionen.

Friederike Habermann charakterisiert diese „Master Voice“ imperialer Allmachtsfantasien als das ,omnipotent, white eye““ (Hall, zitiert nach Habermann 2008: 198): „Die globale Geschichte liege offen und einsehbar dar, konsumierbar mit einem einzigen Blick von einem Punkt privilegierter Unsichtbarkeit aus.“ (ebd.) ,Weiß ‘ fungiert hier sowohl in der Dimension der Unsichtbarkeit - also eher der Farblosigkeit - als auch in der sichtbaren Dimension der Repräsentation des ,Vollkommeneren', die nur von einer kleinen, exklusiven, über die politisch definierte Hautfarbe bestimmten Gruppe von Menschen repräsentiert werden kann. 1777 fasste der schottische Philosoph Edmund Burke dies treffend folgendermaBen: "But now the great map of mankind is unrolld [sic] at once; and there is no

\footnotetext{
${ }^{6}$ Übersetzung M.K., Original: „Se da inicio al largo proceso que culminará en los siglos XVIII y XIX en el cual, por primera vez, se organiza la totalidad del espacio y del tiempo - todas las culturas, pueblos y territorios del planeta, presentes y pasados - en una gran narrativa universal. En esta narrativa, Europa es - o ha sido siempre - simultáneamente el centro geográfico y la culminación del movimiento temporal. [...] Al construirse la noción de la universalidad a partir de la experiencia particular (o parroquial) de la historia europea y realizar la lectura de la totalidad del tiempo y del espacio de la experiencia humana a partir de esa particularidad, se erige una universalidad radicalmente excluyente." (Lander 2000: $16 \mathrm{f}$.)
} 
state or gradation of barbarism and no mode of refinement which we have not at the same instant under our view." (Burke 1777, nach Habermann 2008: 195 f.)

Diese ,große Karte der Menschheit“ wurde mit der Geschichte verknüpft. John Locke sah 1690 in der sogenannten , neuen Welt' eine Linse, durch welche „die Muster der ersten Jahrhunderte in Asien und Europa“ (Locke 1690, zitiert nach Habermann 2008: 196) zu sehen seien. „So war anfangs“, wie er in seinen Abhandlungen über die Regierung schreibt, „,die ganze Welt ein Amerika“ (ebd.). Das gleiche lässt sich auch für das philosophische Ideologem des Naturzustands insgesamt zeigen (Kleinschmidt 2013). Die koloniale Entdeckungsreise stelle nun die Linse zur Verfügung, die den , vollkommeneren“ Menschen die weniger, vollkommeneren“ als Studienobjekt zur Verfügung stellt. In seiner viel diskutierten Antrittsrede in Jena als Professor für Geschichte unter dem Titel Was heißt und zu welchem Ende studiert man Universalgeschichte? formulierte Friedrich Schiller dies folgendermaßen:

\begin{abstract}
„Die Entdeckungen, welche unsere europäischen Seefahrer in fernen Meeren und auf entlegenen Küsten gemacht haben, geben uns ein ebenso lehrreiches als unterhaltendes Schauspiel. Sie zeigen uns Völkerschaften, die auf den mannigfaltigsten Stufen der Bildung um uns herum gelagert sind, wie Kinder verschiedenen Alters um einen Erwachsenen herumstehen und durch ihr Beispiel ihm in Erinnerung bringen, was er selbst vormals gewesen und wovon er ausgegangen ist. Eine weise Hand scheint uns diese rohen Völkerstämme bis auf den Zeitpunkt aufgespart zu haben, wo wir in unserer eigenen Kultur genug würden fortgeschritten sein, um von dieser Entdeckung eine nützliche Anwendung auf uns selbst zu machen und den verlorenen Anfang unseres Geschlechts aus diesem Spiegel wiederherzustellen. Wie beschämend und traurig aber ist das Bild, das uns diese Völker von unserer Kindheit geben!“ (Schiller 1789: 114)
\end{abstract}

Die in menschliche Altersstufen übertragene koloniale Logik der zivilisatorischteleologischen Hierarchisierung verweist bereits auf ein Modell von Entwicklung. Im gleichen Sinne wie die , great map of mankind ' gelang es der biologisierenden Logik der ,great chain of being', die „Geschichte der Menschheit in einem einzigen, stufenförmig aufgeteilten Kontinuum“ (Habermann 2008: 199) zu fassen. Die koloniale Raum-Zeit-Matrix ermöglicht so eine Art Zeitreise. Den Philosophen der Aufklärung erschien es möglich, durch den Blick auf einen Ort jenseits Europas, der kolonisierten oder noch zu kolonisierenden Weltteile, in die Vergangenheit zu sehen. Um auf den Einstieg zurückzukommen: Indien - oder zumindest das als ,nicht-westlich` bzw. ,nicht-modern` Kategorisierte - liegt also in der Vergangenheit, während Europa vor langer Zeit auch einmal ein Indien gewesen sei. 
Bis heute wirkmächtig ist das Modell kolonialer Raum-Zeit-Matrix bei Hegel. Dieser setzt in seinen Vorlesungen über die Philosophie der Geschichte von 1831 das Kriterium des weltgeschichtlichen Fortschritts wie folgt fest: „Die Weltgeschichte ist der Fortschritt im Bewusstsein der Freiheit - ein Fortschritt, den wir in seiner Notwendigkeit zu erkennen haben." (Hegel 1831: 61) Ausgehend davon konstruiert Hegel eine Weltgeschichte, die zugleich eine Geographie der Modernität ist. „Asien“ sei „,der Weltteil des Aufgangs überhaupt“ (ebd.: 163). Und weiter: „Die Weltgeschichte geht von Osten nach Westen, denn Europa ist schlechthin das Ende der Weltgeschichte, Asien der Anfang.“ (ebd.: 168) Er imaginiert vier „welthistorische Reiche“ (Hegel 1821: 496), die als eine Reise des Weltgeistes bzw. vier Entwicklungsstufen dargestellt werden: „1. das orientalische, 2. das griechische, 3. das römische, 4. das germanische.“ (ebd.: 497) Die vier Reiche werden dabei noch als in sich differenziert dargestellt. Beispielsweise geht das orientalische System Chinas demjenigen Indiens voraus, welches wiederum Persien voraus liege. Diese drei „Völkergeister“ verbinde dennoch ihr „orientalischer Charakter", der von Hegel nicht zuletzt in seiner "statarischen Gestalt" (Hegel 1831: 183) - also einer Fortschritt gar nicht oder nur sehr langsam erlaubenden kulturellen Disposition - und dem charakteristischen „orientalischen Despotismus“ (ebd.: 211) - also einer bestimmten Regierungsform - basiere. Der Mensch setzt sich in Hegels Vorstellungswelt qua Entwicklungsstufe immer weiter von der Natur ab. An der Spitze dieser Entwicklung steht natürlich Europa bzw. das „germanische Reich“ (Hegel 1821: 500).

Bei den Schüler_innen finden sich zahlreiche Bezüge zur kolonialen Raum Zeit-Matrix, wie ich im Kapitel zum Eurozentrismus herausgearbeitet habe. Die Vorstellungen von Finn (HS04) erinnern an die Äußerungen der Journalisten, wenn er seine Vorstellungen der ,nicht-modernen' Länder beschreibt und sagt, dass Indien zwar insgesamt nicht so ,fortgeschritten' sei, obwohl es aber schon welche gäbe, die ,modernisiert` sind (3.2.3). Hegels Ideen scheinen bei einigen Schüler_innen auf. Während Mark (Gym09; 3.2.7) den Fortschritt der Weltgeschichte durch die Regierungsform begründet und darüber eine teleologische Linie von den Höhlenmenschen über das antike Griechenland und römische Reich bis zum Europa der Gegenwart zieht, erklärt David (Gym14, 3.2.2) den weltgeschichtlichen Fortschritt über die Fortschrittlichkeit der „Kultur“, die er von Ägypten und Rom bis zum Europa der Gegenwart fortschreiten sieht.

\subsection{Vom Nicht-Eintreten in die Geschichte: Afrika}

Finn (HS04) fokussiert in seinen Darstellungen, wie sehr viele andere Schüler_innen auch, auf Afrika als Gegen-Ort Europas, als sein Negativ. Ebenso wie einige andere bringt auch Finn das koloniale Bild der ,Stämme‘ auf. Diese würden 
„noch sehr weit in der Vergangenheit zurückleben“. Somit lebten sie - im Sinne der kolonialen Raum-Zeit-Matrix - nicht einfach an einem anderen Ort und möglicherweise auf eine andere Weise, sondern gleichzeitig in einer anderen Zeit. Vom verzeitlichten Europa als Gegenwart wird die verräumlichte Vergangenheit als gleichzeitig existierend verortet. Obwohl fast ausnahmslos allen Schüler_innen klar ist, dass die soziale Realität in Afrika nichts mit dem Bild der "Stämme“ zu tun hat, ist dieses Bild wirkmächtig, um ,Afrika' als Gegenbild zur ,Moderne' bzw. zu ,Europa' zu imaginieren. Vor diesem Hintergrund formuliert David (Gym14) - weiter auf der Suche nach einem besseren Leben aller Menschen -, dass die „Lebensart [...] da unten [...] dieser Lebensgedanke dahinter, nicht nur von der Hand in den Mund zu leben, sondern halt sich Häuser zu bauen und all so was und nicht umherzuziehen“. Diese „Lebensart“ ist für ihn der zentrale Differenzmarker zwischen dem Fortschreitenden - ,Europa ‘ - und der nichtgeschichtlichen Stagnation - ,Afrika', das gleichzeitig ein hierarchisches Kontinuum darstellt, auf dem dann der Rest der Welt eingeordnet werden kann. Die Nähe zu und der Austausch mit Europa dient dann als Voraussetzung zum Aufstieg auf dieser Skala. So seien die in Afrika gelegenen „Staaten am Mittelmeer [...] ja schon durch die Nähe zu Europa ziemlich weit“. Die „fortschrittliche Kultur Europas“ habe durch den Handel über die Straße von Gibraltar dort Einzug erhalten. Im Gegensatz dazu sei in Afrika ,nicht so viel“. Dies habe sich erst geändert als die „Kolonialherren halt nach Afrika gegangen sind“ und dort die „fortschrittliche Kultur" hingebracht hätten. Dies sieht er als das Positive des Kolonialismus an, während er den „Rassismus“, der dadurch entstanden sei, kritisiert.

Diese Fortschrittlichkeit der Kultur bezieht er dabei nicht nur auf eine Einstufung innerhalb des kolonialen Stufenmodells der Entwicklung, sondern vielmehr auf die (Un-)Fähigkeit des Fortschreitens einer ,Kultur' selbst. Diese von David und einigen anderen Schüler_innen explizit formulierten Vorstellungen waren in kolonialen Diskursen sehr präsent und diese wiederum scheinen weiterhin prägend für das den Schüler_innen zur Verfügung stehende Wissensarchiv zu sein. Bereits bei Kant überlagert sich die Logik des Strebens zur ,Vervollkommnung der Menschheit ' mit den essenzialisierten, imaginierten Fähigkeiten der ,Rassen “ (Habermann 2008: 209). Hier ist das Streben nach Vollkommenheit selbst - und nicht nur die Annahme ihrer Vollkommenheit - einigen (rassisch konstruierten) Teilen der Menschen vorenthalten, während andere dazu nicht in der Lage wären. Hegel wiederum kommt zu seiner Behauptung, dass Afrika „kein geschichtlicher Weltteil“" sei, denn er habe „keine Bewegung und Entwicklung aufzuweisen“ (Hegel 1831: 163). Afrika sei „noch ganz im natürlichen Geiste befangen“ und höchstens an der „Schwelle der Weltgeschichte“ (ebd.) zu verorten. 
Die eurozentrische Konzeption von Geschichte wird auch am Beispiel der Haitianischen Revolution zwischen 1791 und 1804 deutlich, die als erste siegreiche antikoloniale Revolution und Abschaffung der Sklaverei angesehen werden kann. Haiti liegt zwar geographisch nicht in Afrika, innerhalb der kolonialen Episteme aber sehr wohl, wie im Folgenden deutlich werden sollte. Michel-Rolph Trouillot zeichnet anhand der Rezeption der Haitianischen Revolution eindrucksvoll nach, wie eine Geschichte im herrschenden Diskurs durch die Kolonialität der Episteme undenkbar gemacht wurde und teilweise wird, in der die Kolonisierten als etwas anderes als einem Spielball EUropas gesehen werden (Trouillot 1995). Es war und ist innerhalb dieser verleugnenden und machtvollen Episteme undenkbar, dass die versklavten Menschen selber und aus eigener Motivation heraus für ihre Freiheit kämpften. In den 1790er Jahren wurde beispielsweise versucht, durch verschiedenste verschwörungstheoretische Bemühungen, die Versklavten als bloße Opfer der Agitation versteckter oder fremder Mächte darzustellen - die größte bis dato bekannte Rebellion versklavter Menschen wurde wahlweise den Royalisten, Briten, ,Mulatten' oder republikanischen Konspirateuren zugeschrieben, die die Fäden in der Hand hätten (ebd.: 98). In der kommenden Geschichtsschreibung von Hegel über aktuelle Geschichtsenzyklopädien bis zu kritisch-marxistischen Historikern wie Eric Hobsbawm wird die haitianische Revolution in der Regel mit allgemeinem Schweigen bedacht, was im Laufe der Geschichte eher zu- als abnahm (ebd.: 104). Dies hat sich erst spät - durch die Bemühungen dekolonialer und vor allem Schwarzer Initiativen und Wissenschaftler_innen - und im herrschenden Diskurs bis heute nur teilweise geändert.

Dabei war die Revolution, die 1804 zur Unabhängigkeit St. Domingues und ihrer Umbenennung in Haiti führte, von großer globaler Relevanz. Sogar aus einer eurozentrischen Sicht kann festgestellt werden, dass die Revolution auf französischer Seite mehr Opfer forderte, als der Krieg gegen England um Waterloo (ebd.: 105). Neben dem, das sie auch das Geschehen in Europa, wie die Fortführung der Französischen Revolution, prägte, führte sie vor allem zur Zerschlagung eines der wichtigsten Märkte für versklavte Menschen in Amerika, zur Befreiung von etwa 500000 Menschen aus der Sklaverei und zur Gründung der ersten antikolonialen Republik, die von Schwarzen Menschen vor dem Hintergrund der Erfahrungen der Sklaverei errichtet wurde. Der Umgang mit der Haitianischen Revolution in Diskursen der Kolonialität kann aus meiner Sicht treffend im Anschluss an Bhambra als „epistemische Verleugnung“ (zitiert nach Mecheril 2020: 102) bezeichnet werden, die in der Kolonialität des Wissens und dem eurozentrisch-kolonialen Geschichtsdenken begründet ist.

Um aufzuzeigen, dass die Schüler_innen nicht Hegel gelesen haben müssen, sondern dass sich diese Ideen sehr viel breiter in auch gegenwärtige Diskurse 
eingeschrieben haben, in denen das koloniale Wissensarchiv bzw. das postkoloniale Erbe weiter getragen wird, werde ich an dieser Stelle die berühmte Rede von Dakar von 2007 vom damaligen französischen Staatspräsidenten Nicolas Sarkozy zitieren. Ziel der Rede war es sich für die Fehler des französischen Kolonialismus zu entschuldigen und eine neue französische Afrikapolitik zu begründen, der den Anschein von einem Verhältnis der Gleichberechtigung erwecken sollte. Mit diesem Anliegen scheitert er zum einen an der prinzipiellen Fadenscheinigkeit dieses neokolonialen Anliegens, aber auch deswegen, weil er systematisch koloniale Rhetorik reproduzierte (Schmid 2007):

„Ich bin nicht gekommen, Jugend von Afrika, um Euch Morallektionen zu erteilen. Aber ich bin gekommen, um Euch/Ihnen zu sagen, dass der Teil von Europa, der in Euch ist, zwar aus einem groben Fehlverhaltens durch Arroganz seitens des Westens heraus entstanden ist - dass aber der Teil von Europa, den Ihr in Euch habt, nicht unwürdig ist. Denn er [dieser europäische Anteil] ist der Ruf der Freiheit, der Emanzipation und der Gerechtigkeit und der Gleichheit zwischen den Frauen und den Männern. Denn er ist der Ruf der Vernunft und des universellen Bewusstseins.

Das Drama Afrikas besteht darin, dass der afrikanische Mensch nicht genügend in die Geschichte eingetreten ist. Der afrikanische Bauer, der seit Jahrtausenden mit den Jahreszeiten lebt, dessen Lebensideal darin besteht, im Einklang mit der Natur zu leben, kennt nur die ewige Wiederkehr der Zeit, deren Rhythmus durch die unendliche Wiederholung derselben Bewegungen und derselben Worte bestimmt wird. In dieser Vorstellungswelt, wo alles immer wieder von vorne beginnt, ist kein Platz für das menschliche Abenteuer, und kein Platz für die Idee des Fortschritts. In diesem Universum, in dem die Natur alles bestimmt, entkommt der Mensch der Beklemmung, die den modernen Menschen bedrängt, aber der Mensch verharrt unbewegt in der unveränderlichen Ordnung, in der alles schon im Vorhinein festgeschrieben scheint. Nie wendet sich der Mensch der Zukunft entgegen. Nie kommt ihm die Idee, aus der Wiederholung auszubrechen, um sich ein Schicksal zu erfinden. Das Problem Afrikas, und erlauben Sie/erlaubt es einem Freund Afrikas, dies zu sagen, liegt darin. Die Herausforderung für Afrika liegt darin, mehr in die Geschichte einzutreten. [...] Das Problem für Afrika liegt darin, aufzuhören, immer zu wiederholen, immer wieder alles von Neuem durchzugehen, sich vom Mythos der ewigen Wiederkehr zu befreien."(Sarkozy 2007) ${ }^{7}$

\footnotetext{
${ }^{7}$ Übersetzung M.K., Original: « Je ne suis pas venu, jeunes d'Afrique, vous donner des leçons. Je ne suis pas venu vous faire la morale. Mais je suis venu vous dire que la part d'Europe qui est en vous est le fruit d'un grand péché d'orgueil de l'Occident mais que cette part d'Europe en vous n'est pas indigne. Car elle est l'appel de la liberté, de l'émancipation et de la justice et de l'égalité entre les femmes et les hommes. Car elle est l'appel à la raison et à la conscience universelles. Le drame de l'Afrique, c'est que l'homme africain n'est pas assez entré dans l'histoire. Le paysan africain, qui depuis des millénaires, vit avec les saisons, dont l'idéal de vie est d'être en harmonie avec la nature, ne connaît que l'éternel recommencement du temps rythmé par la répétition sans fin des mêmes gestes et des mêmes paroles. Dans cet imaginaire où tout recommence toujours, il n'y a de place ni pour l'aventure humaine,
} 
Ganz unverschlüsselt formuliert Sarkozy hier die Hegelschen Kolonialgedanken, nach dem afrikanische Menschen durch ihre Unfähigkeit zum Fortschritt imaginiert werden. Das Streben nach „Freiheit, Emanzipation und der Gerechtigkeit und der Gleichheit zwischen Frauen und Männern“, ja „Vernunft“ und „universelles Bewusstsein“ stellt er als europäisch dar, die erst über den Kolonialismus nach Afrika gekommen seien. Die kolonialen Bilder von den zwei dichotomen Kulturen, die sich durch die hierarchischen Gegensätze von Fortschritt/Wiederholung, Bewegung/Verharren, Kultur/Natur, Selbstbestimmung/Rhythmus bestimmt, begründen seine Behauptung, dass Afrika bisher kaum in die Geschichte eingetreten sei.

Die den Vorstellungen der zitierten Schüler_innen zugrunde liegenden Episteme sind also keine gesellschaftlich randständigen oder veralteten Ansichten, sondern vielmehr hochaktuell und einflussreich. Die bei den Schüler_innen am häufigsten vertretene Form der kolonialen Raum-Zeit-Matrix ist allerdings weniger die Rhetorik des Fortschritts und der Vernunft als vielmehr das Sprechen über Entwicklung und Unterentwicklung.

\title{
4.2.2.2.3 ,Entwicklung' und,Unterentwicklung' als koloniale Differenz
}

Dekoloniale Theoretiker_innen haben eine Kontinuität des kolonialen Überlegenheitsdenkens herausgearbeitet, die eine Transformation der die koloniale Ungleichheit begründenden und legitimierenden Rhetorik beobachtet, nicht jedoch ihrer Struktur.

\begin{abstract}
"This epistemic strategy has been crucial for Western global designs. By hiding the location of the subject of enunciation, European/Euro-American colonial expansion and domination was able to construct a hierarchy of superior and inferior knowledge and, thus, of superior and inferior people around the world. We went from the sixteenth century characterization of 'people without writing' to the eighteenth and nineteenth-century characterization of 'people without history', to the twentiethcentury characterization of 'people without development' and more recently, to the early twenty-first-century of "people without democracy'." (Grosfoguel 2011: 7)
\end{abstract}

ni pour l'idée de progrès.Dans cet univers où la nature commande tout, l'homme échappe à l'angoisse de l'histoire qui tenaille l'homme moderne mais l'homme reste immobile au milieu d'un ordre immuable ou tout semble être écrit d'avance. Jamais l'homme ne s'élance vers l'avenir. Jamais il ne lui vient à l'idée de sortir de la répétition pour s'inventer un destin. Le problème de l'Afrique et permettez à un ami de l'Afrique de le dire, il est là. Le défi de l'Afrique, c'est d'entrer davantage dans l'histoire. [...] Le problème de l'Afrique, c'est de cesser de toujours répéter, de toujours ressasser, de se libérer du mythe de l'éternel retour, [...].» (Sarkozy 2007) 
Besonders hervorzuheben sind hier die Arbeiten von Arturo Escobar, der in seinem Werk Encountering Development - The Making and Unmaking of the Third World (1995) eine Art Grundlagentext für die dekoloniale Kritik des Entwicklungsparadigmas geschrieben hat. Hier zeigt er, wie sich das koloniale Entwicklungsnarrativ im Zuge der geopolitischen Neuausrichtung nach dem Zweiten Weltkrieg durchsetzte. Dieses ermöglichte - erneut - die Konstruktion der ,westlichen" Überlegenheit und neoimperialen Machtpolitik als Teil einer selbstlosen Hilfe für den Globalen Süden - die ,unterentwickelten Länder $^{\text {- }}$ - darzustellen. ,Entwicklung' erscheint aus dieser Perspektive als eine Neuformulierung der kolonialen Raum-Zeit-Matrix: „Die Konzepte von Entwicklung und Unterentwicklung waren neue Versionen der Rhetorik der Moderne, da beide geschaffen wurden, um die koloniale spatiale/temporale Differenz neu zu organisieren.“ (Mignolo 2006: 125) Pablo Quintero stellte dazu fest, dass auch die ,zahlreichen Resemantisierungen des Entwicklungsgedanken (nachhaltig, endogen, ökologisch, menschlich, gerecht, ethnisch, von unten, etc.)" als koloniale Kontinuität zu bewerten sind, die sie ,,an einen Erkenntnisraum und in einer Praxis, eingebunden sind, die in der eurozentrierten Modernität/Kolonialität gefangen sind“ (Quintero 2013: 110). Eine weitere Neufassung der Rhetorik dieser kolonialen Raum-Zeit-Matrix, insbesondere der letzten zwei Jahrzehnte, besteht in der Rhetorik der ,good governance', der ,guten Regierungsführung;, in der die koloniale, geopolitische Differenz über die Binaritäten von demokratisch/undemokratisch, rechtsstaatlich/korrupt, Ordnung/Willkür hergestellt wird (Grosfoguel 2011).

Diese Entwicklungsvorstellungen sowie die Rhetorik der ,good governance“ finden sich zahlreich in den Vorstellungen der Schüler_innen. Bei Pascal (Gym12; 3.2.6) beispielsweise wird die koloniale Differenz über die Konstruktion der Regierungen des Globalen Südens als korrupt hergestellt. Dies geht mit weiteren Differenzmarkern zwischen dem ,Westen und dem Rest' einher, die die Regierung der einen mit ,Demokratie', ,Menschenrechten“ und ,Bildungspolitik“ assoziiert und die Regierungen des Globalen Südens eben mit dem Fehlen dieser Attribute. Bei Pascal finden sich Andeutungen dies mit dem Analyseraster der Rentiersökonomie zu verbinden, die die ungleichen Politiken in einen Kontext mit neokolonialen Wirtschaftsstrukturen stellen. Letztlich dominiert aber die kulturalistische Zuschreibung von unterschiedlichen Mentalitäten als Erklärungsmuster, die den Eliten des Globalen Südens einen ,Egoismus“ und eine ,Gier unterstellen und damit ungleiche Formen von Staatlichkeit und Entwicklung erklärt.

Für Jannik (Gym01) und Mark (Gym09) stellt die Staatlichkeit selber den Differenzmarker dar (3.2.7). Hier findet sich ebenfalls das kulturalistische Denken in Mentalitäten, die Staatlichkeit und Ordnung in der Mentalität des Globalen 
Nordens verorten. Dabei formuliert Jannik dies nicht nur abwertend, sondern unterstellt dem Globalen Norden - in diesem Fall Deutschland - eine Mentalität des ,Stock im Arsch', der zwar zu weniger Lebensfreude, aber eben zu mehr ,Ordnung' und damit auch ,Entwicklung' geführt hätte und immer noch führt. Doch diese scheinbare Aufwertung der Mentalität des Globalen Südens - charakterisiert durch Lebensfreude, Lockerheit und so weiter - stärkt die Differenzkonstruktion und steht in einer langen kolonialen Tradition. Dazu gehört auch die Verbindung zum klimatheoretischen Argument, das spätestens seit Montesquieu ebenfalls eine lange koloniale Tradition besitzt, nach dem es eben die unterschiedlichen klimatischen Bedingungen sind, die diese Mentalitäten hervorgebracht haben.

In ähnlicher Weise koppelt auch Mark die Frage der ,Entwicklungsfähigkeit“ an die Frage der (fehlenden) Ordnungsmentalität. Noch expliziter als bei den anderen erscheint Ordnung und Staatlichkeit hier als die Bedingung von ,Entwicklung '. Während er den ,Rest' im Gegensatz zum , Westen ' dadurch gekennzeichnet sieht, dass sie niemals eine Ordnung errichtet, sich deswegen nicht entwickelt und eine Mentalität der Stagnation inne hätten, zeichnet er eine Genealogie bzw. Teleologie von ,Ordnung' und ,Entwicklung' vom römischen Reich bis zu den ,westlichen' Staatsgebilden der Gegenwart. Der Beginn einer ,Entwicklung' in den Ländern des Globalen Südens sei erst durch ihre Kolonialisierung möglich gewesen. Dabei verfügt er über viel Wissen über die Geschichten der westeuropäischen Kolonialismen in verschiedenen Erdteilen, das er jedoch fast ausnahmslos zur Festigung seiner kolonialen Thesen verwendet. Viel Wissen über den Kolonialismus führt hier nicht zu einer kritischen oder reflexiven Haltung.

Die drei beispielhaft für viele andere vorgestellten Denkweisen der Schüler_innen wenden sich dabei gegen koloniale Ungleichheit und reproduzieren aber in dem Zuge die Kolonialität. Ihre argumentativen Suchbewegungen zielen darauf $a b$, die von ihnen als zutiefst ungerecht empfundene globale soziale Ungleichheit verstehbar zu machen, um sie zu verändern. Dabei greifen sie auf ihnen zur Verfügung stehende koloniale Denkmuster zurück. Ihre Intention ist nicht kolonialistisch, ihre Denkmuster sehr wohl. Die Bilder, die ihren Argumenten zugrunde liegen, basieren auf kolonialen Zuschreibungen; die Argumentationsmuster greifen auf Aspekte des ,Entwicklungsparadigmas' und die - beispielsweise durch die Diskurse rund um die UN-Milleniumgoals geprägte - Rhetorik der 'good governance" zurück.

\subsection{Das Entwicklungsparadigma}

Ein gut handhabbarer Begriff zur Analyse und Kritik dieser Denkweisen stellt das Entwicklungsparadigma dar (Kleinschmidt et al. 2015). Arturo Escobar fasst die drei Achsen des Entwicklungsparadigmas so: 
„To sum up, I propose to speak of development as a historically singular experience, the creation of a domain of thought and action, by analyzing the characteristics and interrelations of the three axes that define it: the forms of knowledge that refer to it and through which it comes into being and is elaborated into objects, concepts, theories, and the like; the system of power that regulates its practice; and the forms of subjectivity fostered by this discourse, those through which people come to recognize themselves as developed or underdeveloped.“ (Escobar 1995: 10)

Die drei Achsen des Entwicklungsparadigmas fasst Escobar also als die Wissensformen, das Machtsystem und die Subjektivierungsweisen. Durch die entwicklungsparadigmatischen Wissensformen konstruieren und konstituieren sich die Objekte, Vorstellungen und Theorien, die innerhalb einer post- und neokolonialen Welt die koloniale Differenz und die koloniale Raum-Zeit-Matrix reproduzieren. Das Entwicklungsparadigma funktioniert nur im Zusammenhang mit dem Machtsystem, in dessen Rahmen die die Wissensformen ihre Wirkung entfalten können. Die soziale und politische Ungleichheit erscheint sowohl als Voraussetzung der Wirkmächtigkeit dieser Wissensformen als auch als Effekt derselben, insofern sie zur Legitimation und Reproduktion dieser Ungleichheitssysteme notwendig erscheinen. Beides ist verbunden mit Subjektivierungsweisen, mittels derer der Diskurs und die geopolitische Verortung es Menschen erlauben sich selbst als ,entwickelt‘ oder ,unterentwickelt‘ zu konstituieren.

Ähnlich wie und anknüpfend an Escobar hat Aram Ziai $(2013 ; 2010)$ das Entwicklungsparadigma durch die folgenden drei Punkte (a) Eurozentrismus, (b) Entpolitisierung und (c) Treuhandschaft charakterisiert. Ziais Modell werde ich im Folgenden kurz skizzieren.

(a) Eurozentrismus: Der Entwicklungsdiskurs ist eurozentrisch, da er reale oder imaginierte Prozesse, die in Europa und den europäischen Siedlungskolonien in Nordamerika stattfanden, zum universellen Maßstab erklärte. Diese partikularen Prozesse werden so als menschheitsgeschichtlicher Fortschritt an sich verklärt. Die ,eigene" Gesellschaft wird dabei als Ideal, die ,anderen' als defizitäre Versionen derselben vorgestellt. Dies drückt sich in Attribuierungen als ,unterentwickelt', ,noch nicht so weit', ,rückständig', aber beispielsweise auch innerhalb der Applikation der kolonialen Raum-Zeit-Matrix durch das imaginierte Fehlen von Ordnung und Staatlichkeit oder durch kulturalistische Zuschreibungen der Stagnation aus. Die Gewalt kolonialer Expansion und die Effekte der Kolonialität der Macht auf politischer, kultureller, ökonomischer und sozialer Ebene geraten zugunsten eines idealisierten Bildes von ,Entwicklung' aus dem Blick. ,Entwicklung' steht hier zum einen in der kolonialen Tradition der Zivilisierung 
und der kolonialen Raum-Zeit-Matrix und zum anderen findet sie ihre Fortsetzung im gegenwärtig hegemonialen Diskurs über Entwicklungspolitik der, good governance'.

(b) Entpolitisierung: Als Interpretationsraster vermittelt das Entwicklungsparadigma das Gefühl, dass , wir` über verarmte Weltregionen Bescheid zu wissen glauben. Es legt Erklärungen für eine Vielzahl von alltäglichen Beobachtungen und Bildern nahe. Statt konkrete gesellschaftliche Verhältnisse und (neokoloniale) Produktionsmechanismen globaler Ungleichheit in den Blick zu nehmen, werden beispielsweise Bilder von Armut im Globalen Süden als Symptom einer anderen geschichtlichen Entwicklungsstufe lesbar. Im Entwicklungsparadigma erscheint es wie selbstverständlich, dass „verschuldete Drittweltstaaten und hungernde BäuerInnen ein gemeinsames ,Problem' haben, dass ihnen beiden ein bestimmtes ,Etwas“ fehlt: ,Entwicklung ““ (Ferguson 1990: XIII). Äußerst heterogene Phänomene werden als ,Entwicklungsdefizit" charakterisiert, damit andere Erklärungsweisen, Prozesse und Akteure, wie beispielsweise in den sozialen Kämpfen, unsichtbar gemacht. Dadurch wird Armut entpolitisiert und als technisches Problem dargestellt (Ziai 2013: 18).

(c) Treuhandschaft: Diese als nicht-politisch und als technisch verklärten Problemlagen sollen dementsprechend durch Expert_innen gelöst werden, die dem Prinzip der Treuhandschaft zufolge über das notwendige Wissen über sozialtechnologische Interventionen („Entwicklungsprojekte“) verfügen. In der vermeintlichen Verteilung dieses Wissens gibt es eine Schieflage zuungunsten des Globalen Südens, der oft als ,passiv und unfähig selbst aus dem elenden Zustand zu entkommen“ (ebd.) vorgestellt wird. Trotz aller Rhetorik der ,Hilfe zur Selbsthilfe" besteht das koloniale, paternalistische Motiv der „helfenden Hand aus dem Norden“ (ebd.) fort. In der Geschichte fanden solche treuhänderischen Interventionen im Namen der Entwicklung oft gegen den Willen der Betroffenen statt (Ziai 2010: 401 f.). Statt eine Änderung der Machtverhältnisse fokussiert eine solche entpolitisierte Betrachtungsweise auf einen Lösungsansatz, der im Wesentlichen auf ,größerer Wohltätigkeit der vom System relativ Begünstigten“ (Ziai 2013: 18) besteht. Das Prinzip der Treuhandschaft bestimmt in der Kontinuität der zivilisierenden Mission der Kolonialisierenden bis heute das Verständnis und die Praxis von ,Entwicklungshilfe‘

\subsection{Von der Kolonialität der,Entwicklungshilfe'}

,Entwicklungshilfe' ist eingebettet in den entwicklungsparadigmatischen Diskurs und die damit verbundenen Subjektivierungsweisen. Die große Mehrheit der Schüler_innen sieht ,Entwicklungshilfe“ als zentrales Instrument zu der von ihnen als ungerecht empfundenen globalen sozialen Ungleichheit an. Öfter genannt und 
als wichtiger bewertet als humanitäre Hilfe oder das zur Verfügung stellen von technischer Infrastruktur wird Bildung als Feld der ,Entwicklungshilfe'. Einzelne planen auch nach der Schule ein Auslandsjahr in ,Afrika' zu machen, um selber an diesen Bildungsprozessen mitzuwirken. Ebenso wie die Mehrheit der Lernenden argumentiert David (Gym14; 3.4.3) emphatisch für eine ,Entwicklungspolitik', die die Lebensbedingungen der Menschen im Globalen Süden verbessern soll. David argumentiert hier insofern auf besonders interessante Weise als hier verschiedene Facetten der Lernendenvorstellungen insgesamt gebündelt und in ein Verhältnis zueinander gesetzt erscheinen. Zunächst schreibt er dem Globalen Norden als ehemals kolonisierende Mächte eine besondere Verantwortung zu, sich für eine ,Entwicklung ' der Länder des Globalen Südens einzusetzen, da sie - und mit dieser Ansicht gehört er zu einer Minderheit - einige der gegenwärtigen Probleme im Globalen Süden mitverursacht hätten.

In der Darstellung dieser Verursachung kommen die Kolonisierten aber nicht als Akteur_innen vor, sondern vielmehr als Spielbälle der Kolonisierenden. An Letzteren kritisiert er, dass diese im Kongo zwecks Machtsicherung die „Stämme gegeneinander aufgewiegelt“ hätten und seitdem dort „Blutrache“ herrsche. David spielt hier auf einen wichtigen Punkt an, nämlich die Implementierung rassistischer Unterscheidungssysteme durch Kolonialregime; der Genozid an annähernd einer Million Menschen durch Hutu-Rassist_innen 1994 in Ruanda wäre ohne das deutsche und später belgische Kolonialregime und die Einführung kolonialrassistischer Identifikations- und Administrationspraxen nicht denkbar. Gleichzeitig spricht er damit den Kolonisierten einen Subjektstatus ab, da sie zu keiner eigenständigen ,Entwicklung' oder gar Reflexion fähig erscheinen.

In der Gegenwart sieht David nun den ,Westen' genau aufgrund seiner Mitverantwortung in der Pflicht, die fehlende ,Entwicklung' anzustoßen. Dabei argumentiert er im Sinne des gegenwärtig hegemonialen Diskurses der ,Hilfe zur Selbsthilfe “ vorsichtig und plädiert dafür, diese ,Entwicklung nicht zu „lenken“, „nicht denen vorschreiben“, sondern durch Hilfe ,Entwicklung' zu ermöglichen. Dabei sind aus seiner Sicht militärische Interventionen der Bundeswehr oder der NATO zwar manchmal zielführend, entscheidender sei jedoch Bildung, um die ,noch-nicht-so-weiten ', weiter' zu bringen. Die Idee ist es, dass der ,Westen' als Vorbild fungiert: ,In Europa und Amerika haben wir eine funktionierende Demokratie. Guckt euch doch mal ab, so und so läuft das ganz gut bei uns. Probiert das doch auch mal." (David, Gym14; 3.4.3) Der Globale Norden bzw. die ,westliche' Kultur stellt für ihn das normative Ziel globalgesellschaftlicher Veränderung dar. Während die ,westliche Kultur" sich nach David durch die Werte „Demokratie, Akzeptanz, Multi-Religionismus“, Gewaltlosigkeit, Meinungsvielfalt sowie die Akzeptanz der „Menschenrechte“ und des Prinzips der Rechtsstaatlichkeit 
auszeichnet, fehlen diese in Gesellschaften des Globalen Südens. Diese Werte sollen auch durch ,gut ausgebildete Lehrer“ dort implementiert werden, damit „die das dann langfristig selber machen können“, „bis sie es irgendwann alleine drauf haben und dann selber anderen Ländern helfen können“. Urheber von ,Entwicklung' bleiben so Akteur_innen des Globalen Nordens; als ,Entwicklung“ erscheint ein Prozess nur dann, wenn sich die ,Entwicklung' auf der Linearität der kolonialen Raum-Zeit-Matrix einordnet und das normative Ziel des Entwicklungsparadigmas akzeptiert.

Als hilfebedürftig - also , unterentwickelt ${ }^{*}$ - erscheinen bei ihm Afrika, Asien und Südamerika. Als hilfegebend benennt er ,Europa ' - wobei er hier explizit die „Balkanstaaten“ ausschließt - und die USA. Diese koloniale Differenz spiegelt sich auch in der bei den Schüler_innen stark verbreiteten Auffassung von Bildung als Entwicklungsinstrument wider. Nicht zuletzt auch in den Vorstellungen selber dort zu ,helfen' bleibt unausgesprochen, was sie dazu befähigt, außer der vermeintlichen Zugehörigkeit zu einer als ,entwickelt' imaginierten ,Kultur'. Der Diskurs des Entwicklungsparadigmas führt so zu einer Subjektivierungsweise vieler Schüler_innen, die sich durch diese vermeintliche Zugehörigkeit als überlegen inszenieren. Diese entwicklungsparadigmatische Hierarchie untergräbt aus einer dekolonialen Sicht das Ziel der Schüler_innen, an der globalen Ungleichheit etwas zu verändern.

Die koloniale Überdeterminierung der humanistischen Ziele der Entwicklungshilfe wurde mehrfach im deutschen Kontext analysiert und kritisiert (Bendix/Danielzik 2013; Bendix 2011, 2008, 2007). Die emphatische Haltung einer großen Gruppe von Schüler_innen, sich durch ,Entwicklungshilfe " für weniger globale Ungleichheit einzusetzen, kann auf der einen Seite durch das Begehren erklärt werden, sich als hilfegebend, als wohltätig zu inszenieren. Diese Haltung findet in den Charity Events der globalen Elite wohl ihren perfidesten Ausdruck, was der postkoloniale Autor Chinua Achebe mit folgendem Satz charakterisiert: „Wohltätigkeit [...] ist das Opium der Privilegierten.“ (Achebe 1987: 174) Gleichzeitig ist das Begehren der Lernenden nach globaler Gerechtigkeit als solches ernst zu nehmen und sollte trotz der benannten Problematiken nicht auf diese reduziert werden. Aus einer dekolonialen Perspektive sollte es vielmehr vertieft und ausgeweitet werden, indem es zum Gegenstand von Reflexionsprozessen wird. Dieses Begehren kann Ausgangspunkt für die Herausbildung von kritischer Haltung und Handlungsfähigkeit sein. Eine dekoloniale politische Bildung muss Räume und Instrumente zur Verfügung stellen, um diese Machtverhältnisse zu kritisieren, selbstkritisch die eigene Verstricktheit zu reflektieren und alternative Sichtweisen zu ermöglichen. 


\subsection{Kolonialität und Modernität als zwei Seiten derselben Medaille}

Die Infragestellung der kolonialen Raum-Zeit-Matrix stellt eine zentrale didaktische Herausforderung für eine dekoloniale politische Bildung dar. Der Ansatz der Kolonialität/Modernität (Garbe 2013) kann dabei wichtige Impulse liefern. Walter Mignolo fasst die Moderne selbst als irreduzibel verbunden mit der Kolonialität: „Da die Kolonialität für die Moderne in dem Sinn konstitutiv ist, dass es keine Moderne ohne Kolonialität geben kann, sind die Rhetorik der Moderne und die Logik der Kolonialität zwei Seiten derselben Medaille.“ (2006: 97) Dies betrifft dieser Perspektive zufolge sowohl die ,materielle' Seite der Konstitution kapitalistischer Vergesellschaftungsweisen als auch die ,diskursive' Seite der Moderne - ich bin mir hier der Untrennbarkeit dieser beiden Dimensionen bewusst.

Diese Perspektive dekonstruiert das koloniale Diffusionsmodell, in dem von einer autarken Entwicklung des Kapitalismus und der ,modernen“ Wissenschaft in Europa ausgegangen wird, die dann in den Rest der Welt getragen wurde. Doch die koloniale Ausbeutung stellt ebenso eine Voraussetzung für die Entwicklung des Kapitalismus dar, wie die Konstruktion des kolonialen Anderen für die Konzeption der ,modernen "Wissenschaften. Mignolo zeigt mit Bezug zu Eric Williams (1944) beispielsweise auf, dass die ,Glorreiche Revolution" von 1688 und die Vertreibung der Stuarts, was als einer der Kulminationspunkte der Geschichte der ,Moderne' gesehen wird, den Startpunkt des Freihandels markiert, der dem transatlantischen Sklavenhandel eine neue Dimension verlieh (Mignolo 2006: 103). Spivak arbeitet in ihrem Buch Critique of Postcolonial Reason heraus, dass der koloniale Andere konstitutiv für die Diskurse der ,Moderne“ ist, wie Spivak im folgenden Zitat anhand von Kant, Hegel und Marx aufzeigt:

\footnotetext{
"They take for granted that the ,European" is the human norm and offer us descriptions and/or prescriptions. And yet, even here, the native informant is needed and foreclosed. In Kant he is needed as the example for the heteronomy of the determinant, to set off the autonomy of the reflexive judgment, which allows freedom for the rational will; in Hegel as evidence for the spirit's movement from the unconscious to consciousness; in Marx as that which bestows normativity upon the narrative of the modes of production." (Spivak 1999a: 6)
}

Dieser konstitutive Zusammenhang von ,Modernität' und Kolonialität findet sich dabei punktuell auch in den Schüler_innenvorstellungen. Beispielsweise arbeitet Finn (HS04) heraus, dass die Ausnutzung, der Betrug und die Versklavung in Europa bestimmte Entwicklungen der gesellschaftlichen ,Modernisierung ‘ ermöglicht hätten.

Eine solche Sichtweise stellt eins der zentralen kolonialen Ideologeme der ,Moderne“ infrage, nämlich die Kopplung der kolonialen Raum-Zeit-Matrix mit 
dem Narrativ der damit verbundenen universellen Emanzipation: „Die Kolonialisierung der Zeit und die Institutionalisierung der kolonialen/temporalen Differenz waren für die Moderne als einer Erzählung von Rettung, Emanzipation und Fortschritt zentral.“ (Mignolo 2006: 119) Alternative Interpretationsraster jenseits der kolonialen Raum-Zeit-Matrix zu entwickeln, ist vor allem deswegen eine Herausforderung, weil das Denken von Emanzipation und Gleichheit tief mit der Rhetorik der ,Moderne“ verwoben ist, wie Walter Mignolo beispielhaft bei Jürgen Habermas nachweist (ebd.: 97 ff.). Die strukturelle Ausblendung der Gewalt, die in der Vergangenheit und in der Gegenwart als Voraussetzung für die ,Entwicklung', für die verwobene Ungleichheit, erscheint, ist dabei für die Aufrechterhaltung der behaupteten moralischen Überlegenheit notwendig. Der ungarische Soziologe Josef Böröcz stellt dazu in Bezug auf die Wirkungsweise des Entwicklungsparadigmas für den postsozialistischen Osten folgendes fest:

„Um eine zeitgenössische Sozialform als das erstrebenswerte ,Schon' der strebenden
Reformer des ,Noch nicht` denken zu können, ist es nötig - wie das liberale Denken es
unvermeidlich tut - jeden kausalen Zusammenhang zwischen der ,Rückständigkeit“
derer, die sich ,noch nicht‘ entwickelt haben und dem vorausgegangenen Aufstieg des
,entwickelten“ Vorbilds zu leugnen. Wenn zugegeben wird, dass die Errungenschaften
der ,entwickelten' Sozialformen auf Vorteilen beruhen, die mit dem Elend anderer
erkauft wurden oder wenn das Leiden der Elenden als durch den ,Aufstieg' der Ent-
wickelten verursacht begriffen wird, dann wird das teleologische Modell moralisch
verwerflich und sogar unsinnig.“ (Böröcz 2006: 117, zitiert nach El-Tayeb 2016: 59)

Für die Auseinandersetzung mit der kolonialen Raum-Zeit-Matrix in Bildungszusammenhängen bedeutet das, einen Raum der Aushandlung über die Verhältnisse und Verortungen in der Globalität der Gegenwart zu schaffen.

"In education, this would require what Trinidadian scholar Jacqui Alexander (2005) has called a re-scrambling of 'our here and now' (of this side of the abyssal line) with the 'then and there' (that we attribute to the other side) towards a 'here and there' and 'then and now' (2005, 190)." (Andreotti 2011a: 394)

Dekoloniale politische Bildung muss bisherige Bildungskonzepte auf ihre eigene Verstrickung in die koloniale Raum-Zeit-Matrix einer kritischen Revision unterziehen. Für die zukünftige Gestaltung dekolonialer politischer Bildung gilt es, Lehrende entsprechend $\mathrm{zu}$ sensibilisieren und ihnen die für eine kritische und reflexive Haltung notwendigen Begriffs- und Reflexionsinstrumente zur Verfügung zu stellen. In der Bildungspraxis gilt es, sowohl die koloniale Raum-ZeitMatrix als Problem zum Gegenstand zu machen und historisch und politisch zu 
kontextualisieren, als auch alternative Deutungs- und Interpretationsraster anzubieten und zu erproben. Alternative Interpretationsraster dürfen dabei weder in die Falle der (a) Totalisierung der Dekolonialität noch in die des (b) kulturellen Relativismus tappen.

(a) Ein alternatives Interpretationsraster wäre die Verwobenheit von ,Moderne' und Kolonialität aufzuzeigen und die Gegenwärtigkeit neokolonialer Ausbeutungsstrukturen, Machtverhältnisse und Wissenshierarchien als zentrale Verständnisraster der Wirklichkeit vorzuschlagen. Dabei ist darauf zu achten, die postkoloniale Perspektive nicht zu verabsolutieren, indem alle Aspekte dem Schema der Kolonialität untergeordnet werden. Zwar stimme ich der These zu, dass die Kolonialität der Macht in nahezu allen Lebensbereichen wirkmächtig ist (Garbe 2013: 410); dies bedeutet aber keinesfalls im Umkehrschluss, dass dadurch alle Aspekte aller Lebensbereiche durch diese Perspektive hinlänglich verstehbar würden. Kwame Anthony Appiah formuliert diese Gefahr in Bezug auf das kulturelle Leben in gegenwärtigen afrikanischen Gesellschaften:

\begin{abstract}
"All aspects of contemporary African cultural life including music and some sculpture and painting, even some writings with which the West is largely not familiar - have been influenced - often powerfully - by the transition of African societies through colonialism, but they are not all in the relevant sense postcolonial. For the post in postcolonial, like the post in postmodern is the post of the space clearing gesture." (Appiah 1992: 240-241)
\end{abstract}

Aus meiner Sicht sollte sich eine dekoloniale Perspektive also nicht totalisieren, kann aber sehr wohl in vielfältigen Bereichen Anwendung finden und dort in die Auseinandersetzung um die Hegemonie von Deutungshoheiten eingreifen. Dekoloniale Perspektiven stellen kein neues universales Narrativ zur Verfügung, sondern vielmehr Instrumente kritischen Denkens, die immer wieder neu kontextualisiert und geprüft werden müssen.

(b) Der Anspruch vieler dekolonialer Ansätze ist, aus der universalen - oder besser universalisierenden - Rhetorik der ,Moderne' eine pluriversale zu machen. Dekolonialität bedeutet nicht nur Negation der Kolonialität, im Sinne einer selbstreflexiven Wendung der ,Moderne' gegen sich selbst, sondern auch den Einbezug bisher diskreditierter, marginalisierter Wissensarchive. Kolonialität war entgegen ihres in der Rhetorik der ,Moderne" formulierten Anspruchs nie universal und total. Die Kolonialität wurde immer unterlaufen, umgeformt oder durch Praxen der Resignifkation angeeignet. Das Gegenstück zur ,Moderne“ ist aus einer solchen Perspektive nicht ,Tradition'. ,Tradition' ist vielmehr selbst ein Produkt der ,Moderne', der kolonialen Matrix der Macht: 


\begin{abstract}
“'Tradition' is not outside modernity but in its exteriority: It is an outside invented by the rhetoric of modernity in the process of creating the inside. The outside of 'tradition' is invented in order to insure the inside as the locus of enunciation of knowledge. 'Tradition' is not a way of life that pre-dated 'modernity' but an invention of the rhetoric of modernity." (Mignolo 2007b: 472)
\end{abstract}

Eine dekoloniale Perspektive zielt also nicht auf eine Rückkehr zu irgendeinem kulturellen Ursprung, sondern kritisiert vielmehr das koloniale Konzept eines essenzialisierten Kulturbegriffs. Nichtsdestotrotz ermöglicht eine Pluriversalität des Wissens vor dem Hintergrund der Unmöglichkeit absoluten Wissens Perspektiven $\mathrm{zu}$ vervielfältigen und in der kolonialen Matrix abgewertete oder ausgeschlossene Wissensformen anzuerkennen. Dipesh Chakrabarty beschreibt diese Herausforderung folgendermaßen:

\begin{abstract}
„Den Versuch zu unternehmen, dieses ,Europa“ zu provinzialisieren, heißt, das Moderne als Feld von Auseinandersetzungen zu begreifen. Es bedeutet, die bislang privilegierten Erzählungen der Staatsbürgerschaft mit Erzählungen anderer menschlicher Bindungen $\mathrm{zu}$ überschreiben, die sich von erträumten Vergangenheiten und Zukunftsentwürfen nähren, in denen Kollektivitäten weder durch die Rituale der Staatsbürgerschaft noch durch den Alptraum der durch die ,Moderne“ geschaffenen ,Tradition“ definiert sind.“ (Chakrabarty 1992: 309)
\end{abstract}

\title{
4.2.2.3 Geburtsrechtslotterie und globale soziale Gerechtigkeit \\ 4.2.2.3.1 Staatsbürgerschaft als das moderne Äquivalent feudaler Klassenprivilegien
}

\begin{abstract}
„Nu ne-am născut în locul potrivit.“
„Wir sind nicht am richtigen Ort geboren.“

(Guess Who, 2009) ${ }^{8}$
\end{abstract}

Ayelet Shachar (2009) ist in ihrem Buch The Birthright Lottery - Citizenship and Global Inequality der Frage nachgegangen, wie die Mitgliedschaft zu einer Gemeinschaft als Geburtsrecht weitergegeben wird. Sie stimmt der These zu, dass es in der globalisierten Welt zu einer Vervielfältigung von Mitgliedschaftskonstruktionen und -arrangements gibt: "There is no doubt that growing transnational flows of people across borders have created a wealth of new levels of membership and affiliation, operating within and across territorial borders, as well as above and below the traditional framework of the nation-state." (Shachar 2009: 2)

\footnotetext{
${ }^{8}$ Übersetzung M.K.; Guess Who ist eine rumänische Hip-Hop-Gruppe, die in ihrem Lied Locul Potrivit (Richtiger Ort) die Ungerechtigkeit der Geburtsrechtslotterie thematisiert.
} 
Allerdings ersetzen diese Prozesse und die damit verbundenen Ideen globaler oder lokaler Citizenship keinesfalls die Bedeutung von Staatsbürgerschaft (citizenship) als zentrales Prinzip für die Mitgliedschaft: „But only nation-states have citizens.“ (ebd.) Citizenship wird als Besitz qua Geburt weitergegeben - sowohl im jus soli als auch im jus sanguinis (ebd.: 7). Angesichts der massiven globalen Ungleichheiten zeigt Shachar, wie die Frage des Geburtsortes und der damit verbundene Erwerb einer bestimmten Mitgliedschaft, das Leben auf sehr unterschiedliche Weise determiniert. "For those granted a head start simply because they were born into a flourishing political community, it may be difficult to appreciate the extent to which others are disadvantaged due to the lottery of birth." (ebd.: 3) Mit der durch die Geburt hergestellten, ,geopolitische[n] Position des Individuums“ ist damit weitgehend der Zugang zu Ressourcen bestimmt; wie ,genießbares Wasser, gesundheitliche Versorgung, Essen, halbwegs funktionierende staatliche Infrastruktur und Autorität, Bildung etc.“: „Stochastisch verweist der Geburtsort bzw. der Pass darauf, um es verkürzt zu sagen, was aus der Einzelnen wird." (Mecheril 2020: 108) Vor dem Hintergrund eines globalen Anspruchs von Gleichheit der Menschen erscheint diese allgegenwärtige, als natürlich erscheinende Praxis nicht legitimierbar. Joseph Carens stellt diesen Zusammenhang in den Kontext eines demokratischen Selbstverständnisses:

„In vielerlei Hinsicht stellt die Staatsangehörigkeit in westlichen Demokratien das moderne Äquivalent feudaler Klassenprivilegien dar [...]. Als Bürger eines reichen Staates in Europa oder Nordamerika geboren zu werden, ist als wäre man in den Adelsstand hineingeboren worden (obwohl viele von uns zum niederen Adel gehören).“ (Carens 2017: $167 \mathrm{f}$ )

Aus der Perspektive des Ansatzes globaler sozialer Gerechtigkeit ist dieses feudalisierte Ungleichheitsverhältnis ein zentrales Problem, das als solches auch zu einem zentralen Bestandteil von Bildungsprozessen gemacht werden muss - vorausgesetzt Bildung zielt globale soziale Gerechtigkeit normativ angestrebt wird.

Luka (Gym02, 3.4.2) problematisiert den widersprüchlichen Zusammenhang globaler Ungleichheit und universeller Gleichheit aller Menschen.

S: Ja, also ich denke mir halt: „Wieso eigentlich?“ Also: „Wieso ist es da ausgerechnet günstiger?“ denke ich mir dann. Stelle ich mir dann halt die Frage. Ich meine, ähm, das sind ja auch genauso Menschen wie wir, und wieso ist es denn bei denen günstiger? Okay, vielleicht weil die .../Also die Arbeitsbedingungen sind schlechter. Aber ist da keiner der das kontrolliert? Also da stelle ich mir dann so die Frage so. Ich meine da muss ja das irgendwer kontrollieren. Das kann ja nicht sein, dass wir jetzt hier in 
Deutschland einen höheren Standard haben als da. Das sind ja auch nur Menschen, sag' ich jetzt mal. (Luka, Gym2, 3.4.2)

In Bezug zum Themenkomplex der Kolonialität der Arbeit - also der Ungleichwertigkeit der Arbeit in der internationalen Arbeitsteilung - formuliert er die Frage danach, wie es sein kann, dass die menschliche Arbeitskraft im Globalen Süden „günstiger“ ist und ungleiche Standards akzeptiert werden, obwohl das ja ,auch genauso Menschen“ seien. Solche weit verbreiteten Fragen der Schüler_innen bezüglich des Widerspruchs der empirisch-sozialen Wirklichkeit der neokolonialen Ungleichheit auf der einen und dem Gleichheitsanspruchs qua Menschsein auf der anderen Seite können als Ausgangspunkte für weitergehende Reflexionen dienen. Dabei kann bei den Schüler_innen noch differenziert werden in den universellen Anspruch auf Gleichheit, der als solcher selten vorkommt, sowie den universellen Anspruch auf Chancengleichheit, der deutlich verbreiteter ist. Nach letzterem erscheint nicht die ungleiche Verteilung der Ressourcen als solche als problematisch, sondern vielmehr die ungleichen Chancen qua Geburtsrechtslotterie sich im Wettstreit um die Ressourcen aus eigener Kraft einen Platz zu sichern, der ein gutes Leben ermöglicht. Für die Vertiefung des Verständnisses dieses Ungerechtigkeitsempfinden in Bildungsprozessen bietet der Ansatz der Geburtsrechtslotterie einen hilfreichen Ansatzpunkt, um an weit verbreitete Vorstellungen unter den Schüler_innen anzuknüpfen.

\subsection{Global Citizenship und Kosmopolitismus revisited}

Es stellt sich die Frage, ob diese Zusammenhänge nicht auch schon mit diversen kosmopolitischen Ansätzen hinreichend abgedeckt werden und was jetzt das ,neue " oder besondere an einer solchen dekolonialen Perspektive ist. María do Mar Castro Varela und Nikita Dhawan (2010) diskutieren den kosmopolitischen Paradigmenwechsel, auch der in diesem Kontext relevanten Ungleichheitssoziologie, der in einer Verschiebung vom methodologischen Nationalismus zu einem methodologischen Kosmopolitismus besteht. Am Beispiel von Ulrich Beck (2007) zeigen sie, wie durch die kosmopolitische Perspektive ein ,neuer Horizont von Theorie- und Forschungsfragen" (Castro Varela/Dhawan 2010: 320) eröffnet wird, mit der die Basisunterscheidung bisheriger Ungleichheitssoziologie von national und international von einer transnationalen, grenzüberschreitenden Perspektive abgelöst wird, die zur Überwindung ,organisierter Unverantwortlichkeit“ (Beck 2007: 60) führen soll. Mit der kosmopolitischen Perspektive wird das „Ende der Anderen" (ebd.: 77) postuliert; das heißt, dass die ,kulturell" Anderen als unausgrenzbar erscheinen. Als Mitglieder einer „Weltgefahrengemeinschaft“ (ebd.: 27) 
teilten wir nach Beck gemeinsame, grenzüberschreitende Risiken und Bedrohungen. Dieses globale Risiko und die darin enthaltene Verwundbarkeit aller führe zu der Notwendigkeit einer Verantwortung für andere, deren Zukunft er in einer zukunftsorientierten ,planetarischen Verantwortungsethik“ (ebd.: 41) sieht. Auch wenn die Risiken ungleich verteilt seien, so resultiert daraus nicht die „Betonung der Klassengesellschaft", da sie alle ohne Ausnahme beträfen, da schließlich alle im selben, gemeinsamen „globalen Gefahrenraum“ (ebd.: 111) säßen. Vor diesem Hintergrund sieht er die Möglichkeit eröffnet, die dichteren Verbindungen zwischen ,,den getrennten Sphären des Lokalen und des Fernen, zwischen Verantwortlichen und Opfern“" (Castro Varela/Dhawan 2010: 321) dahingehend zu verändern, dass transnationale Solidarität möglich, Entscheidungs- und Partizipationsprozess demokratisiert und eine transnationale Praxis von „kosmopolitischer Realpolitik“" (Beck 2007: 368) realisiert werden.

Castro Varela und Dhawan kritisieren diesen Ansatz des Kosmopolitismus. Nach ihnen erscheint er "auf den ersten Blick“ dazu in der Lage einen Perspektivenwechsel zu vollbringen, mit dem ,sowohl globale Staatsbürgerschaft als auch transnationale Identitäten und internationale Verflechtungen“ (Castro Varela/Dhawan 2010: 321) mitgedacht werden können. Allerdings sehen sie einen theoretischen Kurzschluss darin, aus einer allen gemeinsamen Verletzlichkeit durch die globalen Risiken auf ein Zusammenrücken aller zu schließen, woraus schließlich ein kosmopolitisches ,Wir‘ entstehen würde. „Doch wissen wir lange schon, dass, obwohl wir alle demselben Sturm ausgesetzt sind, wir doch nicht alle im selben Boot sitzen." (Castro Varela/Dhawan 2010: 321) Dies blende nicht zuletzt auch die Verstrickung der Kosmopolit_innen des Globalen Nordens in die globalen Machtasymmetrien aus. Gegen den Ansatz des Kosmopolitismus wenden sie ein, dass eine Nicht-Reflexion der die kolonialen ,Epistemologien und Vormachtstellung des Nordens privilegierende[n] Verhältnisse“ bei der Analyse sozialer Ungerechtigkeit ,unweigerlich zu theoretischen Schieflagen“ (ebd.: 324) führen müsse. Interdependenz sichtbar zu machen, müsste zunächst bedeuten, die unterschiedliche „Eingebundenheit in transnationale Ungleichheitsformationen anzuerkennen“ (Castro Varela/Dhawan 2010: 325 f.). Einer der Einwände gegen das Projekt des Kosmopolitismus besteht dementsprechend darin, dass die oder der idealtypische Weltbürger_in - das implizite kosmopolitische Subjekt - sich in privilegierten Intellektuellen im Globalen Norden verkörpert. Die normative Idee eines ausgedehnten globalen Bewusstseins und der kosmopolitischen Demokratie ermöglicht es diesen ,Weltbürger_innen', am globalen Geschehen unmittelbar teilzuhaben (Dhawan 2009: 52). Dabei werden die historischen Prozessen, die die "Mitglieder einer globalen Elite“ in eine Stellung gebracht haben, die es 
ihr nun ermöglicht, als „Wohltäterin der Allgemeinheit“ (ebd.: 53) aufzutreten unzureichend berücksichtigt.

Um seine These des Zusammenhangs von globalen Risiken und der Gestaltung einer globalen, demokratischen Öffentlichkeit zu untermauern und zu veranschaulichen, verweist Beck auf die Beispiele der öffentlichen Verhandlungen des Hurrikans Katrina und der Tsunamis, die zu einer „Globalisierung des Mitgefühls“ (Beck 2007: 114) geführt hätten. Aus einer dekolonialen Perspektive erscheint dieses Mitgefühl allerdings ebenso wenig als Ausdruck einer Demokratisierung globaler Verhältnisse wie die Spendenbereitschaft als Ausdruck von Solidarität. Dies gilt unabhängig davon, dass auch beispielsweise die Krisenbewältigung im Anschluss an Katrina wesentlich von Rassismus, Vertreibung und Umverteilung von unten nach oben gekennzeichnet waren (Jakob/Schorb 2008). Die vermeintlichen Anzeichen für ,Demokratisierung' und ,Solidarität' können vielmehr als hierarchisierte Wohltätigkeit verstanden werden. Nikita Dhawan verwendet in ihrer Kritik der Kosmopolitin Martha Nussbaum den Ausdruck des „,ignoranten Wohlwollens“ (Dhawan 2009: 53). Sie sieht in der hier kritisierten Spielart des Kosmopolitismus und den Diskursen globaler Bürgerschaft einen Gestus aufscheinen, „der Welt helfen zu wollen“, der im Anschluss an Spivak als „Übertragung der Bürde des weißen Mannes zu der Bürde des Stärkeren“ (ebd.) erscheint. Die Schwächeren werden hier so imaginiert, dass sie nicht dazu in der Lage seien, sich ,selbst zu helfen noch eigenständig zu regieren“.

Damit wird eine koloniale Differenz anhand der Frage der Agency in Bezug auf diejenigen hergestellt, die Rechte zuteilen und die sie empfangen: „Die Distanz zwischen jenen, die Rechte zuteilen und jenen, die lediglich als Opfer von Unrecht und als Empfänger von Rechten gelten, verharrt somit unter dem Vorzeichen historischer Gewalt.“ (ebd.) Das „,ignorante Wohlwollen“ bekräftigt dabei im Globalen Norden den Eurozentrismus und mithin ein Überlegenheitsgefühl, „da es dazu anrege, sich im Mittelpunkt der Welt zu sehen und überdies suggeriere, dass Menschen aus anderen Ländern der Welt nicht hinreichend global sind“ (ebd.). Vor diesem Hintergrund müssen Konzepte von globaler Bürgerschaft neu überdacht werden. Aus einer dekolonialen Perspektive können Formen ,unkritischer Solidarität“ und „essenzialisierende Diskurse zu globaler Gerechtigkeit und Menschenrechten“ (ebd.) problematisiert und reflektiert werden. Dabei können solidarische Praxen unter Ungleichen nie widerspruchsfrei sein - auch unter Anerkennung und Reflexion von Ungleichheit und Herrschaft bleibt diese Widersprüchlichkeit unaufhebbar. Eine solche Anerkennung ist aber die Voraussetzung dafür, sich nicht so sehr und nicht auf diese Weise von der Kolonialität und den dadurch verursachten Widersprüchen lenken zu lassen. Eine die Dimensionen der Kolonialität ausblendende Konzeption kosmopolitischer Demokratie und 
Global Citizenship läuft nicht nur Gefahr, ins Leere zu laufen, sondern vielmehr Machteffekte kolonialer Verhältnisse zu reproduzieren und zu stärken statt diese zu verringern.

\subsection{Zur (Un-)Möglichkeit globaler Solidarität}

Wie sähe denn aber ein dekoloniales Konzept von Solidarität aus? Schließlich wäre zunächst globale Solidarität möglicher Ausgangspunkt oder normatives Ziel dekolonialer Bildungsprozesse. Neben Empowerment als Praxis von selbst in kolonialen Strukturen Deprivilegierten kann Solidarität als ein Kernpunkt dekolonialer Bildungsprozesse angesehen werden. ${ }^{9}$ Sie würde an die Stelle von die Kolonialität reproduzierenden Strukturen des Kontakts oder der Bezugnahme auf Akteur_innen des Globalen Südens treten bzw. würde vielmehr diese Strukturen überschreiben. Doch dies ist einfacher gesagt, als getan. Dekoloniale Solidarität kann als ein double bind (vgl. 3.4.1) konzipiert werden, wie ich es im Folgenden versuchen werde. Ich werde zwei Dimensionen von Solidarität gegenüberstellen, die beide aus einer dekolonialen Sicht als notwendig erscheinen, obwohl sie in ihren Formen als im Widerspruch stehend oder sogar als sich ausschließend erscheinen werden. Auf der einen Seite steht die Unmöglichkeit von globaler Solidarität im Sinne von Spivak, die sich als Aufgabe der Reflexivität über eigene Verortungen und Praxen sowie Fallstricke herauskristallisiert. Dies könnte ich als eine Strategie der Verundeindeutigung bezeichnen. Demgegenüber steht ein Konzept von Solidarität, das ich in Anlehnung an Massimo Perinelli als eine Strategie der Vereindeutigung bezeichnen könnte. Diese zielt darauf, durch die Realisierung einer politischen Dimension im Sinne von Rancière gemeinsame Perspektiven der Transzendierung neokolonialer Machtverhältnisse zu erschaffen.

Für Spivak erscheint das, was als internationale Solidarität firmiert, bei genauerem Hinsehen oft als Paternalismus, der koloniale Machtverhältnisse festigt, statt sie infrage zu stellen. Nikita Dhawan setzt Spivaks Beobachtung denen von Becks festgestellter ,Globalisierung des Mitgefühls' entgegen (Dhawan 2009: 54). Im Anschluss an den großen Zyklon im Jahre 1991 in Bangladesch waren Helfer_innen von Ärzte ohne Grenzen gekommen, die mit Hilfe von Übersetzer_innen versuchten, humanitäre Hilfe zu organisieren. Spivak traf zu einem

\footnotetext{
${ }^{9}$ Der Schwerpunkt in diesem Kapitel liegt auf dem Verhältnis zu Menschen im Globalen Süden. Die Frage der kolonialen Ungleichheit kann an dieser Stelle also nicht mit der Frage des Rassismus übersetzt werden, auch wenn sie mit ihr verschränkt ist. Spivak stellt immer wieder heraus, dass sowohl ökonomisch erfolgreiche Migrant_innen und Eliten des Globalen Südens nicht mit der Subalterne zu verwechseln sind, auch wenn sie trotzdem in einer spezifischen Position im kolonialen Kontext stehen.
} 
späteren Zeitpunkt in einem Dorf ein, in dem sie früher gearbeitet hatte. Diejenigen, die sie dort antraf, sagten, ,wir wollen nicht gerettet werden, wir wollen sterben, sie behandeln uns wie Tiere" (Spivak 2008c: 26 f.). Hier stellt sie die Frage danach, ob vor dem Hintergrund einer fehlenden gemeinsamen Sprache überhaupt von Solidarität gesprochen werden kann. Über ein Verständnis von Sprache als Kommunikationsmittel hinaus entspringt hieraus die Frage, „ob die Distanz zwischen jenen auf der Geberseite und jenen auf der Nehmerseite nicht ein unfassbarer Beleg für die Grausamkeit der Geschichte sei“ (Dhawan 2009: 54) und ob diese überhaupt - im Sinne einer Solidarität - überbrückbar sei. Denn Solidarität impliziere in gewisses Maß an Augenhöhe und basiert auf einer Gemeinsamkeit. Die Behauptung eines solidarischen Verhältnisses steht aber sehr oft einer Realität in entwicklungspolitischen Kontexten gegenüber, die durch ein hierarchisches Verhältnis gekennzeichnet sind. Dabei kann das (wieder) vermehrte Auftauchen des Sprechens von Solidarität als eine Antwort auf postkoloniale Interventionen zurückgeführt werden; es bleibt aber fraglich, ob der veränderten Rhetorik auch eine veränderte Praxis zugrunde liegt (Glokal 2017d). Die Fallstricke solidarischen Sprechens und Handelns in oder in Bezug auf Nord-Süd-Beziehungen liegt in mindestens zwei Punkten begründet.

Der erste Fallstrick liegt darin, dass sich eine unkritische Solidaritätsarbeit letztlich oft wieder in die Entwicklungshilfe-Logik einschreibt, die irreduzibel mit der kolonialen Raum-Zeit-Matrix verwoben ist.

„This strategy is often linked to the idea of 'making a difference out there' and conflated
with global citizenship in some mainstream educational practices that are categorised
as DE (e.g. school links and fund-raising campaigns). The assumption behind this drive
is that the 'problem' of developing countries is only based on a 'lack' of attributes that
the North possesses (e.g. education, democracy, scientific knowledge, technology, a
more civilised culture, history, universally 'correct' values, etc...) and that the North
is responsible for the South in the same way that it was believed that the white men
had the burden of civilising non-white peoples in colonial times." (Andreotti 2006: 9)

Aus einer dekolonialen Perspektive wäre es notwendig, diese impliziten Hierarchien infrage zu stellen. Spivak formuliert die Notwendigkeit, ein Lernen von unten zu erlernen, das aber voraussetze, die eigene Überlegenheit oder die der ,eigenen ' Gesellschaft oder ,Kultur' hinter sich zu lassen: ,,a suspension of belief that one is indispensable, better or culturally superior; it is refraining from thinking that the Third World is in trouble and that one has the solutions; it is resisting the temptation of projecting oneself or one's world onto the Other" (Spivak, zitiert nach Kapoor 2004: 642). Solidarität wird vor diesem Hintergrund als Einsatz 
für die Armen und Unterdrückten verstanden, also für diejenigen, die sich selbst nicht wehren können. Darin ist bereits ein ,paternalistisches Moment der Bevormundung und Entmündigung" eingeschrieben, mit dem die ,Anderen" nicht als handlungsfähige Subjekte, sondern auf eine Position als „Opfer, Unterdrückte, Hilfsbedürftige“" (Schmitt 2015) festgeschrieben werden. Die vermeintlich Solidarität ausübenden Akteur_innen des Globalen Nordens subjektivieren sich dabei selbst als helfende Retter_innen.

Der zweite Fallstrick entspringt einem Verständnis globaler Solidarität, in welcher der Globale Süden als Projektionsfläche für die Begehren der Subjekte des Globalen Nordens dient. Beispielsweise Kampagnen mit Bezug auf indigene Gemeinschaften reproduzieren häufig „Bilder einer unberührten Natur, eines Lebens im Einklang mit der Natur und Vorstellungen von den ,Edlen Wilden ““ (Schmitt 2015). Diese Romantisierung der vermeintlich authentischen Lebensweise dient dabei insbesondere der Selbstpositionierung der Akteure im Globalen Norden, die hier im ,Vormodernen' eine Art Spiegel ihrer ,modernen' Gesellschaft betrachten, die sie vor diesem Hintergrund kritisieren bzw. sich darin als kritisch oder alternativ inszenieren können. Insbesondere in der Linken gibt es eine lange Tradition der internationalen Solidarität. Zum Globalen Süden als Projektionsfläche sozialrevolutionärer Romantisierung schreibt Pascal Bruckner in seinem Buch Das Schluchzen des weißen Mannes (1984):

„Die Dritte Welt Solidarität ging [...] davon aus, daß ein stummer Pakt die Befreiungsbewegungen mit ihr verband, daß diese Bewegungen sich selbst als Garanten für die Zukunft des internationalen Klassenkampfes sahen. Die südliche Hemisphäre war für die multinationalen Konzerne eine wunderbare Rohstoffreserve, für eine gewisse Linke wurde sie zu einer phantastischen Mine von Illusionen. [...] Im Überschwang ihrer Begeisterung hatte die Linke Menschen und Dinge so gründlich nach ihren Vorstellungen umgemodelt, daß sie lange brauchte, um ihren tragischen Irrtum festzustellen.“ (zitiert nach Schmitt 2015)

Dieses Argument zielt nicht darauf, alle internationalistische Praxis im Globalen Norden der Vergangenheit zu desavouieren; es soll aber wohl einen Finger in die Wunde eines unreflektierten Solidaritätsverständnis legen. Wenn der Globale Süden bzw. die antikolonialen und antiimperialen Kämpfe dort als Projektionsfläche dienen, stellt sich die Frage, ob hier von Solidarität gesprochen werden kann oder ob im Zentrum nicht die Konstruktion des eigenen revolutionären Subjektstatus steht. Dies gilt insbesondere dann, wenn die Kämpfe des Globalen Südens als Ersatz für die vermeintlich ausbleibenden (Klassen-)Kämpfe im Globalen Norden erscheinen. In diesem Prozess der Projektion kommt es zu Romantisierungen und 
Homogenisierungen, die nicht nur den komplexen gesellschaftlichen Verhältnissen der Länder des Globalen Südens nicht gerecht werden - wessen Perspektive wird hier denn eigentlich als repräsentativ für ein ,Volk' oder eine ,Ethnie ‘ bevorzugt? (Andreotti 2006: 9) - sondern führt letztlich auch zu einem Verstummen der subalternen Stimmen. Wenn die projizierten ,revolutionären Subjekte' des Globalen Südens, so lange in der Repräsentation umgemodelt und vereinheitlicht werden, bis sie in die sozialrevolutionären Träume der Linken passen, kommen Stimmen dieser Bewegung nur insofern zum Vorschein, als sie zu diesen Träumen passen. Das Konzept der Subalternität habe ich an anderer Stelle bereits skizziert (3.4.1). Für Andreotti stellt sich dabei die Frage: ,What are the origins and implications of the desire to listen to a transparent, authentic and heroic representative of the South?" (Andreotti 2006: 9).

Diese beiden, auch oft miteinander verwobenen Fallstricke skizzieren die Problematik hier nur kursorisch. Es sollte aber deutlich geworden sein, dass globale Solidarität aus einer postkolonialen Perspektive, beispielsweise mit Spivak, ein Minenfeld ist; dass es fast unmöglich erscheint. Dabei betont Spivak immer wieder, dass es nicht an der persönlichen Einstellung liegt, sondern diese Unmöglichkeit von Solidarität in historischen und strukturellen - ,materiellen und diskursiven - Bedingungen begründet liegt:

„Geschichte ist mächtiger als persönliches Wohlwollen. [...] In diesem Geschäft der Solidarität mit den Ärmsten der Armen im globalen Süden macht persönliches Wohlwollen nichts wett. Es ist christlich zu denken, dass man Tausende Jahre von Unrecht wieder gut machen kann, indem man einfach freundlich ist. Also gehe ich hin und (...) versuche, von ihnen und meinen Fehlern zu lernen. Solidarität? Um Himmels willen. Ich bin eine Kasten-Hindu. Vergessen Sie's!“ (Spivak 2008c)

Ilan Kapoor bezeichnet Spivaks Ansatz dabei als „hyper-self-reflexive“ (2004), denn aus der Annahme der - zumindest unmittelbaren - Unmöglichkeit von Solidarität folgt die notwendige Fokussierung auf sich selbst, der Reflexion der eigenen geopolitischen Verortung und Begehrensstrukturen sowie die daraus resultierenden Reflexionen über die eigene Verstricktheit in globale Machtverhältnisse. Eine solche dekoloniale Selbstreflexivität fokussiert dabei auf eine Sichtbarmachung der Uneindeutigkeiten, der Unterschiede, des tiefen Grabens der Distanz, der durch die Geschichte der kolonialen Gewaltverhältnisse aufgerissen wurde. Der Horizont einer dekolonialen Bildung wäre in diesem Sinne die Veruneindeutigung, von Zweifel, von der Anerkennung der Unterschiede. Eine solche Reflexivität - die auf der Einsicht in die Unmöglichkeit von Solidarität basiert 
- ist aus einer post- oder dekolonialen Perspektive eine Voraussetzung für die Eröffnung eines Horizonts globaler Solidarität.

Die andere Seite des double bind geht von der gegenteiligen Einsicht aus: „Solidarität ist ein gegenseitiger Affekt, es kann sie nur zwischen Ungleichen geben, niemals unter Gleichen." (Perinelli 2019: 90) Hatte das bisher diskutierte Konzept von Solidarität die Unterschiedlichkeit als Problem angesehen, erscheint sie aus dieser Perspektive als ihre Bedingung; Solidarität ist die Realisierung des in der polizeilichen Logik unmöglichen Unterfangens, ausgehend von unterschiedlichen Verortungen eine gemeinsame Subjektivierung des Streits um das ,Wir' und den Anteil der Anteillosen zu bewerkstelligen. Solidarität ist hier also Ausdruck eines politischen Imaginären, dem ein visionäres Begehren nach der Überwindung kolonialer Machtverhältnisse und einer grundlegenden Transformation der Gesellschaften im Globalen Norden und Globalen Süden zielt. Es ist politisch im Sinne von Rancière zu verstehen, insofern es auf die Überwindung des Bestehenden zielt und im Zuge dessen eine unabgeschlossene Subjektivität entstehen lässt.

Insofern zielt ein solches Verständnis von Solidarität nicht auf die Veruneindeutigung, sondern auf ihr Gegenteil, die Vereindeutigung, ab. Dies scheint beispielsweise in den Bewegungen rund um das Weltsozialforum auf, in denen aus der internationalen Zusammenkunft eine transnationale Bewegung wird. Genau wie politische Bewegung braucht eine auf die Infragestellung von Machtverhältnissen zielende Bildung etwas, das als eine Wette auf die Zukunft bezeichnet werden kann. Es braucht die Vision von Hoffnung und die Herstellung von Gemeinsamkeiten und Verbundenheiten, damit sich die die Verhältnisse transzendierenden Visionen entfalten können. Eine dekoloniale Bildung, die nur auf die Reflexion eigener Privilegien abzielt, wird nicht nur ihren Fokus nicht über die Fragen der Repräsentation hinaus auf die Kolonialität der globalen Ressourcenverteilung legen, sondern ebenso wenig die Fragen der Repräsentation hinreichend bearbeiten können. Denn eine nicht mit dekolonialen Visionen eines Gemeinsamen ausgestattete Bildung wird die Überwindung der epistemischen Differenz als unüberwindbar und insofern hoffnungslos erscheinen lassen. Ein dekolonial informierter Ansatz von Global Citizenship verweist auf die Möglichkeit eines solchen globalen bzw. planetarischen (4.2.4.3.2) Verbundenseins in neuen, immer im Entstehen begriffenen Subjektivierungsweisen, an denen im Prinzip alle - als Beliebige, wenn auch nicht als Gleiche - teilhaben könne und in denen sich das Gemeinsame durch die Vision eines dekolonialen Imaginären herstellt, an dessen Horizont sich die Transzendenz neokolonialer Machtverhältnisse abzeichnet. Spivak (1999b) formuliert diese Perspektive unter der Maßgabe, das Planetarische zu denken, wie ich im Abschnitt 4.2.4 ausführen werde. Ein solches Verbundensein, 
das sich im Subjektivierungsprozess des Politischen herstellen kann, muss dabei konsequent im Zusammenhang dieses double binds gedacht werden. Eine solche Vision kann für Menschen, die durch die Kolonialität deprivilegiert werden auch als Zumutung erlebt werden, in dem einfach über unterschiedliche Perspektiven hinweggegangen oder diese vereinnahmt werden.

In der durch dekoloniale Interventionen hervorgerufenen Debatte um die Fallstricke von globaler Solidarität im Entwicklungszusammenhang ist das folgende Zitat von der Murri-Aktivistin Lilla Watson inzwischen häufig vorgebracht worden: „Wenn du gekommen bist, um mir zu helfen, dann verschwendest du deine Zeit. Wenn du aber gekommen bist, weil deine Freiheit mit meiner verbunden ist, dann lass uns zusammenarbeiten." (Watson, zitiert nach Schmitt 2015). Dies bedeutet hier, Solidarität nicht als Solidarität für andere zu verstehen, sondern Solidarität in einem gemeinsamen Kampf für gleiche Ziele zu erleben. Will dekoloniale politische Bildung mehr sein als ein Problematisierungsinstrument eigener Privilegien oder kolonialer Repräsentationsverhältnisse, sondern auch koloniale soziale und politische Ungleichheitsverhältnisse infrage stellen und Handlungsfähigkeit ermöglichen, muss sie diese Dimension des Politischen als zentralen Rahmen annehmen. Ohne diese Praxen der Veruneindeutigung würde dekoloniale Bildung aber auch in der Vereindeutigung scheitern; die Herstellung eines Gemeinsamen würde zur Farce, wenn diese auf Romantisierungen und Projektionen basiert. Der hier vorgestellte double bind ist also nicht aufzulösen und erscheint als ineinander verschachtelt. Ich schlage hier vor, dass eine dekoloniale politische Bildung genau diesen double bind von globaler Solidarität als Unaufgelöstes, als Unauflösbares, zum Ausgangspunkt nimmt.

\subsection{Autonomie der Migration}

Im Denken des Globalen habe ich in den Vorstellungen der Schüler_innen in vielerlei Hinsicht die Kolonialität von Agency - wenngleich auch mit Ausnahmen - aufgezeigt, in denen Arbeiter_innen, Kolonisierte und EntwicklungshilfeEmpfänger_innen als passive Opfer erscheinen (3.4). Die Transformation dieser subalternisierenden Vorstellungen ist eine große Herausforderung einer dekolonialen politischen Bildung. Im Denken der Grenze oder vielmehr der Grenzüberschreitung findet sich zunächst ein ähnliches Bild. Die Mehrheit der Schüler_innen sieht (flüchtende) Migrant_innen als Opfer an, denen keine oder kaum Handlungsfähigkeit zugeschrieben wird. Allerdings finden sich hier in den Vorstellungen der Schüler_innen zahlreiche Ansätze, die als Ausgangspunkte einer dekolonialen politischen Bildung dienen können. Mit einer Perspektive der 
Autonomie der Migration (3.4.1) erscheint die Migration als eine aktive Infragestellung, als das Unterlaufen der modernen Feudalität, die mit dem Ansatz der Geburtsrechtslotterie kritisiert wird:

\begin{abstract}
„Vor diesem Hintergrund kann transnationale und -kontinentale Migration insofern als Versuch verstanden werden, in einem sehr grundlegenden Sinne Einfluss auf das eigene Leben zu nehmen und stellt damit einen Prototyp moderner Lebensführung dar - mit all ihren Ambivalenzen, Illusionen und zweifelhaften Nebenfolgen. Sei mutig, bediene Dich Deines Verstandes und befreie Dich aus der Position, die Dir die geopolitische Ordnung aufgezwungen hat - das ist, in einer Referenz an Immanuel Kant formuliert, das Credo der neuen transnationalen Moderne, die, ohne dass dazu Absicht oder Programmatik erforderlich wäre, von Migrant*innen geformt und formuliert wird.“ (Mecheril 2020: 109)
\end{abstract}

Eine solche Sichtweise findet sich auch bei den Schüler_innen wieder. Dadurch wird explizit oder implizit die koloniale Naturalisierung und Universalisierung der nationalstaatlichen Ordnung der Welt infrage gestellt (3.4.4), die erwartbarerweise auch ins Denken der Schüler_innen eingeschrieben ist. In einer besonders prägnanten Variante findet sich dies beispielsweise bei Mark (Gym09, 3.4.3), der die die Globalisierung begleitenden Migrationsbewegungen als eine Zerstörung einer imaginierten vorkolonialen Ordnung der Welt ansieht, an der ,,jede Rasse“ und ,jede Religion“ an ihrem Platz gewesen sei. Diese Unordnung erscheint für ihn als ein zentrales Problem der Globalisierung. Die Vorstellungen der Schüler_innen, die diese Logik untergraben, eröffnen dabei einen Raum, die faktische Durchlässigkeit von Grenzen als Ansatzpunkt zu nehmen, die naturalisierte Vorstellung der Ordnung der Welt, welche sich nicht zuletzt „,mit Hilfe des kolonialen Imperialismus durchgesetzt hat" (Mecheril 2020: 107) zu hinterfragen.

Bei den Schüler_innen habe ich sieben Denkweisen gefunden, die für eine solche Kritik als offen erscheinen: Der Kampf für ein besseres Leben, ,Gastarbeiter_innen' als Subjekte, Konstruktion von Illegalität durchs Grenzregime, Strategien von Geflüchteten zur Umgehung des Grenzregimes, Recht auf Bewegungsfreiheit, Geflüchtete als Träger_innen von Rechten und subalterne Stimmen (3.4.4). So sieht Mahamadou (Gym04) die Migration im Kontext der globalen Ungleichheit im Sinne des oben angeführten Zitats von Paul Mecheril als einen Kampf für eine Verbesserung der eigenen Lebensumstände. Migration, auch illegalisierte, wird hier nicht als Problem konzipiert, sondern vielmehr als das Handeln von Subjekten, die durch ihr Handeln eine verantwortliche Antwort auf die Kolonialität der globalen Ungleichheit praktizieren, indem sie ihre eigene Lebensbedingungen verbessern und sich nicht mit ihrem geopolitischen, durch die 
Geburtsrechtslotterie zugewiesenen Platz abfinden. Spuren eines solchen Ansatzes - mal expliziter, mal nur in angedeuteter Form - finden sich bei zahlreichen Schüler_innen. Mit der Sicht auf die ,Gastarbeiter_innen' als Subjekte erscheinen Migrant_innen als vollwertige Mitglieder innerhalb der neuen nationalstaatlichen Konstellation; so wird die paternalistische Logik untergraben, in der Migrationsregulierung vor dem Hintergrund des Abwägens über das Maß der Wohltätigkeit und damit der normalisierten Vorstellung der ,modernen' Feudalität diskutiert wird.

Mark (Gym07) stellt den Prozess der Illegalisierung von Migrant_innen selbst infrage und problematisiert diesen als unrechtmäßig. Max (Gym13) diskutiert ausführlich die vielfältigen Strategien von Geflüchteten, das Grenzregime zu umgehen; dabei erscheinen die Migrierenden als kreativ und ihr Handeln als legitim. Vice versa stellt sich hier die Frage nach der Legitimität der Voraussetzungen des Grenzregimes selbst. Da die „Erde [...] ja kein Eigentum“ sei, leitet sich für ihn hieraus ein universelles Recht auf Bewegungsfreiheit ab. Lara stellt die Rolle von Geflüchteten als auf die Mildtätigkeit angewiesene Hilfesuchende infrage, indem sie diese als Träger_innen von Rechten vorstellt. Einerseits bestehen diese Rechte in universellen Menschenrechten, die durch die Geflüchteten aktiv durchgesetzt würden, und andererseits hinterfragt sie das bestehende Recht auf seine Substanz, in denen es auch Schutzbedürftigen oft kaum möglich sei, ihren Rechtsanspruch durchzusetzen. Darüber hinaus konzipiert sie - zumindest durch die Linse meiner Ko-Konstruktion - ein Modell der Hörbarkeit von Stimmen und stellt die Hierarchisierung von Stimmen im politischen Diskurs infrage, in der die geopolitische oder die soziale Klasse betreffende Verortung das Gewicht einer Stimme bestimmt.

Diese Vorstellungen der Schüler_innen sind potenzielle Anknüpfungspunkte für eine Vertiefung. Dekoloniale Bildungsräume könnten hier die Option bieten, diese Ansätze weiterzuspinnen und ihre Implikationen für die Sicht auf die Welt, eigene Positionierungen und Handlungsfähigkeit zu erarbeiten.

\subsubsection{Koloniale Differenz: Von der (Un-)Gleichwertigkeit des Lebens und der Metrik des Sterbens}

„If they're civilized, I'd rather stay savage“ (Mona Haydar, Barbarian, 2018).

\subsection{Kolonialität des Lebens:Von der Metrik des Sterben-Lassens}

Die Lernendenvorstellungen sind geprägt von einer Empathie und einem Detailwissen über die Gefahren der Migration nach EUropa. Gleichzeitig gibt es viele, 
insbesondere Gymnasiast_innen, die sich in die Position der Regierungsvertreter_innen denken und aus dieser Position der Identifikation mit den Herrschenden heraus, das Grenzregime und seine Folgen verteidigen. Dies scheint für sie zwar im Konflikt mit ihrem grundsätzlichen Verständnis für die Beweggründe der Migrierenden zu stehen, führt jedoch bei der Mehrzahl nicht dazu, die Prinzipien des Grenzregimes infrage zu stellen. Nicht wenige nehmen zur Verteidigung des Grenzregimes dabei auch die durch das Grenzregime verursachten Toten explizit in Kauf. Dies wird zwar als bedauerlich dargestellt, erscheint aber als unvermeidlich. Mark (Gym09) erwähnt hier nur beiläufig und ohne eine Bemerkung des Entsetzens oder der Trauer, dass oft bei den Überfahrten ,nur die Hälfte oder ein Drittel von denen“ überleben würde.

Alisha Heinemann beobachtet in diesem Kontext, dass „Tausende Euro [...] zur Rettung eines einzelnen Deutschen ausgegeben [werden], der beim freiwilligen Bergsteigen im Himalaya in Not gerät“" (Heinemann 2020: 210). Dabei werden in den Medien seine Biographie, seine besorgte Familie und seine jahrelang gehegten Träume dargestellt. Zur gleichen Zeit ertrinken „tausende Menschen im Mittelmeer, die sich auf die Flucht begeben, um ihr Leben und das ihrer Familien zu retten“ (ebd.). In den hegemonialen Medien erhalten sie weder „Namen noch individuelle Geschichten“ (ebd.). Geld wird in erster Linie in den bewaffneten Grenzschutz etwa durch Frontex investiert, statt in Rettungsaktionen. Statt für sichere Fluchtwege zu sorgen, werden die Grenzkontrollen ausgeweitet - bis weit vor die territorialen Außengrenzen der EU hinaus; damit werden die Bedingungen, die zum Sterben führen, nicht eingedämmt, sondern erst produziert und verstärkt. Heinemann stellt dazu in Bezug auf die Betrauerbarkeit des Lebens fest: „Farida, Maryam, Asa und die kleine Leia stellen somit keine individuellen Schicksale dar, um die getrauert werden konnte, deren Gesichter sie uns unvergesslich machen konnten - sie werden lediglich als Zahlen repräsentiert.“ (ebd.) Während die einen im medialen Diskurs ,als Menschen“ vorkämen, erscheinen die anderen in erster Linie „als zahlbare Menge“ (ebd.).

Ignoranz und Gleichgültigkeit gegenüber dem Massensterben durch das EUropäische Grenzregime werden, Fatima El-Tayeb zufolge, nur möglich durch zwei Annahmen: „Die Leben, die verloren wurden, sind weniger wert als die europäischer Menschen, und diejenigen, die starben, gehören nicht nach Europa, [...].“ (El-Tayeb 2016: 55) Diese Ungleichwertigkeit des Lebens bzw. diese Kolonialität des Lebens zeigt sich am deutlichsten im Angesicht seiner Auslöschung. Diese Differenz bezeichne ich als die Metrik des Sterbens. Eine Metrik - auch Abstandsfunktion genannt - bezeichnet in der Mathematik eine Funktion, die je zwei Elementen des Raums einen nicht negativen reellen Wert zuordnet, der als Abstand der beiden Elemente voneinander aufgefasst werden kann. 
Zum ersten Mal begegnet - zumindest als von mir problematisch empfunden - bin ich dieser Kolonialität des Lebens in meiner Schulzeit als in den Tagen nach 9/11 Schweigeminuten abgehalten wurden und Mitschüler_innen nicht aufhören konnten zu weinen. Nicht das Betrauern des Todes ist hier das Problem, ganz im Gegenteil, sondern der Kontrast zum Ausbleiben dieser Trauer bei Toten durch imperiale Kriege, neokoloniale Ausbeutungsregime und die Praktiken des EUropäischen Grenzregimes. Damals - in der 11. Klasse - hatte ich keine Worte für mein Unwohlsein. Heute würde ich die damals empfundene Schieflage als eine koloniale Metrik des Sterbens bezeichnen, die selbst eine Form von Gewalt darstellt. Ghassan Hage fasst dies als eine Art imperialen, affektiven Morasts auf, der sich durch die Unterschiedlichkeit der Auslöschbarkeit (exterminability) und Betrauerbarkeit (mournability) von Toten auszeichnet, in der das Lebens des kolonialen Anderen - im Fall von Hage muslimische Menschen - als ungleichwertig erscheint. Dieser affektive Morast umfasse uns alle und besteht in einer Kultur der selektiven Gleichgültigkeit gegenüber dem Mord und Sterben einiger (Hage 2016). In Bezug auf die koloniale Metrik des Sterbens auf dem Mittelmeer trifft zu, was Shadi Kooroshy und Paul Mecheril als „moralische Neutralisierung und die Alltagskultur einer buchhalterisch-administrativen Gleichgültigkeit“" bezeichnen:

„Mit der Wirksamkeit des race-Denkens verbindet sich auch das, was Zygmunt Baumann (2016) Adiaphorisierung nennt, also eine moralische Neutralisierung und die Alltagskultur einer buchhalterisch-administrativen Gleichgültigkeit, die die Anteilnahme an dem Schicksal und Leid Anderer verhindert und damit auch jene politische Einbildungskraft hemmt, die erforderlich ist, um Menschheit politisch wie pädagogisch nicht partikular (,Wir sind das Volk“), sondern allgemein zu denken.“ (Kooroshy/Mecheril 2019: 89)

Die Kolonialität der Ungleichwertigkeit des Lebens wird dabei nicht einfach hingenommen. Didaktisch könnte beispielsweise der tiefe Riss in die Ordnung der Kolonialität an diesem Punkt als Ausgangspunkt gesehen werden, der durch die Black Lives Matter-Bewegung und ihre Internationalisierung im Anschluss an den Mord an George Floyd in Minneapolis (USA) aufgerissen wurde.

\subsection{Kolonialität der Migration}

Wie ist nun diese Beobachtung der kolonialen Metrik des Sterbens in den Vorstellungen der Lernenden analytisch zu fassen? Was sind die Marker, die hier die Ungleichwertigkeit zum Ausdruck bringen? Was macht hier den kolonialen 
Anderen zum Anderen, zum so weit Anderen, dass der Tod als legitim und hinnehmbar erscheint? Ist es ,einfach' Rassismus? Rassismus ist - entgegen eines liberalen Verständnisses von Rassismus - nie ,einfach'. In den Lernendenvorstellungen scheinen sich mehrere Dimensionen zu überlagern, mindestens folgende vier: Staatsbürgerschaft - das Ertrinken eines Menschen mit deutschen Pass dürfte unabhängig von Hautfarbe oder anderen rassialisierenden Phänotypisierungen niemals hingenommen werden. Rassismus - das Ertrinken eines als ,weiß‘ und ,westlich' markierten Menschen erschiene als nicht legitim. Grenzüberschreitung statt Reisen - würden diese Menschen gerade auf dem Weg in den Urlaub sein, während sie in Not geraten, wäre ihnen vermutlich das Mitgefühl sicher. Zu diesen drei Ebenen kommt eine vierte Ebene hinzu, die ich in Anlehnung an Spivak als Klassenargument bezeichne: „It is not just white versus yellow or white versus brown or white versus black. It is a more complicated class argument $[\ldots]$ “ (Spivak 1991: 223).

Mit einer dekolonialen Perspektive werden hier verschiedene Ebenen zusammengebracht, die sonst oft durch die fachdisziplinären Perspektiven als getrennt erscheinen. Verschiedenfach wurde der Versuch unternommen, die Perspektive der Grenzregimeanalyse als Versicherheitlichung mit der Critical Race Theory zusammenzubringen. Beispielsweise Moffette und Vadasaria (2016) zeigen, wie die Versicherheitlichung der Grenzregime und die Normalisierung rassialisierter Gewalt miteinander verschränkt sind und analysieren diese Verschränkung in mehrfacher Hinsicht. So erscheinen die das Grenzregime ermöglichenden Machtverhältnisse selbst als eingebettet in die koloniale ,Moderne'. Und die versicherheitlichenden Praktiken erscheinen bereits selbst als Ausdruck rassialisierter Begehren. Das Zusammenwirken von Kolonialität und Versicherheitlichung ermöglicht einem liberalen Selbstverständnis die Legitimation von etwas, was Moffette und Vadasaria als ungenierte oder ungehemmte Gewalt (uninhibited violence) bezeichnen (ebd.).

Encarnación Gutiérrez Rodríguez entwickelte in der Auseinandersetzung mit diesem Komplex den Begriff der Kolonialität der Migration (2018: 16). Mit diesem Analyseinstrument setzt sie rassialisierten Kapitalismus in Beziehung zum Migrations- und Asylregime. Unter rassialisiertem Kapitalismus versteht sie den konstitutiven Zusammenhang von rassialisierenden und kapitalistischen Strukturen, der im Ansatz der Dekolonialität herausgearbeitet wurde: "Relations of global trade, the organization of waged and unwaged labour, the division of work, in short, the modes of production and social reproduction of global capitalism continue to be organized by the racial matrix sustaining the coloniality of power." 
(ebd.: 20) Dabei stellt sie die Unterscheidungspraxis von Bürger_innen als Mitglieder eines Nationalstaats und Migrant_innen als von dieser Mitgliedschaft ausgeschlossenen in den Kontext der Kolonialität:

\begin{abstract}
"Migration within the emergence of the modern nation-state in the nineteenth century in former European colonies illustrates the divide created between the insider and outsider of the nation. This divide evokes the logic of coloniality, as it creates a racial difference between the insiders, considered members of the nation, and the outsiders, considered 'migrants'. Thus the dichotomy between citizens and migrants is embedded in a racializing logic produced within social relations shaped by the enduring effects of colonial epistemic power." (ebd.: 25)
\end{abstract}

Zur Perspektive der Kolonialität der Migration gehört aber auch die Hierarchisierung von Migrierenden. Encarnación Gutiérrez Rodriguez zeigt, wie historisch in der kolonialen Matrix Migration keineswegs abgelehnt wurde, sondern wie ihr eine rassialisierte Unterscheidung zugrunde lag: "Up until the mid-twentieth century, countries like the United States, Argentina, Brazil, Australia, New Zealand, and Canada explicitly recruited white Europeans." (ebd.: 25) In gegenwärtigen Diskursen in Deutschland und Europa sieht sie den Asyldiskurs zugunsten eines Nützlichkeitsdiskurses verschwinden, mit dem sich Asylgesetzgebung zu einem Regulations- und Kontrollinstrument rassialisierter Arbeitsmigration verfestigt. Gleichzeitig beobachtet sie eine die politischen Lager übergreifende Geste, die Figur des Geflüchteten als das Andere der Nation oder Europas Exteriorität zu konstruieren, mit der gleichzeitig die imaginierte Norm europäischer Whiteness geschaffen wird (ebd.: 24). Mit dem Begriff der Kolonialität der Migration bringt sie also die Normalisierung nationalstaatlicher Grenzregime, die Logik der Produktion rassialisierter Anderer und die Dynamiken der Ausbeutungssysteme im kolonial-modernen Weltsystem sowie die nationalstaatlichen Arbeitsmigrationspolitiken zusammen:

\begin{abstract}
"The coloniality of migration draws attention to this fact by addressing the links between labour, capitalism, and racism. Thus, the asylum-migration nexus needs to be interrogated as an object of governance through racial/ethnic and gender differentiation, as a cultural script for understanding society and as another grammar of thinking through capital." (ebd.: 25)
\end{abstract}

Der Ansatz der Kolonialität der Migration erscheint als sinnvolle Perspektive, um mögliche didaktische Konzepte zu entwickeln, um die vorgefundenen kolonialen Vorstellungen zu irritieren bzw. einen Lernraum zu ermöglichen, in dem der in 
der Regel in den Vorstellungen implizit auftretende Widerspruch zwischen humanistischer Empathie und dem Anspruch universeller Gleichheit auf der einen und der die koloniale Differenz reproduzierende Diskurspraktik auf der anderen Seite zu einem Spannungsverhältnis gemacht werden kann.

\subsection{Von Menschenrechten, bloßem Menschsein und dem liberalen Imaginären}

In den Lernendenvorstellungen findet sich - trotz aller Rechtfertigungen kolonialer Gewalt - eine stark ausgeprägte empathische Haltung, die sich häufig in der Proklamation eines Unrechtsbewusstseins in Bezug auf die globale soziale Ungleichheit und die damit in Verbindung gebrachte Migration ausdrückt. Der ethische Bezugspunkt des universellen Menschseins - es seien ,genauso Menschen wie wir" (Luka, Gym02) - verweist auf den normativen Kontext der Menschenrechte. Diese werden von den Schüler_innen jedoch nur in Ausnahmefällen angeführt, wenn es um das Recht der Geflüchteten auf sichere Fluchtwege geht. Hier kommt der Aspekt der Menschenrechte zum Tragen. In Bezug auf Flucht und Migration können die Menschenrechte als in eine Art Paradox verstrickt erscheinen. In der Anwendung der Menschenrechte findet eine Unterscheidung von Bürger_in und Mensch statt. Mit Arendt werden NichtBürger_innen, also Menschen, die nicht Teil der nationalstaatlichen Gemeinschaft sind, auf ihr bloßes Menschsein reduziert und verlieren damit das Recht, Rechte zu haben. Damit gelten paradoxerweise de facto auch die Menschenrechte nicht mehr für diejenigen, die in die ,abstrakte Nacktheit ihres Nichts-als-Menschsein“ (Arendt 1951: 620) geworfen sind und also den Schutz durch Menschenrechte am nötigsten hätten. Arendt entwickelte diesen Ansatz insbesondere vor dem Hintergrund der staatenlos gewordenen Flüchtlinge. Er ist aber genauso gültig für diejenigen, deren nationalstaatliche Zugehörigkeit geopolitisch nicht auf der ,richtigen' Seite verortet ist. Seyla Benhabib bezeichnet dies als Paradox demokratischer Legitimität und Souveränität. Damit verweist sie auf den Umstand, dass „Bürgerrechte auf Menschenrechten beruhen, aber Bürgerrechte nur einer exklusiven Wir-Gruppe zugesprochen werden, dieses demokratische Paradox wird in seiner Fragwürdigkeit unter gegenwärtigen Bedingungen besonders augenfällig“" (Mecheril 2020: 102).

Auf der anderen Seite dehnen einige Schüler_innen den Menschenrechtsgedanken über sein hegemonial liberales Verständnis hinaus aus. Luka bezieht seine Aussage, dass sie „genauso Menschen wie wir seien“ auf die Ungleichheit der Arbeits- und Lebensbedingungen innerhalb der internationalen Arbeitsteilung. Implizit verweist er - und ähnlich argumentieren zahlreiche Schüler_innen - auf die potenzielle Reichweite der Menschenrechte, die auch die ökonomischen und 
sozialen globalen Ungleichheiten umfassen. Postkoloniale Kritiker_innen sehen in der Praxis der Menschenrechte eine ,schwache Ausprägung im Bereich der wirtschaftlichen, sozialen und kulturellen Rechte" (Kalny 2008: 219). Der Menschenrechtsdiskurs ruft häufig das liberale Imaginäre (liberal imaginary) mit auf den Plan, das mit einer Begrenzung der Reichweite einhergeht (Kapur 2014). Menschenrechtliches Unrecht kann so nur im Kontext des liberalen Rahmens gelöst werden, was bedeutet, dass die Gesetze des freien Handels unangetastet bleiben sowie dass Freiheit nur als individualistische aufgefasst werden kann. Die Menschenrechte erscheinen als etwas, das - mit Spivak gesprochen - etwas ist, was wir ,nicht nicht wollen können'; sie erscheinen einerseits als frei flottierender Signifikant, wie Demokratie, Freiheit, Gerechtigkeit, und ist in der Lage Bezugspunkt für dekoloniale Kämpfe zu sein. Gleichzeitig kann der Menschenrechtsdiskurs das dekoloniale Denken durch die mit ihm transportierten liberalen Prämissen begrenzen:

\footnotetext{
"While human rights, which frame the subject and understandings of freedom strictly within a liberal imaginary, appear to be something that 'we cannot not want', (to paraphrase Gayatri Spivak, writing in a different context), it is important to add - even though it cannot give us what we want." (Kapur 2014)
}

Die Argumentation der Schüler_innen verweist als Spur darauf, diesen Rahmen zu überschreiten. Aus postkolonialer Perspektive gibt es hier eine lange Tradition. Siba N'Zatioula Grovogui zeigt beispielsweise, wie im Zuge der haitianischen Revolution (1791-1804) bereits eine Menschenrechtsverfassung geschaffen wurde, die den liberal-bourgeoisen Rahmen der US-amerikanischen und französischen Formulierungen sprengte, indem aus der Erfahrung des auch von der Plantagenwirtschaft verursachten Leids wirtschaftliche Strukturen und soziale Gerechtigkeit grundlegender Teil dieser Verfassung wurden (Grovogui 2006: 51 f.). Im Gegensatz zur französischen und US-amerikanischen Variante bezog sich ihre Geltungsreichweite auch auf Nicht-Weiße, Nicht-Staatsangehörige, NichtBesitzende und Frauen.

Spivak verweist dabei immer wieder darauf, dass nicht nur die mit der Hegemonisierung des Menschenrechtsdiskurs einhergehenden Privatisierungen als problematisch erscheinen, sondern auch die Frage der Subjekte der Menschenrechte eine Rolle spielt. Im Menschenrechtsdiskurs findet hier eine asymmetrische Aufteilung der Menschheit statt, in jene, die Menschenunrechte erleiden, und jene, die deren Unrechte richten: „Die Trennung, von der ich hier spreche, ist eine Klassentrennung, die vorgibt, eine kulturelle Trennung zu sein, um die ungleiche Verteilung von Handlungsfähigkeit neu zu kodieren.“ (Spivak 2008b: 86, Fn. 18). 
Der Rechtswissenschaftler Makau Mutua kritisiert vor diesem Hintergrund beispielsweise eine Menschenrechtsbewegung, die ein globales Imaginäres herstellt, in dem die Länder des Globalen Südens als ,barbarisch“ und zu keiner eigenen Regierung fähig sind (2002, zitiert nach Castro Varela/Dhawan 2020). Die typischerweise als nicht-westlicher Staat repräsentierten Menschenrechtsbrecher stehen neben den im Zentrum der Menschenrechtspolitiken erscheinenden ,Opfer', denen mit einem viktimisierenden Blick jede Handlungsmacht undenkbar macht (Castro Varela/Dhawan 2020). Nichtregierungs-, und Wohlfahrtsorganisationen wie auch westliche Regierungen erscheinen dann als Retter dieser ,Opfer', die vor den ,Wilden“ gerettet werden müssten (ebd.). „Die Distanz zwischen jenen, die Rechte zuteilen, und jenen, die lediglich als Opfer von Unrecht und als Empfänger_innen von Rechten gelten, verharre unter dem Vorzeichen historischer Gewalt.“ (ebd.)

Dies ist verschränkt mit dem hegemonialen Entwicklungsdiskurs, dessen zentrales Dispositiv die ,gute Regierungsführung ' darstellt. Bereits bei der Verabschiedung der Allgemeinen Erklärung der Menschenrechte 1948, in der es heißt „Alle Menschen sind frei und gleich an Würde und Rechten geboren“, blickten Akteur_innen aus kolonisierten Ländern mit einiger Skepsis darauf. Schließlich war zu dieser Zeit die Dekolonialisierung - verstanden als die weitgehende Aufhebung des formalen Kolonialverhältnisses, nicht der Kolonialität - noch lange nicht abgeschlossen, koloniale Gewalt und Rassentrennung bestimmten die Lebensrealitäten im Globalen Norden und Globalen Süden. Auch heute noch erscheinen aus einer postkolonialen Perspektive viele Menschenrechtsverletzungen als Resultate von Strukturanpassungsprogrammen, die von den gleichen Geldgeber_innen erzwungen werden, die sich für die Menschenrechte einsetzen. Die neoliberale und neokoloniale Strukturanpassungspolitik trägt häufig dazu bei, dass Staaten spezifische Rechte missachten, wie etwa mit dem Verbot gewerkschaftlicher Organisierung, Kinderarbeit, Löhne unterhalb von Mindestlohngrenzen und die Kürzung von Ernährungs- und Bildungssubventionen (ebd.).

Besonders offensichtlich erscheint die problematische Universalisierung und Instrumentalisierung der Menschenrechte im Feld der Frauenrechte. Die Gründe für die Unterdrückung von Frauen werden - so impliziert dies das UN-Abkommen von 1979 (ebd.) - in den Traditionen und der ,Kultur ' der ehemals kolonisierten Länder verortet, während der ,Westen" sich erneut als modernisierende Befreierin inszenieren kann. Unter Ausblendung ökonomischer Aspekte werden „zumeist außereuropäische lokale Kulturen schlichtweg als frauenfeindlich“ (ebd.) essenzialisiert. Ein Beispiel für diese koloniale Aneignung vermeintlich die Frauenrechte unterstützenden Menschenrechtspolitiken sind die zwei Bevölkerungsuhren, die in Hannover vor der HDI-Arena und vor dem Hannoveraner 
Zoo stehen. Diese Uhr zeigt die aktuelle Anzahl der auf der Welt lebenden Menschen. Durch die visuelle und textuelle Rahmung wird hier deutlich gemacht, wofür die ,Stiftung Weltbevölkerung' hier ein öffentliches Bewusstsein schaffen will. Die Bevölkerung steige nicht im Globalen Norden, sondern in den ,Entwicklungsländern', in denen Armut herrsche. Die Projekte der Stiftung wollen die Probleme von Armut, ökologische Probleme und das Verschwinden von Lebensraum für bedrohte Tierarten lösen, indem nicht die falschen Bevölkerungsteile Kinder bekämen. Dies drücken sie darin aus, dass sie Frauen ,helfen' wollen, indem sie ihnen ,Aufklärung' und Frauenrechte brächten.

Das in Frauenrechtsdiskurse verpackte Programm klingt nach einer Ausweitung von Sarrazins Thesen auf den globalen Maßstab, die nicht zuletzt auch in der Tradition der kolonialen These der Überbevölkerung in der Tradition von Tomas Malthus steht. An diesem Beispiel scheint wieder die koloniale Ungleichwertigkeit des Lebens auf, die ich auch als Form epistemischer Gewalt ansehe. „Das klarste Beispiel für eine solche epistemische Gewalt ist das aus der Distanz orchestrierte, weitläufige und heterogene Projekt, das koloniale Subjekt als Anderes zu konstituieren." (Spivak 1988a: 42) Das Sterben auf dem Mittelmeer erscheint so ebenso als Materialisierung epistemischer Gewalt wie die ,Entwicklungshilfemaßnahmen' der Stiftung Weltbevölkerung. Paradoxerweise bleibt diese Gewalt oft als solche unsichtbar. Das Sterben - verursacht durch die EUropäische Migrationspolitik - wird ebenso wenig als eine Folge von Gewalt sichtbar, wie die koloniale ,Entwicklungshilfe' gegen die vermeintliche Überbevölkerung.

\subsection{Menschenrechte und Emanzipation als, westlich' oder universell?}

Oft erscheint die Idee von Menschenrechten als genuin, westlich ` - ebenso wie Freiheit, Emanzipation, Demokratie, Gleichheit. In den Lernendenvorstellungen werden etwa in einem Drittel der Interviews universalistische Ideen, wie Offenheit, Modernität und Freiheit, an die ,westliche Kultur' gekoppelt. (3.2.4). Diese dichotome Konstruktion lässt sich auch in der orientalistischen Differenz in migrationsgesellschaftlichen Kontexten feststellen. (3.3.2). In über einem Viertel der Interviews taucht die Idee auf, dass die Menschenrechte europäischen Ursprungs seien bzw. dass die ,nicht-westlichen 'Gesellschaften diese ,noch nicht" implementiert hätten. Beispielsweise Melina (Gym08) konstruiert universalistische Werte in Abgrenzung zum ,Nicht-Westen'. Demokratische Regierungsform im Gegensatz zum orientalischen oder afrikanischen Despotismus, der Rechtsstaat im Gegensatz zu Korruption, Offenheit und Freiheit im Gegensatz zu den Zwängen der ,kulturellen Traditionen“ erscheinen als Wesensmerkmale der, westlichen 
Kultur“. Die „Gleichberechtigung zwischen Männern und Frauen“ hebt sie dabei als kategoriales Differenzmerkmal besonders hervor.

Sie plädiert dafür, dass die ,nicht-westlichen' Länder die , westliche Kultur" nicht „total übernehmen“, sondern auch ,ihre eigene Kultur behalten“ sollten. Einige Aspekte - und hier meint sie vermutlich die Melina zufolge der ,westlichen Kultur' eigenen, universalistischen Konzepte - sollten aber aus dem ,Westen“ exportiert werden. Hier bringt sie den Aspekt der „Gleichberechtigung zwischen Männern und Frauen“ ein. Diese würde sie an der ,westlichen Kultur ziemlich schätze[n]" und sie sei ihr ,sehr wichtig“. Dies sei ,sogar in den westlichen Kulturen ja noch nicht mal richtig ausgereift". Die von Melina konstruierte Differenz erscheint hier nicht absolut, da sie darauf hinweist, dass die „Gleichberechtigung zwischen Männern und Frauen“ auch im Westen nicht komplett realisiert sei. Gleichzeitig erscheint die „Gleichberechtigung zwischen Männern und Frauen“ als kategoriales Differenzmerkmal. Sie rechnet diese eindeutig der ,westlichen Kultur' zu. In ,nicht-westlichen Kulturen' scheint es nach Melina so etwas nicht zu geben; wenn sie das in ,nicht-westlichen Kulturen' wahrnehmen würde, erschiene es ihr möglicherweise als eine bereits erfolgte Ausdehnung eines ,westlichen' Konzepts. Gleiches gilt auch für die Frage der anderen von ihr genannten Wesensmerkmale der ,westlichen Kultur', wie etwa der demokratischen Regierungsform im Gegensatz zur Alleinherrschaft, des Rechtsstaats im Gegensatz zu Korruption, der Offenheit oder der Freiheit.

Für Timo (Gym19) ist ein Staat per definitionem dann als ,westlich“ anzusehen, wenn er ,demokratisch“ und ,gut entwickelt“ ist und sich ,human“ für seine „Bürger“ einsetzt. Sowohl Melina als auch Timo betonen, dass sich die Länder des Globalen Südens nicht insgesamt kulturell anpassen müssten, sehr wohl aber die universalistischen Konzepte wie Freiheit und Gleichheit ,exportiert" werden müssen. Während Melina dabei durchaus auch im ,Westen' nicht realisierte Gleichheitsversprechen sieht, erscheint für Timo an keiner Stelle eine ,Schieflage ‘ der Demokratien, was wiederum mit seinem Verständnis des ,Westens` zusammenhängt, die er per definitionem an den Universalismus bindet. Gleichzeitig versucht er ihn nicht geographisch zu verorten, um Überlegenheitsbehauptungen einer ,Kultur' gegenüber einer anderen zu vermeiden, konstruiert aber gleichzeitig implizit den orientalischen Anderen, der fehlende Freiheit, Demokratie und Gleichheit verkörpert. Die vorherrschende Form, in der die ,,Verbreitung der westlichen Kultur" und damit der Demokratie, der Freiheit, der Gleichberechtigung und so weiter gedacht wird, ist die der, Entwicklungshilfe " und hier insbesondere Bildung. Die Lösung erscheint hier als ,Entwicklungshilfe ' - und hier insbesondere Bildung - und erinnert in ihrer Rhetorik zum Teil stark an die Diskurse der 
mission civilisatrice. Einige denken aber auch über die Option militärischer Interventionen nach, um Menschenrechte oder Demokratie durchzusetzen, auch wenn dies als zweitrangiges Mittel angesehen wird.

Lara (Gym18) entwickelt eine sehr komplexe und widersprüchliche Argumentation bezüglich der Menschenrechte und ihrer Globalisierung. Diese habe ich im Abschnitt Zur Ambiguität der Menschenrechte (3.2.5) ausführlich diskutiert, weswegen ich an dieser Stelle auf eine Wiederholung verzichte. Ausgehend von Laras komplexen und widersprüchlichen Argumentationen lässt sich im Anschluss daran und in der Problematisierung dessen ein Paradox herausarbeiten, das für eine didaktische Perspektive dekolonialer politischer Bildung als Ausgangspunkt dienen kann. Das Paradox besteht darin, dass es aus einer dekolonialen Perspektive nötig erscheint, zwei Mythen als solche sichtbar werden zu lassen: Den Mythos der Menschenrechte als, westlich“ und den Mythos der Menschenrechte als , universell'.

Der Mythos, der Menschenrechte als genuin, westlich ' erklärt, verwechselt systematisch die historische Ausformulierung der Menschenrechte, auf die sich heute in der Regel bezogen wird, wie beispielsweise im Zuge der Französischen oder US-amerikanischen Revolution, mit der Idee oder dem Prinzip eines universellen Gleichheitsversprechens aller Menschen oder der Menschenwürde, das sich in zahlreichen Traditionen findet, wie etwa „,in Werken des Konfuzianismus, des Judentums, des Islams, des Christentums, des Jainismus, des Buddhismus und des Hinduismus“ (Kalny 2008: 201). Dies soll keine abschließende Liste darstellen, aber deutlich machen, dass es empirisch nicht haltbar ist, die Idee universeller Gleichheit und Freiheit mit den europäischen oder US-amerikanischen Menschenrechtserklärungen gleichzusetzen oder diese zu einer ausschließlichen Wesensart der , westlichen Kultur' zu erklären. Hinzu kommt, dass auch die Französischen oder US-amerikanischen Erklärungen in ihrer globalgeschichtlichen Verwobenheit gesehen werden müssten. Des Weiteren sollte auch der Widerstand der Kolonialmächte nach dem Zweiten Weltkrieg berücksichtigt werden, welche sich als Kolonialländer gegen das Bestreben der immer noch oder ehemals kolonisierten Länder richtete, die Allgemeine Erklärung der Menschenrechte sowie in den folgenden Jahren die verschiedenen UN-Pakten zu verabschieden und damit den Menschenrechtsbegriff zumindest de jure auf alle Menschen und auch auf sozioökonomische Rechte auszudehnen (ebd.: 200 f.).

Der Mythos der Menschenrechte als ,westlich ' basiert dabei auf der systematischen Dethematisierung der durch den ,Westen' verursachten Verbrechen gegen die Menschlichkeit und die sogar im engen juristischen Sinne als solche aufzufassenden massiven Menschenrechtsverletzungen. Innerhalb dieses diskursiven 
Rahmens werden Menschenrechtsverletzungen nicht mit ,westlichen“ Gesellschaften assoziiert, sondern mit Gesellschaften des Globalen Südens; wobei hier innerhalb der Lernendenvorstellungen einige Ausnahmen zu finden sind, wie beispielsweise Laras Erläuterung. Der Mythos der Menschenrechte als ,westlich“ konstituiert ein Überlegenheitsnarrativ, das in den Prinzipien der entwicklungsparadigmatischen Treuhandschaft mündet. Dieser Mythos dient außerdem als Legitimation von neokolonialer und imperialer Machtausübung zeigt, was sich am offensichtlichsten in den ,humanitären Interventionen', die auch als zum größten Teil imperial motivierte Angriffskriege verstanden werden können.

Dem steht der Mythos der Menschenrechte als universell gegenüber. Hier ist zunächst darauf zu verweisen, dass die Menschenrechte historisch große Teile der Menschheit ausgeschlossen haben. Olympe de Gouges wurde 1793 hingerichtet, weil sie die Ausweitung der , universellen“ Menschenrechte auch für Frauen forderte. Fitzpatrick stellt fest, dass der Mensch der Menschenrechte einem impliziten Bild entsprechen muss (Fitzpatrick 2013: 103; ausführlicher in 3.2.5). Die verkündete Universalität der Menschenrechte ist also - wie auch Lara das tut zum einen auf ihre Substanz hin zu überprüfen, was im Übrigen bis heute gilt. Zum anderen erscheint sie als eurozentrisch, da sie in ihrer gegenwärtig institutionalisierten Form häufig für ,westliche“ Vergesellschaftungsmodelle, wie etwa Freihandel und Privatisierung, Subjektivierungsweisen, wie etwa Individualismus und Staatsbürgerschaft, sowie Gerechtigkeitsmodi, wie etwa Rechtsstaatlichkeit und negative Freiheit des Individuums, als eine Art Container fungiert. Diese Ideale dienen gleichzeitig dazu die Universalität der, westlichen' Humanität zu behaupten sowie ,nicht-westliche“ Menschen zu inferiorisieren: „Der bürgerlichen Ideologie, die die Wesensgleichheit der Menschen proklamiert, gelingt es, die ihr eigene Logik zu bewahren, indem sie die Untermenschen auffordert, sich durch die westliche Humanität, die sie verkörpert, zu vermenschlichen." (Fanon 1961: 126).

Der Mythos, der die Menschenrechte als genuin ,westlich`versteht, korrespondiert mit der Vorstellung, dass das Abstrakte und das Universale selbst,westlich “ bzw. ,europäisch' sei und von dort in den Rest der Welt getragen wurde. Mark (Gym09) beginnt seine Erzählung der Globalisierung mit dem problematischen Entdeckungsnarrativ (3.4.3). Problematisch ist es deswegen, weil es eurozentrisch ist, da es die Perspektive der Millionen Menschen ignoriert und abwertet, die bereits in den später so bezeichneten Amerikas gelebt haben. Aus der Perspektive von Kolumbus argumentiert Mark weiter. Diese habe damals die ,,vielen Menschen“ gesehen, die ,noch keine Ahnung von der Religion“ oder dass sie ,einer Religion angehören“ gehabt hätten. In dieser Situation habe Kolumbus sich zur Christianisierung dieser Menschen entschlossen. Korrespondierend mit der 
kolonialen Sicht von ,Amerika' als terra nullius und der Vorstellung des vorzivilisierten Zustands der dortigen Bevölkerung scheint, Mark zufolge, Kolumbus nicht nur das Christentum , gebracht` zu haben, sondern Religiosität überhaupt. Damit sind auch die Vorstellungendes Abstrakten, Universalen und Ethischen überhaupt verbunden.

Walter Mignolo stellt einer solchen Sicht eine Relektüre von Waman Puma de Ayalas Primer Nueva Crónica y Buen Gobierno von 1616 entgegen. Er arbeitet heraus, wie Waman Puma sich das Christliche aneignet, um es von einem anderen Standpunkt aus zu resignifizieren. Dabei erscheint die Aneignung nicht als die Einführung des Universellen in die kolonialisierte Welt, sondern vielmehr dient das Christentum hier - im Rahmen seiner neuen Chronik, die dabei ein neues, transmodernes Narrativ anbietet - als eine mögliche Erzählung, in der das Streben nach einem guten Leben eingeschrieben wird. Hier sieht Mignolo eine Kontinuität bis in die Gegenwart eines dekolonialen Delinking, die aufhört, Befreiung als aus den kolonialen Werten abgeleitet zu betrachten:

\begin{abstract}
„In Waman Puma's argument, Christianity is equivalent to that of the democracy of the pen and the word of the Zapatistas: democracy is not the private property of Western thought and political theory, but rather one of the principles of coexistence, of good living, that has no owner. Waman Puma seized upon Christian principles in spite of and against harmful Christians, just as the Zapatistas seize upon democracy in spite of and against a Mexican government that is complicit with the commercialization of democracy in Washington's market." (Mignolo 2011: 56)
\end{abstract}

Ebenso wie Christianität, Demokratie, Freiheit usw. sind die Menschenrechte aus dieser Perspektive als ein umkämpftes Terrain zu begreifen, das für eine dekoloniale Bewegung einen wichtigen Bezugspunkt darstellen kann - vorausgesetzt die darin enthaltenen Fallstricke der Kolonialität werden reflektiert.

Auch in Laras Darstellung findet sich ein solches Verständnis begründet (3.2.5), indem sie die Menschenrechte vor dem Hintergrund von Versklavung, Kolonialismus und Rassismus gegen den Strich liest und seine Durchsetzung an die Frage von Hegemonie statt an die Frage von ,Fortschritt' und der Diffusion von universalistischen Konzepten aus koppelt. Dies sind Widersprüche und Ambivalenzen, an die eine dekoloniale politische Bildung anschließen kann, wenn sie menschenrechtlich oder mit anderen universalistischen Prinzipien verbundene Verhältnisse in den Fokus nimmt. Aufgabe wäre es, gegenüber kolonialen Interpretationsschemata zu sensibilisieren. Dafür müssen Interpretationsweisen gestärkt werden, die die Kolonialität des Wissens als auch des Denkens von Ethik und Politik problematisieren und alternative Deutungsmuster zur Verfügung stellen. 


\subsubsection{Geteilte Zugehörigkeiten in einer migrationsgesellschaftlichen Welt}

\subsubsection{Zur (De-)Thematisierung von Rassismus}

\subsection{Zur Unsichtbarkeit von Rassismus}

Ich werde im Folgenden der (De-)Thematisierung von Rassismus in den Lernendenvorstellungen nachgehen. In meinen Überlegungen für die Konsequenzen für Didaktik und Bildung werde ich mich auf die Bereiche beschränken, die in einem direkten Verhältnis zu den vor mir ko-konstruierten Vorstellungen stehen. In den Lernendenvorstellungen wird das Thema Rassismus, wie ich in den Abschnitten Farbe als Zugehörigkeitsmarker (3.3.3) und Islam vs. Westen (3.3.2) gezeigt habe, sehr unterschiedlich behandelt. Hier kommt die geteilte - im Sinne von divided - Zugehörigkeit der Schüler_innen zum Ausdruck. Während zahlreiche Schüler_innen von Rassismuserfahrungen berichten, sprechen kaum in rassistischen Verhältnissen privilegierte Schüler_innen diese Themen an. Wenn sie das tun, tun sie das fast ausnahmslos auf eine externalisierende Weise, das heißt auf eine Weise, die nichts mit ihrer Lebenswelt zu tun hat. Entweder Rassismus wird mit dem Nationalsozialismus assoziiert oder in zwei Fällen mit in seiner Tradition stehenden als marginal erscheinenden rechtsextremen Gruppen. Oder Rassismus wird mit dem Kolonialismus oder der Sklaverei verbunden und im gleichen Zuge so historisiert, dass Bezüge zur Gegenwart ausgeschlossen werden. Von diesem Nicht-Sprechen von Rassismus in den Interviews mit einer - keineswegs klar definierten - Gruppe kann keineswegs auf eine Absenz von Rassismus geschlossen werden, sondern vielmehr auf eine Absenz von Rassismuskritik.

Aus einer rassismuskritischen Perspektive stellt dies ein Problem dar. Die Absenz des Sprechens über Rassismus führt nicht zu einer Verringerung der Machtwirkungen, sondern kann diese - aus mehreren Gründen - vielmehr verstärken. Zunächst ist hier zu nennen, dass sich die impliziten Normalisierungspraxen und die damit verbundenen versteckten Hierarchien durch ihre Entnennung verstärken.

„Wenn Weißsein entnannt wird, werden auch die sozialen Positionen, Privilegien, Hegemonien und Rhetoriken verleugnet, die an Weißsein gebunden sind, und wird den Ausgrenzungs- und Gewalterfahrungen, die Schwarze und People of Color durch Weiße real erleben, keine Rechnung getragen. Dadurch wird Weißsein nicht nur verstärkt und naturalisiert, zudem bleibt sein Status als , unmarked marker" und unsichtbar herrschende Normalität' unerschüttert." (Arndt 2005: 348) 
Bildungsräume müssen ein Sprechen über Rassismus ermöglichen. Es müssen rassismuskritische Instrumente zur Verfügung stehen und ein Klima geschaffen werden, in dem ein solches Sprechen möglich ist. Dafür braucht es einen Begriff von Rassismus, der diesen von individualisierenden oder pathologisierenden Verständnissen löst. In Deutschland gilt ganz besonders, dass Rassismus mit dem Nationalsozialismus verbunden wird, was als zentrale Grund angeführt wird, warum Rassismus keine Kategorie der Beschreibung deutscher Realität werden konnte. Rassismus wird mit etwas gleichgesetzt, das nicht sein durfte, nämlich der Kontinuität der bundesrepublikanischen Gesellschaft mit dem Nationalsozialismus (Kalpaka/Räthzel 1986). Die Dethematisierung von Rassismus ist jedoch nicht auf diesen Aspekt zu beschränken. Externalisierungsstrategien von Rassismus, mit denen er als individualisiertes und pathologisiertes Problem erscheint, ermöglichen es auch, der subjektiv möglicherweise als unangenehm empfundenen Einsicht in die eigene Verstricktheit aus dem Weg zu gehen.

Paul Mecheril grenzt einen weiten Rassismusbegriff von externalisierenden Verständnissen folgendermaßen ab:

\begin{abstract}
„Nicht die in solchen Begriffen wie Rechtsextremismus, Fremdenhass oder Feindlichkeit gegen Fremde zum Ausdruck kommende irrationale und , außer-normale ' Gewalt sind das Problem, das antirassistische Ansätze zum Gegenstandmachen, sondern die der europäischen Geschichte in je unterschiedlicher, lokaler Weise eingeschriebene und in institutionellen Strukturen der Gesellschaften verfestigte Option der natio-ethnokulturellen Differenzierung zwischen Wir und Nicht-Wir, in der das Nicht-Wir unter dem plausibilisierenden Bezug auf sein(etwa kulturelles) Wesen oder seine Identität als legitim diskriminierbar verstanden und behandelt wird." (Mecheril 2007: 19)
\end{abstract}

Astrid Messerschmidt problematisiert vier Praktiken im Umgang mit Rassismus, die sie als „Distanzierungsmuster“ (Messerschmidt 2014) bezeichnet. In Anlehnung an Sebastian Fischer könnten diese auch als Strategien der „Externalisierung“ (2013) bezeichnet werden. Diese vier Distanzierungsmuster sind „Skandalisierung, Verlagerung in den Rechtsextremismus, Kulturalisierung und Verschiebung in die Vergangenheit" (Messerschmidt 2014: 41) zeichnen sich dadurch aus, dass sie eine Distanzierung der eigenen Person und des eigenen Handelns vom Rassismus sicherstellen sollen. Das Phänomen der De-Thematisierung kann auch jenseits von deutschen Verhältnissen beobachtet werden. Alana Lentin hat herausgearbeitet, wie in gegenwärtigen Formationen rassistischer Diskurse die Verleugnung von Rassismus ein zentrales Moment seiner Reartikulation darstellt. In der Analyse der Verleugnung von Rassismus in der Haltung des " "not racism", zeigt sie, wie diese Verleugnung selbst zu einer Form rassistischer Gewalt werden 
kann (Lentin 2018). Indem Rassismus als individuelle Rückständigkeit erscheint, kann es sogar zu einer Umdrehung kommen und die vom Rassismus Privilegierten als dessen ,Opfer' dargestellt werden. Sie entwickelt den Ansatz des ,NO RACISM TM'; diese Marke wird von Trump bis zu neurechten Eugeniker_innen vor sich hergetragen und damit gleichzeitig Rassismus verleugnet und reartikuliert (Lentin 2020). Die einzigen, die beispielsweise David (Gym14; 3.4.3) nennt, als er über Rassismus nachdenkt, sind die Taliban als „Musterbeispiel“ einer „kleineren, rückständige, rassistischen, fremdenfeindlichen Kultur [...]“, die dann aber bald durch den ,Westen " und die ,Moderne ",geschluckt" werden wird. Hier findet sich die Konstruktion einer im rassistischen Feld überlegenen Position - die Konstruktion der kolonialen Differenz - in einer Gleichzeitigkeit mit der Externalisierung von Rassismus auf die kolonialen Anderen. David steht hier zwar nur stellvertretend für eine kleine Gruppe von Schüler_innen. Nichtsdestotrotz muss diese Dimension für eine rassismuskritische Perspektive miteinbezogen werden.

Aus einer dekolonialen, rassismuskritischen Bildungsperspektive besteht also eines der zentralen Ziele darin, Rassismus als relevante Struktur- und Subjektivierungskategorie anzuerkennen und ein Sprechen darüber zu ermöglichen. Dabei muss das Feld als geteiltes begriffen werden:

„Das Ziel der Anerkennung der Tatsache, dass Rassismus existent ist, ist häufig erst einmal für diejenigen als sinnvolles Bildungsziel zu verstehen, die sich (noch) nicht der Wirkmächtigkeit von Rassismus bewusst sind. Das sind [...] vor allem jene Personen, die unter Bedingungen rassistischer Unterscheidungen privilegiert positioniert sind.“ (Linnemann/Mecheril/Nikolenko 2013)

Diese Anerkennung ist für Bildungsprozesse dabei nur ein erstes Ziel. Es stellt auch einen Ausgangspunkt für eine Problematisierung der eigenen Verstricktheit in rassistische Ungleichheitsverhältnisse.

\subsection{Die Institution Schule als Teil des Problems}

Im Zuge meiner Erhebung habe ich verschiedene Erfahrungen ko-konstruiert, in denen sich Rassismus als Teil der Institution Schule manifestierte. Beispielsweise im Zuge der Organisation der Interviews an einer Schule stellte sich eine Einstellung der Lehrerinnen gegenüber den von mir für Interviews ausgewählten Schülern heraus, die ich als verandernd und abwertend wahrnahm. Ihnen wurde das sprachliche und kognitive Vermögen abgesprochen, etwas zu meinem Untersuchungsthema aussagen zu können; sie rieten mir dringend dazu, andere Interviewteilnehmer_innen auszuwählen (2.1.2). Darüber hinaus berichtete beispielsweise Memnun (HS08) explizit von Rassismuserfahrungen, die 
sich in schulischen Benachteiligungen und rassistischen Diskriminierungen durch seine Lehrerinnen ausdrückten (3.2.3). In der Diskussion um die Schaffung rassismuskritischer und dekolonialer Bildungsräume muss diese Dimension unbedingt miteinbezogen werden, da die Institution Schule vor diesem Hintergrund zunächst, in ihrer jetzigen Form eher als Teil des Problems, denn als Teil der Lösung erscheint.

Schule kann aus einer rassismuskritischen Perspektive als „Ort und Institution verstanden werden, die einen gewichtigen Beitrag zur gesellschaftlichen Wirksamkeit des Schemas leistet, das zwischen Anderen und Nicht-Anderen unterscheidet" (Mecheril 2012: 23) sowie - auch rassistische - Bildungsungleichheiten zementiert. Was es bräuchte wäre aus meiner Sicht eine Konzeption einer selbstreflexiven Schule, in der eigene Strukturen und Bildungspraxen einer ständigen rassismuskritischen Reflexion unterzogen werden. Diese muss institutionalisiert und selbstverständlicher Teil pädagogischer Professionalität werden. Die Realität ist von einer solchen Utopie aber weit entfernt. Annita Kalpaka beobachtet, dass selbstreflexive Praxen eine Ausnahme darstellen. Statt also „das eigene Handeln in den Kontext von institutioneller Diskriminierung und Rassismus zu stellen und zu reflektieren", seien Formen der Dethematisierung oder problematische Formen der Thematisierung dominierend. Dabei würde die Haltung des ,sich nichts ,zuschulden kommen lassen “ “ als wichtiger angesehen ,als die Konsequenzen, die pädagogisches Handeln unter rassistischen Bedingungen für die von Rassismus und Diskriminierung Betroffenen haben kann oder hat" (Kalpaka 2009: 25). Dies liegt auch darin begründet, dass die Institution Schule der migrationsgesellschaftlichen Realität nicht gerecht wird. Wer, mit welcher Positionierung in der Schule arbeitet und ihre Struktur durch Sichtbarkeiten und Handeln prägt, ist von dieser Schieflage geprägt. Kalpaka sieht die migrationsgesellschaftliche Vielfalt zwar im Küchen- und Reinigungspersonal, keinesfalls jedoch in der Zusammensetzung der Lehrkräfte widergespiegelt (ebd.: 28). Und die verhältnismäßig wenigen Lehrer_innen of Color oder Schwarze Lehrer_innen machen oft die Erfahrungen, dass sie als Delegierte für das Thema Rassismus zuständig erklärt werden.

Der institutionelle Kontext erscheint aber nicht nur in der personellen Zusammensetzung problematisch:

„Pädagoginnen und Pädagogen handeln im Kontext von Institutionen, die in ihrem Selbstverständnis weiterhin ethnozentrisch, monokulturell, monolingual sind, die der Tatsache und der Zusammensetzung der Einwanderungsgesellschaft nicht entsprechen." (Kalpaka 2009: 34) 
Der „monolinguale Habitus“ (ebd.) wird auch im von mir im Lehrer_innenzimmer beobachteten Habitus deutlich, mit dem die Schüler_innen aufgrund ihrer angebliche unzureichenden Deutschkenntnisse abgewertet wurden. Hier drückt sich die defizitorientierte Haltung aus, die Menschen mit anderen Erstsprachen - zumindest geopolitisch abgewertete Sprachen, wie in diesem Fall Arabisch, Türkisch und Bulgarisch - gering schätzt. Aus didaktischer Perspektive wird ein Defizit deutlich, wenn Lara davon spricht, dass ,,alle Autoren“, denen sie im Schulunterricht begegnet, weiß und europäisch seien. Auf ganz verschiedenen Ebenen wird so eine Normalisierung produziert. Vor diesem Hintergrund können auch Maßnahmen, die auf den Fakt der Migration reagieren, aber als ,additiv drangehängt“ (ebd.: 28) erscheinen, nur unzulänglich sein. Das ,Normale“ bleibt unhinterfragt und produziert gleichzeitig eine Einteilung in ,„wir" und ,die Anderen““ (ebd.). Dieses „,Wir“ als die Position von Normalität“ bleibt dabei ,unsichtbar bzw. dethematisiert" (ebd.).

In einer solchen Institutionen entwickeln Pädagog_innen ihre Handlungsstrategien. Wenn Bildung aber einem rassismuskritischen Anspruch gerecht werden will, ist eine Voraussetzung dafür, Räume zu schaffen, in denen die Zusammenhänge zwischen pädagogischem Handeln und strukturellen Rahmenbedingungen thematisierbar und reflektierbar gemacht werden (ebd.: 36). Rassismuskritik und rassismuskritische Selbstreflexion sollte pädagogisches und didaktisches Handeln kontinuierlich begleiten. Davon ist die Realität aber weit entfernt. In Bezug auf die Ausbildung von Lehrer_innen kann festgestellt werden, dass eine gesonderte Auseinandersetzung mit Rassismus in den Vorgaben für die Ausbildung von Lehrer_innen bisher an keiner Stelle Berücksichtigung findet (Fereidooni/Massumi 2015). Hinzu kommt das Problem, dass rassismuskritische Reflexion immer auch mit dem Verlust von Handlungsfähigkeit einhergehen kann. Dies ist an einem Ort wie der Schule, wo ein hoher Handlungsdruck herrscht, kaum möglich, da Irritation, Verunsicherungen und Aushandlungen Zeit und Räume braucht, für die in der Schule oft kein Platz ist. Das Wissen, das in der Schule - quasi als Kanon, ohne eigene zusätzliche Anstrengungen zu investieren - zur Verfügung steht, ist in der Regel so strukturiert, dass es das eigene Handeln im Sinne der Reproduktion rassistischer Ordnungen legitimiert. Die Reflexion dieser Strukturen und des eigenen Handelns muss dabei zunächst überhaupt das Problem als solches thematisierbar machen, da pädagogisches Handeln immer im Widerspruch zwischen dem Gleichheitsanspruch der Institution Schule und der Realität der Selektion und Zuweisung zu gesellschaftlich unterschiedlichen Positionen, nicht zuletzt angesichts der Aufgabe der Schule der Reproduktion der Arbeitskraft, agiert. Um 
diesen Widerspruch als solchen thematisierbar zu machen, muss sich die Struktur von Schule verändern und sich eine Kultur der Selbst- und Rassismuskritik etablieren.

\subsection{Das pädagogische Dilemma zwischen Farbenblindheit und Veranderung}

Ein zentrales Dilemma pädagogischer Praxis entsteht dadurch, dass sowohl das Übersehen als auch das Hervorheben von migrationsgesellschaftlicher Differenz problematisch ist. Das Übersehen von Differenz - also das Leugnen unterschiedlicher Voraussetzungen - läuft Gefahr zu einer „Diskriminierung durch Gleichbehandlung“ und die Hervorhebung von Differenz zu einer „Kulturalisierung/Ethnisierung" (Kalpaka 2009: 34) zu werden. Diskriminierung durch Gleichbehandlung kann auch als Farbenblindheit bezeichnet werden: „Methodisch, pädagogisch und politisch ist ein ,farbenblinder ' Ansatz, der die durch rassistische Strukturen produzierten Ausschlüsse und Hierarchien ignoriert, dazu verdammt, sie zu reproduzieren." (El-Tayeb 2016: 21) Ein Vergessen der Differenz hebt diese nicht auf oder schränkt ihre Wirkungsweisen ein, sondern verschiebt insbesondere diese aus dem Bereich des Sagbaren. „Leben mit ,Differenz', statt sie einfach zu vergessen. Dies ist dem endlosen Vergessen vorzuziehen - dieser historischen Amnesie - und dieser schalen postmodernen Nostalgie, die zum Inventar der Globalisierung gehört.“ (Hall 1991: 805, zitiert nach El-Tayeb 2016: 40) Eine Benennung als Zuschreibungspraxis im Kontext rassialisierter Verhältnisse birgt hingegen Gefahren, hiermit die hierarchisierten Differenzen, Zuschreibungen und Zuweisungen zu vertiefen.

In dem Gedicht For the White Person Who Wants to Know How to Be My Friend reflektiert die afroamerikanische Feministin Pat Parker über dieses Dilemma in Bezug auf Freundschaft mit Weißen. Ihr Gedicht beginnt mit den folgenden zwei Zeilen: "The first thing you do is to forget that i'm black. Second, you must never forget that i'm black." (Parker 1978) Dieses Dilemma gilt auch für Bildungskontexte. Weder der 'farbengleiche', Differenz und Rassismus gleichermaßen verleugnende Ansatz noch der Differenzen zu- und festschreibende Ansatz sind aus einer rassismuskritischen Perspektive annehmbar. Aus einer solchen bedarf es pädagogischen Wissens über rassistische Strukturen und reflexive Praxen, um Umgang mit Widersprüchen zu erproben. Dies wäre die Voraussetzung, um einen rassismussensiblen Bildungsraum zu eröffnen, in dem die subjektiven Voraussetzungen aller Schüler_innen - und nicht nur der Weißen - angemessen berücksichtigt werden können und rassialisierte Ungleichheitsverhältnisse besprech- und reflektierbar würden. 
In meinen kurzen und fragmentarischen Einsichten in die Verhältnisse in den von mir untersuchten Klassen, erschien mir das ,farbenblinde' Paradigma dominant. Zur Erinnerung: Farbenblindheit bedeutet nicht die Absenz von Rassismus, wie am Beispiel der Situation mit den Lehrerinnen in der Organisation der Interviews deutlich geworden sein sollte. Lara redete (Gym18; 2.1.2) mehr als eine Stunde lang auch über Rassismus, Sklaverei und Kolonialismus, vermied aber ihre eigene Subjektposition oder ihre persönlichen Erfahrungen in den Diskurs einzubeziehen. Dies kann unter anderem sowohl auf den Diskursraum Schule als auch auf die Intreviewsituation mit mir als weißen Interviewendem zurückgeführt werden. Nach ein paar Tests, die ich offensichtlich bestanden hatte, änderte sie dies und positionierte sich von ihr aus als Schwarze, deren Mutter selbst Migrationserfahrung hat. Es schien als wäre es eine Art Befreiung. Sie setzte die geschilderten Herrschaftsformen in Bezug zu den Rassismuserfahrungen von ihr und ihrem Bruder. Über die Gründe, die zu ihrer Vorsicht führten, ihre eigene Subjektposition herauszustellen, kann ich nur spekulieren. Es erschien mir so, als würde sie dies verletzlicher machen und ihre Aussagen abwerten, wenn sie von einer nicht dominanzgesellschaftlichen und normsetzenden Position heraus formuliert würden. Dies verweist auf eine Hierarchisierung von Wissen innerhalb des Lernraums Schule und der damit verbundenen Abwertung des Wissens der von Rassismus Deprivilegierten.

\subsection{Rassismuserfahrungen als Normalität: Empowerment}

Einige Schüler_innen berichten über Rassismuserfahrungen innerhalb und außerhalb der Schule. Diese werden als Normalität wahrgenommen. Lara (Gym18) beschreibt bezogen auf die Erfahrungen ihres im Fußballverein, in dem „einem mal ein rassistischer Kommentar" rausrutsche, dass diese Erfahrungen für sie erwartbar sind, was auf einen gewissen Grad an Normalisierung verweist (3.3.3). Memnun (HS08) berichtet beispielsweise über rassistische Ungleichbehandlung durch Lehrkräfte in der Schule, die er auf seine „schwarze Haaren“ zurückführt (3.3.2). Diese Erfahrungen werden nicht als Ausnahme, sondern als Normalität erlebt und dargestellt, auch wenn es in beiden Fällen gleichzeitig als Unrecht wahrgenommen und benannt wird. Die differenzierte Auseinandersetzung beider Schüler_innen, die diese Erfahrungen als Rassismus analysieren und ihr eigenes Handeln in rassistisch strukturierten Feldern reflektieren, hat offensichtlich keinen Platz in der Schule bzw. in der darin gegenwärtigen Struktur der Hierarchie des Wissens und in dem Feld des Sagbaren.

Rassismuskritische, dekoloniale Bildung kann hier an die Strategien der Schüler_innen anknüpfen. Memnun analysiert nicht nur komplexe Wirkungsweisen des Rassismus, sondern praktiziert auch eine Form der Solidarität mit anderen von 
Rassismus Betroffenen, wie etwa einer Mitschülerin, die aufgrund ihres Kopftuchs durch die Lehrkraft stigmatisiert und abgewertet wurde. Auch Lara erklärt sich solidarisch mit Menschen, die von anderen Formen des Rassismus betroffen sind (3.3.2) und stellt damit implizit die Gemeinsamkeit der Rassismuserfahrungen als einen Ausgangspunkt kritischen Denkens und Handelns heraus. Laras Beobachtung und Analyse von alltäglichem Rassismus wird begleitet von einer Kritik des schulischen Kanons, in dem alle Autor_innen europäisch und weiß seien (3.3.3). Dies präge nach Lara das, was als normal aufgefasst würde, sowie die Subjektivierungsweisen von Personen, die Rassismuserfahrungen machen. Gleichzeitig macht sie stark, dass eine Ressource, etwas an den rassistischen Normalisierungen der Gegenwart zu verändern, in einem Geschichtslernen bestünde, das meinem Verständnis einer dekolonialen Bildung entspricht:

\begin{abstract}
S: Ja, also ich finde so Kultursachen und so oder Rassismus oder so, da finde ich, ist es eigentlich heutzutage ziemlich wichtig, den Menschen was dazu beizubringen. Weil ich sehe halt, die meisten interessieren sich gar nicht mehr für die Geschichte. Im Bereich Geschichte zum Beispiel die Geschichte mit den Sklaven und so was in der Art halt. Die dunklen Seiten der Geschichte, sag' ich mal. Also natürlich möchte man nicht an das Schlechte aus der Vergangenheit irgendwie erinnert werden. Aber ich finde, man sollte vielleicht ein bisschen was lernen dazu, um vielleicht ein bisschen anders zu denken. Und dass man irgendwann Menschen nicht nach ihrem Stand oder gesellschaftlichen Ansehen irgendwie beurteilt. Oder Nationalität und so. (Lara, Gym18)
\end{abstract}

Ziel einer dekolonialen politischen Bildung muss es sein, diesen Ideen von Lernenden einen Raum zu schaffen, in dem das Feld des Sagbaren und die Hierarchisierung von Wissen sich so weit verschoben hat, dass solche Ideen nicht nur geäußert, sondern auch gehört und ihre Implikationen für voll genommen werden.

Um dies zu erreichen, kann der Empowerment-Ansatz als ein möglicher Bezugspunkt herangezogen werden. Um die subjektiven Vorstellungen als Ausgangspunkt, die Wissensressourcen aller Schüler_innen wirklich ernst und diese als zentrale Bestandteile didaktischer und selbstreflexiver Bildungsprozesse $\mathrm{zu}$ anzunehmen muss sich dafür aber auch die Einstellung der Lehrenden verändern. Insbesondere vor dem Hintergrund, dass in Deutschland Lehrende mehrheitlich aus der „Weißen Mittelschicht“ (Heinemann 2020: 215) kommen, ergibt sich die Problematik, das Wissensinhalte von Menschen mit Rassismuserfahrungen oder aus dem Globalen Süden Zugewanderte „unsichtbar“ gemacht werden beziehungsweise „,keine Anerkennung finden“ (ebd.: 218). Zur Reflexion der Hierarchisierung des Wissens in Bildungskontexten bezieht sich Alisha Heinemann auf den funds of knowledge approach (ebd.). Auf institutioneller Ebene leitet sich 
aus dieser Problemlage die Notwendigkeit ab, eine Veränderung der Zusammensetzung der Lehrenden zu forcieren, die unter anderem durch Förderprogramme für angehende Lehrende mit Rassismuserfahrungen erreicht werden könnte, sowie die Institutionalisierung selbstreflexiver, dekolonialer Bildungsprozess im Rahmen der Lehrer_innenausbildung und -fortbildung sowie im schulischen Alltag. Die Idee, die vielfältigen Wissensressourcen einzubinden und zu würdigen, bedingt dabei nicht nur eine Offenheit der Lehrenden, sondern auch die Fähigkeit, auch Wissen zu würdigen, die sie selber nicht verinnerlicht haben, das ihnen auf den ersten Blick nicht nachvollziehbar erscheint. Es braucht also eine Veränderung des sonst oft hierarchischen Verhältnisses zwischen Lehrenden und Lernenden.

Im Zuge des Einbeziehens der sonst marginalisierten Wissensressourcen der von Rassismus negativ betroffenen Lernenden, gilt jedoch das oben beschriebene pädagogische Dilemma zu reflektieren. Im Rassismuskritischen Leitfaden zur Reflexion bestehender und Erstellung neuer didaktischer Lehr- und Lernmaterialien für die schulische und außerschulische Bildungsarbeit zu Schwarzsein, Afrika und afrikanischer Diaspora heißt es in Bezug dazu:

„Doch Vorsicht vor Zuschreibungen! Einer Schwarzen Person darf etwa nicht unterstellt werden oder sie dazu aufgefordert werden, über, afrikanische Geschichte ‘ zu erzählen - so als würde sie sich ja schließlich auskennen. Die Lernsubjekte sollten für sich selber bestimmen können, wer sie sind, was sie wissen und wie sie es mitteilen möchten." (Autor*innenKollektiv Rassismuskritischer Leitfaden 2015: 17)

Rassismuskritische Bildungsräume müssen so strukturiert sein, dass es sowohl den von Rassismus Deprivilegierten als auch den durch Rassismus privilegierten Lernsubjekten möglich wird, Rassismus und die damit verbundene Differenzkonstruktion und Ungleichheit als solche zu sehen. Rassismuskritische Bildung zielt insbesondere für weiß positionierte Lernende darauf ab, die als Normalität wahrgenommenen Setzungen zu irritieren, ihre Machtwirkungen sichtbar und die eigene Position darin sichtbar zu machen. Dies gilt es auf eine Art zu realisieren, die nicht auf Kosten von Lernenden of Color geht.

Für die von Rassismus privilegierten Lernsubjekte sind es tendenziell andere Impulse, die hierfür nötig sind, als für durch Rassismus deprivilegierte Lernsubjekte, wie an den geteilten - im Sinne von divided - Perspektiven in Bezug auf Rassismus in den von mir ko-konstruierten Vorstellungen deutlich geworden ist. Daraus ergeben sich einige grundlegende Fragen: Was bedeutet es für Bildungspraxis, wenn klar ist, dass die Schüler_innen sich ganz unterschiedlich innerhalb kolonialer Ordnungen positionieren bzw. positioniert werden? Während die eine Umgangsweise darin besteht, dekoloniale Bildungsräume zu trennen, besteht die 
andere darin, in gemeinsamen Räumen nach Formen zu suchen, die Gemeinsamkeiten und Unterschiede zu reflektieren. Beides kann aus meiner Sicht zu einer Dekolonisierung beitragen. Diese Frage hat auch mit der Frage zu tun, ob Praxis von Weißen überhaupt als dekoloniale - oder eher als kolonialkritische Praxis - bezeichnet werden kann oder vielmehr nur die Selbstermächtigung von Nicht-Weißen dekolonial - als Selbstermächtigung und Überwindung der eigenen Unterdrückung - genannt werden sollte? Scheint hier nicht das Problem auf, das den mit diesem Text vorgelegten Vorschlag einer dekolonialen politischen Bildung adressiert, die sich an alle, auch an Weiße, richtet? Ich werde im Folgenden kursorisch beide Umgangsweisen diskutieren, allerdings werde ich sie nicht gegeneinander diskutieren, da ich der Überzeugung bin, dass es kontextabhängig ist, welche der Umgangsformen zielführender ist.

Aus der Feststellung der geteilten Perspektiven können Bildungspraktisch zwei Arten von Bildungsräume als Schlussfolgerung gezogen werden, einen im Sinne von divided und zum anderen im Sinne von shared. Eine getrennte Bildungspraxis skizziere ich zum einen im Anschluss an die Ansätze von Empowerment für People of Color und Schwarze Menschen, in denen die Herstellung eines solchen Raumes als zentrale Strategie herausgearbeitet und als solche stark gemacht wird. Für weiß positionierte Menschen ergibt sich aus einer solchen getrennten Bildungspraxis ein Bildungsraum, in dem selbstreflexive Praxen und spezifische Formen der Allianz die zentralen Bildungsziele darstellen. Dies werde ich im kommenden Abschnitt darstellen, und im Anschluss einige mögliche Fallstricke kritisch diskutieren. Im Anschluss geht es um einen Ansatz, der auch einen geteilten (shared), nicht anhand der rassialisierten Differenz strukturierten Bildungsraum als anstrebenswert erscheinen lässt. Trotz der in den nächsten Abschnitten referierten Gefahren, die ein gemeinsamer Bildungsraum beinhaltet, möchte ich einen solchen Bildungsraum als Möglichkeit und Option offen lassen; ein Grund dafür ist, dass ich hier - natürlich aus einer weißen Perspektive, aber auch basierend auf Diskussionen politisch aktiver People of Color - auch Potenziale sehe. Dabei sind auch die Erfahrungen von teilnehmenden People of Color und Schwarzen Menschen zu berücksichtigen, die durch die Trennung von Bildungsräumen in bestimmten Kontexten von stigmatisierenden und Zuschreibung verstärkenden Erfahrungen berichten. Aus meiner Sicht ist es kontextabhängig und selbstverständlich abhängig von der Präferenz von beteiligten Schwarzen Menschen und People of Color, welche Form des Bildungsraums sinnvoller erscheint.

In meiner folgenden Darstellung der Konzepte eines getrennten Bildungsraum im Sinne von Empowerments referiere ich einige Ansätze aus dem vielfältigen Feld der Empowermentdiskussionen von People of Color und Schwarzen 
Menschen. Ich habe hier nicht den Anspruch, Hinweise zu diesem Konzept zu entwickeln. Das ist als weiß positionierter Mensch nicht meine Aufgabe. Eine kurze Darstellung an dieser Stelle erscheint mir aber sinnvoll, damit die Vorteile und Potenziale getrennter Bildungsräume verdeutlicht, diese als wichtige Option von politischer Bildungspraxis in die Überlegungen einbezogen wird und auch die Rolle von weiß positionierten Menschen in Bezug zu den Empowerment-Bildungsräumen diskutierbar werden.

Für eine trennende Praxis der Bildungsräume spricht, dass - wie Andrea Meza Torres und Halil Can in ihrem Text Empowerment und Powersharing als Rassismuskritik und Dekolonialitätsstrategie aus der People of Color-Perspektive darlegen - angesichts der rassistischen Verhältnisse, in denen die Perspektiven und Erfahrungen von People of Color systematisch abgewertet, dethematisiert und delegitimiert werden, ein getrennter und damit geschützter Raum Prozesse des Empowerments ermöglichen kann.

„Der ressourcenorientierte und machtkritische Ansatz des Empowerment-Konzepts [..] bildet für People of Color ein wichtiges philosophisches, praktisches und politisches Instrument für die politische Selbstorganisierung, für die Entwicklung einer kollektiven Kultur des selbstbewussten Widerstands gegen Ungleichheit sowie rassistische und diskriminierende soziale Gewalt- und Unterdrückungsstrukturen als auch für Selbststärkung, Selbstbestimmung und Partizipation im Sinne individueller und gesellschaftspolitischer Veränderungen.“ (Meza/Can 2013: 29)

Dabei geht es also um die Überwindung von „Ohnmacht und Unterdrückung und die Entwicklung von Empowerment- und Widerstandsstrategien über das Erinnern, Erzählen und Dokumentieren der ausgeblendeten, verdrängten und verschwiegenen PoC-Empowerment- und Widerstandsgeschichte in Deutschland“ (ebd.: 29). Zentral für den Empowerment-Ansatz von und für People of Color ist dabei ,die Schaffung von mehrfach geschützten Eigenräumen zur Besinnung, Wiedererlangung und Belebung von eigenen Ressourcen“ (ebd.: 35). Sowohl Dekolonialität als auch Empowerment sind dabei, Meza und Can zufolge, „ressourcen- und prozessorientiert“ und basieren auf der Perspektive „,er Veränderbarkeit von herrschenden Verhältnissen“ und zielen auf die Stärkung der „Handlungsfähigkeit des Subjekts [...], sich Fremdbemächtigungen durch resiliente Praxen der Selbstbemächtigung und Befreiung zu widersetzen." (ebd.: 30).

Für Rassismuserfahrungen machende Menschen beschreibt Natascha NassirShahnian diesen Prozess des Empowerments als einen der Dekolonisierung: 
„Bei der Dekolonisierung handelt es sich um einen bewussten Austritt aus der kolonialen Situation. Wenn wir erkennen, dass unsere vermeintlichen Defizite aus einer weißen Norm konstruiert werden, können wir dem Druck hin zur Überkompensation widerstehen - denn wir müssen nichts ,ausgleichen“ um ,mitzuspielen“." (Nassir-Shahnian 2013: 19)

Genau dies tut Lara, wenn sie sich über die Erwartungen an ihre Zukunft hinwegsetzt, indem sie diese als rassistisch strukturiert und in die Kontinuität von Kolonialismus analysiert. Der durch Rassismus strukturierte Erwartungshorizont an sie, dass sie als Schwarze Frau entweder Sängerin werden sollte oder um genau die Entsprechung in die rassistische Einordnung zu entgehen - im Sinne ihrer Mutter - einen „,richtig normal[en]“, einen ,besseren“ Job, wie „Anwältin“ annehmen sollte, wird von ihr kritisch reflektiert. Vor dem Hintergrund dieser Reflexion stellt sie sich bewusst gegen diesen Erwartungshorizont und will „Autorin“ werden. Diese Form der Kritik, die zu einer Steigerung von Autonomie und Selbstbestimmung führt, kann als Empowerment bezeichnet werden. Paulo Freire fasst diesen Prozess so: „Um die Situation der Unterdrückung zu überwinden, muss der Mensch zunächst ihre Ursachen kritisch erkennen, damit er durch verändernde Aktion eine neue Situation schaffen kann, eine, die das Streben nach vollerer Menschlichkeit ermöglicht." (Freire 1971: 34).

Dabei ist dies nicht als individualisierter Prozess zu begreifen. Bündnisse, das Schaffen von Kollektivität und Gemeinsamkeit, die trotz der Unterschiedlichkeit der Erfahrungen das Gemeinsame erkennen, wird in der Diskussion dieses Themas hervorgehoben (Nassir-Shahnian 2013). Diese Herstellung von Gemeinsamkeiten durch gemachte Ausschlusserfahrungen zeigt sich in zahlreichen Interviews, auch bei Lara und Memnun. Für Bildungskontexte stellt Nassir-Shahnian die Relevanz von der Entwicklung einer geteilten Sprache heraus.

„Da unsere Lebenserfahrungen in dominanten Diskursen häufig nicht anerkannt und benannt werden, sondern im Gegensatz abgewehrt und verneint (,Jetzt stell dich mal nicht so an" oder , Übertreib mal nicht'), ist das Ausdrücken und Teilen von Diskriminierungserfahrungen eine wichtige Strategie für den Empowerment-Prozess.“ (Nassir-Shahnian 2013: 21)

Getrennte Räume sind insofern geschützt, als hier alle Teilnehmer_innen an die Rassismuserfahrungen anknüpfen können und diese nicht grundlegend infrage gestellt werden (Yiğit/Can 2006). Unterdrückungserfahrungen rufen oft Sprachlosigkeit hervor. Zusätzlich sind die Lebenserfahrungen von Migrationsanderen oft 
nicht nur unsichtbar, sondern viele machen auch die Erfahrung, dass sie ,abgewehrt und verneint" werden, was sich in Reaktionen wie ,Jetzt stell dich mal nicht so an“ oder ,Übertreib mal nicht' ausdrücken kann (Nassir-Shahnian 2013: 21). Die Infragestellung oder die Dethematisierung der Artikulation von Rassismuserfahrungen kann als ,,sekundäre Rassismuserfahrung“ (Çiçek/Heinemann/Mecheril 2014: 312) bezeichnet werden. Das Ausdrücken und Teilen von Rassismuserfahrungen ist vor diesem Hintergrund eine, ,wichtige Strategie für den Empowerment-Prozess“ (Nassir-Shahnian 2013: 21) und Voraussetzung für das Entwickeln einer gemeinsamen Sprache sowie Selbstbestimmung und Autonomie. Darüber hinaus ist ein solcher geschützter Raum aber auch als ein Raum zu betrachten, in dem People of Color temporär nicht - oder zumindest weniger - der in weiß dominierten Räumen sonst fast dauerhaften Gefahr rassistischer Verletzungen, Einordnungen und Entmündigungen ausgesetzt sind.

„Empowerment bedeutet als People of Color auf unsere eigenen Bedürfnisse in rassistischen Alltagssituationen zu achten. Empowerment bedeutet ohne Kategorisierung existieren zu können. Empowerment bedeutet ich kann ich sein - egal, was du von mir denkst. Empowerment bedeutet Befreiung.“ (ebd.: 24)

,People of Color' ist dabei al seine ermächtigende Selbstbezeichnung zu verstehen, die sich auf alle rassistisch marginalisierten Menschen bezieht. Mit dem Begriff wird die Heterogenität der Rassismuserfahrungen adressiert und er stellt insofern auch eine „Aufforderung“ dar, ,die Vielschichtigkeit interner Differenzen [marginalisierter Menschen] wahrzunehmen und sich auf dieser Basis gleichberechtigt und dialogisch zu verständigen." (Ha/al-Samarai/Mysorekar 2007b: 14) In Anerkennung dieser Differenzen zielt er aber zugleich auf Solidarität und Bündnisse über diese Grenzen hinweg.

\begin{abstract}
„Als politische Plattform zielt sie auf Bündnisse zwischen allen rassifizierten Menschen mit afrikanischen, asiatischen, lateinamerikanischen, arabischen, jüdischen, indigenen oder pazifischen Hintergründen. In gruppenübergreifender (interkommunaler) Weise verbindet sie so jene, die in Weißen Dominanzgesellschaften unterdrückt und durch koloniale Tradierungen kollektiv abgewertet werden." (Ha/alSamarai/Mysorekar 2007b: 12-13, Herv. i. O.)
\end{abstract}

Inzwischen werden meist mindestens noch Sinti und Roma dazugezählt. Die Herausgeber_innen von re/visionen (2007a) sehen in der Wissensproduktion unterdrückter Communities und der als solche sich artikulierende Stimme von People 
of Color-Zusammenhängen eine Durchkreuzung der ,ausgrenzenden Selbstgespräche der Weißen Dominanzgesellschaft“; auf diese Weise wird „Deutschland als vielstimmige[r] postkoloniale[r] Raum“ (Ha/al-Samarai/Mysorekar 2007b: 14 15) enthüllt.

KARFI ist ein rassismuskritisches Arbeitsbündnis von sich als Schwarz positionierenden Frauen, die in ihrer politischen (Bildungs-)Arbeit - neben der Intervention in oder der Allianz mit weiß geprägten Zusammenhängen - auch auf einen Empowerment-Ansatz fokussieren. Ihre Arbeit bewegt sich im „Spannungsfeld von praktischer Bildungsarbeit, politischem Aktivismus und (akademischer) Wissensproduktion“ (Bendler/Digoh-Ersoy/Golly 2019: 17). Dabei begreifen sie politischen Aktivismus und Wissenschaft nicht als zwei getrennte Bereiche, schließlich wird widerständiges Wissen nicht in isoliert akademischen Denkräumen geschaffen, sondern „bildet sich vielmehr dort heraus, wo Menschen dominante Ordnungen unterlaufen und ihre Analysen und Strategien mit anderen teilen“ (ebd.). Auf solche Prozesse fokussiert auch ihre Bildungsarbeit, die sie sowohl innerhalb als auch außerhalb institutionalisierter Bildungsräume anbieten. Für Empowerment-Räume, die sie ,gemeinsam mit und für migrantische und PoC-Akteure*innen unterschiedlicher sozialer Milieus und formaler Bildungsgrade“ schaffen, betonen sie die Relevanz der „Auseinandersetzung mit der eigenen Biographie“ sowie die „Sichtbarmachung der Geschichte/n der eigenen Community/Communities“ und ihrer „Errungenschaften“ (ebd.: 26).

Da das Wissen über die ,,eigene Geschichte“" sowie analytische Werkzeuge und Wissen über Rassismus und mögliche Widerstandsstrategien nicht in den „klassischen Bildungsinstitutionen“ (ebd.) vorkommen, sind solche Empowerment-Prozesse umso wichtiger. Wissen über die Geschichte von Befreiungsbewegungen und über ,das selbstbewusste Handeln anderer Menschen of Color“ kann zur Entwicklung eines starken „Selbstverständnis“ beitragen, mit dem auch die ,eigenen Widerstandskämpfe in Vergangenheit und Gegenwart“ (ebd.) in einem anderen Licht erscheinen. Zur Erreichung oder dem Ausbau von Handlungsfähigkeit betont KARFI dabei die Relevanz davon, „sich zu vernetzen, zu organisieren, gemeinsam aktiv zu werden, sich einer Community anzuschließen, wenn es eine gibt, oder eine Community zu begründen“ (ebd.: 26 f.).

Dafür ist auch die „Überwindung der Sprachlosigkeit“ von entscheidender Bedeutung, denn „das Ausdrücken und Teilen von Diskriminierungserfahrungen sind wichtige Strategien für den Empowerment-Prozess“" (ebd.: 27). Teil eines solchen Prozesses ist dabei auch, über die Räume selber bestimmen zu können. 
„Für uns gehört auch das bewusste Grenzen setzen dazu. Nicht nur in Bezug darauf, welche Fragen wir beantworten, sondern eben auch darauf, wie wir uns entscheiden, welche Räume, Kontakte, Kontexte uns gut tun und welche nicht. Welche bringen uns in unserem politischen Anspruch voran, welche nicht? Und auch wenn wir präsent sind und unsere Stimme erheben, Gesicht zeigen, Raum einnehmen, unbequem bleiben, tun wir das in einem wohlüberlegten, abgestimmten und für uns empowernden Sinne.“ (ebd.)

Eine Strategie besteht dabei für KARFI darin, Bündnisse - auch mit weiß geprägten Zusammenhängen - zu schließen, da solche Bündnisse wichtig sind, um ihr Anliegen einer ,gesamtgesellschaftliche[n] Veränderung“ (ebd.: 21) zu verfolgen.

Dabei formulieren sie aber vor dem Hintergrund ihrer Erfahrungen mit der Zusammenarbeit mit weiß dominierten, insbesondere linken und antirassistisch motivierten Zusammenhängen klare Bedingungen, die die Voraussetzung solcher Bündnisse darstellen. Ihre Erfahrungen bestehen unter anderem darin, dass in Konfliktsituationen weiße Bündnispartner_innen oft dieselben Mechanismen anwenden, die ,,bei den politischen Gegenspieler*innen kritisiert“ (ebd.) werden.

\begin{abstract}
„Was wir beobachten ist, dass in diesen Bündnissen die Schwarzen und Mitstreiter*innen of Color oftmals nicht als Gesprächspartner*innen, als Persönlichkeiten, als politisch Handelnde ernst genommen werden, sondern dass sie lediglich als legitimierende Objekte betrachtet werden, die von den Erfahrungen der weißen Linken lernen können." (ebd.)
\end{abstract}

Ich diskutiere dies vor dem Hintergrund der Annahme, dass weiß positionierte Menschen, die sich für eine dekoloniale politische Bildung einsetzen und dafür engagieren, als eben solche (potenziellen) Bündnispartner_innen angesehen werden sollten. Aus einer weiß positionierten Perspektive halte ich es für wichtig, diese Forderungen zu einem zentralen Ausgangspunkt der Konzeption und Reflexion der eigenen Theorie und Praxis zu machen. Vor dem Hintergrund ihrer Beobachtungen formuliert KARFI drei Bedingungen:

„Was es zum Bestehen solcher Bündnisse bräuchte, wären unserer Meinung nach mindestens drei Dinge:

1) eine kritische Selbstbefragung und eine ehrliche Beantwortung bzgl. der eigenen Motivation für die politische Arbeit sowie selbstkritisches Hinterfragen von Sprache, unausgesprochenen Codes und Annahmen,

2) ein Aufspüren der eigenen Widerstände wenn mensch diese aufgezeigt bekommt und,

3) dass mensch mit den Bündnispartner*innen gemeinsam eine Sprache findet und prüft, ob es gemeinsame Ziele gibt, ob diese nur punktuell geteilt werden oder ob die Interessen soweit divergieren, dass es ehrlicher ist, nicht zusammenzuarbeiten. “ (ebd.) 
Vor diesem Hintergrund werde ich mich im folgenden Abschnitt mit den Fragen weißer Selbstreflexion und möglichen Formen solidarischer Praxis und Formen von Bündnissen aus weißer Perspektive auseinandersetzen.

\subsection{Weiße Rassismuskritik:Von Reflexivität, Verbündetsein und Allianzen}

Beverly Tatum plädiert für ein Verständnis von einem Lehren und Lernen über Rassismus, das als ein Bündnis von ,empowered people of color and their white allies“" (Tatum 1994: 474) begriffen werden sollte. KARFI stellt heraus, was es für solche Bündnis - und insbesondere auch weiße allies darin - braucht: „Es braucht zunächst eine fundierte Analyse rassistischer Dynamiken und Handlungspraxen, in die wir alle hineinsozialisiert worden sind und die einer aktiven Verabschiedung bedürfen, um Bündnisse des Widerstands und der Solidarität zu schaffen." (Bendler/Digoh-Ersoy/Golly 2019: 17) Für weiß positionierte Menschen braucht es also zunächst rassismuskritische Bildung, um Teil eines solchen Bündnisses werden zu können.

Rassismuskritik verstehe ich hier mit Mecheril und Melter (2010) als eine Praxis, die ihrem ,Gegenstand" nicht äußerlich ist, nicht von außen auf ihn herabschauen kann, da alle beteiligten Subjekte irreduzibel mit Rassismus verwoben sind. Dabei beziehen die beiden sich auf einen Kritikbegriff von Foucault, der Kritik als „die Kunst nicht dermaßen regiert zu werden“ (Foucault 1978b: 12) fasste. Rassismuskritik kann also als die Kunst verstanden werden, nicht dermaßen von Rassismus regiert zu werden. Paul Mecheril und Claus Melter nähern sich einer Definition von Rassismuskritik in diesem Sinne als das „Bestreben, nicht dermaBen dem Ensemble rassistischer Deutungs- und Handlungsschemata unterworfen zu sein [...]“ (Mecheril/Melter 2010: 172). Davon ausgehend kommen sie zu einer weiteren Bestimmung:

\footnotetext{
„,Rassismuskritik ' heißt: zum Thema machen, in welcher Weise, unter welchen Bedingungen und mit welchen Konsequenzen Selbstverständnisse und Handlungsweisen von Individuen, Gruppen, Institutionen und Strukturen durch Rassismus vermittelt sind und Rassismen stärken.“ (ebd.)
}

Dabei wird beispielsweise von KARFI herausgestellt, dass das Betreiben von Rassismuskritik nicht für alle gleich, sondern sich vielmehr in Bezug zur durch rassistische Strukturen verursachte Positionen deutlich unterscheidet. Während die einen schmerzhafte, verobjektivierende und diskriminierende Rassismuserfahrungen machen, werden die Anderen, die Weißen, durch diese Strukturen 
privilegiert. In Bezug auf rassismuskritische Aktivist_innen oder Bildungspraktiker_innen bedeutet dies unter anderem auch, dass Rassismus für die Weißen ein ,Thema' darstellt, das sie engagiert verfolgen, aber temporär oder in der Zukunft auch wieder sein lassen können, wenn beispielsweise eine „Lohnarbeitsstelle in Vollzeit angetreten wird oder die Versorgung von Kindern in den Mittelpunkt rückt" (Bendler/Digoh-Ersoy/Golly 2019: 20). Dieses Privileg haben nicht-weiße Akteur_innen nicht; für sie ,gibt es keinen Rückzug, keine Möglichkeit des Ausblendens - und sei es nur für gewisse Zeit“ (ebd.).

Für Weiße ist Rassismuskritik und ein „,verantwortungsvoller reflektierter Umgang“ mit ihr dabei auf eine spezifische Weise ein ,ungewohnter und komplizierter Akt“ (Bönkost 2013: 39), was Joan Lester wie folgt formuliert:

„Acting as an ally is a tricky business, for there is a fine line between being an effective ally, and taking over someone else's struggle. As whites, we are so used to thinking that we should be in charge [...] that we often don't recognize when we are acting on that supremacist belief.“ (Lester 1987: 7)

Rassismuskritische Praxis bedeutet vor diesem Hintergrund auch, Kontrolle und Macht abzugeben. „We become barriers instead of allies when we want to maintain control.“ (Kendall 2006: 186) Für weiß positionierte Rassismuskritiker_innen geht es dabei aus meiner Sicht darum, die durch weiße Subjektivierung verinnerlichten Selbstverständnisse, Selbstverständlichkeiten, Selbstsicherheiten, Deutungshoheiten und Definitionsmacht auf ihre Verwobenheit mit Rassismus hin zu befragen. Dabei besteht eine zentrale Strategie auch darin, zu lernen, sich zurückzunehmen, zuzuhören und Räume zu lassen. Dementsprechend zielt ein Prozess des Werdens eines Verbündeten nicht darauf, den Reflexionsprozess ,abzuschließen" und dann autonom und unabhängig rassismuskritische Praxis zu betreiben. Eine kritische Reflexion des eigenen Weiß-Seins beinhaltet vielmehr „die Einsicht, immer auch nicht zu wissen“ und das Erkennen, „Rassismus nicht zu kennen“ (Bönkost 2013: 28, Herv. i. O.) Dies hat auch Konsequenzen für eine rassismuskritische Praxis: „Folglich umfasst sie immer auch das Eingestehen, auch nicht am besten zu wissen, was Rassismus entgegengesetzt werden kann. Dies läuft der weißen Erfahrung entscheidend zuwider.“ (ebd.)

Dies bedeutet keinesfalls Inaktivität oder aber die Abgabe der Verantwortung an People of Color. Ganz im Gegenteil geht es darum, eben auch dann in weiß dominierte Zusammenhänge zu intervenieren, wenn keine People of Color anwesend sind. Dabei muss bedacht werden, dass eine Inaktivität keinesfalls eine neutrale Position darstellt: ,There is no neutral position to take; one either decides to work against it or to go along for the ride.“ (Allen 2004: 130) Als weiße 
Verbündete - so Beverly Tatum - agieren weiße Personen dann, wenn sie ihre weiBen Privilegien und Macht für einen Abbau der Privilegienungleichheit einsetzen (Tatum 2007: 37). Diese Macht kann dabei unter Umständen für die Intervention in weiß dominierte Räume andere Wirkungsweisen entfalten, als die von People of Color. Joan Lester schreibt in diesem Sinne:

„As whites, we have our own power to intervene in other white peoples' actions and sometimes attitudes, which is a different power from the strength of those who organize or act against oppressions of themselves. We can often be heard, on the topic of racism, where a person of color couldn't be.“ (Lester 1987: 7)

Virulente Muster der Abwehr von Rassismuskritik bestehen darin, die als People of Color positionierten Kritiker_innen als übersensibel und betroffen abzuwerten sowie damit ihre Wahrnehmung infrage zu stellen. Diese Abwehrstrategien werden untergraben, wenn Weiße rassismuskritisch intervenieren und dabei ihre Definitionsmacht einsetzen: „Others can't rationalize away the information with the explanation , she is just oversensitive' when an ally is speaking up about an experience which doesn't directly target her." (ebd.)

Eine andere Form als verantwortlich handelnde Verbündete zu agieren, stellt das Powersharing dar, in der es um die Umverteilung von Macht geht. Es kann als „Pendant zum Empowerment-Konzept“ (Bönkost 2013: 40) verstanden werden. Halil Can fasst diesen Ansatz folgendermaßen zusammen: „Dies bedeutet, aus der Position von Machtdominanz als solidarisches Prinzip die verfügbaren Ressourcen und Privilegien in positiver und stärkender Wirkung - hier im Sinne von People of Color - zu nutzen, zu teilen oder abzugeben." (Can 2013: 37) Diesem Ansatz folgend kann der Verzicht von Weißen auf ihre weißen Privilegien ermächtigend für auf People of Color wirken. Jule Bönkost stellt heraus, dass „Powersharing kein Akt des Wohlwollens" (Bönkost 2013: 40, Herv. i. O.) sein darf. Es ist wichtig, dass das Abgeben von Privilegien - was durchaus ein schmerzvoller Prozess sein kann - dabei im eigenen Interesse erfolgt (ebd.). Andernfalls besteht die Gefahr der Reproduktion eines paternalistischen Verhältnisses, mit dem auch eine Objektivierung des dann zum Hilfenehmenden Degradierten einhergeht. Bevor ich dieses eigene Interesse von Weißen diskutiere, möchte ich einige weiße Abwehrstrategien benennen, die auch von Weißen immer wieder verwendet werden, für die Rassismuskritik ein zentraler Bestandteil ihres Selbstverständnisses ist.

Eine Praxis als rassismuskritische, weiße Verbündete baut auf der Bereitschaft zur Machtabgabe auf. Das ist manchmal - wie ich auch in Bezug auf mich sagen kann - kein ganz einfaches oder widerstandsfreies Unterfangen. Grada Kilomba 
identifiziert mit Bezug auf Paul Gilroy fünf verschiedene Mechanismen, die insofern als Stufen interpretiert werden können, als das normative Ziel die fünfte Stufe darstellt, und insofern nicht als Stufen interpretiert werden sollten, als das dies keinen abschließbaren, abhakbaren Prozess darstellt, durch dessen ,Abschluss“ man eine Stufe erreicht hätte:

„In a public speech Paul Gilroy described five different ego defense mechanisms the white subject goes through in order to be able to 'listen', that is in order to become aware of its own whiteness and of itself as a performer of racism: denial/guilt/shame/recognition/reparation.“ (Kilomba 2008: 20)

Verleugnung, Schuld, Scham, Anerkennung und Wiedergutmachung können dabei durchaus gleichzeitig oder in verschiedenen Kontexten spezifische Formen annehmen. Die Anerkennung der eigenen Verstrickung in Rassismus umfasst nach Kilomba auch ein Aufgeben der Deutungshoheit, ,wie das Eigene und ,die Anderen' beschaffen sind" (Bönkost 2013: 38). Damit einher geht die Anerkennung des Subjektstatus der ,Anderen'. In der Anerkennung im Sinne Kilombas sehe ich bereits eine die weiße Dominanz untergrabene Praxis, mit der, wir' aufhören, wissen zu meinen, was , die Anderen' wollen und vielmehr lernen zuzuhören. Dafür braucht es auch die Anerkennung der eigenen Perspektivität als weiß positioniertem Mensch, die Anerkennung der eigenen Wissenslücken und den Willen, eigene Verunsicherungen auszuhalten. Die Anerkennung vorausgesetzt, besteht das Ziel einer Wiedergutmachung in einer Praxis des Verbündet-Seins: "Reparation [...] is the act of repairing the harm caused by racism by changing structures, agendas, spaces, positions, dynamics, subjective relations, vocabulary, that is, giving up privileges." (Kilomba 2008: 22, Herv. i. O.)

Es gibt zahlreiche Ausweichstrategien, die ein solches Ziel verunmöglichen. Jule Bönkost sieht den Grund für diese Ausweichstrategien in der „Vermeidung der unbequemen Konsequenzen, die eine Auseinandersetzung mit Rassismus für uns mit sich bringt" (Bönkost 2013: 14). Unbequem sind sie deswegen, weil sie eine Angst davor hervorrufen können, dass eine Rassismuskritik so weit geht, dass sie tatsächlich das eigene Selbstverständnis delegitimiert und als selbstverständlich empfundene Privilegien untergräbt. "There is an apprehensive fear that if the colonial subject speaks, the colonizer will have to listen. It would be forced into an uncomfortable confrontation with 'Other' truths." (Kilomba 2008: 21) Grada Kilomba analysiert diese Zusammenhänge aus psychoanalytischer Sicht. Dieses aktive Fernhalten anderer Wahrheiten interpretiert sie als eine Verdrängungsleistung des weiß positionierten Subjekts. „It is that process by which unpleasant truths are rendered unconscious due to the extreme anxiety, guilt or shame they 
cause." (ebd.) Sie stellt fest, dass es nicht so sei, dass die rassialisierten ,Anderen“ nicht gesprochen hätten, sondern vielmehr wurden ihre Stimmen durch Rassismus systematisch unhörbar gemacht (ebd.).

\begin{abstract}
"This impossibility illustrates how speaking and silencing emerge as an analogous project. The act of speaking is like a negotiation between those who speak and those who listen, that is, between the speaking subjects and their listeners. Listening is, in this sense, the act of authorization towards the speaker. One can (only) speak, when one's voice is listened. And those who are listened, are also those who belong, as well as those who are not listened, become those who 'do not belong.' The mask re-creates this project of silencing, it controls the possibility that the colonized might one day be listened and consequently might belong." (ebd.)
\end{abstract}

Konfrontiert mit diesen unbequemen Wahrheiten führt der Prozess der Verdrängung - der eben kein Nicht-Wissen, sondern eine psychische Praxis darstellt - zu Abwehr.

\begin{abstract}
"When confronted with these unpleasant truths, the white subject commonly argues: 'not to know...,' 'not to understand..., 'not to remember...' or 'not to believe...'. These are expressions of this process of repression, in which the subject resists making the unconscious information, conscious. That is, one wants to make the known, unknown." (ebd.)
\end{abstract}

Daraus folgt die Herausforderung für weiße Subjekte, die rassismuskritisch agieren wollen, diese Verdrängung zu unterlassen, sie aufzuarbeiten und sie als solche intelligibel zu machen. Im Zuge dieser Auseinandersetzung müssen auch negative Gefühle zugelassen werden, die durch den Kontrollverlust ausgelöst werden. Statt diese Gefühle zu unterdrücken und damit wiederum Prozesse der Verdrängung zu ermöglichen, müssen sie einen Raum in Bildungsprozessen haben.

Ein häufig zu beobachtender Mechanismus ist, dass diese nicht ,bearbeiteten“, negativen Gefühle auf rassistisch diskriminierte Menschen umgeleitet und - um im Kontext der Psychoanalyse zu bleiben - projiziert werden. Im Sinne dieser Projektion erscheinen die People of Color, die weiße Vorherrschaft infrage stellen, als die Ursache des Problems, statt als diejenigen, die das Problem - nennen wir es Rassismus - aus dem Zustand der Unbesprechbarkeit und Normalisierung herausholen und auf die politische Tagesordnung setzen. Dies führt nicht nur zu einer Dethematisierung von Rassismus durch Weiße, sondern auch zu verletzendem Verhalten gegenüber People of Color.

Ein weiterer Mechanismus der Dethematisierung der eigenen, weißen Verstricktheit betrifft insbesondere rassismuskritisch engagierte, weiß positionierte 
Menschen. Hytten und Warren nennen diesen Mechanismus den „discourse of fix-it" (Hytten/Warren 2003: 75 f.). Dieser Mechanismus baut auf der Annahme auf, die „Komplexität der diskursiven Wirkungsweise von Weißsein (bereits) zu durchschauen“" (Bönkost 2013: 29). Dies ermöglicht einem weiß positioniertem Subjekt, die eigene Verstricktheit zu verleugnen, da diese als überwunden ausgegeben wird. Ein weißer Reflexionsprozess über die Verstricktheit in rassistische Verhältnisse kann jedoch niemals abgeschlossen sein, zum einen, weil Rassismus kein individuelles Problem darstellt und er auch unabhängig von unseren Intentionen und Praxen wirkt, zum anderen, weil das Wissen von Weißen über Rassismus immer auch auf Unwissen aufbaut. Der Glaube, es verstanden zu haben, ist schon mit einem weiß positioniertem Begehren nach Rückgewinnung der Kontrolle verbunden und muss als solches problematisiert werden.

Ein Dilemma für die weiße Reflexion über Rassismus und die eigene Verstricktheit darin resultiert daraus, dass Rassismus unmöglich in einem weißweißem Selbstgespräch analysiert werden kann, da Perspektiven von People of Color eine unumgänglich Ressource für rassismuskritische Weiße sind und die Grundlage für eine solche Reflexion darstellen. Gleichzeitig kann es als eine Zumutung gesehen werden, die Bearbeitung der weißen Psychopathologien People of Color zu überlassen. Dies kann verletzend sein und am Ende dreht sich wieder alles um das weiße Subjekt, das von den Perspektiven von People of Color profitiert - so wie ich in meiner akademischen, den hier vorliegenden Text eingeschlossen, und meiner politischen Praxis. Dieses Dilemma kann nicht aufgelöst, sollte aber dauerhaft für das eigene Handeln sowie die Konzeption von Bildungsräumen einbezogen werden. Die Rollenzuweisung von People of Color als Trainer_innen - oder Psycholog_innen - der weißen Subjekte kann problematisch sein und Weiße sollten sich auch nach anderen Methoden umsehen - das Wissen verbündeter Weißer als Ressource, Bücher und Videos von People of Color oder ähnliches - um die eigenen Bildungsprozesse weiterzubringen.

In Bezug zu Beverly Tatum thematisiert Jule Bönkost das Problem, dass eine rassismuskritische Reflexion nicht in die gegenwärtige Form institutionalisierter Bildungsräume passt.

„You can't bring a complex conversation about race to closure in the two hours of a single afternoon workshop [...]. Too often what is accomplished in that period of time is just enough to generate anxiety, and anxiety often leads to avoidance. Put simply, ,I don't want to talk about it' becomes a common response." (Tatum 2007: 124)

Institutionalisierte Bildungsräume, die auf schnelle, messbare und verwertbare „Outcomes“ (Andreotti 2011a: 395) setzen, stehen im Kontrast zu dieser Art von 
Bildungsprozessen, in denen es Raum für Verunsicherungen, den Umgang mit negativen Gefühlen und Reflexionsprozesse braucht. Bönkost stellt heraus, dass „Vorübergehende oberflächliche Auseinandersetzung mit Rassismus in Diversitätstrainings und antirassistischen Trainings“ sogar „kontraproduktiv“ (Bönkost 2013: 27) wirken können. Die mit diesen Lernprozessen verbundenen negativen Emotionen rufen dabei oft Widerstand der Lernenden hervor. Eine lebenslange Sozialisation als Weißer ist eben nicht einfach abzuschütteln oder zu ,'entlernen““ (ebd.) - vielmehr müssen solche Lernprozesse als unabschließbar verstanden werden. Bönkost plädiert in ihrem offenen Brief Liebe weiße Mitmenschen-Statements von weiß zu weiß dafür ein Klima der Fehlerfreundlichkeit zu schaffen, was ich in Bezug zur Konzeption von weißen Bildungsräumen als zentral ansehe, in denen das eigene Weiß-Sein problematisiert wird:

„Wir müssen uns selbst und anderen gegenüber fehlerfreundlich sein, uns eingestehen,
dass wir niemals vollkommen rassismusfrei handeln können. Wir müssen Rassismus
so gut wir können herausfordern und dabei Spannungen aushalten, anstatt ein ras-
sismusfreies Verhalten anzustreben. Das ist kein Freifahrtschein für unreflektiertes
und rassistisches Verhalten. Wir müssen unser Handeln kontinuierlich überprüfen und
Verantwortung dafür übernehmen, aus unseren ,Fehlern` zu lernen.“(Bönkost 2020)

Vor diesem Hintergrund müssten im Sinne einer dekolonialen Bildung die bildungsinstitutionellen Settings grundlegend verändert werden, die es ermöglichen, Rassismus zu einem dauerhaften (Querschnitts-)Thema zu machen, in denen auch selbstreflexiv die institutionellen Praxen thematisiert werden können. Dies stellt eine Voraussetzung dar, um rassismuskritische Bildung für weiß positionierte Lernende nachhaltig zu realisieren. "You have to give enough to make some real progress, to get past the initial discomfort, and persist to the point where you can really begin to see the benefits." (Tatum 2007: 125).

Worin bestehen aber die eigenen Vorteile? Was sind also mögliche Motivationen für weiß positionierte Menschen, sich selbst mit diesen oft unbequemen Fragen zu beschäftigen? Die Auseinandersetzung - Beantwortung erscheint mir hier, jedenfalls für mich, zu hoch gegriffen - mit diesen Fragen ist zentral für eine weiße rassismuskritische (Bildungs-)Praxis. Diese Auseinandersetzung wird, wie im letzten Abschnitt gezeigt, auch beispielsweise von KARFI als Bedingung für Bündnisarbeit mit rassismuskritischen Weißen (Bendler/Digoh-Ersoy/Golly 2019: 21), aber auch von weißen Rassismuskritiker_innen (Bönkost 2019: 84) eingefordert. Dies setzt zum einen eine intensive und dauerhafte Auseinandersetzung mit Rassismus als Herrschaftssystem voraus, da sich die „Idee des Verbündet-Seins“ als ,spezifische Form von Solidarität [...] gegen Macht- und 
Herrschaftsverhältnisse und die dadurch hergestellte Exklusion“ (Perko/Czollek 2014: 153) richtet und nur im Zusammenhang mit diesen Verhältnissen verstanden werden kann. Im Sinne eines normativen Begehrens von Social Justice kann Verbündet-Sein dann als eine Form der „politischen Freundschaft“ verstanden werden, ,wo die Anliegen der Anderen die je eigenen Anliegen sind“ (ebd.). Vor dem Hintergrund dieser durch Freundschaft verbundenen Anliegen kann auch das eigene Glück und das eigene Streben nach einer gerechteren Welt nicht ohne die Befreiung der (rassialisierten), Anderen' gedacht und gefühlt werden. Auch wenn ich diesen von mir hier formulierten Gedanken für zutreffend halte, ist er doch viel zu kurz gedacht, da er tautologisch das Resultat - politische Freundschaft und verbundene Anliegen - als Ursprung präsentiert und sich ergebende Widersprüchlichkeiten ausklammert. Ein_e verbündete_r Weiße_r ist nicht nur Verbündete_r, sondern bleibt weiß positioniert. Aus meiner Sicht kann autobiographische Auseinandersetzung hier hilfreich bzw. ein möglicher Zugang sein, um - vielleicht nicht die Antworten zu finden - aber zumindest relevante Fragen zu stellen.

In einem solchen Prozess verstehe ich ,das ,Ich', das hier schreibt, selbst als ein ,artikuliertes“" (Stuart Hall 1990: 26), was die Sache zusätzlich verkompliziert. Wenn Stuart Hall davon schreibt, dass ,,wir alle [...] einen bestimmten Ort, eine bestimmte Zeit, eine spezifische Geschichte und Kultur, von denen aus wir schreiben und sprechen“ und das, ,was wir sagen, [...] immer 'in einem Kontext" "steht und „positioniert“ (ebd.) ist, so ist die Bestimmung dessen nicht mit der Benennung allgemeiner gesellschaftlicher Verhältnisse, wie etwa Weiß-Sein in rassistischen Verhältnissen, abgetan. Das sich artikulierende und selbst artikulierte ,Ich“ gelangt im Zuge von Reflexionsprozessen nicht zu einem ,Bewusstsein' seines Selbst, sondern erfindet vielmehr eine Erzählung oder mehrere Erzählungen, mit denen wiederum das ,Ich` oder ein ,Ich' der Gegenwart artikuliert wird.

Ein in seiner Artikulation auf Selbstlegitimation zielendes ,Ich' könnte über ,mich`zum Beispiel folgende Geschichte erzählen: Es war einmal ein weiß positioniertes Subjekt, mein früheres ,Ich, das in weißen Zusammenhängen antikapitalistisch und internationalistisch motiviert und engagiert von einer besseren Welt träumte. Auf der Suche nach revolutionären Subjekten und Verbündeten - getragen von dem Wunsch der Selbstinszenierung als transnational vernetztes und informiertes Subjekt - ging ich zahlreiche Arbeitsbündnisse in vor allem antirassistisch Ausgerichteten Gruppen ein. Dies hat dazu geführt, dass ich mich zahlreichen - auch schmerzhaften und anstrengenden, für sich, aber besonders für die anderen - Auseinandersetzungen stellen musste, aber auch, dass ich zahlreiche soziale Beziehungen entwickelte, die von politischer und persönlicher Freundschaft bis zu Familie und Liebe (Apraku 2019) reichten, die es mir von da an unmöglich machten, meine Anliegen als nicht geteilt wahrzunehmen; die es von 
da an unumgänglich machten, mein eigenes Glück als irreduzibel verbunden mit den rassialisierten ,Anderen' zu sehen und mich dazu motivieren, mich tagtäglich den auch unangenehmen Auseinandersetzungen zu stellen. Die Verletzungen der rassialisierten ,Anderen“ verspüre ich als durch Freundschaft verbunden selbst - wenn auch nicht in dem Maße und nicht auf die gleiche Weise - als eigenen Schmerz, der es mir unmöglich macht, mich angesichts dieser wohl zu fühlen.

Ein in seiner Artikulation auf Selbstdelegitimation zielendes ,Ich k könnte eine andere Geschichte erzählen: Es war einmal ein weiß positioniertes Subjekt, mein früheres ,Ich', das durch seine politische Arbeit in Widersprüche geriet bzw. vielmehr durch Schwarze Menschen und People of Color mit der eigenen Position konfrontiert wurde und dadurch eigene Selbst- und Weltwahrnehmungen infrage zu stellen begann. Die anfängliche Verunsicherung, die eine tiefe Freundschaft und gemeinsamen Aktivismus mit People of Color ermöglichte, wich durch die akademische Arbeit einem Gefühl, Bescheid zu wissen. Seitdem mache ich - ausgehend von den Wissensressourcen, die ich dank meiner Freund_innen of Color erworben habe - mit rassismuskritischen Perspektiven Karriere (mehr oder weniger zumindest). Während meine Freund_innen of Color nun zum Teil als Sozialberater_innen, Gärtner_innen oder Küchenkräfte arbeiten, profiliere ich mich mit dem durch sie gewonnenen Wissen im akademischen Raum. Meine weiße Privilegierung und meine Klassenposition habe ich genutzt, um mir - profitierend von den Wissensressourcen meiner Freund_innen - eine berufliche Zukunft zu ermöglichen. Ich bin sehr gut darin, meinen Aktivismus und mein Handeln als rassismuskritisch zu inszenieren, dies kaschiert jedoch eher meine weiterhin bestehende Verstrickung in rassistische Machtverhältnissen. Trotz jahrelanger Auseinandersetzungen zwinge ich sogar - oder eher insbesondere meine engsten und intimsten Freund_innen immer wieder dazu, mir meine weißen Abwehrmechanismen vor Augen zu führen - wenn es zu unangenehm wird, habe ich nichts gehört oder gesehen und bin handlungsunfähig - und in aufreibende Auseinandersetzungen zu gehen.

Das war ein für mich persönlich gutes Beispiel, wie die Prozesse der eigenen Selbstreflexion unangenehm sein können, da die Annahme der zweiten Geschichte für mich unerträglich erscheint, obwohl vermutlich viele dieser Punkte auf eine gewisse Weise zutreffen. Doch ich stimme hier Francis Kendall zu, wenn sie vom Unangenehmen und Angenehmen bzw. Unbequemen und Bequemen ((un-)comfortable) schreibt: „The task is [...] to become ,comfortable with the uncomfortable und uncomfortable with the too comfortable. " (Kendall 2013: 145) In diesem Sinne macht es aus meiner Sicht Sinn, sich selbstkritische Fragen manchmal so unangenehm wie möglich zu stellen. 
Die Relevanz der unangenehmen Fragen - des Unbequemwerdens - gilt dabei nicht nur für die Reflexion autobiographischer Erzählungen oder persönlichen Handelns, sondern ebenso für die theoretischen Prämissen, in denen diese Erzählungen und Handlungen stattfinden. Diese Befragung der theoretischen Prämissen gestaltet sich für mich oft als schwierig. In der Auseinandersetzung erscheint es mir oft ununterscheidbar, was weiße Abwehrmechanismen und was sinnvolle Kritik ist. Zum einen macht es Sinn, entgegen der weißen Sozialisation und des damit verbundenen Habitus, die ,Wahrheit' zu kennen und es ,besser' zu wissen, zu lernen, zuzuhören und Dinge annehmen zu lernen. Zum anderen gibt es aber keine ,Wahrheit". Angesichts der Vielfältigkeit von Perspektiven von Schwarzen Menschen und People of Color muss ich mich der Schwierigkeit dieser Auseinandersetzung stellen, auch wenn dies mit großen Unsicherheiten verbunden ist. Es kann eben auch eine Art sein, bequem zu werden, wenn beispielsweise die rassismuskritischen Kategorien, wie weiß und Schwarz, zu fixen Kategorien werden und dadurch die Rolle des Verbündet-Seins klar und ausbuchstabiert erscheint. Hier besteht aus meiner Sicht die Gefahr der Reduktion eines komplexen Problems, da Rassismus kein abgeschlossenes Phänomen ist, sondern als soziales Verhältnis durch Fragen der sozialen Klasse, Gender und die internationale Arbeitsteilung sowie die Frage des Politischen überdeterminiert ist bzw. diese überdeterminiert. Vor diesem Hintergrund halte ich eine kritische Befragung der hier beschriebenen Ansätze für zielführend, der ich mich in den kommenden Abschnitt widme. Dabei kann der Verweis auf andere Herrschaftsformen auch als Dethematisierung von Rassismus interpretiert werden, obwohl dies nicht in meinem Sinne ist. Diese Befragung zielt nicht auf die Delegitimation oder Abkehr von den hier erörterten Ansätzen. Vielmehr ist es der Versuch, zum einen meine Auseinandersetzung mit diesen Ansätzen durch die Referenz auf Kritik zu vertiefen, zu schärfen und zu differenzieren, zum anderen den eigenen Rahmen rassismuskritischer Reflexion eher als Spannungsverhältnis, denn als fertiges Theoriegebäude zu begreifen.

\subsection{Gedanken zu den Fallstricken von Critical Whiteness}

Für die Konzeption von rassismuskritischen, selbstreflexiven Bildungsräumen stellen einige Ideen des Ansatzes von Critical Whiteness einen wichtigen, zentralen und unhintergehbaren Bezugspunkt dar. Allerdings hat diese Perspektive auch ihre Fallstricke und Begrenzungen, die ich im Folgenden aus meiner Perspektive skizzieren werde. Chandra Mohanty kritisiert an einem von ihr beobachteten Bildungssetting, dass dort die binäre Codierung Bildungsmöglichkeiten verschließt: „Potentially this implicitly binary construction (Third World students vs. white students) undermines the understanding of coimplication that students must 
take seriously in order to understand ,difference" as historical and relational.“ (Mohanty 2013: 203) Ihr Konzept der Ko-Implikation aller Subjekte schreibt sie auch vor dem Hintergrund der Reflexion ihrer eigenen Erfahrungen, dass sie sich je nach Kontext innerhalb des Hindu-Kasten-Systems in Indien, der nigerianischen Gesellschaft und der - sich wandelnden - US-amerikanischen Gesellschaft ganz unterschiedlichen Zuschreibungen ausgesetzt sah und unterschiedliche Selbstpositionierungen entwickelte (ebd.: $127 \mathrm{ff}$.). Auch vor diesem Hintergrund beschreibt sie ihr Konzept der Ko-Implikation folgendermaßen:

\footnotetext{
"Coimplication refers to the idea that all of us (First and Third World) share certain histories as well as certain responsibilities: ideologies of race define both white and black peoples, just as gender ideologies define both women and men. Thus, while 'experience' is an enabling focus in the classroom, unless it is explicitly understood as historical, contingent, and the result of interpretation, it can coagulate into frozen, binary, psychologistic positions.“(Mohanty 2003: 203)
}

Sie thematisiert die Gefahren einer trennenden Bildungspraxis, da die Komplexität der situierten Subjekt- und Wissenskonstellationen möglicherweise durch eine spezifische individualistische Kodifikation und Kommodifizierung von rassialisierten Subjektpositionen und damit einem ,kulturellen' Pluralismus überschrieben werden könnte (ebd.). Sie verwendet bewusst die Möglichkeitsform in ihrer Kritik. Chandra Mohanty lehnt als Feministin nicht die Idee ab, dass es selbstorganisierte Frauenzusammenhänge geben sollte, obwohl Männer ebenso sehr durch patriarchale Strukturen geprägt sind, wie Frauen. Dies gilt in ähnlicher Weise für den Zusammenhang von Rassismus. Aber ebenso, wie sie die Kategorisierung Frau als politisches Subjekt aus postkolonialer Perspektive - beispielsweise in ihrem berühmten Text Under Western Eyes (ebd.: 17-42) - kritisch in den Blick nahm, warnt sie in solidarischer Weise vor der Gefahr der Essenzialisierung und Homogenisierung durch die Organisierung entlang von rassialisierten Differenzlinien. Dies könnte auch ausgehend von weitgehenden Ausschlussprozessen von ost- und südosteuropäischen Migrant_innen aus den POC-Zusammenhängen diskutiert werden. Dabei können außerdem auch andere Differenzlinien übergangen und zugunsten der rassialisierenden Logik dethematisiert werden, wie etwa Klasse und Verortung in der internationalen Arbeitsteilung.

Es gibt in einer Auslegung von Critical Whiteness, die in Deutschland möglicherweise zur verbreitetsten gehört, eine Tendenz, die Benennung der Positionierung in den Mittelpunkt - Ausgangs- und Endpunkt - dieser reflexiven Praxis zu stellen. Aus der Perspektive von politischer Bildung kann diese Reduktion auf die Selbstreflexivität als problematisch erscheinen. In dieser Praxis werden nicht nur Ungleichheiten der sozialen Klasse und die Reichtumsverteilungen oft 
unsichtbar. Dabei würden sich ausgehend von den Schüler_innenvorstellungen zahlreiche Anknüpfungspunkte finden, wie rassifizierte Unterscheidungspraxen in einem Verhältnis zu sozialen Ungleichheiten stehen - ob in Bezug auf globale Ungleichheit oder innerhalb der Migrationsgesellschaft. Vielmehr kann diese Form der Selbstreflexivität auch in Bezug auf die von ihr sichtbar gemachten Subjektpositionen und Privilegien im rassistisch strukturierten Raum problematisch sein.

Andrea Smith beobachtet und reflektiert die empirisch stattfindenden Bildungspraxen einer privilegienkritischen Critical Whiteness und sieht hier die Praxis der Beichte an die Stelle der Transformation von Verhältnissen treten: „It did not appear that these individual confessions actually led to any political projects to dismantle the structures of domination that enabled their privilege. Rather, the confessions became the political project themselves." (Smith 2013) Innerhalb dieser Praxen der Beichte geständen die Privilegierten ihre Privilegien und ihren Umgang damit, die Nicht-Privilegierten sind dabei temporär in der machtvollen Rolle der Erteilung von Absolution (ebd.). Innerhalb dieser Logik der Privilegien kommt hier denen kulturelles Kapital zu, die am meisten unterdrückt erscheinen. Smith beobachtet hier eine durch das Bildungssetting hervorgebrachte, merkwürdig anmutende Strukturierung des Begehrens bei Weißen: „Consequently, people aspired to be oppressed. [...] Consequently, the goal became not to actually end oppression but to be as oppressed as possible." (ebd.) Im Zuge dieser Rituale wird zwar temporär ein Machtverhältnis verschoben, letztlich wird aber durch diese Rituale das Weiße, dominante Subjekt als fähig zur Selbstreflexivität neu konstituiert und das kolonisierte oder rassialisierte Subjekt fungiert als Gelegenheit für dieses (ebd.). Die hier inhärente Privilegienlogik verbleibt auf der Vorstellung eines individualisierten Selbst, das den Anderen für seine Konstitution braucht (ebd.).

Vor diesem Hintergrund stellt sich Melanie Bee die Frage, wie und warum Critical Whiteness in einigen Kreisen zu „einem Synonym für antirassistische Arbeit" (Bee 2012: 25) geworden sei. Sie zeigt, wie der Theorietransfer aus den USA sehr selektiv diesen Ansatz in den deutschen Kontext übersetzte, während es in den USA nur ein Ansatz unter vielen ist. Andere, in der antirassistischen Praxis verbreitetere Ansätze seien dort zum Beispiel „,, white privilege, ‘, white supremacy, ' and ,accountability““, die „,zugleich die Rolle des Weißen in antirassistischen Kämpfen“ (ebd.: 24) beschreiben. Während andere Ansätze, die auf die Transformation rassistischer Ungleichheitssysteme zielen, in den sozialen Bewegungen in den USA viel dominanter seien, sei in Deutschland die einseitige Rezeption des Ansatzes Critical Whiteness zu beobachten, die ihren gesellschaftstransformierenden Charakter oft verloren zu haben scheint: 
„Wenn die Reflexion über Privilegien nicht mit politischen Aktionen verbunden ist, ist das Ziel nicht mehr soziale Veränderung, sondern die Bildung und Aufrechterhaltung von ,guten' Subjekten, die miteinander um den Status des_der ,Reinsten“ und von Herrschaft ,Befreitesten“ konkurrieren. Dabei wird der Fokus von sozialen Strukturen auf Individuen, von transformativer auf moralische Politik verlegt.“ (Bee 2013)

In ihrer Wahrnehmung des deutschen akademischen und ,politischen ' Kontexten, wie der ,linken Szene“ (Bee 2013), sieht sie die Beobachtungen von Andrea Smith bestätigt.

Jule Karakayalı, Vassilis Tsianos, Serhat Karakayalı und Aida Ibrahim haben im Anschluss an die Auseinandersetzungen und Zerwürfnisse auf dem NoBorderCamp 2012 in Köln eine polemische Kritik an der deutschen Rezeption und Praxis des Critical Whiteness-Ansatzes formuliert. In ihrem Artikel Decolorise it! argumentieren sie aus meiner Sicht zu polemisch und pauschalisierend gegen den Ansatz von Critical Whiteness als solchem, ohne dies als ein vielfältiges und heterogenes Feld anzusehen, nichtsdestotrotz erscheinen mir viele Kritikpunkte als wertvolle Impulse zu einer Diskussion über rassismuskritische und antirassistische Praxen. Ein zentrales Problem des „Whiteness-Konzeptes“ sehen sie darin, dass die Kategorien ,white" und ,of Color" essenzialisiert würden.

\begin{abstract}
„Differenz und rassistische Hierarchie müssen im Sprechen über Rassismus immer sichtbar gemacht werden, die Einteilungen in , white " und , of Color' allerdings werden schnell zu Etiketten, die als Labels stabiler Kategorien erscheinen. Spätestens wenn ein Nachweis über die Herkunft der Eltern verlangt wird, zeigt sich, wo das WhitenessKonzept aufhört, kritisch zu sein.“ (Karakayalı/Tsianos/Karakayalı/Ibrahim 2012)
\end{abstract}

Sie stellen damit nicht in Abrede, dass Rassismus unterschiedliche Positionierungen produziert und diese die Subjekte präge. Sehr wohl stellen sie aber ein Paradigma infrage, dass die Subjekte darauf reduziere und damit die rassistischen Kategorien verabsolutiere. Durch die das Subjekt auf seine Positionierung im rassistischen Feld festnagelnde Praxis wird subjektive Erfahrung aufgrund der rassialisierten Positionierung gleichgesetzt mit der Subjektivität, womit Handlungsspielräume der Subjekte negiert werden (ebd.). Wenn die Perspektive von rassismuskritischer Bildung ausschließlich darin besteht, die unterschiedlichen Positionen durch selbstreflexive, letztlich individualisierte Prozesse sichtbar zu machen, besteht die Gefahr, die sie ermöglichenden (auch materiellen) gesellschaftlichen Strukturen und das Denken ihrer Transzendierung aus dem Blick zu verlieren. Die Positionen erscheinen so vielmehr als zwar abstrakt historisch entstanden, aber nichtsdestotrotz in Bezug auf die subjektiven Lebenswelten als statisch und nicht überwindbar. 
Dabei sehen die Autor_innen von Decolorise it! auch ein Problem der Bestimmung dessen, was oder vielmehr wer denn als Weiß und of color angesehen wird. Viele, die von Rassismus betroffen sind, werden in Critical WhitenessZusammenhängen ausgeschlossen, da sie nicht durch den Kriterien von of Color entsprechen. Menschen aus Russland oder südosteuropäischen Staaten, wie Rumänien oder Bulgarien, die in Deutschland massivem und gewaltvollem Rassismus ausgesetzt sind, werden in Critical Whiteness-Zusammenhängen oft schlicht als Weiß definiert und so aus diesen Zusammenhängen ausgeschlossen. Karakayalı et al. fragen vor diesem Hintergrund, ob durch diese Festschreibung, wer als weiß und of color sowie der damit verbundenen Festschreibung, wer von Rassismus deprivilegiert und wer von Rassismus privilegiert wird, nicht letztendlich wieder rassistische Essenzialisierungen und Unterscheidungspraxen restabilisiert werden, indem Hautpigmentierung zum entscheidenden Differenzkriterium wird. Gerade vor dem Hintergrund des (selektiven) Theorieimports in den deutschen Kontext und der von den USA abweichenden (Kolonial-)Geschichte in Bezug auf Ost- und Südosteuropa (4.2.1.4) stellt sich die Frage, ob Whiteness hier das angemessene Konzept darstellt. Es scheint als würde - statt die Konjunkturen des Rassismus als Ausgangspunkt zu nehmen - der Kolonialismus Afrikas bzw. die Geschichte der Unterdrückung Schwarzer Menschen in den USA als eine Art Blaupause des Rassismus angesehen, zu dem sich andere Formen des Rassismus in gradueller Abschwächung in Beziehung setzen müssten. Dabei muss aber berücksichtigt werden, dass derlei Quasi-Essenzialisierungen auch als Abwehrreaktion auf rassistische Dethematisierungsstrategien und Relativierungsstrategien $\mathrm{zu}$ verstehen und als solche ernst zu nehmen sind. Als vielleicht ausgeprägteste Form solcher Abwehrstrategien von Weißen gegen Rassismuskritik kann aus meiner Sicht die Umkehrung, also die Behauptung eines ,Rassismus gegen Weiße', angesehen werden, die nur auf der Grundlage der Ausblendung existierender Machtstrukturen und mit dem Ziel der Delegitimierung rassismuskritischer Interventionen verstehbar ist.

Eine solche essenzialisierende, dichotome Festschreibung der Kategorien in einigen Rezeptionsweisen von Critical Whiteness steht aber nichtsdestotrotz zum einen in Kontrast $\mathrm{zu}$ der empirischen Wirklichkeit, in der die postmigrantischen Lebenswirklichkeiten negiert werden, etwa „unsere Freundeskreise, WGs, Familien, unsere Nachbarschaften, unsere Arbeitsstellen und unsere politischen Zusammenhänge“, die eben nicht „ethnisch segregiert“ (Karakayalı/Tsianos/Karakayalı/Ibrahim 2012) sind. Diese ignorierten Lebenswirklichkeiten beschreiben die Autor_innen als ,tausendfach verschachtelten und komplizierten Geschichten von vielen von uns, die sich der schnöden Opposition ,weiß" versus ,color" entziehen“ (ebd.). Zum anderen würde durch die 
Fixierung der Kategorien ein Begriff des Politischen untergraben, ,der gerade darin besteht, nicht auf das festgelegt zu werden, was oder , wo' man vermeintlich ist" (ebd.). Ein solcher Begriff des Politischen ist beispielsweise von Jacques Rancière geprägt worden (2.3.2.5) und stellt keineswegs die hierarchischen Positionierungen und Zugehörigkeitsregime in Abrede. Ganz im Gegenteil stehen sie als zu Transzendierendes im Fokus. Zentraler Punkt bei Rancière ist, dass die Subjektivierungen, die durch das Politische, das Durchbrechen der Ordnung, entstehen, genau die von der Ordnung gezogenen Grenzen zwischen den Subjekten durchbricht.

Dies impliziert Andrea Smith zufolge den Horizont der Veränderung der Strukturen, die uns die Subjektpositionen zuweisen. Henry Giroux fasst das Verhältnis von Reflexion und Gesellschaftsveränderung und die Gefahr der Reduktion rassismuskritischer Praxen auf Selbstreflexion folgendermaßen: „Changing consciousness is only a precondition to changing society and should not be confused with what it means to actually transform institutional relations of power." (Giroux 2006: 169) Smith fasst dies in Bezug auf Critical Whiteness so: "That is, the undoing of privilege occurs not by individuals confessing their privileges or trying to think themselves into a new subject position, but through the creation of collective structures that dismantle the systems that enable these privileges." (Smith 2013) Wenn 'wir' die Privilegienungleichheit untergraben wollen, müssten , wir" die Strukturen ändern, in denen, wir' leben, sodass, wir' im Zuge dieses Prozesses andere Menschen werden (ebd.). Die Fragen, die mich beschäftigen, sind dabei, wer dieses ,Wir' ist, wen es in welchen Kontexten umfasst und wen nicht, wie es sich angesichts welcher Konstellationen konstituiert? Mit Rancière beginnt diese neue Subjektivität des Politischen nicht erst nach der Schaffung der neuen Strukturen, sondern durch die Subjektivierung des Streits um diese Strukturen. Dieser Streit um die Ordnung kann - muss aber nicht, wie Manuela Bojadžijev (2008) mit ihrem Begriff der Kämpfe der Migration gezeigt hat - sich in der Form des Antirassismus manifestieren. Aus meiner Sicht macht es Sinn, die Frage des ,Wirs' nicht abschließend zu beantworten, sondern als zentrale Frage immer wieder zu stellen.

\subsection{Die Transzendenz des Politischen als Bildungshorizont}

Warum schreibe ich das? Sind dies nicht eigentlich Fragen, die ich aus weißer Perspektive lieber anderen überlassen sollte? Wahrscheinlich ist die Antwort ja. Ich schreibe dies alles nicht, um den Ansatz der Empowerment- und Selbstorganisierung von durch rassistische Verhältnisse Deprivilegierte zu delegitimieren. Vielmehr unterstütze ich diese, soweit es gewünscht ist. Mir geht es aber darum, diesen Ansatz nicht als einzige bildungspraktische Antwort anzusehen und die 
Vorstellung stark zu machen, dass unterschiedliche Kontexte unterschiedliche Antworten verlangen. Ich werde ausgehend von Spivaks ethischem Imperativ des Planetarischen (4.2.4.3) die Hoffnung formulieren, Formen von Bildungsprozessen zu entwickeln, in denen - ohne im Prozess die Unterschiede zu dethematisieren - ein dekolonialer Horizont Menschen zu neuen temporären, politischen Subjektivitäten zusammenschließen lässt, die die rassialisierende Logik überschreiben, ohne diese und ihre Wirkungen dabei zu negieren. Dies wäre auch eine Zielperspektive, eine unter anderen.

Eine sich als politisch verstehende politische Bildung darf aus meiner Sicht auf den selbstreflexiven Ansatz beschränkt sein, sondern die angesprochene Dimension des Politischen als zentralen Ausgangspunkt oder vielmehr Fluchtpunkt denken. Anders herum darf sie aber nicht hinter den Anspruch der Selbstreflexion zurückfallen. Paul Mecheril und Karin Scherschel kritisieren beispielsweise den antirassistischen Ansatz dahingehend, dass er im Gegensatz zur Rassismuskritik eine „eingeschränkte Problemsicht“ (Mecheril/Scherschel 2009: 51) hätte, da er seine Perspektive auf die Absicht der Veränderung der Gesellschaft beschränke und so eine moralisierende Haltung einnehme. Im Selbstverständnis des oft weißen, antirassistisch Handelnden gelingt es oft, die eigene Verstricktheit mit rassistischen Hierarchien und Positionierungen auszublenden und sich selbst als außerhalb - oder oberhalb - der rassistischen Verhältnisse zu stellen. Das Fehlen der Selbstreflexivität kann zu Paternalismus und letztlich der Reproduktion rassistischer Rollenverteilungen und Selbstverständnisse führen. Diese Diskussion zwischen Selbstreflexivität und dem Politischen ist keinesfalls eine Frage des Entweder-Oder. Das Politische im Feld der Rassismuskritik zielt auf die Veränderung der Verhältnisse, zu der ja selbst auch die Reflexion gehört. Es geht hier vielmehr darum, dass eine politische Bildung die Gleichzeitigkeit einer selbstreflexiven Praxis und dem Moment des Politischen adressiert, der den Horizont einer Transzendenz rassistischer Zugehörigkeitsregime eröffnet und dabei neue Allianzen denkbar macht. Dieser Moment des Politischen kann wiederum auch für die Reflexivität eine Ressource darstellen.

Um diesen Moment des Politischen in politische Bildungsprozesse einzubeziehen, können beispielhaft die Lernendenvorstellungen als ein Ausgangspunkt dienen (3.4.4). Viele Schüler_innen stellen die Normalität und Legitimität des Zugehörigkeits- und Grenzregimes und der entsubjektivierenden Sicht auf Migrant_innen infrage. Auch wenn diese Perspektiven fast ausschließlich von Schüler_innen benannt werden, die selbst von Rassismuserfahrungen negativ betroffen sind, weist dieser Horizont im Sinne der Autonomie der Migration doch auf eine Transzendenz der Verhältnisse, die als gemeinsamer Fluchtpunkt fungieren kann. Didaktisch erscheint es sinnvoll, die Kämpfe der Migration 
- beispielsweise von Kotti und Co über Geflüchtetenkämpfe bis zu den Grenzübertrittspraxen selbst - sichtbar zu machen, diese in Verbindung zur Lebenswelt der Lernenden zu setzen und auf diese Weise das Politische diskutierbar zu machen. Dieser Bildungshorizont der Transzendenz rassialisierter Zugehörigkeitsregime eröffnet ein anderes Verständnis der subjektiven Verortung und Orientierung in migrationsgesellschaftlichen Verhältnissen.

Massimo Perinelli fasst das, Wir` und die Perspektive antirassistischer Kämpfe folgendermaßen:

\begin{abstract}
„Wir können uns nur über Glück und Befreiung vergesellschaften und nicht über das Verbrechen. Das heißt, dass Begegnung, Kommunikation und gemeinsames Handeln den Raum für Veränderungen öffnen muss, statt ihn in Vorwegnahme möglicher Verletzungen an den vermeintlichen oder realen Sicherheitsbedürfnissen verletzter oder traumatisierter Menschen auszurichten und hermetisch abzudichten. Das ist nicht leicht und auch kein Plädoyer für Härte oder Ignoranz gegenüber realen Unterdrückungserfahrungen, sondern ein Vorschlag ihrer Transzendierung - die einzige Möglichkeit der Überwindung rassistischer Spaltungen in der Gesellschaft. Dieses ,wir' soll dabei weder gegeben noch voluntaristisch erscheinen. Abgrenzungslinien haben ihre Begründung und sind oft wichtig. Dieses, wir" kann sich nur in konkreten Kämpfen ausbilden, es ist ein solidarisches Wir. Solidarität ist ein gegenseitiger Affekt, es kann sie nur zwischen Ungleichen geben, niemals unter Gleichen. Was fehlt ist eine Vorstellung solidarischer, die auf gegenseitige Kritik, unterschiedliche und gemeinsam beschlossene Lebensweisen begründet sind. Es ist dies eine Politik und eine Haltung, die auf ein besseres Leben in der Zukunft ausgerichtet sind. Das ist das genaue Gegenteil einer auf Schulden aus der Vergangenheit abgesicherten politischen Moral. Vielmehr ist dieser Kampf ein Wechsel auf die Zukunft, der potentiell alle miteinschließt - selbst die traurigen Gestalten mit ihren schönen Privilegien." (Perinelli 2019: 90)
\end{abstract}

Die Perspektive der Transzendenz der Ordnung steht so der Gefahr durch eine Restabilisierung der rassialisierten Differenz durch seine ausschließliche Reflexion entgegen. Anders herum würde eine antirassistische Praxis ohne die Dimension der selbstreflexiv angelegten Rassismuskritik wirkungslos sein bzw. unter Umständen die Verhältnisse reproduzieren, die sie doch zu kritisieren vorgibt. Dieses Spannungsverhältnis erscheint mir als eine der zentralen Herausforderungen, die sich eine dekoloniale politische Bildung stellen muss, um ihrem Anspruch der Dekolonisierung gerecht werden zu können. 


\subsubsection{2 "almost the same, but not quite" - (Nicht-)Zugehörigkeit postmigrantisch}

\subsection{Das orientalistische Paradigma, postliberaler Rassismus und Kritik am antimuslimischen Rassismus}

Während in den Lernendenvorstellungen im Nachdenken über globale Ungleichheit und ,Entwicklung ',Afrika' als diskursives Gegenstïck zum ,Westen' am häufigsten auftaucht, ist es in Bezug auf die Migrationsgesellschaft der ,Islam' und Muslim_innen. Diese stellen das am häufigsten genannte, konstruierte Andere dar. Meine Analyse der Vorstellungen hat ergeben, dass die natio-ethnokulturelle Differenz insbesondere über die drei Felder Säkularität und Religiosität, Geschlechterrollen und Freiheit konstruiert wird (3.3.2). Gleichzeitig ist ein Toleranzdiskurs in den Lernendenvorstellungen sehr verbreitet. Er ist rein quantitativ die verbreitetste Form über Muslim_innen zu sprechen, in dem das Ausleben einer Religion als Teil der individuellen Freiheitsrechte angesehen wird. In der Diskussion des Toleranzdiskurses findet häufig ein Perspektivenwechsel statt, mit dem sich in die Position von möglicherweise Abwertung oder Beschränkung erlebenden Muslim_innen hineingedacht wird. Dabei ist ein argumentatives Abwägen zu beobachten, das in ambivalenten Formationen das ,Problem' zwischen dem Recht auf kulturelle Selbstbestimmung und dem ,Problem` der - schwer zu überwindenden und gesellschaftlich Problem verursachenden - ,kulturellen' Differenz in Bezug auf den ,Islam' diskutiert. Der Toleranzdiskurs verlässt dabei aber nicht die orientalisierende Sprechposition des Okzidentalismus. Im Zuge der Behauptung von Toleranz wird der ,Islam‘ und die Muslim_innen weiterhin geothert. Der Toleranzdiskurs reproduziert also die orientalistische Reproduktion der ,Wir'- und ,Nicht-Wir'-Gruppe und birgt das Potenzial der Aufhebung der durch die orientalistisch konstruierte Überlegenheit der Mehrheitsgesellschaft gewährten Toleranz. Der Toleranzdiskurs kann ein Anknüpfungspunkt für dekoloniale Bildungsprozesse, keinesfalls jedoch ihren normativen Fluchtpunkt oder diskursiven Rahmen darstellen.

Die Schüler_innen diskutieren anhand der drei genannten Felder eine Dichotomie, in der ein national verorteter Okzidentalismus mit Säkularität, Geschlechtergleichheit und Freiheit assoziiert und der imaginierten muslimischen ,Kultur ${ }^{6}$ Religiosität, Geschlechterungleichheit und Unfreiheit zugeschrieben wird. Dabei finden sich auch an diese Dichotomie anknüpfende Gegenüberstellungen von Vernunft, Aufklärung, Gerechtigkeit, Menschenrechte, Selbstbestimmung und Autonomie auf der einen und Begrenztheit des Denkens, Kulturbezogenheit, Zwang und Fremdbestimmung auf der anderen, der orientalistisch konstruierten Seite (3.3.2). Ich spreche hier von der muslimischen ,Kultur', weil nicht eindeutig ist, über wen die Schüler_innen hier sprechen. Es findet keine - wenn, dann 
nur angedeutete - Gleichsetzung mit dem politischen Islamismus statt. Oft geht es offensichtlich auch nicht um ihre Religion praktizierende Muslim_innen. Das, was vielen Schüler_innen hier als homogene Gruppe der Muslim_innen erscheint, ist eine schwer zu erfassende Gruppe, die sich in vielfältiger Hinsicht als sehr heterogen darstellt.

Der Begriff muslimische ,Kultur' scheint mir hier deswegen angebracht zu sein, weil er auf die orientalistische Kulturkreistheorie verweist, in der Menschen im Zuge eines Othering-Prozesses als Muslim_innen kategorisiert werden, unabhängig davon, ob sie ,ihr Leben nach den Grundsätzen des Islams ausrichten und sich selbst primär als Muslim_innen bezeichnen“ oder aber sich „selbst gar nicht, anders, mehrfach oder ambivalent im Zusammenhang mit dem Islam positionieren“ (Attia 2013). Beispielsweise fluktuieren die Begriffe Muslim_innen, Araber_innen, Islamist_innen und andere im antimuslimischen Rassismus oft ununterscheidbar. Dabei wird die Differenz zwar in der Rhetorik der Religion, aber dennoch keinesfalls ausschließlich religiös begründet. „Antimuslimische Diskurse verweben Kategorien wie ,Kultur', ,Religion', ,Ethnizität', ,Geschlecht" und ,Klasse“ zu einem komplexen Geflecht" (Shooman 2014: 14). Diese Zusammenhänge hat Yasemin Shooman im Rahmen ihrer Diskursanalytische zum antimuslimischen Rassismus anhand von zahlreichen Diskursen, wie etwa zu Thilo Sarrazin, herausgearbeitet. Antimuslimischer Rassismus als analytische Kategorie grenzt sich von Islamfeindlichkeit, Islamophobie und Antiislamismus ab (Karakaşoğlu/Wojciechowicz 2017: 507). In der Analyse des antimuslimischen Rassismus geht es nicht ausschließlich um die Diskriminierung von Muslim_innen, sondern um eine Analyse des antimuslimischen Rassismus als gesellschaftliche Strukturkategorie: „Erst in der Wechselwirkung mit Geschlecht, Sexualität, Klasse, Rasse, Kultur, Körper, Religion entfaltet der antimuslimische Rassismus als ein Strukturmerkmal dieser Gesellschaft seine Effekte." (Attia 2013) Während die „Feindlichkeit gegenüber Schwarzen Menschen Whiteness konstruiert und die Ablehnung von Menschen jüdischer Herkunft Ariertum, so produziert der anti-muslimische Rassismus Okzidentalität" (Dietze 2009: 24).

Die Konstruktion des ,Anderen ' der , westlichen Kultur' bringt so die ,Identität‘ des ,Westens“ hervor (Attia 2009). „Okzidentalismuskritik versteht sich in diesem Zusammenhang als systematische Aufmerksamkeit gegenüber identitätsstiftender Neo-Rassismen, die sich über eine Rhetorik der ,Emanzipation" und Aufklärung definieren." (Dietze 2009: 24) In diesem Zusammenhang wurde auch der Begriff des postliberalen Rassismus geprägt. Dieser baut auf dem Begriff des differenziellen Rassismus auf, mit dem analytisch an die Stelle der grundlegenden Differenz von biologisch begründeten ,Rassen` die irreduzible Differenz und 
Unvereinbarkeit von ,Kulturen' trat. Mit dem Begriff des postliberalen Rassismus wird eine Form des Rassismus beschrieben, in der "egalitäre Ideologeme“ (Pieper/Panagiotidis/Tsianos 2011: 195) zum Feld der rassistischen Differenzmarkierung erklärt werden. Diese Differenzkonstruktion erscheint in der Rhetorik von Gleichstellungspolitiken. Durch die Instrumentalisierung einer spezifischen Form des Feminismus, eines Homo-Nationalismus, einer Kritik des Antisemitismus, einer Verteidigung der Demokratie, „neolaizistischer Anti-Religiosität“ (ebd.) oder einfach die Herstellung von Sicherheit wird ein dichotomes Bild des Anderen und des Eigenen geschaffen. (ebd.; Tsianos 2014: 60; El-Tayeb 2013: 307). In den Lernendenvorstellungen wird an einigen wenigen Stellen sogar das egalitäre Ideologem des nicht-nationalistisch oder ,fremdenfeindlich“ (3.4.3) Seins als rassialisierendes Differenzmerkmal angebracht. ,Wir' seien nicht homophob, wären gendergerecht, demokratisch etc. Im Zuge dieser Diskurse sind selbst antifeministische Konservative auf einmal zu Vorreitern des Feminismus mutiert.

Momente dieses postliberalen Rassismus sind in den Lernendenvorstellungen sehr verbreitet, in Bezug auf die Konstruktion des orientalisierten Anderen sind sie als dominant zu bezeichnen (3.2.2). Allerdings argumentieren viele Schüler_innen sehr viel ambivalenter als die Diskurse, die den hier skizzierten Analysen des antimuslimischen - und postliberalen - Rassismus zugrunde liegen. Selbst Jannik, (Gym01), der die orientalistische Differenz sehr strikt einführt, formuliert Zweifel an seiner eigenen Theorie. Ausgehend von seinen Ideen, dass es in der ,deutschen “ oder ,westlichen“ "Kultur “ - im Gegensatz zur „östlichen Welt“ oder den ,islamischen Ländern“ einen „Trieb zum Freiheitsdenken“ gäbe. Dies führt er an Beispielen der individuellen Freiheit, der FKK-Kultur und der Demokratie aus. Nichtsdestotrotz stellt er die von ihm selbst eingeführte Dichotomie infrage, indem er die Kategorien der ,westlichen Welt und der ,östlichen Welt“ zwar nicht prinzipiell aufgibt, sie ihm jedoch unbestimmtes Unbehagen bereiten. An mehreren Stellen geben Schülerinnen zu bedenken, dass die Gleichstellung der Geschlechter auch im ,Westen' keine Realität sei. Dies sind didaktische Ansatzpunkte, von denen aus das orientalistische Paradigma irritiert werden kann.

In den Lernendenvorstellungen nimmt die Frage des Kopftuchs, wie auch in den öffentlichen Diskursen, eine große Rolle ein. Auf dem Körper der Muslima wird so ein Streit ausgetragen, er wird zum Symbol des Anderen, das die eigene ,Wir'-Gruppe gerade nicht ist. Gleichzeitig gibt es zahlreiche Schüler_innen vor allem Schülerinnen - die sich in die Position von Muslima hineindenken und es als massive Einschränkung ihrer persönlichen Freiheit beschreiben, wenn sie kein Kopftuch tragen dürfen. Lara (Gym18) kritisiert eine Art Blickregime, mit dem Muslima abgewertet würden und so in ihrer Freiheit eingeschränkt werden. Darüber hinaus kritisiert sie die Verknüpfung von der Assoziation 
von Muslim_innen mit Terrorismus, da es genauso Christen gäbe, die „Dinge falsch machen“. Von solchen Argumentationsfiguren aus können gesellschaftliche Praktiken der Zuschreibung und Homogenisierung problematisiert werden. Insgesamt vier Schüler_innen bringen die Lebenswirklichkeit von als Muslim_innen gelesenen Menschen mit - als solchem explizit bezeichneten - Rassismus in Verbindung. Memnun (HS08) schildert einen Vorfall in seiner Klasse (3.2.2). Als eine Mitschülerin nach den Sommerferien wieder zur Schule kam, trug sie ein Kopftuch, woraufhin die Lehrerin sie ,angemacht“ habe: „Warum trägst du ein Kopftuch? Haben Deine Eltern dich gezwungen? Du brauchst das nicht zu machen?" Er stellt dieses Verhalten in den gesellschaftlichen Kontext, in dem „viele denken“, ,,also andere Menschen, also Deutsche und so“, dass die „Ausländer immer [von unseren Eltern] gezwungen“" würden, ein Kopftuch zu tragen. Die Mitschülerin habe hingegen erklärt, dass sie es „freiwillig“ mache. Dies sei der Lehrerin aber egal gewesen. Memnun hält das Verhalten der Lehrerin für „rassistisch“. Durch das Überhören der Perspektive der Mitschülerin wurde ihre Selbstbestimmung doppelt negiert. Durch dieses Verhalten erhebt sich die Lehrerin in die Rolle der okzidentalen Retterin des orientalen Mädchens, das vor dem orientalen Patriarchat beschützt werden muss. Die ,,angenommene Unterdrückung einer Kopftuch tragenden Frau“ wird dabei zur „Folie, auf der man sich einer Wertgemeinschaft" versichert, die auf der Ablehnung ,orientalischer Sitten" basiert, oder anders ausgedrückt, einen Okzident konstruiert (Dietze 2009: 24). Memnun - dessen Wissen und intellektuelle Fähigkeiten vor dem Interview massiv durch seine Lehrerinnen abgewertet wurden (2.1.2) - analysiert hier die Artikulation von antimuslimischem Othering über die Rhetorik der Gendergleichheit. Eine dekoloniale politische Bildung kann hier anknüpfen und die Machtwirkungen des antimuslimischen Rassismus zum Thema machen, der für viele Lernende selbst ein zentrales Element ihrer Lebenswelt darstellt.

\subsection{Zum Integrationsparadigma als Verhandlungsraum von (Nicht-)Zugehörigkeit}

Das Sprechen um die Frage nationaler Zugehörigkeitskonstruktionen wurde in den Lernendenvorstellungen oft in Bezug auf ,Integration' thematisiert (3.3.4). Mit ,Integration' wurde anhand der Frage des Zugehörigwerdens die Frage der Differenzmarker des Zugehörigseins mitthematisiert. Dabei konnte ich die drei Felder Sprache, Arbeit und Kultur ausmachen, in denen Bedingungen für ,Integration" verhandelt wurden. Während über die Hälfte der Schüler_innen die Diskussion der (Nicht-)Zugehörigkeit mit Sprache verbindet, wurde Arbeit nur von etwa einem Fünftel thematisiert. Während ,Kultur' oder die vermeintliche 
Unterschiedlichkeit von Wertesystemen zwar häufig als Differenzmarker fungiert, wird es in den Vorstellungen über den Prozess und die Bedingungen des Zugehörigwerdens nur selten thematisiert. Quer dazu liegt meine Analyse der Vorstellungen über ,Integration', die diese Vorstellungen in ein Spektrum einordnet, das sich von einer vereindeutigenden Differenzkonstruktion, der damit zusammenhängenden Homogenisierung der Dominanzgesellschaft und der Vereinseitigung des Anpassungsimperativs an die Migrationsanderen über ambivalente Haltung hin zu einer Perspektive der Migrationsanderen und der Machtwirkungen des Integrationsparadigmas erstreckt.

Für Michael (HS18; 3.3.4) sind die Vorstellungen von ,Integration “ mit einer klaren Unterscheidung in ,Wir' und die ,Anderen' verbunden und bestehen im Imperativ der Dominanzgesellschaft an Migrationsandere sich anzupassen. Wobei das Ziel nicht ist, die Differenz durch Assimilation zu überwinden. Vielmehr bestimmt der Imperativ die Bedingungen, die die Anwesenheit der Migrationsanderen rechtfertigt. Aus einer dominanzgesellschaftlichen Perspektive wägt er die Kosten für die Gesellschaft und den Sozialstaat ab, ,wir die hier behalten“. Dies impliziert die Legitimierung einer Verfügungsgewalt der einen über die andere Gruppe. Die beiden von ihm genannten Bedingungen für die Anwesenheit in Deutschland sind Sprache und Arbeit. Sie sollten eine Arbeit haben und Deutsch sprechen. Insbesondere im öffentlichen Raum erscheinen.

Michael findet, dass „die ja eigentlich auch Deutsch reden“ könnten. Sein „Können“ scheint eher ein Sollen zu meinen. Er formuliert mit dieser Vorstellung die Hoffnung auf einen Imperativ des Deutsch Redens im öffentlichen Raum. Er schränkt dies für diejenigen ein, die noch nicht so lange hier seien und deswegen noch nicht genug Zeit gehabt hätten, genügend Deutsch zu lernen. Diese Befürwortung eines Imperativs des Deutsch Redens im öffentlichen Raum untermauert er mit einem Beispiel. So redeten viele in seiner Stadt Türkisch. Wenn dann Türkisch gesprochen werde, könne man ja nie wissen, ob man gerade beleidigt werden würde.

Auf Nachfrage stellt er eine Situation vor, in der er möglicherweise auf Türkisch beleidigt worden sei, er und sein „Kumpel“ aber nur auf Deutsch hätten reden können, also keine Möglichkeit gehabt hätten, miteinander zu reden, ohne von den anderen verstanden zu werden. Implizit erkennt Michael hier die Kompetenz der Mehrsprachigkeit an. Damit ist er vielen Diskursen in und um Schulen weit voraus. Er nimmt dabei aber die Kompetenz der Mehrsprachigkeit als Bedrohung wahr. In den in seiner Vorstellung ethnisch strukturierten Konflikten wünscht er sich eine Art kommunikative Chancengleichheit, die dadurch erreicht werden könnte, dass alle im öffentlichen Raum Deutsch sprechen müssten. 
Melina (Gym08; 3.3.4) ist weniger offen exkludierend, formuliert aber fünf Aspekte, die für sie zentral für ,Integration' und gleichzeitig für die natio-ethnokulturelle Zugehörigkeit seien: „Akzentfreies Deutsch“, ,höfliche“ Umgangsformen, eine ,wohlbehütete“, monogame Familie mit einer angemessenen Anzahl an Kindern, ein ,gutes“ Bildungsniveau und ein ,geregeltes Leben“. Hier konstruiert sie eine Art Blaupause dafür, wie zugehörige Subjekte in einer nationalen Ordnung, von der sie sich als Teil begreift, strukturiert sein sollten. Sie konstruiert hier also eine natio-ethno-kulturelle Norm. Die Akzentfreiheit von Sprache verweist hier auf eine nationale Sprachgemeinschaft, dessen Gemeinschaftlichkeit weit über die Kommunikationsfähigkeit hinausgeht und dabei offensichtlich Menschen, die Deutsch nicht als Erstsprache gelernt haben, aus diesem nationalen Kollektiv ausschließt. Die Umgangsformen verweisen auf eine kulturalisierte Differenz, die entweder auf unterschiedliche, kulturelle ' Mentalitäten verweist. Gleiches gilt für die Familienstruktur, mit der hier implizit das Bild der migrantischen Großfamilie und die imaginierte muslimische Polygamie als Differenzmarker angesprochen werden. Das Familienbild scheint auf eine heteronormative Kernfamilie zu referieren. Bemerkenswert ist das Bildungsniveau, mit dem sie zu der Genderdimension noch den Aspekt der sozialen Klassierung in ihre Blaupause einschreibt. Diese Aspekte fungieren dabei zugleich ex negativo als Zuschreibungen für Migrationsandere. Sie problematisiert dabei selber ihr Bild und führt an, dass dies natürlich nicht immer so und ein ,typisches Bild“ sei, doch diese Differenzmarker sind wenn auch nicht offensiv vorgetragen, so doch präsent in ihren Vorstellungen von ,Integration“ und Zugehörigkeit.

So gibt es auch eine große Gruppe an Schüler_innen, deren Integrationsverständnis ich als entspannten Anpassungsdruck charakterisieren würde. Der Ausdruck entspannter Anpassungsdruck soll durch die Spannung zwischen den Begriffsteilen ,entspannt " und ,Druck' deutlich machen, dass zum einen keine repressiven oder explizit ausschließende Maßnahmen befürwortet oder erwähnt werden, sondern Offenheit und Vielfalt befürwortet werden, aber zum anderen gleichzeitig ein Normalisierungsregime und ein Erwartungshorizont konstruiert wird, der von vielen nicht als entspannt, sondern eben als Druck empfunden wird. In diesem Rahmen werden zwar einseitige Anpassungsleistungen von Seiten der Migrationsanderen erwartet, es wird aber immer betont, dass man - wie etwa Clara (Gym11) - ,man sich hier einleben“ sollte, aber ,immer noch man selbst bleiben“ könne. Zentral für den Prozess der Anpassung ist für sie die Sprache, die man ,einigermaßen [...] beherrschen“ sollte. Diese Haltung als entspannt zu bezeichnen, soll nicht die Verwobenheit zu den machtvollen und gewaltvollen Wirkungen des Integrationsparadigmas dethematisieren. Dieser Ausdruck macht 
nur Sinn in Relation zum repressiven Duktus der ,Integration“ in der Öffentlichkeit. Dabei bleiben die prinzipiellen Problematiken des Integrationsparadigmas bestehen. So führt sie zum Beispiel aus, dass ,Integration ' für sie bedeuten würde, dass „,du [...] immer noch normal reden“ kannst. Die normalisierende, exkludierende Sprachgemeinschaft stellt hier ihre Denkvoraussetzung dar, mit der sie das Gegenüber - „du“ - anspricht und unterscheiden kann, wer „normal“ redet und dazu gehört - und wer eben nicht.

Dabei müssen auch die damit verbundenen Regierungstechniken in den Blick genommen werden, die in den letzten Jahren, beispielsweise durch das 2005 ratifizierte Zuwanderungsgesetz insbesondere Sprache und Arbeit als wesentliche Felder der juristisch-staatlichen Bestimmung des Bleibe- und Aufenthaltsrechts etabliert haben. Diese migrationspolitische Ebene kann durch Bildung - möglicherweise mit Bezug zu den Kämpfen um Teilhabe - ein didaktischer Ausgangspunkt sein.

Um ein Misstrauen oder eine kritische Reflexion von ,Integration“ in Bildungsräumen zu ermöglichen, kann an zahlreiche Lernendenvorstellungen angeknüpft werden. Schwierig zu fassen und didaktisch umzusetzen scheint mir aber die vorherrschende Strategie von als Migrationsanderen gelesenen Schüler_innen zu sein, die Logik und Begriffe der ,Integration', möglichst auszusparen (3.3.4). Dabei ist es natürlich ein aussichtsreiche Strategie, das durch die Logik von ,Integration" strukturierte Feld, erst gar nicht zu betreten, zumindest wenn es vermeidbar ist. Diese Strategie muss auch didaktisch ernst genommen werden und kann darin münden, Unterrichtsinhalte dementsprechend zu gestalten, dass migrationsgesellschaftliche Fragen ohne den Frame des Integrationsparadigmas behandelt werden. Gleichzeitig ist das Integrationsparadigma gesellschaftlich und in den Lernendenvorstellungen derart wirkungsmächtig, dass die Erfolgsaussichten dieses Ansatzes begrenzt sind.

Es gibt aber weitere kritische Umgangsweisen mit diesem Thema. Ein didaktischer Ansatz könnte darin bestehen, Perspektiven von als zu ,integrierenden“ Gelesenen sichtbar zu machen und mit in den Unterricht einzubeziehen. So könnten die machtvollen Wirkweisen des Integrationsparadigmas sichtbar gemacht werden. Beispielsweise Özgür (Gym15) schildert eine Strategie, wie Migrationsandere mit dem durch ,Integration' bestimmten Feld umgingen. Die von ihm geschilderte Strategie zielt darauf ab, möglichst nicht aufzufallen. Auffallen tut man scheinbar aus seiner Perspektive in dem Moment, wo man als Migrationsanderer gesehen wird. Nach Özgür müsse man sich anstrengen, sich zu integrieren, „um zu lernen, wie man sich verhalten soll möglichst, um eben nicht so [...] aufzufallen“. Es geht hier also nicht um den Prozess des Zugehörigwerdens, sondern vielmehr darum, weniger - nicht in diesem Maße - als nicht-zugehörig gesehen zu 
werden. Das Ziel der Erlangung nicht-prekärer Zugehörigkeit scheint für ihn nicht in Sicht - eine mission impossible - zu sein. Hier wird deutlich, wie gewaltvoll diese Prozesse des Otherings und das damit verbundene Integrationsparadigma offenbar ist. Für Bildungsprozesse erscheint eine solche Sichtbarmachung von Widerstands- und Überlebensstrategien von Migrationsanderen aber auch als problematisch. Eine solche Sichtbarmachung birgt die Gefahr, Schutzräume von Migrationsanderen zu nehmen und damit Verletzlichkeit zu erhöhen. Für einen geschützten auf Empowerment zielenden Bildungsraum kann dies hingegen Teil eines Austausches über Rassismuserfahrungen und Widerstandsstrategien sein und in diesem Sinne stärkend wirken.

Bilal (HS15) eröffnet die Perspektive einer Verschiebung des Sprechens über Integration, in dem er Integration nicht als Erbringungsleistung der Migrant_innen für die möglicherweise gestattete Zugehörigkeit oder im Sinne einer Funktionalität für die Dominanzgesellschaft fasst, sondern als den schwierigen Prozess der Erlangung der Fähigkeiten, in der neuen Gesellschaft ein gutes und selbstständiges Leben führen zu können. Er hält es dabei nicht für nötig, dass sich Zugezogene „komplett integrieren“ würden. Mit komplett integrieren meint er scheinbar, dass die eigene Lebensart sich an die Dominanzgesellschaft anpassen würde. Als Beispiel führt er an, dass man auch „Alkohol und so trinken“ würde. Dies weist implizit die unterstellte Überlegenheit der Dominanzgesellschaft zurück, da aus seiner Sicht Alkohol trinken nichts Erstrebenswertes darstellt - oder zumindest nichts, was eine Überlegenheit rechtfertigen würde. Eine solche Perspektive, die Perspektiven weg von der normsetzenden dominanzgesellschaftlichen Perspektive verschieben und über satirische Spiegelungen die Substanz des Integrationszwangs infrage stellen, können ein Anknüpfungspunkt darstellen, um den Prozess der hierarchisierten Differenzierung der Zugehörigkeiten, der sich im Zuge des hegemonialen Sprechens über ,Integration“ vollzieht, deutlich zu machen. Eine ähnliche Umkehrung der Perspektive findet sich bei Niklas (HS17), der zunächst eine klare Unterscheidung von der Wir- und der Nicht-Wir-Gruppe einführt, die er an einseitige Anpassungsleistungen von Migrationsanderen knüpft. Doch im Interviewverlauf dreht er diesen Imperativ um und formuliert als zentrale Bedingung von Integration, dass - in seinem Beispiel - die aufnehmende Schulklasse sich wie gegenüber einem Gast verhält, nicht ausschließend agiert und ihn ,in die Gruppe aufnimmt“. Dabei läuft das Bild des Gastes natürlich Gefahr, ähnlich wie in der Zeit der ,Gastarbeiter_innen', die diskursive Hoheit bei der Dominanzgesellschaft zu belassen, die letztlich auch das Recht behält, den Gastaufenthalt beenden zu können.

Sabine Achour beschäftigt sich als eine von wenigen im Feld der politischen Bildung mit ,Integration“ und Muslim_innen (Achour 2013). Dabei erscheint 
aus einer Perspektive dekolonialer politischer Bildung die - wenn auch um den Aspekt der ,politischen Integration“ (Achour 2013: 11) erweiterte - Übernahme der prinzipiellen Rahmenbedingungen des Integrationsparadigmas als problematisch. Mit ihrem Integrationsbegriff schließt sie an Esser an und fügt seinen vier Kategorien der kulturellen, strukturellen, sozialen und identifikativen ,Integration ${ }^{\text {* }}$ die politische hinzu (ebd.). Ein solcher Ansatz läuft Gefahr, die machtvollen Implikationen des Integrationsparadigmas zu reproduzieren bzw. zumindest anschlussfähig für eine solche Perspektive zu bleiben. Andreas Lutter problematisiert in seiner empirischen Studie die „Integration im Bürgerbewusstsein von SchülerInnen“ (Lutter 2011). Dabei arbeitet er unter anderem das problematische Verständnis von ,Integration ' heraus, die als einseitige Assimilationsleistung von Migrationsanderen verstanden wird. Aus einer dekolonialen, rassismuskritischen Perspektive müssen jedoch noch andere Aspekte mitberücksichtigt werden. In seinem Text Deutsche Integrationspolitik als koloniale Praxis geht Kien Nghi Ha einigen dieser Aspekte nach und stellt dabei folgendes fest: „Obwohl die rassistischen Ambivalenzen und Widersprüche der sich liberal und tolerant gebenden Integration(an)gebote offenkundig sind, werden sie selten diskutiert.“ (Ha 2007a: 117) Vor diesem Hintergrund werde ich im Folgenden kurz dekoloniale und rassismuskritische Problematisierungen von ,Integration“ skizzieren.

Serhat Karakayalı beschreibt ,Integration' ausgehend von seiner Analyse des Nationalen Integrationsplans als „catch-all-phrase“ (Karakayalı 2007), der Fördermaßnahmen von Migrant_innen umfasst und sich als Neuformulierung einer konservativen, nationalistischen ,Leitkultur' präsentiert. Manuela Bojadžijev stellt gegenwärtige Integrationspolitiken in den Kontext der Geschichte der Kämpfe der Migration. In den späten 1950er Jahren im Rahmen der Anwerbungspolitik der sogenannten ,Gastarbeiter' wurde von einer begrenzten Aufenthaltsdauer ausgegangen und für diese Politik war dementsprechend „die Vorstellung der ,Nichtintegration““ (Tsianos 2014: 61) konstitutiv. Spätestens im Zuge der Politik des Anwerbestopps 1973 wurde klar, dass ein großer Teil der Migrant_innen bleiben würde. Längst schon hatten sich Migrant_innen in zahlreichen Feldern sozialen Bewegungen angeschlossen oder diese initiiert, die für eine ,Integration', also gesellschaftliche Teilhabe und Ende der exkludierenden Strukturen, eintraten. „Integration bezeichnete im Kontext der ausländerpolitischen Maßnahmen der 1970er Jahre eine Rekuperation der Widerstandspraktiken und Kämpfe der MigrantInnen.“ (Bojadžijev 2006) Im Rahmen dieser Rekuperation tauchen die Forderungen der Migrant_innen in staatlichen Politiken wieder auf - nur unter veränderten Vorzeichen: 
„Benannten MigrantInnen in ihren Kämpfen die Ausschlussmechanismen ihrer Kinder aus dem nationalen Schulsystem, so taucht dies als Maßnahme zur Prävention möglicher zukünftiger ,Konfliktherde“ im Integrationsforderungskatalog wieder auf. Diesmal aber umgekehrt zur Artikulation in den Kämpfen der Migration: Es geht nicht mehr um ein Recht auf Bildung, sondern um die Pflicht der so genannten zweiten Generation, sich sprachlich, kulturell und ,staatsbürgerlich ' für ein unbefristetes Aufenthaltsrecht zu qualifizieren. Kämpften MigrantInnen in den Mietstreiks um angemessene Wohnverhältnisse, taucht dies in der administrativen Verordnung, ein Wohnraum von mindestens 12 qm pro Person müsse zur Gewährung einer Aufenthaltserlaubnis gewährleistet werden, repressiv und restriktiv wieder auf. Forderten MigrantInnen eine soziale Infrastruktur zur Artikulation und Repräsentation ihrer ,Bedürfnisse', schlägt sich dies in den 1970er Jahren in der institutionalisierten Form der ,Ausländerpädagogik ' nieder, die ,Ausländer' als neues Klientel funktionalisiert.“ (ebd.)

Die Forderung nach gleichen Rechten wird dabei im „Dispositiv der Integration“ (ebd.) absorbiert. Die Forderung nach Kollektivrechten wurde in individuell zu erbringende Leistungen übersetzt und die Bevölkerung auf ,dubiose Weise neu homogenisiert" (ebd.).

,Integration“ erscheint im hegemonialen Diskurs als unhintergehbares Deutungsmuster von Wirklichkeit. Im Anschluss an Paul Mecheril (2011) kann ,Integration“ als ein Dispositiv verstanden werden, das Wirklichkeit schafft. Unter diesem Dispositiv versteht Mecheril „Bündel von Vorkehrungen, Maßnahmen und Interpretationsformen, mit dem es in öffentlichen Debatten gelingt, die Unterscheidung zwischen natio-ethno-kulturellem, Wir ${ }^{\text {‘ }}$ und ,Nicht-Wir " plausibel, akzeptabel, selbstverständlich und legitim zu machen“ (2011). Max Czollek betont in seinem Buch Desintegriert euch!, dass ,,jedes Integrationsdenken“ ein Zentrum imaginiert, ,das schon lange nicht mehr der gesellschaftlichen Realität entspricht, in der ich oder meine Freund*innen leben“ (Czollek 2018: 16). Diese Realitätsferne zeige sich ,,besonders deutlich im beständig wiederkehrenden Gewese um die deutsche Leitkultur“ (ebd.). Aus einer jüdischen Perspektiven problematisiert er nicht nur die Ausgrenzung von Muslim_innen, sondern ebenso die Vereinnahmung des Jüdischen für die Konstruktion dieser nationalen Leitkultur (Czollek 2018). Wenn die Annahmen des Integrationsparadigmas an der migrationsgesellschaftlichen Lebensrealität der meisten Menschen vorbei gehen, stellt sich die Frage, der Sinnhaftigkeit.

Doch ,Integration“ zielt nicht auf die Suche nach einer Möglichkeit, gleichberechtigt und demokratisch das gemeinsame Leben zu organisieren, sondern stellt vielmehr eine Form dar, das natio-ethno-kulturelle Zugehörigkeitsregime zu reorganisieren und damit zu perpetuieren. Dabei entfaltet das Integrationsdispositiv in 
seiner Negation seine „,normative Kraft“ (Mecheril 2011). Es basiert auf „Negativnarrativen über die, verweigerte', ,misslungene', die , verpasste' oder gar die ,unmögliche“ Integration“ (ebd.). Im Integrationsparadigma werden so in erster Linie Menschen zu nationalen Anderen gemacht. Auch von Menschen, die seit Generationen in Deutschland wohnen und die weiterhin als ,Menschen mit Migrationshintergrund" geandert werden, werden Integrationsleistungen verlangt, - positiv oder negativ - bewertet und damit die Möglichkeit der Aberkennung der Zugehörigkeit permanent offengehalten. María do Mar Castro Varela analysiert ,Integration“ als eine Form der Gouvernementalität, die als - staatliche und nicht-staatliche - Regierungstechnik verstanden werden kann, mit der ein Normalisierungs- und Disziplinierungsregime etabliert wird, das in soziale Prozesse und Subjektivierungsweisen hineinwirkt (2013: 33).

Mit diesem Punkt haben sich auch Markus Schmitz und Kien Nghi Ha beschäftigt. In ihrem Text Der nationalpädagogische Impetus der deutschen Integrations(dis)kurse im Spiegel postkolonialer Kritik (2006) analysieren sie das Programm und die Praxen der Integrationskurse als Überwachungs- und Disziplinierungstechnik. Diese stellen sie in eine Tradition sowohl des deutschen Nationalismus mit seinem Volksbegriff und der nationalistischen Pädagogik als auch des Kolonialismus, in dem kulturelle Hierarchisierungen den Ausgangspunkt der zivilisatorischen Mission darstellten. ${ }^{10}$ Die Integrationskurse erscheinen als eine Art Eignungsprüfung für die nationale Nutzbarkeit, das mit einem System von Sanktionierungen durchgesetzt wird (Ha/Schmitz 2006). Auch Naika Foroutan stellt die gegenwärtige „Kopplung“ der Migrationsfrage an die Diskursfigur der ,gescheiterte[n] Integration“ in den Kontext der „Nachwirkungen kolonialer Strukturen" und sieht ein Wissen über diese koloniale Kontinuität als

\footnotetext{
${ }^{10}$ Ich habe in meiner Skizze (mindestens) zwei konkurrierende Theoriestränge der Rassismuskritik einfach zusammengeführt bzw. nebeneinander gestellt. Die dahinter liegende Überlegung will ich kurz transparent machen. Beispielsweise Pieper, Panagiotidis und Tsianos (2011: 198) formulierten eine Kritik an Kien Nghi Ha, dem sie vorwarfen durch die Herausarbeitung der Kontinuitäten kolonialer Logiken das Theorem eines quasi überhistorischen Rassismus vorauszusetzen, indem Kämpfe und Verschiebungen ausgeblendet würden. Damit eröffnen sie aus meiner Sicht einen problematischen Widerspruch. Ich finde ihr Ziel überzeugend, ausgehend von einer materialistischen Analyse von Herrschaft die Kämpfe und die von ihr eingeleiteten Verschiebungen bzw. Konjunkturen des Rassismus zu analysieren. Dabei suggerieren die Kritiker_innen aber, dass solche Kämpfe vor 1949 nicht stattgefunden hätten und blenden damit mindestens ein Jahrhundert der Kämpfe der Migration in Deutschland aus. In der rekuperativen Transformation von Herrschaft ist dabei ein Zurückgreifen auf koloniale Techniken durchaus plausibel und erscheinen als wichtige Bestandteile einer rassismuskritischen Analyse.
} 
zentral an, um ,strukturelle, politische und rechtliche Ungleichheiten sowie symbolische Ausschlüsse“ (Foroutan 2019: 53) angemessen kontextualisieren und verstehen zu können. Im Sammelband No integration?! wird aus verschiedenen kulturwissenschaftlichen Perspektiven gezeigt, wie die Hegemonie von ,Integration“ nicht nur als eine ,konjunkturelle Schwankung“, sondern vielmehr als ein „Paradigmenwechsel“ (Hess/Moser 2009: 13) zu verstehen ist.

Die Initiative Integration? Nein Danke!, die sich im Zuge der Auseinandersetzungen um die Veröffentlichung der rassistischen Thesen von Sarrazin gegründet hat und in den Diskurs intervenieren wollte, fasst ihre Kritik am Integrationsparadigma folgendermaßen:

"Ein Wort, das ein Angebot vortäuscht und Rassismus verschleiert. Der Begriff Integration hört sich harmlos gar positiv an, aber dahinter verbirgt sich eine systematische Politik der Ausgrenzung. Unter Androhung von Repressalien sollen sich die integrieren, die eh schon zu den Entrechteten gehören." (aus dem Kampagnenflyer von Integration? Nein Danke!)

Explizit thematisieren sie hier die Problematik, dass der Begriff ,Integration“ zunächst kaum problematisierbar erscheint. Dafür bedarf es angesichts der Unschärfe des Integrationsbegriffes Konzepte, die sprachliche Instrumente zur Verfügung stellen, mit denen die integrationsparadigmatischen Machtwirkungen in der Gesellschaft, aber auch in der eigenen Lebenswelt, sichtbar und problematisierbar gemacht werden können.

Gerade aus Sicht einer politischen Bildung ist ein weiterer Aspekt relevant, den ich hier kurz anführen werde. Das Netzwerk Kritische Migrations- und Grenzregimeforschung (kritnet) hat 2010 die Stellungnahme Demokratie statt Integration veröffentlicht:

„Wir wollen das offensichtliche klar stellen. Wir leben in einer Einwanderungsgesellschaft. Das bedeutet: Wenn wir über Verhältnisse und das Zusammenleben in dieser Gesellschaft sprechen wollen, dann müssen wir aufhören, von Integration zu reden. Integration heiß0t, dass man Menschen, die in diesem Land arbeiten, Kinder bekommen, alt werden und sterben, einen Verhaltenskodex aufnötigt, bevor sie gleichberechtigt dazugehören. Aber Demokratie ist kein Golfclub. Demokratie heißt, dass alle Menschen das Recht haben, für sich und gemeinsam zu befinden, wie sie miteinander leben wollen. Die Rede von der Integration ist die Feindin der Demokratie.“ (Kritnet 2010, zitiert nach Castro Varela 2013: 46 f) 
Eine dekoloniale politische Bildung hätte die Aufgabe, auch solche Perspektiven in Bildungsräumen sichtbar zu machen. Dabei kann sie an die zahlreichen Vorstellungen der Schüler_innen anknüpfen, in denen sie auf die eine oder andere Weise ihr Unwohlsein mit dem Integrationsparadigma gezeigt haben, es aber selten artikulieren konnten. Um das Integrationsparadigma zu denaturalisieren, seine Grundannahmen und die von ihr geschaffene Wirklichkeit als eine unter mehreren möglichen erscheinen zu lassen, braucht es alternative Sichtweisen im Unterricht. Ohne die Möglichkeit, mehrere Perspektiven miteinzubeziehen, kann politische Bildung ihrem Ziel, Lernende zu befähigen, sich als mündige Subjekte in der Gesellschaft zu bewegen, über sie zu reflektieren und in ihr reflektierte Handlungsfähigkeit zu entwickeln, nicht näher kommen. Aus einer dekolonialen Perspektive erscheint es unerlässlich, die Machtwirkungen des Integrationsparadigmas und die damit verbundene Konstruktion einer Eigengruppe sowie einer Fremdgruppe und damit das natio-ethno-kulturelle Zugehörigkeitsregime zu unterlaufen und zu kritisieren.

\subsection{Prekarisierungen postmigrantischer Zugehörigkeiten}

Das Integrationsparadigma kann auch als eine Reaktion darauf verstanden werden, dass das „Phantasma des natio-ethno-kulturellen ,Wir“ in eine Krise geraten ist" (Mecheril 2011). Mit den Vorstellungen über und den Umgangsweisen mit der Transformation dieses natio-ethno-kulturellen Wirs setze ich mich in diesem Abschnitt auseinander. Aus den Lernendenvorstellungen habe ich vier verschiedene Typen des Umgangs mit Prozessen der Veruneindeutigung und der Vorstellung ,kultureller 'Vielfalt in der postmigrantischen Gesellschaft herausgearbeitet. Diese sind im Abschnitt zu Hybridität zusammengefasst (3.3.5). Hybridität ist ein komplexer, oft widersprüchlich verwendeter Begriff und nicht zuletzt angesichts seiner langen Geschichte als Kategorie kolonialer Rassendiskurse höchst problematisch (Ha 2010b). Nicht trotz, sondern aufgrund dieser problematischen Geschichte erscheint er als geeignet, um die gegenwärtigen Prozesse zu beschreiben. Unter Hybridität werden in der Analyse die Vorstellungen von, Vermischung ‘ und vice versa auch ,Reinheit ' ,kultureller' ,Identitäten“ gefasst. Bei einer kleinen Gruppe der interviewten Schüler_innen löst die Vorstellung der Auflösung klarer ,identitärer' Grenzen, insbesondere in Bezug auf die erhöhte Präsenz von Migrationsanderen im öffentlichen Leben, Irritationen oder Ängste aus. Dabei kann eine Mehrheit der Lernendenvorstellungen dem zweiten und dritten Typ zugeordnet werden. Der zweite Typ befürwortet die Hybridisierung von ,kulturellen Identitäten', da der Andere hier als konsumierbar oder als eine Erweiterung der insbesondere kulinarischen - Konsummöglichkeiten angesehen wird. Ähnlich wie der zweite, konsumierende Typ befürwortet der dritte migrationsgesellschaftliche 
Grenzverwischungen, da dies die Möglichkeit der Erweiterung des persönlichen Erfahrungsraums mit sich brächte. Der vierte Typ von Vorstellungen, die ich bei etwa einem Viertel der Schüler_innen vorfinden konnte, betont die Normalität einer gelebten Hybridität. Damit meine ich, dass die Überschreitung der Grenzen vermeintlich nebeneinander stehender ,kultureller ' Identitätskonstruktionen als Normalität angesehen wird. Diese Vorstellungen gehen meistens mit einem Verweis auf die eigene Lebenswelt einher, die von eigener oder familiärer Migrationserfahrung und migrationsgesellschaftlichen Mehrfachzugehörigkeiten geprägt ist.

In Bezug auf den hier zentralen Begriff der Kultur unterscheiden sich die drei ersten Typen wesentlich nur in der Frage der Einstellung, nicht jedoch dem Begriffsverständnis nach. Bei allen drei liegt ein differenzieller, tendenziell essenzialistischer Kulturbegriff zugrunde, der eine ,Kultur' an etwas koppelt, das ich hier mal übergangsweise als ,Ethnizität ' bezeichne. Nichtsdestotrotz bringt die unterschiedliche Einstellung sehr unterschiedliche Vorstellungen hervor. Für den ersten Typ, bei dem Hybridität Angst und Irritation auslöst, stehen beispielsweise Lennart (HS02) und Marcel (HS06). Lennart sieht in Deutschland und Europa ein Verschwimmen der Kulturen. Es sei nicht mehr so „einheitlich“ wie vor „vierzig, fünfzig Jahren“. Dadurch diagnostiziert er ein weniger an ,Kultur" und die Aufgabe, die nationale Bräuche sowie „unsere Werte“ „ein bisschen hoch[zu]halten“ und an die „Kinder weiterzugeben“. Andernfalls - so seine Angst - ginge diese „verloren“. „Unsere Werte“ - mit ,uns" meint er wahrscheinlich die nationale Gemeinschaft - seien „Pünktlichkeit, Sauberkeit, Ordnung und so was halt“. Auf die Frage, ob andere ,Kulturen' da ganz anders seien, führt er an, dass Menschen aus China oder Japan auch „ordentliche Menschen“ seien. In der Denkbewegung, welche ,Kultur' sich grundlegend von der deutschen unterscheiden würde, assoziiert er antiziganistisch und antisemitisch begründete Gruppen, deren Gültigkeit er jedoch wieder zurückzieht. Seine Diagnose, dass es durch weniger ,kulturelle“ Einheitlichkeit weniger an ,Kultur' gäbe, basiert auf der Vorstellung, dass der Gradmesser einer ,Kultur' in seiner Homogenität liege (vgl. dazu den Exkurs zu Herder in 4.2.4). Marcel (HS06) diskutiert das Thema der Vermischung über die Frage der Ehe zwischen Menschen unterschiedlicher ,Kulturen'. Sein Beispiel der Heirat eines „Türken oder Kurden“ mit einer , deutschen“ Frau erzeugt bei ihm keine Ablehnung, sondern Irritation. Dann sei ,ja auch alles durcheinander“.

Für den zweiten Typ, der den Anderen als begrüßenswerte Erweiterung der - insbesondere kulinarischen - Konsummöglichkeiten fasst, ist der Verweis auf unter ethnischem Lable firmierende Restaurants charakteristisch. Der dritte Typ die Erweiterung des Erfahrungsraums - bezieht sich eher auf kulturelle Praktiken, 
von denen man aufgrund des Kontakts zu ,kulturell` Anderen etwas mitbekommen würde. Alexander (Gym05) beschreibt, dass „,immer mehr Afrikaner und so“ kämen, die „eine andere Hautfarbe haben und so“. Diese als ,kulturell“ Andere konzipierte Gruppe ist nicht auf „Afrikaner“ beschränkt, aber verweist in Bezug auf die Hautfarbe auf eine phänotypisch konstruierte Differenz, mit dem ein bestimmter Grad der kulturalisierten Andersheit verbunden ist. Diese ,kulturell' Anderen brächten auch andere Dinge mit. Im Anschluss an klassische koloniale Bilder behauptet er, dass „die [...] Rhythmus im Blut“ hätten. Dies begrüßt er sehr. Davon sei zu profitieren und es könnte sich ,hier ein bisschen was erneuer[n]". Im zweiten und dritten Typ wird insgesamt eine ,kulturelle“ Differenz konstruiert, die durch Migrationsandere verkörpert wird. Von dieser Differenz kann nun individuell oder national profitiert werden. Dabei war in der Analyse oft nicht klar zu ermitteln, inwiefern hier die ,kulturelle“ Differenz als statisch gedacht wird oder inwiefern sich durch eine ,Vermischung ' im vorgestellten Prozess der multikulturellen Begegnung etwas neues, eine neue ,kulturelle Formation entwickelt. Bei Alexander ist zweiteres der Fall; der, deutschen ",Kultur' wird durch migrationsgesellschaftliche Prozesse mehr Musikalität zu eigen. Er begrüßt migrationsgesellschaftliche Vielfalt - was nicht gleichbedeutend mit Migrationsprozessen ist - und ,multikulturellen' Austausch.

Hinzu ziehen möchte ich hier noch die Analysekategorie der ,Anderen als Kultur'. In einigen Lernendenvorstellungen wird dabei das ,kulturelle ' Andere einem ,nicht-kulturellen' Eigenen gegenübergestellt (3.3.6). Durch Globalisierungsprozesse bzw. die Gleichheit der Produkte durch den globalisierten Konsum gäbe es, beispielsweise Lara zufolge, in den ,westlichen“ Ländern ,nicht wirklich viel Kultur“. In „Hannover [...,] Amerika oder in Spanien“ sähen alle gleich aus. In Deutschland gäbe es dementsprechend ,im Prinzip keine Kultur“. Als Ausnahme benennt sie Bayern, das sie mit „Lederhosen und Dirndl“ assoziiert. Damit etwas als ,Kultur' fungiert, muss es einen differenziellen Charakter haben, also als Spezifisches einer als ,kulturell' verstandenen - ethnischen, nationalen, regionalen oder ähnliches - Gruppe zuzuordnen sein. Ohne diesen differenziellen Charakter wird eine ,kulturelle' Praxis zu einer ,Nicht-Kultur'.

In den von mir analysierten Lernendenvorstellungen wurde deutlich, dass ein Kulturbegriff in den Vorstellungen des migrationsgesellschaftlichen Zusammenlebens maßgeblich ist, der größtenteils pluralistisch, offen und tolerant erscheint und gleichzeitig eine ,kulturelle' Differenz und Essenz produziert, die bestehende Zuschreibungen des ,Eigenen “ und des ,Fremden', des ,Normalen“ und des Anderen hervorbringt. Existierende Formen der Abwertung, Hierarchisierung und Verurteilung erscheinen eher marginal - und nichtsdestotrotz stellt sich 
dieses essenzialistische Verständnis von ,Kultur' aus einer dekolonialen Perspektive als problematisch dar. Diese ,kulturelle" Differenz werde ich anhand von Bhabhas Konzept der kolonialen Mimikry interpretieren. Anhand von zwei unterschiedlichen Aspekten von Mimikry werde ich zwei verschiedene Wege gehen. Zunächst werde ich diskutieren, wie diese ,subtile', ,kulturelle' Differenz eine Vision von Gleichheit untergraben kann. In einem zweiten Schritt werde ich unter Einbezug weiterer Lernendenvorstellungen zur ,Normalität ${ }^{\star}$ hybrider Verhältnisse aufzeigen, welche dekolonialen Prozesse hier aus meiner Sicht als mögliche aufscheinen.

Bhabha charakterisiert Mimikry als eine postkoloniale Form, in der ,kulturelle Differenz erscheint, als ,die besondere Form der Differenz, die die Mimikry ausmacht - fast dasselbe, aber nicht ganz“ (Bhabha 1994: 132). Hier knüpfe ich argumentativ an den letzten Abschnitt zum Integrationsparadigma an. Die in den Lernendenvorstellungen konstruierte Form der ,kulturellen ' Differenz ist ambivalent. Sie erscheint nicht - nur in Ausnahmefällen - als eine totale, unüberwindbare Differenz; die migrationsgesellschaftlich verorteten Subjekte erscheinen als „fast dasselbe“. Aber die Differenz ist nicht verschwunden - „fast dasselbe, aber nicht ganz", sie schwelt weiter in den Vorstellungen - mal offener, mal versteckter - und perpetuiert das Potenzial aus dieser Fast-Gleichheit eine exkludierende Nicht-Zugehörigkeit werden zu lassen. Mit Bhabha kann diese Form der Differenz als eine spezifische Organisierung der (Nicht-)Zugehörigkeit verstanden werden, die die Dichotomie von Inländer_innen und Ausländer_innen übersteigt. Im Rahmen der Mimikry bedeutet „Anglisiertsein ganz ausdrücklich [...], nicht Engländer zu sein“ (Bhabha 1994: 129, Herv. i. O.). Diese postmigrantische Organisation von (Nicht-)Zugehörigkeit kann als - „binäre Differenzierungen und Prozesse der Exklusion“ übersteigende - ,neuartige Prozesse einer limitierten Inklusion“ angesehen werden: „Eine neue Staatsbürgerschaft bedeutet nicht eine bedingungslose staatsbürgerliche Anerkennung für ihre Subjekte, sie kann nachträglich eingeschränkt, also auch rückgängig gemacht werden.“ (Tsianos/Karakayalı 2014) Exemplarisch steht dafür die - sehr selten genutzte und dennoch symbolisch wirkmächtige - Möglichkeit der Ausbürgerung von vormals Eingebürgerten.

Diese Form der Differenz - die fast dasselbe ist, aber nicht ganz - wird auch an der wohl derzeit gängigsten Bezeichnung für die migrationsgesellschaftlichen Anderen deutlich, den sogenannten ,Menschen mit Migrationshintergrund". Dieser Begriff trat im Kontext einer postmigrantischen Gesellschaft in den Vordergrund, in der die Kämpfe und Sichtbarkeiten von eingebürgerten Migrationsanderen die „Grenze zwischen ,Ausländern“ und ,Deutschen ' [...] aufzuweichen drohte“, und reformulierte so die „Zugehörigkeitsgrenze“ (Castro Varela 2013: 14). 
Der Begriff ,Menschen mit Migrationshintergrund 'trat an die Stelle und an die Seite von vorherigen Begriffen der migrationsgesellschaftlichen Anderen, wie ,Gastarbeiter‘, ,Ausländerinnen', ,ausländische Bevölkerung, ,Zuwanderinnen“, ,Migranten“, ,Einwanderer“ usw. (ebd.: 12). „,Deutsche“ wurden zu ,Menschen mit Migrationshintergrund" und damit zu ,Anderen Deutschen“" (Castro Varela 2013: 14) Dabei ist bedenkenswert, dass diese Unterscheidung nicht primär entlang der Dichotomie der gemachten oder nicht gemachten Migrationserfahrung - ob nun eigene oder familiärer - verläuft: „Denn nur wenige haben bei der Bezeichnung Migrationshintergrund die Kinder
schwedischer oder britischer Einwanderer vor Augen. Die meisten denken dabei an
Kinder arabischer, muslimischer, Schwarzer Menschen - also phänotypisch sichtbare
oder am Namen erkennbare Personen aus Ländern, die hierarchisch abgewertet und als
mit Deutschland ,kulturell inkompatibel“ im kollektiven Bewusstsein verankert sind.“
(Foroutan 2019: 67)

Dabei werden beispielsweise Kinder türkisch-deutscher Familien über mehrere Generationen hinweg als Migrant_innen oder,mit Migrationshintergrund' klassifiziert, während diese Bezeichnung selbst für einen selbst eingewanderten Schweden möglicherweise nicht angewendet wird (ebd.: 56). María do Mar Castro Varela sieht in diesem Sinne in der ,Operation der Definierung ,Anderer Deutscher“" die Reifizierung des ,biologistische[n] Abstammungsnarrativ“ (Castro Varela 2013: 15). Bhabha fasst dies unter der, ,inneren Inkompatibilität von Empire und Nation“, die in der Figur der Mimikry einen ,ethnischen und kulturellen Vorrang“ diagnostiziert, durch das ,das ,Nationale’ nicht mehr naturalisierbar ${ }^{11}$ ist" (Bhabha 1994: 129).

María do Mar Castro Varela spricht in diesem Zusammenhang von DeutschWerden und Anders bleiben (Castro Varela 2013: 16). Diese Veranderungsprozesse können als ,koloniale Mimikry“ aufgefasst werden, in dem zum einen das „Begehren nach einem reformierten, erkennbaren Anderen als dem Subjekt der Differenz, das fast, aber nicht ganz dasselbe ist" (Bhabha 1994: 126) durchscheint. In Bezug auf das im letzten Abschnitt diskutierte Integrationsparadigma analysiert Castro Varela hier das Paradox, das in der Integrationsanrufung steckt: „Letztlich zielen auch Integrationspolitiken auf die Produktion von Subjekten, die sich deutsch verhalten, Deutsch sprechen, deutsche Werte und Normen teilen - was immer auch damit gemeint sein soll - und die gleichzeitig nie Deutsche

\footnotetext{
${ }^{11}$ Um Missverständnisse zu vermeiden weise ich hiermit auf eine Problematik des Übersetzens hin: Auf Englisch bedeutet naturalisation Einbürgerung.
} 
sein können." (Castro Varela 2013: 17) Für diese Form postmigrantischer Zugehörigkeit, die für die fast gleichen, aber nicht ganz gleichen, eine Prekarität der Zugehörigkeit zur Folge hat, lassen sich zahlreiche Beispiele finden.

Dirk Lange und ich haben dies beispielsweise anhand vom Diskurs zu Mesut Özil analysiert (Kleinschmidt/Lange 2020). Wurde dieser bis kurz vor der Fußballweltmeisterschaft 2018 noch als Musterbeispiel gelungener ,Integration" angesehen, wurde seine nationale Zugehörigkeit nach einem Fotoshooting mit dem türkischen Staatspräsidenten grundlegend infrage gestellt. Hier geht es nicht darum zu kritisieren, dass er Wahlkampfhilfe für einen antidemokratische, militaristische und menschenverachtende Politik vorantreibenden Politiker stark machte. Diese Kritik sehe ich als mehr als angebracht. Allerdings wurde anhand dieser Auseinandersetzungen die Fragilität postmigrantischer Zugehörigkeitskonstruktionen offenbar. Mesut Özil, in Gelsenkirchen geboren und aufgewachsen, Schlüsselspieler und Weltmeister mit der deutschen Männer-Nationalmannschaft, sollte auf einmal eindeutige Bekenntnisse zu seiner nationalen Zugehörigkeit bringen. Plötzlich war er der Schuldige für das sportliche Scheitern. In diesem Prozess wurde vorgeführt, wie das nationale Lob der Vielfalt in identitäre Logik umschlagen kann, die nach einer Differenz verlangt, einem Entweder-Oder, das kein Dazwischen akzeptiert. Der Fall steht hier symbolisch dafür, dass die hart erkämpfte Zugehörigkeit für Andere Deutsche scheinbar nie vollständig oder abgeschlossen ist und immer potenziell reversibel und prekär bleibt.

Dies lässt sich auch in gegenwärtigen Formen des Rechtspopulismus sehen, wobei ich diesen nicht am Rand der Gesellschaft, sondern in deren Mitte eingelassen ansehe. Hier wird die postmigrantische Differenz nicht erfunden, sondern nur anders als in liberalen Kreisen interpretiert: „Die Ambivalenz der kolonialen Autorität wandelt sich wiederholt von der Mimikry - einer Differenz, die fast nichts ist, aber nicht ganz - zur Bedrohung - einer Differenz, die fast total ist, aber nicht ganz." (Bhabha 1994: 136) Die Bedrohung kann in zahlreichen Feldern artikuliert werden, von sicherheitspolitischen bis zur Frage der Ressourcenverteilung. Eine besondere Bedrohung entsteht jedoch dadurch, dass - wie beispielsweise auch bei Lennart (HSO2) und Marcel (HS06) - die Differenz selbst uneindeutig wird. In einer postmigrantischen Gesellschaft sind Zugehörigkeiten von Veruneindeutigung geprägt. Der Rechtspopulismus versucht wahnhaft, diese Eindeutigkeit wieder herzustellen. Aus Sicht des Mimikry-Ansatzes von Bhabha erscheint das Problem auch dadurch verursacht, dass die Anderen Deutschen zwar wiederholen, aber nicht das Nationale repräsentieren können. Fatima El-Tayeb fasst diesen Zusammenhang unter Aneignung des für antirassistische Zwecke umgedeuteten Begriffs des Kanaken so: 
„Die Kanaken drohen die angeblich klare Trennung von Deutschen und ,Fremden“ zu gefährden, sie sind weder ganz das eine noch das andere, sondern verkörpern jenen Widerspruch zum internalistischen Modell, der die Gesamtstruktur dessen, was deutsch sein kann und darf, in Frage stellt.“ (El-Tayeb 2016: 65)

\subsection{Postmigrantische Strategien}

Juliane Karakayalı und Paul Mecheril verstehen diese Formen der Zugehörigkeitsordnungen auch als Antwort auf die Kämpfe der Migration. Sie diskutieren die Frage, wie es zu der dominanten Kriseninszenierung kommen konnte, die „ab Beginn des 21. Jahrhunderts [...] Migration als Integrationsproblem“ (Karakayalı/Mecheril 2018: 231) inszenierte. In dieser Kriseninszenierung geht es nicht nur um die normierend-disziplinierende Zuschreibung der Position der „Integrationswilligen“ und „Integrationsverweigernden“, sondern auch um die (Wieder-)Herstellung der ,fraglos integrierten Position des, authentischen Deutschen“" (ebd.). Diese Kriseninszenierung reagiert dabei auch auf „migrantische Strategien der Bewältigung eines mit Restriktionen durchsetzten Alltags“, welche ,alternative Praktiken der sozialen Selbstinklusion und subversiven Praktiken der Zugehörigkeitsaneignung" ebenso umfassten, wie über Jahrzehnte dauernde politische, kulturelle und alltagsweltliche Kämpfe „um die Anerkennung des Lebens von Eingewanderten als respektierter Teil der gesellschaftlichen Realität" (ebd.: 230). Diese Kämpfe stellten das Zugehörigkeitsregime ebenso infrage wie das Verständnis dessen, was Deutsch-Sein bedeutete.

\footnotetext{
„Dieses Verständnis wurde herausgefordert durch die Praktiken von migrationsgesellschaftliche Pluralität affirmierenden, nicht zuletzt migrantischen oder als Migrant_innen adressierten Akteur_innen, die zu einer Verflüssigung und Entgrenzung eben dieser Zugehörigkeitsordnung beitrugen. Je intensiver umkämpft die natioethno-kulturell kodierte Zugehörigkeitsordnung ist, desto größeres Gewicht erhalten Kriseninszenierungen, die wir als Einsätze im Kampf um die legitime Interpretation der Gegenwart begreifen.“ (Karakayalı/Mecheril 2018: $230 \mathrm{f}$ )
}

Ein solches Verständnis begreift das Zugehörigkeitsregime nicht einfach als Machtausübung oder Herrschaft, sondern vielmehr als Resultat gesellschaftlicher Kämpfe, die so in ihrer „Dynamik und Ambivalenz“ (ebd.: 229) erfassbar werden. Theoretischer Referenzrahmen ist hier der Ansatz der Autonomie der Migration (3.4.1), welcher wiederum auf den Ansatz des Operaismus referiert. Der Ansatz des Operaismus ist im Italien der 1960er Jahre entwickelt worden und begriff die Entwicklungen der kapitalistischen Produktionsweise nicht im Sinne eines Fortschritts, sondern als maßgeblich durch die Kämpfe der Arbeiter_innen vorangetrieben, die „entweder offensiv (Streik) oder in alltäglichen Praktiken 
(Sabotage, krankfeiern, langsam arbeiten) gegen ihre Rolle im Produktionsprozess“ (ebd.: 230) kämpften. In Bezug auf das Feld der Migration bedeutet es, vom Konflikt her auf das Moment der Regulation zu blicken und dieses als „Produkt komplexer Aushandlungen ungleicher Akteur_innen sichtbar zu machen“ (ebd.). Ein solches Verständnis verändert die Sicht auf die Konstruktion des natioethno-kulturellen Zugehörigkeitsregime und kann als wichtige Perspektive einer dekolonialen politischen Bildung fungieren.

Ein solches Moment steckt auch in Bhabhas Begriff von Mimikry - ich komme hier also zum anderen Aspekt seines Begriff, anhand dessen ich hier die Schüler_innenvorstellungen und Konsequenzen für die Bildung diskutieren will. Mimikry wird bei Bhabha auch als eine Form des Widerstands verstanden, die zu einer Destabilisierung von Differenzsystemen führen kann: „Unter dem Schutz der Tarnung ist die Mimikry, wie der Fetisch, ein Teil-Objekt, das die normativen Systeme des Wissens über die Autorität von Rasse, Schreiben, Geschichte radikal umwertet.“ (Bhabha 1994: 134) Indem hybride Identifikationen artikuliert und besetzt werden, entsteht ein Ort des „Da-zwischen“ (ebd.: 324), in dem „Differenz weder Eines noch das Andere, sondern etwas anderes daneben, dazwischen, “ (ebd.: 327, Herv. i. O.) ist. Er bezeichnet die sich dadurch ergebenden Räume dementsprechend auch als dritte Räume (third spaces). Dabei ist sein Konzept von Hybridität nicht etwa dadurch gekennzeichnet, dass hier migrantisierte Subjekte einen Ort jenseits von eigentlich festen Identifikationen einnehmen, sondern vielmehr wird von diesen Orten des Da-zwischen, diesen Orten der Mimikry „Ambivalenz des kolonialen Diskurses“ und die Illusion von Identitäten enthüllt und damit ,gleichzeitig dessen Autorität“ (ebd.: 130) aufgebrochen. In den Lernendenvorstellungen kann hier der vierte Typ eines Hybriditätsverständnisses (3.3.5) wichtige Hinweise geben, den ich als Normalität gelebter Hybridität bezeichne.

Memnun (HS08) beschreibt sich selbst als „halb Deutsch und halb Palästinenser", was im Kontext seiner Ausführungen aber nicht als additiv verstanden wird. Diese doppelte Identifikation ist mehr - oder weniger - als die Doppelung zweier Identifikationen. Er bezeichnet es als „so ein Mischmasch“. Dieser ,Ort' der Identifikation ist nicht sowohl-als-auch und auch nicht weder-noch. Dies wird besonders durch seine Kontextualisierung deutlich, die seine Identifikation in einen Kontext mit seiner Begeisterung für Hip Hop setzt, die er damit begründet, dass dort Migrationsandere ihre Erfahrungen als Migrationsandere reflektieren. Die Gruppe, mit der er sich hier identifiziert, beschreibt er als ,so Ausländer, die hier so herkommen nach Deutschland - aus dem Iran, türkische Kurden oder irgendwie so was - und dann so rappen, wie die so aufgewachsen sind hier. Und wie da." Seine Identifikation begründet sich hier nicht auf einer ,kulturellen', 
essenzialistischen Differenz, sondern durch die Erfahrung als Migrationsanderer. Statt die Position der Dominanzgesellschaft einzunehmen und die als ,kulturell anders Vorgestellten daraufhin zu sehen, inwiefern sie für die Dominanzgesellschaft irritierend oder bereichernd sein können, erscheint für ihn diese Form der von ihm selbst und anderen gelebten Hybridität als alltäglich und normal. Das koloniale Begehren nach Vereindeutigung ist bei ihm nicht feststellbar. Erol Yıldız hat ähnliches im Rahmen einer Studie zu postmigrantischen Verortungspraktiken festgestellt:

„Gerade Jugendliche der zweiten und dritten Generation setzen sich sowohl mit der Migrationsgeschichte ihrer Eltern als auch mit der Gesellschaft, in der sie aufgewachsen sind, auseinander und entwickeln daraus hybride Welten. In dieser Rekonstruktionsarbeit betreiben sie eine Art ,Erinnerungsarchäologie ‘ und versuchen andere Geschichten, die bisher nicht erzählt wurden, in das öffentliche Gedächtnis zu bringen. Dabei geht es nicht mehr um Eindeutigkeit und binäre Zuordnungen, sondern um Überschneidungen, Grenz- und Zwischenräume, um Kreuzungen und simultane Zugehörigkeiten, die eine völlig andere Sicht auf die Migrationsgesellschaft eröffnen.“ (2013: 144 f)

Solche dynamischen und prozesshaften Identifikationen des Da-zwischens stehen ,vereindeutigenden Migrationsdiskursen gegenüber, die ein statisches Bild migrantischer Identitäten zeichnen“ und die dementsprechend an ,vermeintlich eindeutige ethnische oder kulturelle Zugehörigkeit gebunden sind“" (Ploder 2013: 147). Andrea Ploder zählt zu diesen vereindeutigenden Konstruktionen sowohl pejorative als auch ,positive Essenzialisierungen, die MigrantInnen auf die ,Exotik ihrer Heimatkultur' festlegen, und ein friedliches Miteinander in einer ,multikulturellen Gesellschaft" propagieren“ (ebd.).

Memnun entzieht sich hier einer Vereindeutigung. Dies kann als ,widerständige Positionierungen im Sinne Bhabhas“ (ebd.: 148) gedeutet werden.

\footnotetext{
„Durch dieses Dazwischen-Sein, durch ihre Grenzlage oder Liminalität ermöglichen third spaces Identifikation als widerständigen Prozess. Sie ermöglichen ein Hin- und Herspringen, eine wiederholte Grenzüberschreitung, die die Frage nach Zugehörigkeit im Chaos der Antworten verhallen lässt. Diesen Prozess versteht Bhabha als ,Performativität im Sinne einer kreativen, differenzbewussten Ausgestaltung von postkolonialer Repräsentation und Handlungsmacht‘ [...]“" (ebd.).
}

Aus meiner Perspektive auf dekoloniale politische Bildung erscheint es mir wichtig, diese sich der Vereindeutigung entziehenden Räume anzuerkennen. Es geht hier nicht um eine Romantisierung hybrider Subjektpositionen. Es geht 
auch nicht darum, die postmigrantischen Strategien aus einer weißen Perspektive oder für weiß Positionierte zu entdecken, zu analysieren und zu verwerten. Es geht aber sehr wohl auch aus einer weiß positionierten Perspektive darum, die Lebensrealitäten der migrationsgesellschaftlich Geanderten anzuerkennen, diese als handlungsfähige Subjekte anzusehen, nach Strategien der Unterstützung zu suchen und diesen Formen der Identifikation auch in Bildungssettings einen Platz zu kommen zu lassen. Im Zuge dessen geht es darum, ein Verständnis zu problematisieren, nach dem ,kulturelle, ethnische, religiöse und nationale Einheitlichkeit und Eindeutigkeit als Maß der Normalität“ konstruiert wird und „Vielheit [...] als Ausnahme“ (Foroutan 2019: 127) gilt. Es stellt sich auch die Frage, inwiefern solche hybriden Subjektpositionen bzw. die durch sie ausgelösten Irritationen Momente für eine Sichtbarmachung und Destabilisierung natio-ethno-kultureller Zugehörigkeitsregime und dem diesen zugrunde liegenden Begehren dichotomer Vereindeutigung darstellen können, ohne hier Romantisierung oder Othering hervorzurufen. Dabei sind auch die Vorstellungen von dominanzgesellschaftliche Identifikationen vornehmenden Schüler_innen häufig von einer Unsicherheit oder einer Ambivalenz durchzogen, die durch Irritationen vertieft werden könnten.

Die Identifikation als ein Da-zwischen bzw. als ein „Mischmasch“ (Memnun) bedeutet dabei keineswegs, orientierungslos oder handlungsunfähig zu sein. Im Zuge seiner Kritik des rassistischen Lehrerinnenhandelns spricht Memnun von einem ,Wir' aus; in der rassistischen Unterstellung gegenüber den Eltern seiner Mitschülerin spricht er von „unseren“ Eltern. Was ist das für ein ,Wir"? Memnun ist in Deutschland geboren, hat die deutsche Staatsbürgerschaft und eine als deutsch geltende Mutter und gleichzeitig ist dieses ,Wir' eines das die Lehrerin aus- und seine Rassismus erfahrene Mitschülerin einschließt. Dieses ,Wir ' bedeutet nicht Nicht-Deutsch, aber auch nicht Deutsch. Es scheint vielmehr auf etwas zu verweisen, was ich weiter oben als anders deutsch (El-Tayeb 2016) bezeichnet habe. Auch Şahin (HS21; 3.3.4) spricht von einem ,Wir', das ähnlich strukturiert zu sein scheint. Er stellt dieses ,Wir' einer Gruppe gegenüber, die er als „Ausländerfeindliche“ bezeichnet, die für ihn „Nazis oder allgemein auch normale Menschen" darstellen können. Rassistische Äußerungen sieht er dabei gelassen entgegen, denn die kämen ,eh nicht durch“. Als Grund führt er folgendes an: „Ja, wir sind halt zu viele. Ohne uns würden die vieles schaffen.“ Wer ist nun dieses ,Wir' und dieses ,Uns', mit dem Şahin hier eine postmigrantische Selbstsicherheit präsentiert, die auf eine Welt verweist, die nicht so sehr und nicht auf diese Weise vom Rassismus strukturiert ist? Ich sehe in diesem ,Wir' eine postmigrantische Ambivalenz, die sich auch in Şahins Beschreibung - „die Ausländer, also die nicht ausländerfeindlich sind“ - findet. Diese Ambivalenz werde ich im Folgenden diskutieren. 
Das eine ,Wir' bestimmt sich über die Form der (Nicht-)Zugehörigkeit bzw. der Gleichzeitigkeit der Zugehörigkeit und Nicht-Zugehörigkeit, die nichtsdestotrotz sowohl bei Memnun als auch Şahin als „Ausländer“ bezeichnet ist. „Wir sind einfach zu viele" verweist auf die postmigrantische Realität, in der das Statistische Bundesamt für 2018 11,2 Millionen ,Ausländer' und 20,8 Millionen Menschen als ,mit Migrationshintergrund“ zählte. Damit wurde etwa einem Viertel der Bevölkerung in Deutschland ein ,Migrationshintergrund' attestiert, was beim Statistischen Bundesamt einer Person zugeschrieben wird, wenn sie selbst oder mindestens ein Elternteil nicht mit deutscher Staatsangehörigkeit geboren wurde. Diese Zahl kann in einigen urbanen Zentren durchaus höher ausfallen, so liegt der Anteil von Kindern ,mit Migrationshintergrund" unter sechs Jahren in Frankfurt am Main beispielsweise bei 75,6 \% oder der Anteil von Menschen , mit Migrationshintergrund“ unter 18 Jahren in Hannover bei über der Hälfte.

Dieses ,Wir' kann Şahin meinen, insofern er diese ,Wir'-Gruppe nicht nur passiv durch die Zuschreibung als ,mit Migrationshintergrund', also als ,Ausländer' und Andere Deutsche, definiert, sondern sich als Gruppe begreift und dabei „nicht ausländerfeindlich“ ist. Seine Aussage „Ohne uns würden die vieles schaffen" verweist zum einen darauf, dass diese Gesellschaft substanziell von Menschen getragen wird, deren Zugehörigkeit nicht, nur teilweise oder nur prekär besteht. Zum anderen impliziert es ein postmigrantisches Subjekt des Widerstands gegen Rassismus. Dieses, Wir' verweist auf eine Art strategischen Essenzialismus der Differenzpolitik. Hier wird der Ort im ,identitätspolitischen Regime der Differenz“ zum Ausgangspunkt von „Politiken der Rassismuskritik“, in der ,,sowohl die Zurückweisung der rassistischen Markierung als auch ihre strategische Aneignung“ (Tsianos/Karakayalı 2014) ein politisches Subjekt erschaffen. Ein Beispiel dafür wäre das Label Kanak Attak (ebd.). Tsianos und Karakayalı sehen hier ein Paradox postmigrantischer Repräsentationspolitik:

„Einerseits werden die Teilungslinien, die der Rassismus in die Gesellschaft einzieht, zum konstitutiven Ausgangspunkt der Politik gegen den Rassismus; andererseits kann rassistische Diskriminierung nur dann thematisiert werden, wenn das Kriterium, entlang dessen der rassistische Ausschluss erfolgt, benannt wird. Hannah Arendt brachte es zur berühmten Formel: ,daß man sich immer nur als das wehren kann, als was man angegriffen ist"." (ebd.)

Diese Form der Aneignung der Zuschreibung, wie sie etwa durch die Gruppe Kanak Attak praktiziert wurde, hat eine empowernde Wirkung und untergräbt schon als solche die rassistischen Zuschreibungen. 
Eine andere, aber keine widersprechende Interpretation des, Wir ' von Memnun und Şahin könnte darin bestehen, ein ,Wir' vorzustellen, das über die Grenzen der (Nicht-)Zugehörigkeit hinweg das „Gleichheitsversprechen“ (Foroutan 2019: 69) der postmigrantischen Gesellschaft realisieren möchte. Dieses ,Wir ${ }^{6}$ konstituiert sich also ebenso über die Infragestellung des Zugehörigkeitsregimes, jedoch über die durch es hergestellte Differenz hinweg, ohne diese dabei ausblenden zu müssen. Vom Begriff der postmigrantischen Gesellschaft her gedacht, dreht sich der „Kernkonflikt in postmigrantischen Gesellschaften“ (ebd.: 71) nur an der Oberfläche um Migration. Naika Foroutan zufolge geht es dabei vielmehr grundsätzlicher um die Frage der „Aushandlung und Anerkennung von Gleichheit als zentralem Versprechen der pluralen Demokratie" (ebd.), also um die Frage, wie ,wir" das Zusammenleben gestalten wollen. „Ohne uns würden die vieles schaffen“ würde hier dann bedeuten, dass diese ,Wir'-Gruppe dafür kämpft, dass die Gesellschaft nicht oder zumindest nicht in diesem Maß und nicht auf diese Weise durch ein natio-ethno-kulturelles Zugehörigkeitsregime bestimmt wird.

Der Begriff des Postmigrantischen oder der postmigrantischen Gesellschaft steht nicht im Widerspruch zum Begriff der Migrationsgesellschaft. Zwar wurde der Begriff der postmigrantischen Gesellschaft dafür kritisiert, dass er sich über das Präfix ,post" vom falschen Objekt distanziere, da es nicht um eine Distanz oder Überwindung vom Migrantischen gehe, sondern um die Kritik an migrationsgesellschaftlichen Phänomenen und Reglementierungen (Mecheril 2014). Naika Foroutan macht dagegen den Begriff stark. Sie sieht mit dem Begriff die Möglichkeit gegeben, klarer - empirisch - diejenigen gesellschaftlichen Phänomene in den Blick zu nehmen, die letztlich nicht mehr mit Migration zu tun haben und - normativ - binäre Codes zu erweitern, um das Gleichheitsversprechen realisieren zu können (Foroutan 2019: 55). Migrationsgesellschaft und postmigrantische Gesellschaft beschreiben im Prinzip mit ähnlichen Perspektiven ähnliche Phänomene und können aus meiner Sicht nicht als konkurrierende, sondern als sich ergänzende Interpretationsraster von Wirklichkeit angesehen werden. Ausgehend von den Lernendenvorstellungen habe ich mich für diesen Abschnitt auf das Konzept der postmigrantischen Gesellschaft bezogen, da hier ein Aspekt - den ich im Folgenden darstelle - stärker hervorgehoben wird, den ich in meiner Ko-Konstruktion der Schüler_innenvorstellungen aufscheinen sehe; wobei dies prinzipiell auch im Konzept der Migrationsgesellschaft eingeschrieben ist.

Das Konzept der postmigrantischen Gesellschaft zielt nicht darauf ab, „die Tatsache der Migration zu historisieren“ (Tsianos/Karakayalı 2014), sondern zielt darauf ab, dass ,die Gesellschaft über Politiken, Diskurse, Sichtbarkeiten, Freundeskreise, Partnerschaften, Konsumgewohnheiten, Sport, Kulturproduktion, Medien etc. als Ganzes durch [die] Erfahrung der Migration strukturiert ist“" 
(Foroutan 2019: 56). Hier erscheint also die postmigrantische Durchdringung aller Lebensbereiche als ein unhintergehbarer Fakt, der in politische Stärke umgedeutet und als solche mobilisiert werden kann. Die gegenwärtigen Verhältnisse erscheinen vor diesem Hintergrund als Resultat von Kämpfen der Migration, deren Sichtbarmachung in emanzipatorischen Bildungsprozessen wichtig ist. Eine dekoloniale politische Bildung kann beide Konstruktionen eines auf die Einlösung des postmigrantischen Gleichheitsversprechens zielenden ,Wirs“ als normativen Fluchtpunkt ins Auge fassen - ein ,Wir', das sich entlang der strategischen Aneignung der rassialisierten Zuschreibung bildet und eines, das über diese Grenzen hinweg das Zugehörigkeitsregime destabilisieren will. Neben der Infragestellung des normativen Begehrens nach Vereindeutigung und des damit zusammenhängenden Ziels der Veruneindeutigung der Eindeutigkeiten des Zugehörigkeitsregimes stellt eine dekoloniale politische Bildung eine weitere Frage. In den Schüler_innenvorstellungen wurden Ansätze deutlich, die Frage des Politischen der postmigrantischen Gesellschaft zu stellen, also die Frage danach, wie , wir' zusammen leben und welche Solidaritätslinien und Allianzen denkbar sind, um Prozesse der Infragestellung und Verschiebung hin zur Realisierung des postmigrantischen Gleichheitsversprechens voranzutreiben. Eine dekoloniale politische Bildung kann hiervon inspiriert an diese Prozesse anknüpfen und Räume zur Verfügung stellen, die Frage des Politischen zu vertiefen.

\subsubsection{Exkurs/Modell: Differenzmarker des Zugehörigkeitsregimes vor dem Hintergrund des Erbes der Aufklärung}

In diesem als Exkurs konzipierten Abschnitt entwerfe ich ein Modell in welchem von mir in den Lernendenvorstellungen vorgefundene Differenzmarker des natioethno-kulturellen Zugehörigkeitsregimes durch die Darstellung der Artikulation dieser Differenzmarker in der Philosophie der Aufklärung kontextualisiert werden. Der Charakter dieses Abschnitts als Exkurs ist insofern durchaus ernst gemeint, als dass es durchaus möglich ist, wenn Leser_innen dieses Buches diesen Teil einfach überspringen; er ist nicht wesentlich für das Argument und bringt aber dennoch aus meiner Sicht einen solchen Mehrwert an Erkenntnis mit sich, dass er als Abschnitt Sinn ergibt. Für Leser_innen jedoch, die eine solche Genealogie natio-ethno-kultureller Differenzmarker in der Ideengeschichte der Aufklärung nicht für unmittelbar zielführend - oder schlicht für langweilig - halten, besteht hier die Möglichkeit, den Exkurs einfach zu überblättern.

In den Lernendenvorstellungen habe ich innerhalb der Prozesse des Selfings und Otherings in der Migrationsgesellschaft (3.2) fünf Differenzmarker vorgefunden, über die die Prozesse konstruiert werden: ,Rasse', Sprache, ,Kultur', 
Werte und Leistung. Diese Liste ist genauso wenig als abschließend gedacht, wie das Modell dieses Exkurses als eine Totalisierung zu verstehen ist. Jeden dieser Differenzmarker werde ich im Rahmen dieses Exkurses mit einem Denker der Aufklärung verknüpfen und anhand dieses Denkers exemplarisch herausarbeiten, wie Nation und der jeweilige Differenzmarker gedacht wurde: Kant für die Nation als ,rassische' Gemeinschaft, Fichte für die Nation als Sprachgemeinschaft, Herder für die Nation als Kulturgemeinschaft, Renan für die Nation als Wertegemeinschaft und Sieyès für die Nation als Leistungsgemeinschaft. Anhand dieser fünf Denkern des 18. und 19. Jahrhunderts versuche eine dekonstruktive Lesart der Ideengeschichte der Nation-Form zu entwickeln, die hoffentlich dazu beiträgt, die Kolonialität heutiger Zugehörigkeitsregime in ihrer Widersprüchlichkeit und ihrer langen Verstricktheit mit der Tradition der Aufklärung - respektive koloniales Erbe - besser verstehen zu können. Durch die Fixierung auf diese fünf weißen, europäischen, alten Männer reproduziere ich eine problematische Art Geschichte zu schreiben, obwohl ich diese ja nutze um koloniale Momente herauszuarbeiten. Doch wiegt aus meiner Sicht der Nutzen dieses Defizit auf. Es sind nun mal nicht zuletzt weiße Männer wesentlich für die Konstruktion des kolonialen Erbes verantwortlich und en passant erlaubt dieser Exkurs, die identitätsstiftend-affirmative Rezeption der Autoren der Aufklärung in der Gegenwart infrage zu stellen. Dabei werde ich mich auf den deutschen und französischen Kontext begrenzen, da ich mich hier am besten auskenne.

Ich verfolge mit diesem Exkurs mindestens zwei Ziele. (1) Erstens möchte ich herausstellen, dass verschiedene Formen natio-ethno-kultureller Zugehörigkeit nicht einer Genealogie entsprechen, die beispielsweise vom biologischen Rassismus zum Kulturalismus führt. Vielmehr ist die Konstruktion nationaler Zugehörigkeit schon immer umstritten und mehrschichtig. Es existierten und existieren mehrere Differenzmarker, die konkurrieren oder sich ergänzen. Die Konstruktion von natio-ethno-kulturellen Markern der Differenz und (Nicht-)Zugehörigkeit sind aus meiner Sicht nicht als trennscharfe Konstruktionen, sondern eher als Assemblagen zu verstehen. Die Vorstellung der Genealogie des Rassismus oder der nationalen Zugehörigkeit, nach der es genealogisch erst biologischen Rassismus gegeben habe, der heute verklausuliert in ,Kultur' wiederkehrt, ist weit verbreitet. Dieser erscheint dann als eine Art Urform des Rassismus und nationaler Zugehörigkeit. Die Vorstellung wurde aber auch schon häufig kritisiert. Beispielsweise Franz Fanon formulierte 1956 in seinem Aufsatz Rassismus und Kultur (1956) eine alternative Sichtweise und entwickelte den Begriff eines „,kulturellen Rassismus“ (Fanon 1956: 40). Balibar zeigt dies anhand des Antisemitismus der Reconquista, in dem er bereits einen „kulturalistischen Rassismus“ (Balibar 1988c: 32) sieht. Statt einer der Teleologie zuneigenden Genealogie des 
Rassismus möchte ich dafür plädieren, für die Sichtbarmachung und die Kritik von normalisierten Formen natio-ethno-kultureller Zugehörigkeiten eher in Assemblagen zu denken. Rassismus hat immer schon verschiedene Elemente vermischt und in Stellung gebracht, um Ausschluss und Identität zu rechtfertigen (Balibar 1988c). Wie im Modell deutlich werden wird und wie in der Analyse der Schüler_innenvorstellungen deutlich wurde, kommt keines der Elemente in Reinform vor, sondern immer in Bezug zu anderen Elementen - diese Unschärfe in der Darstellung sehe ich dabei nicht als Makel, vielmehr ist sie Programm. In der liberalen Tradition der Theorie der Nation wird in der Regel die Unterscheidung zwischen einem vermeintlich bösen - blutsrechtlichen, völkischem - und einem vermeintlich guten - verfassungsbasierten, auf Werten beruhenden - Nationenverständnis eingeführt; einem nationalen Staatsbürgerschaftsverständnis des ethnos und einem des demos. Diese Tradition macht es sich aus meiner Sicht zu leicht und übersieht so zahlreiche Fallstricke, die in der irreduktiblen Verwobenheit beider Konzepte liegen.

(2) Zweitens möchte ich herausarbeiten, wie die von mir ausgehend von den Schüler_innenvorstellungen ko-konstruierten Differenzmarker in einer Kontinuität zum Erbe des historischen Kolonialismus stehen, also wie dieses Erbe in den Lernendenvorstellungen aufscheint. Die Rückbindung der Lernendenvorstellungen an die ideengeschichtliche Tradition der europäischen Kolonialität macht deutlich, dass dies nicht einem Defizit ihres Denkens entspringt oder gar als Überbleibsel des Nationalsozialismus externalisiert werden können, sondern vielmehr zum europäisch-kolonialen Erbe gehören. Dieses wiederum war prägend für die Nation-Form selbst und seine Umsetzung in Deutschland sowie aber auch für die Entstehung des mit der Nation-Form verbundenen Systems der bürgerlichen Demokratie. Natio-ethno-kulturelle Zugehörigkeitsregime und die Verbindung von Rassismus und Nationalstaatlichkeit sind der bürgerlichen Demokratie meinem Exkurs zufolge nicht äußerlich, sondern eng mit ihr verknüpft und in sie eingeschrieben. Ich werde auch einige Spuren in den Werken der fünf Autoren verfolgen, um genau dies deutlich werden zu lassen. Eine dekoloniale politische Bildung steht vor diesem Hintergrund aus meiner Sicht vor der großen Herausforderung, die Logik des Nationalen selbst transzendieren.

Mit dem Aufzeigen der kolonialen Kontinuität der natio-ethno-kulturellen Differenzmarker will ich nicht suggerieren, dass diese überhistorisch oder unabhängig von den Kämpfen der Migration und den damit verbundenen Transformationen des Zugehörigkeitsregimes sind. Allerdings ermöglicht es, die Sichtbarmachung kolonialer Kontinuitäten, so zumindest meine Hoffnung, sowie Fragmente des Zugehörigkeitsregimes besser verstehen und kritisieren zu können. Shadi 
Kooroshy und Paul Mecheril zufolge kann die vorherrschende Krisensemantik einer Migrations- und Flüchtlingskrise auf eine „Krise der Legitimität und Funktionalität der nationalstaatlichen Ordnung" (Kooroshy/Mecheril 2019: 80) zurückgeführt werden. Der Nationalstaat braucht „das Phantasma der Nation“ (Mecheril 2020: 110) und muss diese unentwegt produzieren. Die Nation kann als etwas verstanden werden, ,das uns definiert, aber zugleich undefinierbar bleibt“ (Salecl 1994: 14, zitiert nach ebd.) Die so entstehende „symbolische Lücke“ muss gefüllt werden. „Je bedeutsamer die Schwierigkeit der Bestimmung der Grenze wird, desto attraktiver wird die phantasmatische Absicherung und Iteration des Wir." (Mecheril 2020: 110) Dabei stellen Kooroshy und Mecheril fest, dass „Race und Nation“ nicht identisch sind, allerdings „eine strukturelle Verwandtschaft zwischen den Vereindeutigungspraktiken des Rassismus und der Logik des Nationalstaats“ (Kooroshy/Mecheril 2019: 82) existiert, die eine enge Wechselbeziehung konstituiert.

Um diesen Zusammenhang theoretisch aufzuschlüsseln, hat Étienne Balibar den Begriff der Nation-Form entwickelt, dessen Theorien für diesen Abschnitt einen zentralen Referenzrahmen darstellen. Entgegen der vorherrschenden Naturalisierung der Form des Nationalen zeigt er auf, dass die Durchsetzung der Nation-Form keine naturwüchsige Entwicklung war, sondern kontingent - es hätte sich also auch eine ganz andere oder mehrere, konkurrierende Formen durchsetzen können. Mit Bezug auf Wallerstein und Braudel führt Balibar beispielsweise das Reich oder die im Westeuropa des 17. Jahrhunderts dominanten politisch-kommerziellen Netze wie die Hanse als historisch wirkmächtige, konkurrierende Staatsformen an (Balibar 1988b: 111). Étienne Balibar plädiert dafür, die Entstehung von Nationen ausgehend von der globalen Weltwirtschaft und Machtstrukturen zu rekonstruieren (Balibar 1988b: 110). Balibar stellt klar, dass es nicht angemessen ist, die „Nation-Form aus den kapitalistischen Produktionsverhältnissen ,abzuleiten““ (ebd.). In Anlehnung an die Weltsystemtheorie von Braudel und Wallerstein verbindet er die

\footnotetext{
„Konstituierung der Nation nicht mit der Abstraktion des kapitalistischen Marktes [...], sondern mit seiner konkreten historischen Form: die ,Welt-Wirtschaft ${ }^{4}$, die immer schon so organisiert war und hierarchisiert ist, daß es ein ,Zentrum ' und eine ,Peripherie" gibt, denen unterschiedliche Akkumulations- und Ausbeutungsformen der Arbeitskraft entsprechen und deren Beziehungen durch ungleichen Tausch und durch Herrschaft gekennzeichnet sind“ (ebd.).
} 
Balibar zufolge konstituieren sich die ,nationalen Einheiten [...] gegenseitig als konkurrierende Instrumente der Herrschaft des Zentrums über die Peripherie“ (ebd.).

Für ihn ist damit ,jede moderne ,Nation“ ein Produkt der Kolonisation: sie war stets bis zu einem gewissen Grad eine kolonisierte oder eine kolonisierende Macht, mitunter sogar beides“ (ebd.). Die gegenwärtige Welt, die als eine Welt der Nationalstaaten strukturiert ist, in der die Nation-Form quasi universalisiert und naturalisiert ist, erscheint auch unter diesem Gesichtspunkt als wesentlich durch koloniale Prozesse strukturiert. Ich werde in diesem Modell die Analyse der materiellen Entstehungsbedingungen des Nationalen nicht weiter vertiefen, sondern eine ideengeschichtliche Re- und Dekonstruktion des Denken des Nationalen verfolgen. Ranabir Samaddar kritisiert in diesem Sinne an der konstruktivistischen Theorie der Nation, alles auf die Formel zu bringen: Nation ist Narration. „Nation, as these people famously said, was narration." (Samaddar 2012: xx) Systematisch würden so die Aspekte von Klasse, Arbeit und Reichtumsverteilung zugunsten von Fragen der kulturellen Signifikation ausgeblendet (ebd.). Diese Spur werde ich im Rahmen des hier vorliegenden Textes aber nicht weiter verfolgen.

Nach Balibar hat keine Nation eine „ethnische Basis“ (Balibar 1988b: 115). Nichtsdestotrotz ist Ethnizität ein konstitutiver Bestandteil der Nation-Form. Balibar entwickelt hierfür den Begriff der fiktiven Ethnizität. Darunter versteht er, die durch den Nationalstaat geschaffene Gemeinschaft (Balibar 1988b: 118). Fiktion darf hier aber nicht, ,im Sinne einer bloßen Illusion ohne historische Auswirkungen“ aufgefasst werden, sondern ,,analog zur persona ficta der juristischen Tradition, im Sinne einer von den Institutionen ausgehenden Wirkung, einer , Konstruktion“" (ebd.). ,Ethnizität" ist also eine Konstruktion, wenngleich auch eine real wirkmächtige.

\footnotetext{
„Keine Nation besitzt von sich aus eine ethnische Basis, sondern in dem Maße, wie die Gesellschaftsformationen einen nationalen Charakter bekommen, werden die Bevölkerungen ,ethnizisiert", die sie umfassen, die sie sich teilen oder die sie dominieren; d. h. diese werden für die Vergangenheit und Zukunft so dargestellt, als würden sie eine natürliche Gemeinschaft bilden, die per se eine herkunftsmäßige, kulturelle und interessenmäßige Identität hat, welche die Menschen und die gesellschaftlichen Bedingungen transzendiert.“ (Balibar 1988b: 118, Herv. i. O.)
}

Dieser Prozess der Ethnisierung, der Konstruktion des Volks, kann vor diesem Hintergrund auch als ,verspätete Nationalisierung der Gesellschaft" bezeichnet werden, ,so verspätet, daß sie letztlich als eine permanente Aufgabe erscheint“ (ebd.: 113). Selbst wenn das Volk ,tendenziell konstruiert ist, existiert es nicht 
ein für allemal“ (ebd.: 115). Nach Balibar bedarf der Prozess der Herstellung des Volkes einer ,spezifischen Ideologie-Form“.

\begin{abstract}
„Sie [diese Ideologie-Form] muss zugleich ein Massen- und ein Individuationsphänomen sein, eine ,Anrufung der Subjekte " (Althusser) leisten, die wesentlich wirksamer und tiefgehender ist als die einfache Anerziehung politischer Werte; oder anders gesagt: sie muss diese Anerziehung der Werte in einen elementareren (oder auch ,primären') Prozess integrieren, in dessen Verlauf die Affekte Liebe und Hass sowie die ,Selbst ${ }^{\circ}$-Vorstellung fixiert werden. Sie muss eine Vorbedingung für die Kommunikation zwischen den Individuen (den ,Bürgern') und zwischen den sozialen Gruppen werden - nicht, indem sie alle Unterschiede auslöscht, sondern sie relativiert und sie sich unterordnet, so daß schließlich der symbolische Unterschied zwischen ,uns' und ,den Fremden“ obsiegt und als irreduktibel erlebt wird.“ (ebd.)
\end{abstract}

Ein Volk kann also dann als tendenziell konstruiert angesehen werden, wenn in den Selbstverhältnissen (Subjektivierungsweisen der Individuen) und sozialen und politischen Artikulationen und Gruppenbildungen (Vergemeinschaftung) das Nationale einen dominierenden, wenn auch nicht ausschließlichen Faktor darstellt.

Die nationalistische Erzählung erschafft die Illusion der ,Selbstentfaltung des nationalen Wesens" (ebd.: 107). Diese Illusion charakterisiert Balibar als eine zweifache: Zum einen besteht sie in der Annahme, dass sich „die Generationen, die jahrhundertelang auf einem annähernd gleichbleibenden Territorium unter einer annähernd einheitlichen Bezeichnung aufeinandergefolgt sind, eine unveränderliche Substanz übermittelt haben" (ebd.). Zum anderen besteht sie außerdem in der Überzeugung, dass die „Entwicklung, deren Elemente wir im Nachhinein so anordnen, daß wir uns selbst als ihr Resultat begreifen, die einzig mögliche war, daß sie schicksalhaft war" (ebd.). Diese Schicksalsgemeinschaft wird gleichermaßen in die Vergangenheit als auch in die Zukunft projiziert.

Das Problematische an der Nation-Form ist nach Balibar nicht, dass eine Nation eine imaginäre Gemeinschaft ist und insofern auf einer Konstruktion basiert. Nach Balibar und Anderson ist nämlich jede soziale Gemeinschaft, die durch das Wirken von Institutionen reproduziert wird, imaginär (Anderson 1983: 6; Balibar 1988b: 115). Nicht nur nationale Gemeinschaften beruhen auf der „Projektion der individuellen Existenz in das Geflecht einer kollektiven Geschichte, auf der Anerkennung eines gemeinschaftlichen Namens und auf den Traditionen, die als Spuren einer unvordenklichen Vergangenheit erlebt werden (selbst wenn sie erst in jüngerer Zeit geschaffen und den Menschen anerzogen wurden)" (Balibar 1988b: 115). Das Spezifische an der Nation ist dementsprechend nicht, dass die ihr zugehörige Gemeinschaft imaginär ist, sondern dass das Imaginäre der Nation die Form des ,Volks` annimmt (ebd.). Im 
Folgenden wird sich dementsprechend alles um die Frage drehen, was ein Volk ist bzw. wie es hergestellt wird. Häufig werden zwischen dem Verständnis des Volks als demos und ethnos unterschieden. Im Sinne eines emanzipatorischen Begriffs von Citizenship erscheint es als sehr attraktiv, beide Elemente als gegensätzliche Auffassungen von Citizenship zu deuten. Die Wirklichkeit scheint jedoch komplexer, da beide Elemente konstitutiv miteinander verschränkt sind, was anhand der für beide konstitutiven Rolle der Differenz deutlich wird.

Zur Konstruktion der fiktiven Ethnizität braucht es die Differenz, die Figur des Anderen. Sie ist konstitutiv für die Konstruktion einer nationalen Identität. Die Differenz schreibt sich dabei in die Identität ein, deren Konstruktion - analog zu der des , Volks ‘ oder der, Ethnie“ - immer unabgeschlossen, brüchig und ambivalent ist und bleibt. Die konstitutive Rolle des Othering für die Herstellung der fiktiven Ethnizität bringt Stuart Hall in folgendem oft angeführten Zitat zum Ausdruck: „Sie [die Identität] muss durch das Nadelöhr des Anderen gehen, bevor sie sich selbst konstruieren kann.“ (Hall 1991: 45) Beide Seiten der Differenz sind also Fiktionen, die aber sehr reale Auswirkungen haben. Paul Mecheril und Thomas Teo beschreiben dies plastisch für den deutschen Kontext anhand von „,fiktiven Idealtypen“:

\begin{abstract}
„Mit anderen Worten: ethnische, nationale, kulturelle Identitäten sind Konstruktionen, die von einem fiktiven Idealtyp genährt werden. Die Deutsche und noch vielmehr der Deutsche - das sind Ideen, Vorstellungen, Konzepte, Schemen, Phantasien, Träume, Programme, Entwürfe, Fiktionen, Wünsche, doch keine greifbare Realität: Sie und ihn gibt es nicht. [...] So wie wir die Konstruktionen des Deutschen kennen, so kennen wir die des Nicht-Deutschen: Na klar, er ist schwarz, er ist braun, und er sieht aus wie ein Türke.“ (Mecheril/Teo 1994: 9)
\end{abstract}

In der Re- und Dekonstruktion der Nationsbegriffe der fünf Autoren werde ich immer auch die Frage nach dem Anderen stellen, dem Anderen als konstitutives Element für das Eigene.

Étienne Balibar schlägt vor, in der Analyse von zwei großen konkurrierenden Wegen auszugehen, nämlich von der Konstruktion der Ethnizität über die Sprache und die ,Rasse“ (Balibar 1988b: 119). Auf den ersten, oberflächlichen Blick scheint die Konstruktion über die ,Rasse“ als verschlossen, während die Sprachgemeinschaft ja allein insofern jeder_m dadurch offen steht, sich die Sprache anzueignen. Die Realität sieht jedoch anders aus. Auch die ,erbliche Substanz“, so Balibar weiter, ,muss immerfort neu definiert werden: gestern das , Germanentum', die ,französische ' oder ,angelsächsische' Rasse, heute das ,Europäertum ‘ oder die ,Okzidentalität“, morgen vielleicht die ,mediterrane Rasse“" (ebd.: 127). 
Und obwohl es ja unbestritten Menschen möglich ist, sich sprachliche Kompetenz anzueignen, ist die Offenheit der Sprachgemeinschaft nur ideell. Zwar ist sie „formal egalitär“, wird jedoch praktisch zum Ausschlussfaktor und schafft ein Netz von „Spaltungen“ und „differentiellen“ (ebd.) Normen. „Die Produktion der Ethnizität, das bedeutet auch die Rassisierung der Sprache und die Verbalisierung der Rasse.“ (ebd.) Ich stimme seiner Idee der wechselhaften Überschreibung der sprachlich und ,rassisch' konstruierten Nation zu, bin jedoch skeptisch gegenüber seiner mir etwas vorschnell erscheinenden Reduktion auf diese zwei Elemente der Sprache und der ,Rasse'. Ich plädiere mit meinem Modell dafür, den Blick für weitere mögliche Differenzmarker zu öffnen und die ,Liste" nicht zu schließen, was ich auch mit diesem Modell nicht anstrebe. Zusätzlich verkompliziert sich die dadurch, dass das natio-ethno-kulturelle Zugehörigkeitsregime mit supranationale Identifikationen überschrieben wird, die Paul Mecheril als ,umständlichere natioethno-kulturell kodierte Konstruktionen mit territorialer Referenz wie Europa oder der Westen“ (Mecheril 2020: 110) fasst.

\subsection{Kant: Nation als, rassische' Gemeinschaft}

Immanuel Kant (1724-1804) steht in der bürgerlichen Ideengeschichte symbolisch für einen Vorreiter für Aufklärung, Kosmopolitismus, Weltbürgertum und Demokratie. Sein Text Zum ewigen Frieden gilt einigen als inoffizielles Gründungsmanifest der UNO und einer kosmopolitischen Haltung. Im ersten Definitivartikel seiner berühmten Schrift Zum ewigen Frieden von 1795 heißt es beispielsweise: „Die Form der Regierung [...] betrifft die auf die Konstitution (den Akt des allgemeinen Willens, wodurch die Menge ein Volk wird) gegründete Art, wie der Staat von seiner Machtvollkommenheit Gebrauch macht: und ist in dieser Beziehung entweder republikanisch oder despotisch." (Kant 1795: 12) Kant favorisiert natürlich die republikanische Form. Jürgen Habermas sieht bei Kant die Idee demokratischer Selbstbestimmung umgesetzt, die noch „nicht den kollektivistischen und zugleich ausschließenden Sinn der Behauptung nationaler Unabhängigkeit und der Verwirklichung nationaler Eigenart" (Habermas 1996: 166) habe. Vielmehr habe sie „den inklusiven Sinn einer alle Bürger gleichmäßig einbeziehenden Selbstgesetzgebung“ (ebd.). Eine solche liberale Interpretation zielt zwar darauf, einen nicht exklusiven Begriff von Bürgerschaft stark zu machen, der dann einem ,schlechten' Demokratie- und Nationsverständnis entgegengestellt werden kann. De facto löscht eine solche Interpretation aber die Verwobenheit von Exklusion und ,Demokratie“ als Institution in der Nation-Form aus, indem herrschaftliche und ausschließende Aspekte unsichtbar gemacht und so dethematisiert werden. 
Im Folgenden wird Kant von einem anderen Standpunkt aus thematisiert, nämlich eines nations- und rassismuskritischen, in der Hoffnung, dass eine Reflexion von Herrschaft und Exklusion mehr zu ihrer Überwindung beitragen kann als die Apotheose der bürgerlichen Aufklärung. Kant als Vertreter eines ,rassischen ' Nationsverständnisses zu wählen (und nicht beispielsweise seinen auch in der herrschenden Geschichtsschreibung als Rassetheoretiker geltenden Göttinger Mitdiskutanten Christoph Meiners) ist der Möglichkeit geschuldet anhand von Kant die tiefe und irreduktible Verwobenheit von einem rassistischen Bürgerschafts- und Nationenverständnis mit der Tradition der europäischen, bürgerlichen Aufklärung aufzuzeigen. Dafür wird an einigen Stellen auch die rassistische Sprache Kants wiedergegeben. Obwohl mir bewusst ist, dass eine Reproduktion rassistischer Sprache unter Umständen verletzend und Herrschaftsdiskurse reproduzierend wirken kann, erscheint es mir vor dem Hintergrund der Herrschaft dethematisierenden Kantrezeption als angemessen.

In seinen Schriften zur pragmatischen Anthropologie verwendet er die Begriffe Nation und Volk weitgehend synonym (Speich Chassé 1997: 3). Zu Beginn des Abschnitts über den „Charakter des Volks“ definiert Kant seinen Begriff des Volks: „Unter dem Wort Volk ( populus) versteht man die in einem Landstrich vereinigte Menge Menschen, in so fern sie ein Ganzes ausmacht.“ (Kant 1798: 311) Neben der Bedingung der Territorialität muss also auch diejenige des aktiven Zusammenschlusses erfüllt sein. Die Unterscheidung von Menschen, die auf einem Territorium wohnen, in Bürger und Nicht-Bürger hat bereits eine lange Tradition. Ein wichtiger Referenzpunkt stellt hier Rousseau dar, der im Contrat Social (Buch 1, Kapitel 5) die Unterscheidung von der Menge (multitude) und der Gesellschaft (société) bzw. der Anhäufung (agrégation) und dem Zusammenschluss (association) einführt (Rousseau 1762: 15). Rousseau stellt hier eine Frage, deren Beantwortung sich viele Generationen bürgerlicher Philosoph_innen widmen werden, nämlich, dass die Frage, wodurch ein ,Volk' zum ,Volk' wird, der Frage, wie das ,Volk' einen König wählt, vorausgeht und das eigentliche Fundament der Gesellschaft darstellt. ${ }^{12}$ Kant führt die Differenz auf folgende Weise ein:

„Diejenige Menge oder auch der Theil derselben, welcher sich durch gemeinschaftliche Abstammung für vereinigt zu einem bürgerlichen Ganzen erkennt, heißt Nation ( gens ); der Theil, der sich von diesen Gesetzen ausnimmt (die wilde Menge in diesem Volk), heißt Pöbel ( vulgus ), dessen gesetzwidrige Vereinigung das Rottiren

\footnotetext{
${ }^{12}$ Übersetzung M. K., Original: « Avant donc que d'examiner l'acte par lequel un peuple élit un roi, il serait bon d'examiner l'acte par lequel un peuple est un people; car cet acte, étant nécessairement antérieur à l'autre, est le vrai fondement de la société.» (Rousseau 1762: 16)
} 
( agere per turbas ) ist; ein Verhalten, welches ihn von der Qualität eines Staatsbürgers ausschließt.“ (Kant 1798: 311)

Turba ist der lateinische Ausdruck für ,Schar', ,Volkshaufen', ,Getümmel' oder auch ,Lärm‘. Rottiren ist ein altertümlicher Ausdruck für nicht gesetzeskonformen Zusammenschluss, insbesondere verwendet für den Zusammenschluss von Armen, protestierenden Handwerker_innen und Arbeiter_innen, der sich am ehesten im gegenwärtigen, vor allem für Tiere verwendeten Ausdruck der Zusammenrottung wiederfindet. Diese Varianten der Konstruktion des Pöbels, der keine Stimme hat, sondern Lärm macht, und insofern keinen Anteil am auf ,Vernunft ${ }^{*}$ begründeten Zusammenschluss der Bürger haben kann, verweist auf die systematischen Einschränkungen des nur scheinbar egalitären Verständnisses von Staatsbürgerschaft in der Aufklärung.

An dieser Stelle interessiert mich aber insbesondere Kants Begriff der gemeinschaftlichen Abstammung, durch den sich die Menschen einer Nation zu einem bürgerlichen ganzen erkennen würden. Im Folgenden erstellt Kant eine Art Tableau der Charakteristiken der verschiedenen Völker bzw. Nationen der Welt. Für ihn hat dabei jedes Volk seinen eigenen Charakter (Speich Chassé 1997: 6). Die Gründe für diese wesensmäßigen Unterschiede liegen dabei für Kant nicht im Klima oder der Regierungsform. Als Begründung führt er an, dass ein Volk trotz Wanderungsbewegungen seinen Charakter behalten würde bzw. er argumentiert, dass der Ursprung des Charakters einer Regierungsform im Charakter der Nation liegen müsse und nicht anders herum (Kant 1798: 313). Er unterscheidet dabei zwischen dem ,angebornen, natürlichen Charakter, der [...] in der Blutmischung der Menschen liegt“ und dem ,erworbenen künstlichen (oder verkünstelten)“ Charakter der Nationen (ebd.: 319). Das „Naturell, was sie jetzt wirklich haben [...] müßte dieses von dem angebornen Charakter des Urvolks ihrer Abstammung hergeleitet werden“ (ebd.).

Eine ,Vermischung' von ,Völkern' sieht er als große Gefahr an. So steht dem „flatterhaften und kriechenden der jetzigen Griechen“ ihre eigene ruhmreiche Vergangenheit gegenüber. Diesen vermeintlichen Niedergang sieht Kant in der „Vermischung der Stämme“ begründet, ,welche nach und nach die Charaktere auslöscht" und „dem Menschengeschlecht, alles vorgeblichen Philanthropismus ungeachtet, nicht zuträglich“ (ebd.: 321) ist. Auf Kants Tableau der Völker der Welt werden im Gegensatz zu den Charakterzeichnungen von Frankreich, England und Deutschland die „Charakterzeichnung der übrigen“ kürzer gefasst, da „,deren Nationaleigenthümlichkeit" nicht in erster Linie in ihrer „verschiedenen Cultur“ begründet ist, sondern aus der „Anlage ihrer Natur durch Vermischung ihrer 
ursprünglich verschiedenen Stämme“ (ebd.: 315) entspringe. So sei beispielsweise der ,,aus der Mischung des europäischen mit arabischem (mohrischem) Blut entsprungene Spanier“ aufgrund dieser ,Blutsmischung' zurückgeblieben:

„er lernt nicht von Fremden, reiset nicht, um andere Völker kennen zu lernen; in den Wissenschaften wohl Jahrhunderte zurück; schwierig gegen alle Reform ist er stolz darauf, nicht arbeiten zu dürfen, von romantischer Stimmung des Geistes, wie das Stiergefecht, [...] und zeigt in seinem Geschmack zum Teil außer-europäische Abstammung" (ebd.: 316).

Ich will an dieser Stelle zwei Punkte hervorheben, die mir für Kants Nationenverständnis zentral erscheinen. (1) Er hierarchisiert die Nationen danach, inwiefern sie zum Fortschritt geneigt sind (,wohl Jahrhunderte zurück"). Die zentrale Begründungsstruktur für die Bestimmung der fortschrittlichsten bzw. ,zivilisiertesten' Völker - Frankreich, England, Deutschland - im Gegensatz zum Rest ist der Wille zur Arbeit (,stolz darauf, nicht arbeiten zu dürfen“). Für Kant sind alle Völker aus warmen Klimazonen der Arbeit abgeneigt - wie hier im Beispiel der unter dem Einfluss der ,außer-europäischen Abstammung" stehenden Spanier. Dieses Defizit wird auch nicht durch eine Umsiedlung in andere Klimazonen aufgehoben, sondern bleibe Teil der Anlage des jeweiligen Volks. Dies wird unter anderem am antiziganistischen Figur des,$Z^{*} \mathrm{~s}^{13}$ in Kants Werk deutlich, der als Prototyp dafür gelten kann, da es laut Kants kolonial-nationalistischen Vorstellungen niemand dieser Volksgruppe es jemals geschafft habe, ,ein Geschäfte [zu] treiben, was man eigentlich Arbeit nennen kann“ und „niemals einen zu ansässigen Landanbauern oder Handarbeitern tauglichen Schlag abgeben wollen“ (Kant 1788: 174). (2) Neben dem Aspekt des Arbeitsethos als grundlegendem Kriterium der Unterscheidung der Anlage zur Fortschrittlichkeit der Völker wird am Beispiel ,des Spanier" wiederum die in Kants Werk zentrale Diskussion um die Weisen, Effekte und Gefahren der ,Vermischung' deutlich. Die Charakteristik ,des Spaniers' und ,seines' Volkes muss nicht - wie bei den ,civilisirtesten“ - über die gelebte ,Cultur', sondern über die ,Blutsmischung ' erklärt werden. Das Ideologem der ,Vermischung' respektive der ,Reinheit' ist ein zentrales Charakteristikum des ,rassischen“ Nationsverständnisses und hat eine lange Geschichte in Kolonialismus und Antisemitismus (Ha 2010).

Interessant ist, dass viele Völker sich nach Kant nicht zu Völkern entwickelt haben oder keine mehr sind. Das Volk ist nämlich für Kant nicht einfach qua

\footnotetext{
${ }^{13}$ Stark diskriminierende Wörter, wie das $\mathrm{N}^{*}$-Wort oder das $\mathrm{Z}^{*}$-Wort werde ich hier nicht ausschreiben, da es auch innerhalb einer kritisch intendierten Schrift verletzen kann und sie nicht noch ständig reproduziert werden müssen.
} 
Natur da, sondern nur die natürlichen Anlagen liegen bereit und warten darauf verwirklicht zu werden - der aktive Zusammenschluss des Volkes ist also nicht nur die republikanische Durchsetzung des volonté génerale, sondern dieser könne sich nur aus den natürlichen Anlagen eines Volkes entwickeln, wofür ,Reinheit" die Voraussetzung darstelle. Wenn diese Entwicklung noch nicht vollzogen oder schon vergangen ist, stellt das betreffende Volk für Kant kein existierendes Volk dar:

„Da Rußland das noch nicht ist, was zu einem bestimmten Begriff der natürlichen Anlagen, welche sich zu entwickeln bereit liegen, erfordert wird, Polen aber es nicht mehr ist, die Nationalen der europäischen Türkei aber das nie gewesen sind noch sein werden, was zur Aneignung eines bestimmten Volkscharakters erforderlich ist: so kann die Zeichnung derselben hier füglich übergangen werden." (Kant 1798: 319)

Es ist dabei kein Zufall, dass die Auswahl der, entwickelten Völker' auf die westeuropäischen fällt, an deren Spitze er die drei ,civilisirtesten Völker auf Erden“ (ebd.: 311) Frankreich, England und Deutschland sieht. Kants Theorie der Nation ist eng mit Rassismus und der kolonialen Weltordnung verbunden.

In Kants Werk insgesamt ist so der Begriff des Volkscharakters nicht stringent. Wird er im Kontext der Nation als die auf Abstammung und Blutslinie basierende Kontinuität einer mit einem Territorium verbundenen Bevölkerung verstanden, finden sich auch Stellen, an denen der Volkscharakter nicht an die Nation, sondern an ein supranationales Rassenverständnis gebunden wird. So nimmt er beispielsweise in seinem Text Bestimmung des Begriffs einer Menschenrace an, dass es keine ,erblichen Volkscharaktere [...] als die genannten vier gebe“ (Kant 1785: 93). Diese vier ,Rassen“ konstruiert Kant über die Hautfarbe und imaginiert die ,Rasse“ „der Weißen, der gelben Indianer, der $\mathrm{N}^{*}$ und der kupferfarbig $=$ rothen Amerikaner" (ebd.). Die Farbenlehre des Rassismus war lange auch in der kolonialen Literatur und Wissenschaft umstritten und hat sich so erst in der Zeit Kants begonnen durchzusetzen; die Farbgebung in diese vier erscheint zwar vielen als natürlich, hat aber weniger mit Pigmentierungen als vielmehr mit einer naturalisierenden Konstruktion politischer Kategorien zu tun (Hund 1999: 15 ff.). Auch zu Zeiten von Kant kann die biologistische Rassenkonstruktion über die Hautfarbe als umstritten bezeichnet werden. Als Beispiel sei hier ein Zitat von Georg Forster, einem Vertrauten Herders, angeführt: „Die meisten alten Eintheilungen der Menschengattung sind ohne dies schon längst verworfen. Noahs Söhne; die vier Welttheile; die vier Farben, weiß, schwarz, gelb, kupferroth, - wer denkt noch heut zu Tage an diese veralteten Moden?“ (Forster 1789: 151). 
Der Entwicklung einer philosophisch fundierten und systematisierten Rassenlehre sind große Teile von Kants Werk gewidmet. Eindeutig ist, dass viele Elemente aus Kants Rassenlehre auch in seinen Begriff der Nation eingeflossen sind. So ist das Ideologem der ,Vermischung " und der ,Reinheit" und die damit verbundene Gefahr des Niedergangs der Volkscharaktere in der Rassenlehre ein zentrales Element. Auch hier wird die ,Rasse“ über die „Zeugungsverwandtschaft durch Einheit der Abstammung" (Kant 1788: 177) konstruiert, mit deren imaginierten Funktionsweisen von ,Vererbung', ,Entartung', ,Anartung ' und den vielfältigen Effekten der sogenannten ,Rassenmischung' sich Kant ausführlich auseinandersetzt. Auch die Hierarchisierung der Völker, wie sie sich in seinem Begriff der Nation zeigte, hat seine Entsprechung in der Rassenlehre. Die vier von Kant konstruierten ,Rassen“ sind klar hierarchisiert: „Die Menschheit ist in ihrer größten Vollkommenheit in der Rasse der Weißen. Die gelben Indianer haben schon ein geringeres Talent. Die $\mathrm{N}^{*}$ sind weit tiefer, und am tiefsten steht ein Teil der amerikanischen Völkerschaften.“ (Kant 1802: 316) Träger von Fortschritt und Vernunft sind dabei für Kant nur die Weißen (Kleinschmidt 2013). Dabei zeichnet Kant akribisch, bildreich, systematisierend und ausführlich in zahlreichen Beiträgen eine Märchenwelt kolonialer Fantasien.

Nicht gänzlich geklärt bleibt das Verhältnis von ,Rasse“ und ,Nation“. Es finden sich lediglich einige Andeutungen, die für Kant unübliche begriffliche Uneindeutigkeiten beinhalten: So bezeichnet Kant die Nationen als „Familienschlag und den Varietäten, oder Spielarten [...], die sich in einer und derselben Rasse bemerken lassen“ (Kant 1798: 320). Hier habe die Natur vorgesehen, ,in einem Volk von derselben Rasse (z. B. der weißen)" sich nicht anzugleichen, sondern , in demselben Stamme I und gar in der nämlichen Familie, im Körperlichen und Geistigen, ins Unendliche zu vervielfältigen“ (ebd.). Volk wird hier abwechselnd anhand der Familie bzw. ,Rasse“ oder aufgrund der Nation bestimmt. Diese Ungereimtheit zieht sich durch zahlreiche koloniale, postkoloniale und nationalistische Diskurse. Die Ordnung der Welt in ,Rassen' referiert dabei auch auf die Einteilung der Welt in Nationen. Nationale Identitätskonstruktionen sind in zahlreichen historischen und gegenwärtigen Kontexten eng mit einem ähnlich wie Kant vorgelegten Konstrukt von ,Rassen“ verknüpft.

Balibar sieht zwar keine Notwendigkeit, die vom Rassismus zum Nationalismus oder andersherum führt, ausgehend von der Analyse zahlreicher historischer Einzelfälle führt er aber den Begriff des ,historischen Reziprozitätszyklus von Nationalismus und Rassismus" (Balibar 1988a: 68) ein. Das bedeutet, dass der „Rassismus [...] aus dem Nationalismus“ und anders herum der „Nationalismus [...] aus dem Rassismus“ (ebd.) hervorgeht. Es steckt jedoch - und hier liegt vielleicht der Grund für die Kontinuität der Unklarheit der Beziehung von 
Nation und ,Rasse' in der rassistischen Theorie - auch ein Widerspruch in dem Verhältnis bestimmter Formen. Als Beispiel führt Balibar hier historische Konstellationen an, wie etwa die entstehenden Widersprüche nationaler und rassistischer Zugehörigkeit beim Versuch der Assimilation einer kolonisierten Bevölkerungsgruppe wie etwa in Algerien. Er definiert Rassismus insofern nicht als „Ausdruck des Nationalismus“, sondern als eine ,innere Ergänzung des Nationalismus, die immer über ihn hinausschießt, für seine Konstituierung aber stets unerläßlich ist und nie ausreicht, um sein eigenes Projekt zu realisieren“ (ebd.: 69).

Nochmal zusammenfassend zu den Aspekten aus Kants Werk, die für eine Theorie der Nation als Abstammungsgemeinschaft relevant sind: In diesem „Modus der Ethnisierung“, also der Herstellung des ,Volks“ über die ,Rasse‘, wird der Zusammenhalt nach dem Schema der Genealogie über die Abstammung konstruiert. Hier liegt die Vorstellung zugrunde, dass ,,jede Generation der anderen eine biologische und geistige Substanz übermittelt und sie gleichzeitig in eine zeitliche Gemeinschaft stellt, die man ,Verwandtschaft" nennt" (Balibar 1988b: 123). Um die Fiktion einer ,rassischen“ Identität zu erzeugen, also als natürlich und vererbbar imaginierte Differenzen zwischen sozialen oder vorgestellten Gruppen herzustellen, werden vielfältige sichtbare oder unsichtbare somatische und psychologische Merkmale konstruiert und in spezifische Verhältnisse gesetzt (ebd.: 122). Die Konstruktion einer auf ,Rasse' basierenden Konstruktion eines nationalen Volkes ist eng mit der Konstruktion des Rassismus verbunden. Nationale, auf dem Ideologem der , Rasse' basierende Identität ist also immer im Zusammenhang mit transnationalen Diskursen zu sehen. Die Eliten der kolonisierenden Nationen haben gemeinsam die „Idee von einer ,weißen“ Überlegenheit, von der Verteidigung der Zivilisation gegen die Wilden aufgebaut" (ebd.). Das koloniale Ideologem der „Bürde des weißen Mannes“ hat in entscheidender Weise dazu beigetragen, ,die moderne Vorstellung von einer europäischen oder westlichen, supranationalen Identität zu schaffen." (ebd.)

Oft wird suggeriert, es gäbe einen Wandel, der das ,rassische“ Verständnis von nationalen oder supranationalen Identitäten in der Vergangenheit verortet und behauptet, dies sei von einer neuen Form zum Beispiel Sprache oder Kultur abgelöst worden. Es ist zuzustimmen, dass die vielfältigen antirassistischen und antikolonialen Kämpfe der letzten Jahrzehnte dafür gesorgt haben, dass eine explizite Artikulation weißer Überlegenheit selten mehrheitsfähig ist. Implizit ist aber die Kopplung von Zugehörigkeits- und Überlegenheitskonstruktion nach wie vor eng an somatische Vorstellungen gekoppelt. Dies hat sich auch im Rahmen der Analyse der Farbe als Zugehörigkeitsmarker gezeigt, in der deutlich wurde, dass ein auf biologischen , Rassen“ begründeter Rassismus zwar nicht häufig offen artikuliert, in der Wahrnehmung der negativ von ihm Betroffenen aber virulent ist. 
Leider ist Achille Mbembes Einschätzung zuzustimmen, dass die Welt eine „Welt der Rassen" geblieben ist:

„In mehrfacher Hinsicht ist unsere Welt, auch wenn sie das nicht zugeben möchte, bis heute eine ,Welt der Rassen“ geblieben. Der Rassensignifikant ist immer noch die unumgängliche, wenngleich gelegentlich bestrittene Sprache der Darstellung des Selbst und der Welt, des Verhältnisses zum Anderen, zum Gedächtnis und zur Macht.“ (Mbembe 2014: 111)

\subsection{Fichte: Nation als Sprachgemeinschaft}

Johann Gottlieb Fichte (1762-1814) ist einer der umstrittensten Philosophen des Deutschen Idealismus: Von konservativen Kräften als Atheist und Sozialist verunglimpft, galt er in kritisch-liberalen Kreisen als nationalistisch oder gar Vordenker des Nationalsozialismus; die Interpretation Fichtes schwankt so zwischen der Bewertung als „Herold der Freiheit“ oder „Wegbereiter des Totalitarismus“ (Balibar 1997: 122; zur Rezeptionsgeschichte siehe auch Becker 2000: 17 ff.). Letzteres wurde nicht zuletzt durch die Nutzung seines Werks durch antidemokratische und national-konservative Kräfte im und nach dem Ersten Weltkrieg sowie durch den Nationalsozialismus bestärkt. Insbesondere seine Reden an die deutsche Nation gelten - international - als Schlüsseltext zum Verständnis des völkischen und chauvinistischen deutschen Nationalismus. Unbestritten ist, dass sie in Kriegszeiten für nationalistische Mobilisierung genutzt wurden. Sie gehörten beispielsweise zur Standardausstattung der Feldbibliotheken der deutschen Truppen im Ersten Weltkrieg; es gibt auch Hinweise darauf, dass die Reden 1915 nachgedruckt und zu vielen Tausenden an die Soldaten verteilt wurden (Lamarre 2002: 1; Balibar 1997: 122). Beide Thesen - die des Vordenkers des Nationalsozialismus, inklusive eines essentialistischen, überhistorischen und aggressiven Nationsbegriffs, sowie der eines republikanisch-freiheitlichen Vordenkers - treffen aus meiner Sicht nur sehr eingeschränkt zu. In der von mir in Anlehnung an Balibar entwickelten Lesart stellt Fichte vielmehr einen Vertreter eines Nationsbegriffs dar, der weniger bzw. anders essentialisiert, als es die gängigen Interpretationen den Anschein machen. Aus meiner Perspektive begründet er die Nation nicht mit dem Paradigma von ,Rasse' und Abstammung, sondern auf Grundlage eines Begriffs der Sprachgemeinschaft, der die lebendige Sprache zur Essenz der Nation erklärt - und dies erscheint mir das wirklich Problematische an Fichtes Nationsbegriff.

Fichte war ein glühender Anhänger der französischen Revolution und des Egalitarismus. Im Gegensatz zu Kant hat er eine weitgehende Demokratisierung der Gesellschaft gefordert. Der Preis für seine Befürwortung des Atheismus und 
der Demokratisierung war ein Leben in Prekarität, da er aus politischen Gründen keine feste Anstellung finden oder diese nicht lange behalten konnte. Erst seine Reden an die deutsche Nation von 1807 bis 1808 und seine Rolle in der aufkommenden nationalistischen Bewegung machten ihn 1810 zum Rektor der Berliner Universität. Statt eine Geschichte des frühen, kosmopolitischen, ,guten * Fichte hin zum alten, nationalistischen, ,bösen' Fichte zu schreiben, schlage ich in Anlehnung an Balibar (1997: 122 ff.) eine Lesart vor, die nach den Widersprüchen und Paradoxien in Fichtes Werk suchen, um damit auch den paradoxalen und brüchigen Funktionsweisen nationaler Zugehörigkeitsregime nachzuspüren. Dabei werde ich mich weitestgehend auf die Reden beschränken und mich dabei mit den drei Begriffen ,innere Grenzen“, „Ursprünglichkeit“ und „Bildung“ auseinandersetzen.

Das folgende Zitat beinhaltet bereits alle wesentlichen Komponenten, die ich anschließend darstellen werde:

\begin{abstract}
„Zuvörderst und vor allen Dingen: Die ersten, ursprünglichen, und wahrhaft natürlichen Grenzen der Staaten sind ohne Zweifel ihre innern Grenzen. Was dieselbe Sprache redet, das ist schon vor aller menschlichen Kunst vorher durch die bloße Natur einer Menge von unsichtbaren Banden aneinandergeknüpft; es versteht sich untereinander, und ist fähig, sich immerfort klarer zu verständigen, es gehört zusammen, und ist natürlich Eins, und ein unzertrennliches Ganzes. Ein solches kann kein Volk anderer Abkunft und Sprache in sich aufnehmen und mit sich vermischen wollen, ohne wenigstens fürs erste sich zu verwirren, und den gleichmäßigen Fortgang seiner Bildung mächtig zu stören. Aus dieser innern, durch die geistige Natur des Menschen selbst gezogenen Grenze ergibt sich erst die äußere Begrenzung der Wohnsitze, als die Folge von jener, und in der natürlichen Ansicht der Dinge sind keineswegs die Menschen, welche innerhalb gewisser Berge und Flüsse wohnen, um deswillen Ein Volk, sondern umgekehrt wohnen die Menschen beisammen, und wenn ihr Glück es so gefügt hat, durch Flüsse und Berge gedeckt, weil sie schon früher durch ein weit höheres Naturgesetz Ein Volk waren.“ (Fichte 1808: 193)
\end{abstract}

Was macht nach Fichte ein Volk zum Volk? Die Einheit eines Volkes ist nicht territorialer oder - wie bei Kant - ,rassischer', sondern sprachlicher Natur, die der staatlichen Einheit vorausgeht. Sprache ist dabei etwas Geistiges; die durch sprachliche Identität zum Ausdruck kommenden Grenzen sind in diesem Sinne keine ,äußeren', sondern ,innere“ Grenzen. Die Verlagerung auf die Innerlichkeit ist dabei auch der historischen Situation der Besatzung ,Deutschlands' durch die napoleonischen Truppen geschuldet. Die äußeren Grenzen (insofern es angesichts der brüchigen Souveränität der deutschen Staaten und der Fiktion des RömischDeutschen Reichs überhaupt zulässig ist, von deutschen Grenzen zu sprechen) sind durchbrochen und zerstört. Napoleon verkündet in Berlin die Auflösung des 
Heiligen Römischen Reichs Deutscher Nation und schreibt einen Teil von dem als ,Deutschland“ proklamierten Territoriums dem Rheinbund zu. Die ,innere Grenze“ von Fichte kann in dieser Situation sowohl als Refugium und Zufluchtsort als auch als Bollwerk des Widerstands verstanden werden (Balibar 1997: 127 f.). In jedem Fall fordert sie von jedem ,Deutschen' die Schaffung, innerer Grenzen ' in Abgrenzung zur, ausländischen ' Besatzungsmacht und gegen die ,Französierung ‘ In der Auslegung der Organisatoren der Freiwilligenverbände, die die ,nationalen Befreiungskriege' von 1813 (hier liegt Balibar zufolge übrigens der Ursprung dieses Begriffs) vorbereitet hatten und von denen einige auch unter Hörern der Reden von 1808 gewesen waren, wurde darunter jedenfalls der Aufruf zum Widerstand und auch ganz praktisch der Ruf zu den Waffen verstanden (ebd.: 129).

Im oben aufgeführten Zitat begegnen wir wieder dem Ideologem der, Vermischung ' - allerdings in grundlegend anderer Form als bei Kant, der einem primär ,rassischen “ Verständnis folgt. Fichte sagt, ein Volk kann „kein Volk anderer Abkunft und Sprache in sich aufnehmen und mit sich vermischen wollen, ohne wenigstens fürs erste sich zu verwirren, und den gleichmäßigen Fortgang seiner Bildung mächtig zu stören“ (Fichte 1808: 193). Die „unsichtbare Bande“, die eine bloße Menge zu einem Volk aneinanderknüpfe, ist bei Fichte nicht etwa die vorgeschichtliche Anlage, die sich dann entfalten müsse, sondern wird hergestellt (,gleichmäßige[r] Fortgang seiner Bildung“ (ebd.)). Das Volk ,versteht sich untereinander, und ist fähig, sich immerfort klarer zu verständigen“ (ebd.). Es geht also nicht um eine ,rassische" oder wie auch immer auf organizistisch-biologischen Abstammungsfantasien basierende Genealogie, sondern um die Verbesserung der Verständigungsfähigkeit einer Menge, die dadurch zum Volk wird, zu einem „unzertrennliche[n] Ganze[n]“ (ebd.).

Nachdem er empirisch dargelegt hat, dass kein germanisches Volk die „Reinheit seiner Abstammung“" (ebd.: 53) behaupten könne, führt er sein Konzept der „ursprünglichen Sprache“ ein:

„Bedeutender aber, und wie ich dafürhalte, einen vollkommenen Gegensatz zwischen den Deutschen, und den übrigen Völkern germanischer Abkunft begründend, ist die zweite Veränderung, die der Sprache; und kommt es dabei [...] weder auf die besondere Beschaffenheit derjenigen Sprache an, welche von diesem Stamme beibehalten, noch auf die der andern, welche von jenem andern Stamm angenommen wird, sondern allein darauf, daß dort Eigenes behalten, hier Fremdes angenommen wird; noch kommt es an auf die vorige Abstammung derer, die eine ursprüngliche Sprache fortsprechen, sondern nur darauf, daß diese Sprache ohne Unterbrechung fortgesprochen werde, indem weit mehr die Menschen von der Sprache gebildet werden, denn die Sprache von den Menschen." (ebd.: 53) 
Ins Auge sticht natürlich die Behauptung der Überlegenheit der Deutschen. Die von Fichte oft vertretene Ansicht der Überlegenheit über andere Völker ist ein wesentlicher Anschlusspunkt für imperiale Großmachtfantasien deutschnationaler Bestrebungen. Die gleichzeitige Verwerfung des Abstammungsmythos macht die Sache allerdings komplexer und auch fruchtbar für diese Analyse. An die Stelle von beispielsweise der prinzipiell ,egalitären Vielfalt der ethnischnationalen Kulturquellen“ (Balibar 1997: 138), die Herder verteidigt, tritt ein ,Urvolk' (die Deutschen) oder vielleicht zwei (die Deutschen und die Griechen). Kernbegriffe, wie „das Volk einer Ursprache“ und von ,einem Volke, das in seiner ursprünglichen Sprache sich fortbildet" (Fichte 1808: 83), die den meisten Interpretationen nach auf einen quasi vorhistorischen, essenzialisierten Ursprung verweisen, erscheinen so in einem völlig anderen Licht. Nicht die Abstammung, sondern die ohne Unterbrechung fortgesprochene Sprache zählt. Ursprünglichkeit bezieht sich also nicht auf einen Zeitpunkt in der Vergangenheit oder auf eine überzeitliche Entität, sondern liegt in der Zukunft - oder genauer: In der Möglichkeit des „gleichmäßigen Fortgangs seiner Bildung“ (ebd.: 193). Diese Umkehrung des Ursprungsbegriffs führt dazu, dass die Frage, was ein Volk zum Volk macht als Effekt des Verhältnisses des Volkes zur sprachlichen Herkunft verstanden wird. Die Kontinuität des Wesens der Nation ergibt sich nicht über die ,natürliche' Abfolge der Generationen, sondern über die Sprache. Die Aussage, dass weit mehr die Menschen von der Sprache gebildet werden, verweist auf ein Verständnis von Sprache, der ein ,unermesslicher Einfluß“ zugeschrieben wird, da sie den „Einzelnen bis in die geheimste Tiefe seines Gemüths bei Denken und Wollen begleitet" und die ,gesammte Menschenmenge, die dieselbe Sprache redet, auf ihrem Gebiete zu einem einzigen gemeinsamen Verstande verknüpft, welche der wahre gegenseitige Durchströmungspunkt der Sinnenwelt und der der Geister ist" (ebd.: 64).

Es drängt sich die Frage auf, an der sich alles zu entscheiden scheint: Was ist denn nun die „ursprüngliche Sprache“ bzw. die „Ursprache“"? Die romantischen Sprachtheoretiker in der Epoche Fichtes hatten die klassisch-rationalistische Frage nach dem Ursprung der Sprachen, wie etwa bei Rousseau, durch die Frage nach der historischen ,Ursprache' ersetzt. Mit den neuen Methoden der vergleichenden Grammatik wurde auf die Vorgängigkeit des Indogermanischen geschlossen und in den kolonial und eurozentristisch strukturierten Wissenschaften über genealogische Tableaus disputiert. Diesen genetischen Gesichtspunkt lässt Fichte allerdings völlig außer Acht. Auch wenn er mit diesen Begriffen spielt, sind sie nicht sein Thema - genau wie er auch über die linguistische Beschaffenheit der Sprache und der Grammatik hinwegsieht. Auch das Ideologem der ,Reinheit", das für Fichtes Begriff der Nation eine wichtige Rolle spielt, bietet keine hinreichende 
Erklärung der Ursprache. Zwar behauptet er, dass es nur darauf ankäme, dass „dort Eigenes behalten, hier Fremdes angenommen wird“ und die „Sprache ohne Unterbrechung fortgesprochen" (ebd.: 53) wird. Allerdings wird an vielen Stellen deutlich, dass der Zugang zur Sprachgemeinschaft Menschen anderer Herkunft prinzipiell offen steht. Es sind nicht die Deutschen, sondern die deutsche Sprache, die den anderen Nationen überlegen sei; dabei kann „der Ausländer“ die deutsche Sprache erlernen, auch wenn Fichte diesen Prozess als „höchst mühsam“ (ebd.: 64) bezeichnet.

Fichtes Begriff der Ursprache erklärt sich über das Begriffspaar der lebendigen und der toten Sprache. Der Begriff der lebendigen Sprache bestimmt sich durch die Beziehung von Bildung und Sprache des Volkes: „Beim Volke der lebendigen Sprache greift die Geistesbildung ein ins Leben; beim Gegenteile geht geistige Bildung und Leben jedes seinen Gang für sich fort.“ (ebd.: 68) Das Ursprüngliche der Ursprache ist also kein Verweis auf eine reine, unverfälschte Vergangenheit bzw. - mit Derrida - eine vergangene und zu vergegenwärtigende Präsenz; in einer lebendigen Sprache ,vermehren und verändern die Worte und ihre Bedeutungen“ sich immerfort, es „werden neue Zusammenstellungen möglich“ und lebendige Sprache ist eine, „die niemals ist, sondern ewigfort wird“ (ebd.: 77). Dies gilt für Fichte aber nur, wenn „nur in ihr wirklich gelebt wird“ (ebd.). In einem Volk einer toten Sprache würden die ,gebildeten Stände vom Volke sich scheiden, und es letztern nicht weiter, denn als eines blinden Werkzeugs ihrer Pläne achten“" (ebd.: 65). Fichte plädiert insgesamt für eine Nationalerziehung, womit nicht in erster Linie eine Erziehung zu nationalistischem Denken gemeint ist, sondern eine Erziehung, die alle Stände des Volkes erfasst. Er plädiert für eine Demokratisierung von Bildung. Es geht ihm darum, dass die geistige Bildung, also die Wissenschaften und die Künste (und insbesondere die Philosophie) Teil des Lebens, des Alltags der Menschen des Volks werden. Für Fichte sind der „Gedanke“ und die „Thätigkeit" nur in ,der Erscheinung auseinanderfallende Formen, jenseits der Erscheinung aber sind sie [...] dasselbe Eine absolute Leben"; es ist nicht „der Gedanke um des Thuns, oder das Thun um des Gedankens willen“ (ebd.: 69). Eine lebendige Sprache bringt nach Fichte beides zusammen; in einer Nation einer lebendigen Sprache sei das ,große Volk bildsam, und die Bildner einer solchen erproben ihre Entdeckungen an dem Volke, und wollen auf dieses einfließen" (ebd.: 65). Fichte folgert hieraus, dass das Volk einer lebendigen Sprache mit ,aller Geistesbildung rechter eigentlicher Ernst“ sei und sie wollen würden, dass „dieselbe ins Leben eingreife“ (ebd.).

Dies steht im Gegensatz zu einer toten Sprache, die auf der Trennung von Geistesleben und alltäglichem Tun basiere und für die das Geistesleben nur ein „genialisches Spiel“ sei. Deswegen hätten die Völker der lebendigen Sprachen 
zum bloßen Geist auch noch „Gemüth“ (ebd.). Daraus folge, so Fichte weiter, dass die Völker der lebendigen Sprachen ,redlichen Fleiß und Ernst in allen Dingen“ hätten, während die der toten Sprachen sich im „Geleite ihrer glücklichen Natur gehen lassen“ (ebd.) würden. Über den auf der Sprachgemeinschaft basierenden Begriff der Nation wird hier das Arbeitsethos als Überlegenheitsmerkmal des Deutschen eingeführt. Dies ist ein wichtiger Baustein für damit in Verbindung stehende Legitimationsmuster von Ressentiments gegen „Neulateiner“ (ebd.: 64), wie im Antiziganismus, Antisemitismus und anderen Formen von Rassismus; die prototypischen und konstitutiven Negativa der imaginierten, deutschen Nation. In der früheren Schrift Beitrag zur Berichtigung der Urteile des Publikums über die französische Revolution von 1793 finden sich beispielsweise ,passende 'Passagen, die Aufschluss über mögliche Denkfiguren des Nationalismus geben können.

Auch wenn das Judentum in Fichtes Spätwerk, wie auch in den Reden, kaum eine Rolle spielt, sind dort implizit darauf bezogene Argumentationsfiguren präsent. In dem genannten Text von 1793 wird „,das Judentum“ als ein „mächtiger, feindselig gesinnter Staat“ imaginiert, das „,ich zu dem den Körper erschlaffenden, und den Geist für jedes edle Gefühl tötenden Kleinhandel verdammt hat und verdammt wird" (Fichte 1793: 114). Zur Untermauerung seiner Forderung der Nicht-Vergabe von Bürgerrechten an Jüdinnen und Juden halluziniert er die Angst, dass „der erste Jude, dem es gefällt, mich ungestraft ausplündert“ und so den Deutschen die „bürgerliche Ehre und mit Würde verdientes Brot“ (ebd.) genommen wird. Fichte sieht die deutsche Nation vom Judentum bedroht und will deswegen verhindern, dass Jüdinnen und Juden Bürgerrechte verliehen werden:

\begin{abstract}
„Aber ihnen Bürgerrechte zu geben, dazu sehe ich wenigstens kein Mittel, als das, in einer Nacht ihnen allen die Köpfe abzuschneiden, und andere aufzusetzen, in denen auch nicht eine jüdische Idee sei. Um uns vor ihnen zu schützen, dazu sehe ich wieder kein anderes Mittel, als ihnen ihr gelobtes Land zu erobern und sie alle dahin $\mathrm{zu}$ schicken.“ (Fichte 1793: 115)
\end{abstract}

Hier geht es nicht in erster Linie um die physische Liquidierung einer Menschengruppe, sondern um „deren gewaltsame Assimilation“ (Hentges 1999: 119). Einerseits wird so eine unumstößliche Differenz behauptet, die nur durch Vernichtung aufgehoben werden könne und andererseits auch eine vollständige Veränderbarkeit unterstellt, die auf die Assimilation zielte. Nur wenn die Juden ihr Jüdisch-Sein abgelegt hätten, dürften sie zu Bürgern des Nationalstaats wer$\operatorname{den}^{14}$ (Rommelspacher 2009: 35). Das Problem, das Fichte im Judentum - dem

\footnotetext{
${ }^{14}$ Damit greift Fichte einer Aktion des späteren napoleonischen Staates voraus, der geistlichpolitische Führer der jüdischen Bevölkerung in Frankreich 1806 und 1807 eine Erklärung
} 
„Staat im Staate“ (Fichte 1793: 115) - sieht, ist also ihr vermeintlicher Unwillen zur Assimilation bzw. Integration.

Der Hauptvorwurf Fichtes in den übrigen Textpassagen ist die vermeintliche Nicht-Akzeptanz der Menschenrechte durch das Judentum (ebd.: 114 ff.). Und genau die Achtung ,republikanischer“ Werte, wie der Menschenrechte - um wieder zurück auf unseren Ausgangstext, die Reden zu kommen - ist ein mit der Präsenz der lebendigen Sprache korrelierendes Attribut, das Fichte insbesondere den Deutschen zuschreibt: „Die deutsche Nation ist die einzige unter den neueuropäischen Nationen, die es an ihrem Bürgerstande schon seit Jahrhunderten durch die That gezeigt hat, daß sie die republikanische Verfassung zu ertragen vermöge." (Fichte 1808: 94) Für diese ,universelle Mission' Deutschlands führt Fichte nicht etwa irgendwelche Prädestinationen oder natürliche Überlegenheiten, sondern die spezifische historische Konstellation an. Sein Geschichtsbild lässt sich leicht zusammenfassen: Vom römischen Imperialismus über seine Fortsetzung im Mittelalter mit dem Traum einer universellen Monarchie, in der sich die römische Staatsauffassung mit der kirchlichen Autorität verbindet, werden die nationalen Besonderheiten negiert. In Bezug auf Tacitus behauptet Fichte, dass diese Herrschaft von Anfang an im Widerstand der Germanen ihre Grenze fand (ebd.: 205). Der Imperialismus wollte alle sich gleich machen und hinterließ dabei ,nur eine leere Stätte [...], in der sie nur immer die eigene Gestalt wiederholen können; selbst ihr anfängliches scheinbares Hineingehen in fremde Sitte ist nur die gutmütige Herablassung des Erziehers zum jetzt noch schwachen [...] Lehrlinge" (ebd.: 204). Für Fichte findet bei Völkern, die ,selbst ihre Eigenthümlichkeit beibehalten und dieselbe geehrt wissen wollen“ und ,auch den anderen Völkern die ihrige zugestehen, und sie ihnen gönnen und verstatten“ (ebd.: 203), eine „höchst wohltätige Wechselwirkung der gegenseitigen Bildung und Erziehung statt, und eine Durchdringung, bei welcher dennoch jeder, mit dem guten Willen des andern, sich selbst gleich bleibt" (ebd.: 204). Von der natürlichen Unabhängigkeit schreitet ein solches Volk zum Selbstbewusstsein voran, das heißt zum „Bewusstsein des ,Selbst“ in Kultur und Erziehung“" (Balibar 1997: 130).

Neue historische Subjekte treten nun gegen die staatliche und kirchliche Uniformität auf, die sich aus den Fürsten und ihrer Völker ergeben - „die einen herrschend, aber getrieben von partikularen Interessen, die anderen Untertan, aber Vertreter von allgemeinen Interessen, also in Wahrheit aktiv" (ebd.: 132, Herv. i. O.). Wenn sich diese Interessen verbinden, schreitet die Menschheit voran,

hat abgeben lassen, in der es unter anderem hieß: „Heutzutage bilden die Juden keine Nation mehr, sie genießen vielmehr den Vorzug, in die Große Nation eingegliedert zu sein, was sie als ein politische Erlösung betrachten.“ (zitiert nach Estel 2013: 241). 
wie zum Beispiel in der Reformation (Fichte 1808: 86 ff.). Die damit beginnende neue Epoche ist nach Fichte gekennzeichnet durch die Selbstsucht der Völker. Sie gehorchen nun dem „Trieb zur Selbstbehauptung auf Kosten der anderen; sie werden zum Werkzeug ehrgeiziger Dynastien“ (Balibar 1997: 132). Diese Situation nimmt - untermauert durch den Westfälischen Friedens - die Form eines europäischen „Gleichgewichts“ (Fichte 1808: 195) an. Das Problem dieses Gleichgewichts und der Grund warum es niemals zu wahrem Frieden führen kann, lägen aber darin, dass es auf Selbst- und Habsucht aufbaut und dies keine Grundlage zur inneren und äußeren Befriedung darstellen kann. Die einzelnen Teile des „,christlichen Europas“ buhlten um eine ,gemeinschaftliche Beute [...] nach der jeder auf die gleiche Weise begehrte, weil alle sie auf die gleiche Weise gebrauchen konnten, und die jeder mit Eifersucht in den Händen des anderen erblickte“ (ebd.: 194). Dies stellt den Grund für die „geheime Feindschaft und Kriegslust aller gegen alle dar" (ebd.). Fichte plädiert nun dafür, dass Deutschland sich nicht ,die entbehrlichen Waaren, die in fremden Welten erzeugt werden, zum Bedürfnisse" (ebd.: 198) mache, wie es die anderen Völker getan haben. Deutschland habe nach Fichte Glück gehabt, keine Kolonialmacht gewesen sei bzw. in seinen Worten „keinen unmittelbaren Antheile am Raube der anderen Welten“ (ebd.: 194) gehabt zu haben, und solle ,lieber unserm freien Mitbürger erträgliche Bedingungen“ machen, ,als von dem Schweiße und Blute eines armen Sklaven jenseits der Meere Gewinn ziehen zu wollen“ (ebd.: 199). Dies hätte die anderen Nationen zu einem „Marktplatz [...] zu Grunde gerichtet“ (ebd.).

Fichte bezieht sich hier explizit auf ein anderes Werk von ihm, den Geschloßnen Handelsstaat von 1800, aus dem ich im Folgenden für die Nachvollziehbarkeit seiner Argumentation in den Reden kurze Auszüge darstellen werden. Dieser war ein extrem umstrittener Text, der Ironie und Gespött von Hegel und anderen Liberalen seiner Zeit auf sich zog und später als egalitaristische Utopie, Neuformulierung eines archaistischen Merkantilismus, Vorwegnahme sozialistischer Planwirtschaft oder im Sinne eines ökonomischen Nationalismus gedeutet wurde (Balibar 1997: 133). Von seinen Spöttern am stärksten hervorgehoben werden dabei vermutlich die Forderung nach der Abschaffung des Rechts auf Grundbesitz im Namen des Rechts auf Arbeit sowie die Schließung der Grenzen für jeden Güter- und Personenverkehr mit Ausnahme von Gelehrten und Künstlern, die dem Kulturaustausch dienen (ebd.). Das Ziel des von Fichte favorisierten geschlossenen Handelsstaates besteht dabei sowohl in der Herstellung des sozialen Friedens im Innern als auch des allgemeinen Friedenszustands nach außen. Beides scheitert insbesondere an einem: der Macht des Geldes. Im geschlossenen Handelsstaat oder auch dem „Vernunftstaate“ (Fichte 1800: 11), in dem die „Bürger mit dem Ausländer keinen unmittelbaren Handel treibt“ (ebd.: 47), soll es zwar auch Geld 
geben. Der Wert des Geldes ist dabei aber nicht dem Weltmarkt überlassen, sondern wird zum einen den ,vernünftigen ' Entscheidungen des Staates und zum anderen der tatsächlich innerhalb einer Nation existierenden Menge an Waren angepasst (ebd.: 45 ff.). Das Geld wird also komplett nationalisiert und jede Beziehung zum Weltmarkt gekappt. Der Überschuss des ,inneren Reichtumes der Nation“ wird dann für den „Gebrauch des Volkes in Anspruch genommen“ (ebd.: 46).

In impliziter, aber eindeutiger Kritik an Kant, welcher seinen Begriff des Kosmopolitismus und Weltbürgertums immer als die grenzüberschreitende Zirkulation sowohl von Ideen als auch von Waren gesehen hat, sieht Fichte im Kosmopolitismus eine Diskrepanz zwischen dem, was er sagt und dem was in seinem Namen tatsächlich geschieht. Kosmopolitismus ist keineswegs die Auflösung der nationalen Rivalitäten, sondern Ausdruck derselben. Nach Balibar sind für Fichte der moderne Imperialismus napoleonischer Prägung und der wirtschaftliche Liberalismus die ,,französische“ und ,englische“ Variante des Weltbürgertums“ (Balibar 1997: 135), die beide beanspruchen das europäische Gleichgewicht zu ihren Gunsten aufzuheben. Sie sind insofern gleich, als dass sie ein Ungleichgewicht etablieren und den Grund für die Kriege und für die Aufrechterhaltung des Gegensatzes zwischen dem ,einfachen Volk' und den Gebildeten aller Nationen darstellen. Beide Formen sind „Veräußerlichungen des sozialen ,Bandes', in der das ,Selbst' sich verliert, indem es sich (im ,Fremden', dem ,Auslande") vergeblich außerhalb seiner selbst sucht" (ebd.).

Deutschland - um auf das Geschichtsbild aus den Reden zurückzukommen - habe nach Fichte hier das ,Privileg', dass es als nicht-staatliches Gebilde solche Dynamiken nicht entfalten konnte. Fichte sieht in diesem Nicht-Staat „im Mittelpunkte von Europa“ (Fichte 1808: 195) die Möglichkeit das unheilbringende Gleichgewicht aufzulösen. „In der Mitte von Europa hätte der feste Wall der Deutschen“ (ebd.: 196) der Rivalität und den Kriegen trotzen können. Aber nach Fichte war es „,das Ausland“, das mit „,ausländischer Schlauheit“ die ,deutsche Unbefangenheit und Verdachtslosigkeit" ausnutzte und aus der vereinigten „gemeinschaftlichen Kraft“ eine zerteilte Vielheit werden ließ - im Sinne von Kleinstaaterei und dem Auseinanderklaffen des gemeinen Volks und der Gebildeten -, um das vermeintliche Gleichgewicht zu erhalten und Deutschland selbst zur Beute zu machen. Aufgrund dieser historischen Konstellation komme nach Fichte Deutschland die Bürde zu, die gegenwärtige Situation aufzulösen. Die Unabhängigkeit und nationale Vereinigung Deutschlands ist aus diesen Gründen also nicht nur im Interesse des deutschen Volks, sondern ganz Europas, wenn nicht der ganzen Welt. 
Wie aber stellt sich Fichte nun die Herstellung dieser Einheit vor? Wir haben bereits gesehen, dass die Herstellung der Ursprache nicht in der Vergangenheit, sondern in der Zukunft liegt. Fichte ist dabei die Notwendigkeit des staatlich induzierten Prozesses des Nation-Buildings mehr als präsent: „Der vernunftgemäße Staat läßt sich nicht durch künstliche Vorkehrungen aus jedem vorhandenen Stoffe aufbauen, sondern die Nation muß zu demselben erst gebildet und herausgezogen werden." (Fichte 1808: 91) Dementsprechend sind die Reden auch die Grundlegung eines Programm zur ,deutschen Nationalerziehung“ (ebd.: 147). Es ist ,diejenige bestimmte Erziehung, von der wir uns die Rettung der deutschen Nation versprechen“ (ebd.: 136). Charakterisiert wird diese Nationalerziehung insbesondere durch die Aufhebung des Unterschieds der sozialen Stände, die die Bedingung für die Herstellung eines tatsächlichen einheitlichen Willens der Nation darstellt:

\begin{abstract}
„Wir wollen durch die neue Erziehung die Deutschen zu einer Gesammtheit bilden, die in allen ihren einzelnen Gliedern getrieben und belebt sei durch dieselbe Eine Angelegenheit; so wir aber etwa hierbei abermals einen gebildeten Stand, der etwa durch den neu entwickelten Antrieb der sittlichen Billigung belebt würde, absondern wollten von einem ungebildeten, so würde dieser letzte, da Hoffnung und Furcht, durch welche allein noch auf ihn gewirkt werden könnte, nicht mehr für uns, sondern gegen uns dienen, von uns abfallen, und uns verloren gehen. Es bleibt sonach uns nichts übrig, als schlechthin an alles ohne Ausnahme, was deutsch ist, die neue Bildung zu bringen, so daß dieselbe nicht Bildung eines besonderen Standes, sondern daß sie Bildung der Nation schlechthin als solcher, und ohne alle Ausnahme einzelner Glieder derselben, werde, in welcher, in der Bildung zum innigen Wohlgefallen am Rechten nämlich, aller Unterschied der Stände, der in andern Zweigen der Entwicklung auch fernerhin stattfinden mag, völlig aufgehoben sei, und verschwinde; und daß auf diese Weise unter uns keineswegs Volks-Erziehung, sondern eigenthümliche deutsche National-Erziehung entstehe.“ (ebd.: 17)
\end{abstract}

Das Ziel der Nivellierung der sozialen Unterschiede lässt sich auch als Demokratisierung bezeichnen. Es geht Fichte dabei nicht um Volks-Erziehung, wo auch den unteren Schichten etwas beigebracht wird, was diese zur Ausführung einfacher Arbeiten befähigt oder zu gefügigen Untergebenen macht, sondern um eine Nationalerziehung, die eine gleichberechtigte Teilhabe aller Staatsbürger (zu Frauen äußert er sich hier nicht) am geistigen Leben der Nation gewährleistet; für ,,jedweden Zögling, auch aus dem niedrigsten Stande geboren, indem der Stand der Geburt wahrhaftig keinen Unterschied in den Anlagen macht" (ebd.: 147). Hier scheint der intrinsische Zusammenhang von Nationalisierung und Demokratisierung auf. 
Da bei Fichte die Einheit der Nation und ihr geistiges Leben in der in der Zukunft liegenden Ursprünglichkeit der, eigenen' Sprache begründet ist, wendet sich die Nationalerziehung gegen die Französierung, aber auch gegen regionale Dialekte. Diese Vorstellung hat seinen Niederschlag auch in der teils gewaltvollen Durchsetzung und Herstellung der vereinheitlichten Nationalsprache gefunden. Dafür spielen insbesondere die National-Erziehung und das damit in Verbindung stehende allgemeine und allgemein verpflichtende Schulsystem eine zentrale Rolle. Balibar zufolge besteht eine ,enge historische Korrelation zwischen der nationalen Formation und der Entwicklung der Schule als ,volksnaher' Institution“ (Balibar 1988b: 120). Die Institution Schule ist dabei eben nicht auf die Vermittlung von Spezialausbildungen oder auf die Kultur der Eliten beschränkt, sondern greift in die gesamte Sozialisation aller Individuen innerhalb einer vorgestellten nationalen Gemeinschaft ein. Die primäre Aufgabe, die die Institution Schule für die Bildung des Nationalstaats spielt, ist die Einübung der Nationalsprache. Hier setzt sich Balibar implizit mit der Ideologietheorie Louis Althussers und seinem Begriff des ideologischen Staatsapparates auseinander. Balibar hebt an dieser Stelle hervor, dass die Schule zwar ein Ort ist, an dem eine ,nationalistische Ideologie verbreitet - mitunter auch in Frage gestellt wird“" (ebd.). Dies sei jedoch ein „,abgeleitetes Phänomen“ (ebd.). Balibar sieht - eben aufgrund der Einübung der Nationalsprache - im allgemeinen Schulbesuch, „die wichtigste Einrichtung zur Konstituierung der Ethnizität als Sprachgemeinschaft" (ebd.). Wobei die Schule nicht der einzige Ort ist, an dem diese Nationalsprache vermittelt wird. Es sind auch die staatlichen Verwaltungseinrichtungen, der Wirtschaftsverkehr, die Familien, Vereine usw., die „Organe der idealen Nation“ darstellen und die an ,einer ,gemeinsamen', ihr , wesenseigenen 'Sprache erkennbar ist" (ebd.). Dabei muss die ,Muttersprache" nicht unbedingt die Sprache der ,realen" Mutter sein, wie anhand von sogenannten ,Einwanderern der zweiten Generation" oder auch die zugunsten der Nationalsprache Dialekte hinter sich lassende Nachkommen von Menschen, die schon seit mehr als einer Generation an einem Ort leben, vorstellbar wäre. Am Bild der ,Muttersprache ' wird hier deutlich, wie die Nationalsprache eine Verbundenheit erzeugt, die der imaginierten Sprachgemeinschaft eine familiale Dimension zuschreibt, die aber nicht auf Abstammung zu reduzieren ist. Denn: „Die sprachliche Gemeinschaft ist eine aktuelle Gemeinschaft, die das Gefühl vermittelt, daß sie immer existiert hat, die für die aufeinanderfolgenden Generationen jedoch nicht schicksalsbestimmend ist.“ (ebd., Herv. i. O.)

Da Sprache erlernbar ist, ist die nationale Sprachgemeinschaft - im Gegensatz zur Abstammungsgemeinschaft - ideell offen für jede_n. Ideell; denn tatsächlich wird Exklusion über die Nation als Sprachgemeinschaft ebenso betrieben wie über 
andere Formen. Dies wird nicht zuletzt an der Rolle der Sprache in den gegenwärtig in Deutschland hegemonialen Diskursen um ,Integration ' oder den als Disziplinierungsinstrument fungierenden Integrationskursen (Ha/Schmitz 2006) deutlich. Hier wird deutlich, wie Nationalsprache als Ausschluss-, Distinktionsund Hierarchisierungsinstrument wirkt (4.2.3.2; Ha 2007a). Die ausschließende Funktion der Sprachgemeinschaft rekurriert immer auch auf andere Formen der nationalen Gemeinschaft (Balibar 1988b: 126), wie etwa Abstammung. Auch Fichte - bekannt für seine begriffliche Schärfe und stringente Argumentation - streut in seine Herleitung der Nation als Sprachgemeinschaft immer wieder Anteile eines auf Abstammung basierenden Nationsverständnis ein. In der Verwendung von Begriffen wie „Ausländer“ oder „wahre Deutsche" (Fichte 1808: 64) schillern immer wieder Andeutungen auf, die die (Nicht-)Zugehörigkeit unabhängig von der Sprache und in Bezug auf Abstammung oder ,Rasse' zu deuten meint. Zwar behauptet Fichte - um bei diesem Beispiel zu bleiben -, dass ,der Ausländer ohne eine höchst mühsame Erlernung der deutschen Sprache den wahren Deutschen niemals verstehen kann“ (ebd.). Es ist dem „Ausländer“ also möglich den „wahren Deutschen“ verstehen zu lernen. Nichtsdestotrotz rekurriert die kategoriale Ausgangsunterscheidung bereits auf eine Herkunftszuschreibung; Fichte scheint mit dieser Mehrdeutigkeit zu spielen. Und genau diese Ambiguität in der Konstruktion nationaler (Nicht-)Zugehörigkeit ist nicht die Ausnahme, sondern die Regel. Kommt ein Diskurs nationaler Inund Exklusion in einem Moment nur mit sprachlichen Argumenten aus, bezieht er sich im nächsten Moment doch auf eine Abstammung, nur um dann wieder den Schwenk zu den Bewohner_innen eines Territoriums und ihrer politischen Selbstbestimmung zu nehmen. Oder anders ausgedrückt: In der Unschärfe oder Brüchigkeit der Konstruktion nationaler (Nicht-)Zugehörigkeit in Fichtes Reden manifestiert sich die Flexibilität dieser Konstruktion, die dem Umstand geschuldet ist, dauerhaft dadurch infrage gestellt zu werden, dass Menschen ihre gesellschaftliche Teilhabe einfordern und damit die Grenzen von (Nicht-)Zugehörigkeit verschieben.

\subsection{Herder: Die Nation als Kulturgemeinschaft}

Johann Gottfried Herder (1744-1803) war ein früher Schüler Kants. Doch bereits in den 1770er Jahren deutete sich ein Konflikt an, der dazu führte, dass beide sich in den 1780er Jahren endgültig zerstritten (Kühn 2003: 343). Im Zentrum des Konflikts stand dabei insbesondere die Frage der Existenz von ,Rassen', die auch mit einem anderen Verständnis der Wissenschaft und Erkenntnistheorie verknüpft war. Kant schrieb eine Reihe seiner rassetheoretischen Texte als direkte Replik auf Herder. Herder hatte nämlich in seinen Texten die Existenz von ,Rassen“ 
grundlegend bestritten, was Kant dazu bewog, seine Rassentheorie zu verteidigen und wissenschaftlich zu fundieren. Nachdem Herder in den 1770er Jahren insbesondere seinen Text Auch eine Philosophie der Geschichte zur Bildung der Menschheit (1774) vorgelegt hatte, führte er dieses Projekt in den 1780er Jahren fort. Zwischen 1784 und 1791 veröffentlichte er nach und nach die verschiedenen Teile seiner Ideen zur Philosophie der Geschichte der Menschheit. Nach der Veröffentlichung des ersten Teils 1784 schrieb Kant eine vernichtende Rezension. Im zweiten Teil bezog Herder dann erneut Stellung in Bezug auf die Frage der ,Rassen':

\begin{abstract}
„Endlich wünschte ich auch die Unterscheidungen, die man aus rühmlichem Eifer für die überschauende Wissenschaft dem Menschengeschlecht zwischengeschoben hat, nicht über die Grenzen erweitert. So haben einige z.B. vier oder fünf Abteilungen desselben, die ursprünglich nach Gegenden oder gar nach Farben gemacht waren, Rassen zu nennen gewaget; ich sehe keine Ursache dieser Benennung. Rasse leitet auf eine Verschiedenheit der Abstammung, die hier entweder gar nicht stattfindet oder in jedem dieser Weltstriche unter jeder dieser Farben die verschiedensten Rassen begreift. Denn jedes Volk ist Volk: es hat seine Nationalbildung wie seine Sprache. Zwar hat der Himmelsstrich über alle bald ein Gepräge, bald nur einen linden Schleier gebreitet, der aber das ursprüngliche Stammgebilde der Nation nicht zerstöret. Bis auf Familien sogar verbreitet sich dieses, und seine Übergänge sind so wandelbar als unmerklich. Kurz, weder vier oder fünf Rassen noch ausschließende Varietäten gibt es auf der Erde. Die Farben verlieren sich ineinander, die Bildungen dienen dem genetischen Charakter, und im ganzen wird zuletzt alles nur Schattierung eines und desselben großen Gemäldes, das sich durch alle Räume und Zeiten der Erde verbreitet." (Herder 1785: 255)
\end{abstract}

Vor diesem Hintergrund wundert es umso mehr, dass Herder ebenso wie Fichte stark von den rechtsnationalen Kräften in Deutschland vereinnahmt wurde. Aber warum verwundert es? Es verwundert nur dann, wenn der Rassismusbegriff und die Kritik am Verständnis nationaler Exklusionsmechanismen auf die biologische Abstammung begrenzt bleibt, wie es oft in liberal-humanistischen Ansätzen der Fall ist, die die Lösung des Problems von nationaler (Nicht-)Zugehörigkeit in der Stärkung eines ,rein ' republikanischen, nicht auf biologischer Abstammung basierenden Verständnisses sehen. Herder bezieht sich - wie im Folgenden gezeigt werden wird - insbesondere auf die Kategorie der ,Kultur' als Bestimmungsmerkmal der (Nicht-)Zugehörigkeit zur nationalen Gemeinschaft.

Herders Verständnis einer Nation basiert auf dem Begriff einer ,Kultur‘. Eine Nation hat bei Herder eine ,Kultur'; und eine ,Kultur' ist einer Nation eigen. Um eine Nation zu verstehen, muss man Herder zufolge das ,ganze lebendige Gemälde von Lebensart, Gewohnheiten, Bedürfnissen, Landes- und 
Himmelseigenheiten“ (Herder 1774: 29) verstehen. Auffällig ist hier, dass Herders Verständnis keineswegs eines von sogenannter ,Hochkultur ' ist, sondern die Art und Weise der Menschen, den Alltag zu bewältigen - wozu dann auch wieder die Gelehrten gehören. Eine solche ,Kultur' wird aber als national gedacht, sodass er zu der Behauptung kommt, dass eine solche ,Kultur' Ausdruck des spezifischen „Charakter[s] einer Nation“ (ebd.) sei. Er behauptet, es läge eine „Tiefe in dem Charakter nur einer Nation" (ebd.: 28), wobei wir wieder beim Topos der Innerlichkeit wären. Mit einer solchen nationalisierten Auffassung von ,Kultur“ knüpfte er an eine Tradition an und brachte sie in eine für viele Fortschreibungen dieser Tradition „für die Folgezeit verbindliche Form“ (Welsch 1995: 1). So wurde ,Kultur' schon bei Pufendorf von einem auf einzelne Praktiken beschränkten Begriff auf sämtliche menschliche Lebensäußerungen ausgeweitet und zu einem ,autonomen Begriff, zu einem Kollektivsingular, der nun - in einer kühnen Vereinheitlichung - sämtliche Tätigkeiten eines Volkes, einer Gesellschaft oder einer Nation zu umfassen beanspruchte" (ebd.).

Ich werde meine weitere Lesart von Herders Nationsverständnis aus folgendem Zitat entwickeln: ,jede Nation hat ihren Mittelpunkt der Glückseligkeit in sich, wie jede Kugel ihren Schwerpunkt!“ (Herder 1774: 35) Im Folgenden werde ich zwei Facetten herausarbeiten, die sich aus dieser Kugelanalogie ergeben: (1) Erstens die Analogie von Natur und Gesellschaft, um Herders erkenntnistheoretischen und kulturanthropologische Prämissen für seinen Begriff der Nation herauszustellen, und (2) zweitens seinen politischen Begriff der Nation bzw. der ,Kultur' als ein Kugelmodell. Für letzteres werde ich mich maßgeblich auch mit dem Ansatz der Transkulturalität von Wolfgang Welsch befassen.

\section{1) Analogie von Natur und Gesellschaft}

Die Analogie von Naturwissenschaft und dem Verständnis von Gesellschaft ist keineswegs ein rein rhetorischer Zug, sondern ein inhaltliches Argument Herders. Die Unterschiede erklärt er damit, dass die „Natur die Gaben unterschiedlich ausgeteilt“ habe: „Die Natur hat ihre Gaben verschieden ausgeteilt; auf unterschiedlichen Stämmen, nach Klima und Pflege, wachsen verschiedne Früchte.“ (Herder 17931797: 225) Klima als durch die Natur gesetztes und auf ein Territorium bezogenes Element und die Pflege als die menschliche Einflussnahme auf diese Anlage sieht er als die beiden Faktoren, die eine national verstandene ,Kultur" prägen würden. Die Pflege - um in dem Bild zu bleiben - ist nötig, da keine Nation von sich aus ihre Anlagen entfaltet: „Was ist eine Nation? Ein großer, ungejäteter Garten voll Kraut und Unkraut.“ (ebd.) Weiterhin sei die Nation ein Sammelplatz ,,von Torheiten und Fehlern sowie von Vortrefflichkeiten und Tugenden" (ebd.). Stolz auf ihre Nation könnten also nur Narren sein: „Unter allen Stolzen halte ich den Nationalstolzen 
sowie den Geburts- und Adelstolzen für den größesten Narren.“ (ebd.) Es ginge darum, was eine Nation erschaffen würde, nicht was sie von sich aus sei.

Den Grund für die unterschiedlichen Anlagen der Nationen durch die Natur sieht Herder in ihrer Produktionsweise - um einen Begriff aus dem erst später entstehenden Marxismus zu übernehmen. In diesem Sinne schreibt Herder Auch eine Geschichte zur Bildung der Menschheit (1774), in der er eine Art Stufenmodell entwickelt, das in jener Zeit und bis in die Gegenwart hinein in ähnlicher Form Anwendung findet. Die Stufe des Kindes wird hier durch „Morgenlande“ bzw. den „Orient" (Herder 1774: 11) repräsentiert. Es zeichne sich durch das nomadische Wander- und Hirtenleben aus. Darauf folgt das „Knabenalter“ (ebd.: 14), wofür das alte Ägypten figuriert. Das Wanderleben sei hier zu Ende gewesen und das Leben sei bestimmt durch Ackerbau. Damit habe sich auch die ,Kultur' geändert. Das Zeitalter des ,Jüngling[s]“ stellt das antike Griechenland dar. Das Leben der Menschen im antiken Griechenland sei nicht mehr in erster Linie durch die „Arbeitskünste“, sondern durch die „schönen Künste“ (ebd.: 22) bestimmt gewesen. Mit Rom sei das „Mannesalter“ erreicht worden. Hier seien die Künste durch den männlichen Aufbau eines Imperiums, dem „Weltbau“ (ebd.: 28) abgelöst worden. In klassischen eurozentrisch-kolonialen Geschichtsschreibungen der Aufklärung würde nun Europa als die höchste Stufe erfolgen (Kleinschmidt 2013). Implizit schwingt dies auch bei Herder mit, aber er sträubt sich dagegen, da der Kern seines Kultur- und Nationenbegriffs auf etwas anderes zielt. So relativiert er die Gültigkeit seines Stufenmodells unter anderem in den zehn Jahre später erscheinenden Ideen:

,und doch war es mir nie eingefallen, mit den wenigen allegorischen Worten, Kindheit, Jugend, das männliche, das hohe Alter unseres Geschlechts, deren Verfolg nur auf wenige Völker der Erde angewandt und anwendbar war, eine Heerstraße auszuzeichnen, auf der man auch nur die Geschichte der Kultur, geschweige die Philosophie der ganzen Menschengeschichte mit sicherm Fuß ausmessen könnte.“ (Herder 1784: 11)

Er betont an gleicher Stelle, dass in der Rezeption seines Werks von 1774, also Auch eine Geschichte zur Bildung der Menschheit, in der Regel das „Auch“ nicht beachtet wurde. Dabei ist es ihm gerade wichtig, den universalistischen Erkenntnisanspruch der Aufklärung durch eine kulturrelativistische Perspektive infrage zu stellen: „Wir Deutschen wollten uns mit den Griechen vergleichen? Und welches wäre der genau bestimmte, der unverfälschbare Maßstab? Und wer wäre der unparteiische Richter?" (Herder 1793-1797: 225) Dies ist eine rhetorische Frage, denn es gibt nach Herder keinen universellen Richter; und hier kommt wieder das Kugelmodell ins Spiel. Für ihn ist der Maßstab nicht eine globale Erkenntnis, die nach ihm eben nicht tatsächlich universell wäre, sondern die Überhöhung einer partikularen Perspektive. 
Dies unterscheidet ihn grundlegend von Kant, für den Wahrheit oder Vernunft nicht kulturabhängig ist. Das heißt, Herder führt hier das erkenntnistheoretische Prinzip der Perspektivität ein. Diese Perspektivität ist aber an eine ,Nationalkultur' gebunden und kann insofern als essenzialisierender Kulturrelativismus bewertet werden. Eine weitere Unterscheidung zu Kant stellt auch das der Glückseligkeit dar. Es geht Herder nicht um ein Fortschreiten der Menschheit als solcher, sondern um die Glückseligkeit, die innerhalb einer Nation sowohl definiert als auch realisiert wird.

Dementsprechend lehnt Herder auch die Universalgeschichte anderer Aufklärer ab. Es gehöre zur menschlichen Natur, dass sie sich unterschiedlich organisiere: ,zur Vollkommenheit der menschlichen Natur gehört, daß sie unter jedem Himmel, nach jeder Zeit und Lebensweise sich neu organisiere und gestalte" (Herder 1783: 471). Dementsprechend ergäbe sich aus der Natur, dass es verschiedene Nationen gäbe, die sich durch unterschiedliche ,Kulturen ' auszeichneten. Diese ,Kulturen ' basieren - wie aufgezeigt - nicht auf Abstammung, sondern auf der gelebten ,Kultur' eines Volkes, einer Lebensweise, die ein Volk vor dem Hintergrund einer Klimazone und der damit im Zusammenhang stehenden Produktionsweise entwickelt hat. Die Ablehnung des Universalismus hindert ihn keineswegs daran, wie etwa im folgenden Zitat aus seinen Briefen zur Beförderung der Humanität an einem universellen Humanismus festzuhalten:

„Du aber, Mensch, ehre dich selbst. Weder der Pongo noch der Longimanus ist dein Bruder; aber wohl der Amerikaner, der N[*]. Ihn also sollst du nicht unterdrücken, nicht morden, nicht stehlen; denn er ist ein Mensch, wie du bist; mit dem Affen darfst du keine Brüderschaft eingehn." (Herder 1785: 255)

Der Kolonialismus erscheint aus der Sicht seines Humanismus als falsch - allerdings aus den falschen Gründen und mit den falschen Schlüssen, wie ich im folgenden Abschnitt darstellen werde.

\section{2) Zu den Implikationen der Nation/Kultur als Kugelmodell}

Wenn Herder sich eine Nation als Kugel vorstellt - ,jede Nation hat ihren Mittelpunkt der Glückseligkeit in sich, wie jede Kugel ihren Schwerpunkt!“ (Herder 1774: 35) - ergeben sich daraus zahleiche Konsequenzen für die ,Pflege“ einer Nation. Hier begegnen wir wiederum dem Ideologem der ,Reinheit', wenn auch in anderer Form. Nach Herder würde die Abgrenzung eines Volkes gegen andere dieses stärken: „Das Vorurteil ist gut, zu seiner Zeit: denn es macht glücklich. Es drängt Völker zu ihrem Mittelpunkte zusammen, macht sie fester auf ihrem Stamme, blühender in ihrer Art, brünstiger und also auch glückseliger in ihren Neigungen und Zwecken.“ (ebd.: 36) Mit dem Kugelmodell werden (nationale) 
,Kulturen` als klar voneinander abgegrenzte Entitäten imaginiert. Eine ,kulturelle Vermischung würde - um das Bildhafte dieses Modells zu thematisieren - nur die figürliche Harmonie der Kugel mit ihrem Schwerpunkt stören. Herders Kugelmodell zeichnet sich dementsprechend durch ein ,internes Homogenitätsgebot und ein externes Abgrenzungsgebot“" (Welsch 2010: 40) aus. ,Kulturelle` Praktiken werden damit von , unschuldigen ' Praktiken der Alltagsbewältigung zu Symbolen und Ausdrucksweisen einer nationalen und inkludierend-exkludierenden Gemeinschaft. Der Lesart von Welsch zufolge soll die ,Kultur“ im Kugelmodell ,das Leben der jeweiligen Gesellschaft im ganzen wie im einzelnen prägen, sie soll jede Handlung und jeden Gegenstand zu einem unverwechselbaren Bestandteil gerade dieser Kultur machen“ (Welsch 1995: 1).

Wolfgang Welsch sieht einen solchen Kulturbegriff auch in Ansätzen der Interkulturalität und Multikulturalität am Werk. Die „Misere“ dieser Konzepte komme daher, dass sie die „Prämisse des traditionellen Kulturbegriffs unverändert mit sich“ fortschleppen würden, also ,noch immer von einer insel- bzw. kugelartigen Verfassung der Kulturen“ (ebd.: 2) ausgeht. Beide Konzepte erschaffen sich ihr Problem selbst, indem sie davon ausgehen, dass die als separiert und jeweils tendenziell homogenen ,Kulturen “ - wenn sie aufeinandertreffen - in einem schwierigen Verhältnis zueinander stehen. Beide Konzepte suchen vor diesem Hintergrund nach Möglichkeiten, wie sich die Mitglieder der , verschiedenen ' ,Kulturen ' trotzdem (sic!) verstehen können. Sie suchen dazu nach „Chancen der Toleranz, Verständigung, Akzeptanz und Konfliktvermeidung oder Konflikttherapie“ (ebd.). Wolfgang Welsch qualifiziert diese Ansätze deswegen als ,gut gemeint, aber ergebnislos“ und „bloß kosmetisch“ (ebd.). Ich werde an dieser Stelle auf eine Diskussion darüber verzichten, inwiefern sich einige Diskurse in den interkulturellen Ansätzen hin zu einem weniger essenzialistischen Kulturbegriff verschoben haben. Worum es an dieser Stelle geht, ist dass der Herdersche Kulturbegriff in seiner nationalisierten und ethnisierten Form auch in der Gegenwart eine zentrale Stellung einnimmt.

Welsch schlägt ein alternatives Konzept vor: Transkulturalität. Mit dem Ansatz der Transkulturalität würde ,Kultur' ,nicht mehr nach dem alten Modell klar gegeneinander abgegrenzter Kulturen, sondern nach dem Modell von Durchdringungen und Verflechtungen“ (Welsch 2010: 1) verstanden werden. Welsch führt als Grund gesellschaftliche, insbesondere mit Migration verknüpfte Prozesse an. Er argumentiert hier also nicht - zumindest nicht in erster Linie - normativ, indem er den Herderschen Kulturbegriff aufgrund seiner problematischen, exkludierenden Effekte ablehnt. Stattdessen stellt er dem Kugelmodell das empirische Argument entgegen, dass „Kultur heute [...] de facto derart permeativ und nicht separatistisch" (ebd.) strukturiert sei. Die Annahmen des traditionellen Kulturkonzepts seien „heute unhaltbar geworden“; von einer „Einheitlichkeit der Lebensformen“ könne 
heute „nicht mehr die Rede“ (Welsch 1995: 1) sein. Dieses auf dem „nicht mehr“ basierende Argument stellt einen Kernpunkt der Argumentation dar. Dies ist aber deswegen problematisch, da das nicht-mehr-Argument suggeriert, dass es an einem Zeitpunkt der Vergangenheit einen Zustand gegeben habe, wo es tatsächlich Homogenität und Separiertheit der ,Kulturen' gegeben habe, ,Kulturen' also zurecht als Kugeln betrachtet wurden oder zumindest legitimerweise als solche hätten betrachtet werden können. Leider führt Welsch nicht aus, auf welchen Zeitraum er sich hier bezieht. Falls ,Kulturen ' als an nationale Gebilde gekoppelt betrachtet würden, läge das 19. Jahrhundert als Referenzrahmen nahe, da hier in einigen westeuropäischen Territorien die Prozesse des nation-building eine intensive Phase durchliefen. Der Bezug zu Herder würde eher auf das 18. Jahrhundert als derjenigen Epoche verweisen, in der das Kugelmodell tendenziell der Realität entsprochen hätte. Oder aber es geht um einen Bezug auf eine Zeit, lange bevor es große Herrschaftsreiche gegeben hätte und es referiert auf eine Art separiert voneinander wohnender, indigener Volksgruppen, die im Sinne der kolonialen Sprache als ,Stämme ‘ bezeichnet werden würden. Ohne lange historische Forschungen aufzuarbeiten, sollte offensichtlich sein, dass auf alle diese ,Epochen“ das Kugelmodell nicht zutrifft. Schließlich ist das Kugelmodell - mit den Imaginationen eines Zentrums und der Abgrenzung voneinander, der Homogenität und der Separiertheit - nicht Analyse vom Prozess der Nationalisierung und der Durchsetzung der Nation als Episteme, sondern vielmehr selbst Praxis innerhalb des Konstruktionsprozesses. In der Kritik des Kugelmodells geht es also nicht um ein ,nicht mehr“, sondern vielmehr um die Analyse des Kugelmodells als eine Form der Konstruktion von Ethnizität und nationalistischer Erzählung.

Auch wenn Herder unter anderem von den Nazis affirmativ verwendet wurde, spricht vieles dafür, ihn - und auch seine Mitstreiter, wie beispielsweise Georg Forster - eher als frühe Formen eines multikulturellen Humanismus zu sehen. Balibar sieht in Herders Werk die ,egalitäre Vielfalt der ethnisch-nationalen Kulturquellen“ (Balibar 1997: 138) als zentrales Theorem des Nationsbegriffes. Die Nation als Kulturgemeinschaft wird so - wenn auch vor grundlegend anderen normativen Vorzeichen - in Geschichte und Gegenwart von ganz unterschiedlichen politischen Gruppierungen verwendet. Während die normativen Ausrichtungen liberaler Multikulturalismen und - ebenfalls in der EU der Gegenwart sehr weit verbreiteten - rechtspopulistischen Ethnopluralismen differieren, teilen sie weitgehend erkenntnistheoretische Prämissen. Sabine Hess stellt heraus, dass ,differenzkulturalistische-ethnizistische Argumentationsweisen nicht als die andere, bessere Seite von Rassifizierungspraktiken und rassistischem Wissen" (Hess 2014: 213) gelesen werden dürfen. Der ,essentialisierende Kulturbegriffs in der Migrationsdebatte“ funktioniere ähnlich „wie ,Rasse“ im kolonialen Rassismus, 
indem er Kultur naturalisiert und als ,zweite Haut' bzw. als ,Schicksal' betrachtet" (ebd.). Die Wirkmächtigkeit weist sie für den gegenwärtigen Diskurs um die Frage des ,Islams ‘ und der ,, Nichtintegrationsfähigkeit ' bzw. ,-willigkeit‘ muslimischer Migrantinnen und Migranten“ nach, in dem sie über die „,Religionisierung der Einwanderungsthematik“ hinaus in der forcierten „Koppelung zwischen Rassismus und Migrationsfragen“ (ebd.) einen wirkmächtigen antimuslimischen Rassismus analysiert.

\subsection{Renan: Nation als Wertegemeinschaft}

Auf den ersten Blick scheint die Religion keine konstitutive Rolle für den Prozess der Nationalisierung zu haben. Der Prozess der Nationalisierung, des nationbuilding, geht vielmehr mit einer Veränderung der gesellschaftlichen Rolle der Religion einher. Während vorher in der christlichen Welt ein Monismus der Religion und ein Pluralismus der Sprachen praktiziert wurden, war es in den entstehenden nationalen Formationen, die sich als liberal verstanden, genau umgekehrt. Aus der Indifferenz gegenüber der Sprache wurde eine Verpflichtung, Sprache wurde zum Zugehörigkeitsmarker, und die Religion wurde zweitrangig; sie wurde zur Privatsache erklärt, gegenüber der der Staat sich zumindest dem theoretischen Anspruch nach neutral zu verhalten hat (Brubaker 2015: 95). Sprachtests zur Einbürgerung gehören heute zur Routine, während ein Religionstest in einer sich als liberal deklarierenden Gesellschaft als unpassend empfunden würde (ebd.). Die Hegemonie der nationalen Form hat zu einer Säkularisierung geführt (ebd.: 103, 116). Auch wenn das Konzept der Nation als Säkularisierung, im Sinne eines Modernisierungsprozesses, zu recht stark kritisiert wurde (ebd.: 116), halte ich die These einer spezifischen Form der Säkularisierung aufrecht. Das bedeutet nicht, dass die Religion keine Rolle in nationalen Formationen spielen würde. So gibt es zahlreiche Verschränkungen im Bereich der Rhetorik, der Legitimationsfiguren, der Symboliken, der Konstruktion von Zugehörigkeit oder institutioneller Verschränkungen von Kirche und Nationalstaat. Einige Nationalstaaten haben die religiöse Identität zu einem offiziellen Kernelement ihres Selbstverständnisses gemacht. Doch sehe ich insgesamt im Anschluss an Rogers Brubaker den Kern nationaler Gesellschaftsformationen in der Nation: „Nations are seen as legitimately entitled to ,their own' polities and as ,owning' those polities once they are established; authority is seen as legitimate only if it arises from ,the nation'." (ebd.: 117) Ich werde modellhaft an Ernest Renan im Folgenden versuchen, dieses - aus meiner Sicht komplexe - Verhältnis von Nation und Religion analytisch zu fassen zu bekommen.

Ernst Renan (1823-1892) ist bekannt für seine Rede von 1882 in der Sorbonne Qu'est-ce qu'une nation? (Was ist eine Nation?), darin insbesondere für 
den Ausspruch, dass eine Nation ein ,tägliches Plebiszit“ (1882) sei. In populären Darstellungen wird Renan als ,modernes“, prototypisches Gegenbild zu essenzialistischen Definitionen, wie etwa von Fichte herangezogen (siehe beispielsweise die Wikipedia-Einträge zu Nation auf Deutsch, Englisch und Französisch). Von einigen Autor_innen in der gegenwärtigen Theorie zur Nation und Nationalismus wird er sogar als intellektueller Vorläufer der Theorie der ,imagined communities ‘ von Benedict Anderson und einem konstruktivistischen Nationsverständnis angesehen (so zu finden z. B. in Eley/Suny 1996: 41). Ich werde im Folgenden die Argumentation von Renan nachzeichnen und zeigen, dass diese Interpretationen nicht nur einfach zu kurz greift, sondern konstitutive Elemente von Renans Nationsverständnis auslässt und so entscheidende Machtwirkungen seines Verständnisses unangesprochen und ausgeblendet bleiben. Dafür werde ich die Rede von 1882 in seinem Werk kontextualisieren. Ich werde zeigen, wie der hauptsächlich als Orientalist arbeitende Renan die Haltung zur Religion zum Bestimmungsmerkmal einer Nation macht - eine spezifische Haltung, die aus der Abkehr von der Religion, aber nicht von irgendeiner, sondern von dem Christentum besteht. Renan steht an dieser Stelle dann als Prototyp für ein Nationsverständnis, das auf dem Prozess der christlichen Säkularisierung als nationales Distinktionsmerkmal und der Abgrenzung zum anderen, insbesondere ,dem Islam‘, basiert. Dafür werde ich seine Kontroverse mit dem muslimischen Gelehrten Jamāl al-Dīn al-Afghānī thematisieren. Die Weiterführung dieser Debatte, insbesondere in nicht-westlichen Kontexten werde ich hier nicht weiterverfolgen (vgl. dazu Schäbler 2016). Doch zunächst komme ich zu seiner berühmten Rede, die ich aufgrund seiner zentralen Rolle in der ideengeschichtlichen Entwicklung bis heute ausführlich darstellen werde.

Renan stellt also 1882 an der Sorbonne die Frage danach, was eine Nation sei. Er zeichnet zunächst ein Bild der Entstehung der Nationen in Westeuropa. Ausgangspunkt dieses Bildes ist das Frankenreich, das durch seine Eroberung West-, Mittel- und Südeuropas ,für einen Augenblick die Einheit des Abendlandes wieder“ (Renan 1882) hergestellt hätte. Auf das für Renans Werk zentrale Sujet des Abendlandes, das hier den Ausgangspunkt seiner Geschichtsschreibung der Nationen bildet, werde ich weiter unten zu sprechen kommen. Der Vertrag von Verdun, unterzeichnet im Jahr 843, steht symbolisch für den Zerfall dieses Reiches sowie die Entstehung der Nationen:

„Der Vertrag von Verdun zeichnet die letztlich unabänderlichen Grenzen vor, und seitdem sind Frankreich, Deutschland, England, Italien, Spanien auf vielen Umwegen und unter unzähligen Abenteuern zu ihre vollen nationalen Existenz aufgebrochen, wie wir sie heute vor uns haben." (Renan 1882) 
Renan fährt fort und stellt fest, dass die Nationen sich durch ,die Verschmelzung der Bevölkerungen, die sie bewohnen“ (ebd.), auszeichnen. Er kontrastiert die Entwicklung in den westeuropäischen Nationen mit der der Türkei. Während in der Türkei, ,wo der Türke, der Slawe, der Grieche, der Armenier, der Araber, der Syrer, der Kurde auch heute noch so verschieden sind wie am Tag der Eroberung", die „Menschen nach ihrer Religion“ (ebd.) scheide, haben die westeuropäischen Staaten eine gemeinsame Sprache und eine gemeinsame Religion angenommen. Im Folgenden begründet er dann in fünf Unterpunkten, warum die Konzepte von ,Rasse', Sprache, Religion, Interessen und Geographie kein Fundament für die Nationen darstellen.

Die Ablehnung des Konzepts der ,Rasse“ für sein Nationsverständnis ist vielleicht am überraschendsten. Immerhin ist das Konzept der ,Rasse“ im Werk von Renan von entscheidender Bedeutung, das er zu einer zentralen Kategorie sozialer und historischer Analyse erhob (Brubaker 1992: 140). Djamel Kouloughli zeigt auf, wie das Werk Renans, als einer Figur des intellektuellen Pantheons Frankreichs (2007: 91), von einem systematischen Rassismus und Antisemitismus durchzogen ist (ebd.: 95). Kouloughli wählt den Ausdruck des , gelehrten Antisemiten', da Renan oft nicht offensichtlich (ab-)wertend, sondern vielmehr wissenschaftlich vorgeht. Sein Verhältnis zum ,Rasse'-Konzept ist aber immer von Spannungen geprägt. Kurt Weinberg hat hierfür den treffenden Ausdruck der Heimsuchung gewählt: „Die Werke von Ernest Renan erscheinen wie vom Gespenst der ,Rasse“ heimgesucht."15 (Weinberg 1958: 129) Zum Verständnis der Gründe für die Ablehnung des 'Rasse'-Konzepts für das Nationsverständnis in seiner Rede von 1882 führen Autor_innen an, dass sich Renans Grundhaltung stark durch die politischen Geschehnisse der 1870er Jahre verändert habe. Kouloughli führt insbesondere „Schock“ durch den deutsch-französischen Krieg und die Erfahrungen der Commune an, aus denen Renan die Forderung nach einer nach dem Vorbild der siegreichen Deutschen erschaffene quasi-aristokratische Demokratie ableitete, die die gesellschaftliche Führung einer gebildeten Elite überlässt, die das Volk vor den Versuchungen fernhält (Kouloughli 2007: 94).

$\mathrm{Zu}$ nennen ist auch die erbitterte öffentliche Debatte mit dem deutschen Intellektuellen David Friedrich Strauss, der - wie Renan - über die Verweltlichung der Bibel und insbesondere der Person Jesus seine Posten verloren hatte, in der gesellschaftlichen Stimmung des aggressiven Nationalismus der 1870er aber dennoch keinen Verbündeten Renans abgab, sondern vielmehr zu einem ,Blut und

\footnotetext{
${ }^{15}$ Übersetzung M.K., Original: „Les ouvrages d'Ernest Renan sont comme hantés par le spectre de la ,race‘." (Weinberg 1958: 129).
} 
Eisen '-Mann geworden war. Renan hatte lange von der deutsch-französischen Verständigung geträumt und bewunderte das deutsche System, in dem er durch den Kulturprotestantismus eine harmonische Balance zwischen Religion und Wissenschaft geschaffen sah (Schäbler 2007). Möglicherweise sind es diese Impulse, die Renan zu einem anderen Nationsverständnis bewogen, da ,Rasse' für diese ihn in Widersprüche stürzenden Entwicklungen keine gangbaren Erklärungsmuster anbot. Letztlich macht sich hier aber das spannungsgeladene, heimsuchende Verhältnis zur ,Rasse' bemerkbar, das im nicht aufrecht zu erhaltenen Widerspruch zwischen einer Affirmation als historische Analysekategorie und einer Ablehnung für die Analyse zeitgenössischer Entwicklungen fluktuiert.

So kritisiert er den Zeitgeist für den „schwerwiegenden Irrtum“, an „die Stelle des Prinzips der Nation“ das der „Ethnographie“ (Renan 1882) zu setzen. Dabei verwendet er ein normatives und ein empirisches Argument. Zunächst zum normativen: „Während das Prinzip der Nationen gerecht und legitim ist, ist das Urrecht der Rassen eng und voller Gefahren für den wahrhaften Fortschritt.“ (ebd.) Die Verwendung einer ethnographischen Analyse führt in die Irre, da es keine „reine Rasse“ gäbe: „Die Wahrheit ist, dass es keine reine Rasse gibt und dass man die Politik auf eine Chimäre bezieht, wenn man sie auf die ethnographische Analyse gründet.“ (ebd.) Dass es - zumindest in Westeuropa - keine ,reinen Rassen“ gibt, zeigt er anhand der Geschichte der ,Bevölkerungsmischungen “ - oder nach Renan treffender ,Rassenmischungen " - durch Eroberungen, aber auch durch die Geschichte der Regierungsweise in Westeuropa. Das Bündnis des ,uneingeschränkten Universalismus“ des Christentums mit dem römischen Reich habe dafür gesorgt, dass die „ethnographische Vernunft von der Regierung der menschlichen Dinge für Jahrhunderte ferngehalten“ (ebd.) worden sei. Eine ,Blutsmischung' ist nach seinem Nationsverständnis nichts negatives, sondern ist ganz im Gegenteil Charakteristikum der „,edelsten“ und „fortschrittlichsten“ (ebd.) Nationen. „Die edelsten sind jene Länder - England, Frankreich, Italien -, bei denen das Blut am stärksten gemischt ist.“ (ebd.) Eine Nationalität hat also nach Renan keinen ,rassischen' Ursprung, gründet sie sich doch aus verschiedensten ,Mischungen“ der ,Rassen“. So seien die ,ersten Nationen Europas [...] Nationen von gemischtem Blut“ (ebd.). „Der Franzose ist weder Gallier noch Franke noch Burgunder. Er ist aus dem großen Brutkasten hervorgegangen, in dem, unter dem Vorsitz des Königs von Frankreich, die verschiedensten Elemente gärten.“ (ebd.) Es ist also nicht die ,Rasse', sondern vielmehr - um im Bild zu bleiben der Gärungsprozess unter einer staatlichen Souveränität, der zur Entstehung einer Nation führen kann. Interessanterweise sieht Renan die ,Rassen “ als etwas an, das historisch vergänglich ist: „Die Rasse ist also in unserem Verständnis etwas, was entsteht und wieder vergeht.“ (ebd.) Zentral ist dabei aber seine Unterscheidung 
zwischen ,Rasse“ als Analysekategorie und Faktor in der Politik: „Ihr Studium ist für den Gelehrten, der sich mit der Geschichte der Menschheit beschäftigt, von größter Bedeutung. Aber in der Politik hat die Rasse nichts zu suchen." (ebd.)

Ebenso strikt lehnt er die Sprache als Grundlage der Nation ab. Auch hier bringt er, analog zur ,Rasse', ein normativ-empirisches Argument. Diese lassen sich als zwei verschiedene, wenn auch verbundene Argumententeile darstellen. Er zeigt auf, dass es mehrsprachige Länder gibt (Schweiz), in einigen Ländern bis vor einigen Jahrhunderten noch andere Sprachen gesprochen wurden (,Slawisch in Preußen), einige Sprachen in vielen Nationen und Regionen gesprochen werden und deswegen noch keine Nation sind (Spanisch, Englisch). Er folgert daraus, dass die Sprache nicht als Grundlage zur Bestimmung einer Nation taugt und führt hier bereits in sein Nationsverständnis der Rede ein: „Beim Menschen gibt es etwas, was der Sprache übergeordnet ist: den Willen.“ (ebd.) Der zweite Teil des Arguments bezieht eine andere Ebene mit ein. Sie stellt Fortschritt und Vernunft über die Sprache: „Geben wir das Grundprinzip nicht auf, dass der Mensch ein vernünftiges und moralisches Wesen ist, ehe er sich in diese oder jene Sprache einpfercht, ein Angehöriger dieser oder jener Rasse, ein Mitglied dieser oder jener Kultur.“ (ebd.) Bevor es die eine „französische, deutsche, italienische Kultur“ gegeben hätte, hätte es eine „,menschliche Kultur“ (ebd.) gegeben. „Menschlich“; spätestens seit Fanon, Althusser und Foucault lässt dieses - scheinbar so unschuldige und universalistische - Wort hellhörig werden. Wer ist der Mensch, auf den sich Renan hier bezieht bzw. was macht das allgemein Menschliche aus, das diesem Ausdruck zugrunde liegt? Er gibt direkt die Antwort:

\footnotetext{
„Die großen Menschen der Renaissance waren weder Franzosen noch Italiener noch Deutsche. Durch ihren Umgang mit der Antike hatten sie das wahre Geheimnis des menschlichen Geistes wiedergefunden, und ihm gaben sie sich mit Leib und Seele hin. Wie gut sie daran taten." (ebd.)
}

Es ist eine bestimmte Traditionslinie, nämlich die des klassischen Eurozentrismus, die das Menschliche - oder zumindest den Teil dieser, der die Menschheit fortschreiten lasse - als eine Geschichte von der Antike (Griechenland) über die Renaissance (Westeuropa) bis in die Gegenwart erzählt. Der Mensch, für den die Sprache also nicht das zentrale Merkmal seiner Nationszugehörigkeit ist, da er Anteil an der menschlichen Kultur hat, ist also ein Westeuropäer (ohne weibliche Form).

Ebenso wenig wie die ,Rasse" und Sprache stelle die Religion keine Grundlage der Nation dar, da sie ,eine individuelle Angelegenheit geworden“ sei, die „,nur das Gewissen eines jeden“ (ebd.) angeht. Auch sein vierter Punkt, die 
Gemeinschaft der Interessen, sei als Prinzip einer Nation unzureichend. Eine Gemeinschaft der Interessen könne Handelsverträge schließen, die jedoch niemals die „Gefühlsseite“ einer Nationalität - sie sei „Seele und Körper“ zugleich - hervorbringen könne. Um ein weiteres, viel zitiertes Bonmot von Renan in Erinnerung zu rufen: „Ein ,Zollverein“ ist kein Vaterland.“ (ebd.)

Auch die Geographie liefert keinen hinreichenden Grund für eine Nationalität, denn bei der ,Formung dieser geheiligten Sache, die man ein Volk nennt, ist der Mensch alles“ (ebd.). In Abgrenzung zur Geographie beginnt er die Darstellung seiner eigenen Konzeption: „Eine Nation ist ein geistiges Prinzip, das aus tiefen Verwicklungen der Geschichte resultiert, eine spirituelle Familie, nicht eine von Gestaltungen des Bodens bestimmte Gruppe.“ (ebd.) Renan fasst seine negative Bestimmung der Nation folgendermaßen zusammen:

„Ich fasse zusammen. Der Mensch ist weder der Sklave seiner Rasse, seiner Sprache, seiner Religion noch des Laufs der Flüsse oder der Richtung der Gebirgsketten. Eine große Ansammlung von Menschen, gesunden Geistes und warmen Herzens, erschafft ein Moralbewusstsein, welches sich eine Nation nennt. In dem Maße, wie dieses Moralbewusstsein seine Kraft beweist durch die Opfer, die der Verzicht des einzelnen zugunsten der Gemeinschaft fordert, ist die Nation legitim, hat sie ein Recht zu existieren." (ebd.)

Renan führt auch an, dass die Nationen „,nichts Ewiges“ seien; sie ,haben einmal angefangen, sie werden enden. Die europäische Konföderation wird sie wahrscheinlich ablösen“ (ebd.). Renans Konzeption der Nation rekurriert also auf den Konstruktionsprozess der Nationen, die als Entitäten nichts Überhistorisches sind. Auf seine Vision einer post- oder neonationalen, europäischen Konföderation werde ich weiter unten zu sprechen kommen. Hat Renan also tatsächlich eine nicht-essenzialistische Konzeption der Nation, eine ,rein' republikanische, die kein dem Prozess der nationalen Willensgemeinschaft zugrundeliegendes Prinzip hat? Am Ende der folgenden Auseinandersetzung mit Renans Konzeption wird hoffentlich einleuchten, warum dies die falsche Frage ist und das Konzept eines ,rein' republikanischen Nationsverständnis, das meint ethnos und demos durch die reine Proklamation der Trennung tatsächlich getrennt zu haben, problematisch ist.

Für Renan macht die Nation als „Seele“ und ,geistiges Prinzip“ zwei Dinge aus: „Das eine ist der gemeinsame Besitz eines reichen Erbes an Erinnerungen, das andere ist das gegenwärtige Einvernehmen, der Wunsch zusammenzuleben, der Wille, das Erbe hochzuhalten, welches man ungeteilt empfangen hat." (ebd.) Es ist also der Besitz eines nationalen Erbes und dem Willen der Bürger der Nation, dieses Erbe hochzuhalten. Renans Begriff des Erbes schwankt zwischen 
einem substanzialistischen - „das man ungeteilt empfangen hat“ - und einem konstruktivistischen - ,der Wille, das Erbe hochzuhalten“:

\begin{abstract}
„Der Mensch improvisiert sich nicht. Wie der einzelne ist die Nation der Endpunkt einer langen Vergangenheit von Anstrengungen, von Opfern und von Hingabe. Der Kult der Ahnen ist von allen am legitimsten; die Ahnen haben uns zu dem gemacht, was wir sind, eine heroische Vergangenheit, große Männer, Ruhm (ich meine den wahren) - das ist das soziale Kapital, worauf man eine nationale Idee gründet. Gemeinsamer Ruhm in der Vergangenheit, ein gemeinsames Wollen in der Gegenwart, gemeinsam Großes vollbracht zu haben und es noch vollbringen wollen - das sind die wesentlichen Voraussetzungen, um ein Volk zu sein. Man liebt - im rechten Verhältnis - Opfer, in welche man eingewilligt, Übel, die man erlitten hat. Man liebt das Haus, das man gebaut hat und das man vererbt. Das spartanische Lied: ,Wir sind, was ihr gewesen seid; wir werden sein, was ihr seid', ist in seiner Einfachheit die abgekürzte Hymne jedes Vaterlandes.“ (ebd.)
\end{abstract}

In diesem Kontext ist auch sein berühmtes Zitat des täglichen Plebiszits platziert:

„Eine Nation ist also eine große Solidargemeinschaft, getragen von dem Gefühl der Opfer, die man gebracht hat, und der Opfer, die man noch zu bringen gewillt ist. Sie setzt eine Vergangenheit voraus, aber trotzdem fasst sie sich in der Gegenwart in einem greifbaren Faktum zusammen: der Übereinkunft, dem deutlich ausgesprochenen Wunsch, das gemeinsame Leben fortzusetzen. Das Dasein einer Nation ist - erlauben Sie mir dieses Bild - ein tägliches Plebiszit, wie das Dasein des einzelnen eine andauernde Behauptung des Lebens ist." (ebd.)

Dieses „tägliche Plebiszit“ ist also keineswegs als eine Assoziation freier Individuen zu verstehen, bezieht seinen Gehalt also nicht, einfach' durch den Willen frei in der Welt flottierender Individuen, die - einer Kommune ähnlich - entscheiden zusammen wohnen zu wollen. Die Grundlage dieser Gemeinschaft ist das geteilte Erbe. Die Frage, die sich dann stellt, ist, ob dieses Erbe angenommen und fortgeführt wird. Was ist aber ein solches Erbe, das abgelehnt oder fortgeführt werden kann? Und - um mit Stuart Hall (1999) zu sprechen - wessen Erbe ist es? Wer ist die Erbengemeinschaft, die Renan als ,spirituelle Familie“ oder auch ,geheiligte Sache, die man ein Volk nennt" (1882), bezeichnet?

Zur Annäherung an diese Fragen werde ich ein Jahr in die Zukunft blicken und Renans Rede von 1883 untersuchen, die er ebenfalls an der Sorbonne gehalten hat. Sie wurde im Nachhinein unter dem Titel Der Islam und die Wissenschaften publiziert. Selbsterklärtes Ziel der Rede ist die Auflösung von Missverständnissen, der durch einen ,Mangel an Genauigkeit bei Anwendung von Wörtern, welche Nationen und Rassen“ (Renan 1883a) bezeichnen, entsteht. Er knüpft an zentrale Ideen 
seiner Rede aus dem Vorjahr an und kritisiert, dass von „Griechen, Römern und Arabern“ gesprochen werden, ,als ob diese Wörter Menschengruppen bezeichneten, die immer mit sich selber identisch gewesen" (ebd.). Die Wirklichkeit - gekennzeichnet durch Eroberungen, Moden und vielfältige andere geschichtliche Faktoren - sei hingegen sehr viel komplexer. So seien ,wir Franzosen“ unter anderem „Römer der Sprache, Griechen der Civilisation, Juden der Religion nach“ (ebd.). Die Kategorie der ,Rasse" stellt nach wie vor einen Nebenschauplatz für das Verständnis der Nationen dar bzw. seine Bedeutung liegt in der Vergangenheit:

\begin{abstract}
„Die Rasse als solche, von höchster Wichtigkeit für den Beginn der Geschichte einer Nation, verliert ihre Bedeutung in dem Maasse als die grossen universalgeschichtlichen Thatsachen: griechische Civilisation römische Eroberung, germanische Eroberung, Christenthum, Islam, Renaissance, Philosophie, Revolution gleich zermalmenden Walzen über die frühesten Varietäten der Menschenfamilie hinweggehen und sie in mehr oder minder homogene Massen zusammendrängen." (ebd.)
\end{abstract}

Nationen sind also nicht die Fortführung irgendwelcher Abstammungsgemeinschaften, sondern durch weltgeschichtliche Entwicklungen entstanden und bestimmt. Dafür malt er ein Bild, das zumindest die grobe Struktur der Nationen, ihre weltgeschichtlichen Bedeutung und ihre dadurch bestimmte innere Verfasstheit berücksichtigt. Dieses Bild teilt die Welt in ,mehr oder minder homogene Massen" und ordnet diese Massen anhand einer teleologischen Weltgeschichte ein. Ähnlich wie Hegel geht es Renan dabei um die vermeintliche Nähe bzw. Ferne der Völker zur Vernunft (Kleinschmidt 2013).

Diese Beziehung zur Vernunft wird bei Renan allerdings durch die jeweils gesellschaftliche Rolle von Wissenschaft und Religion definiert. Biographisch spielt sein Verhältnis zum Christentum eine zentrale Rolle; hatte er doch nach einer erfolgreichen Ausbildung zum Priester mit der Kirche gebrochen. Im Zentrum seiner historisch-kritischen Bibellektüre stand sein Werk Leben Jesu von 1863, das als eines der berühmtesten Bücher des 19. Jahrhunderts in Frankreich gilt (Schäbler 2007). Er propagierte ein Modell, das eine auf Wissenschaft begründete Religion vorsah, da so eine Balance zwischen Wissenschaft und Religion hergestellt werden könnte. Genau diesen Prozess der Abkehr von der Religion durch eine Zuwendung zur Wissenschaft sah er in der christlichen Tradition, den ,christlichen Gesellschaften ' gegeben. Das Gegenstück, der Andere, dieser Geschichtsschreibung und Weltsicht stellt der Islam dar. Dementsprechend pejorativ beschreibt der Orientalist und Semitist Renan die „mahomedanischen Länder": 
„Jede Person, die nur einigermassen an dem Geistesleben unserer Zeit theilnimmt, erkennt deutlich die, gegenwärtige Inferiorität der mahomedanischen Länder, den Niedergang der vom Islam beherrschten Staaten, die geistige Nichtigkeit der Rassen, die einzig und allein ihre Kultur und ihre Erziehung jener Religion verdanken.“ (Renan 1883a)

Die Dominanz des Islam habe also den Niedergang der „Staaten“ und „Rassen“ bewirkt. „Rasse“ ist an dieser Stelle nicht Ursache, sondern vielmehr das Material, dessen Entwicklung der Islam verhindern würde. Nach Renan verhindere der Islam in all seinen Formen zu den verschiedenen Zeitpunkten jede Modernisierung. Er malt ein aberwitziges Bild von Muslim_innen, an deren Ende die vermeintliche Einsicht steht, dass der Islam alle anderen Unterschiede einebnen würde:

\begin{abstract}
„Wer immer im Orient oder in Afrika gereist ist, dem musste die Wahrnehmung sich aufdrängen von der thatsächlichen Geistes-Beschränktheit eines wahrhaft Gläubigen, von jener Art eisernen Reifens, der um sein Haupt geschlagen ist und dasselbe der Wissenschaft geradezu verschliesst, es unfähig macht, irgend etwas zu lernen, irgend eine neue Idee in sich aufzunehmen. So wie es in seine Religion eingeweiht ist, um das zehnte bis zwölfte Lebensjahr, wird das muselmännische Kind, das bis dahin zuweilen noch ziemlich geweckt war, plötzlich fanatisch, von jenem Dünkel gesättigt, es besitze Alles, was ihm als die absolute Wahrheit gilt, wie über ein Vorrecht über das glücklich, was gerade seine geistige Inferiorität ausmacht. Dieser dumme Hochmuth ist das Laster, welches das ganze Sein des Muselmanns bestimmt. Die scheinbare Einfachheit seines Gottesdienstes flösst ihm eine wenig gerechtfertigte Verachtung vor den andern Religionen ein. Ueberzeugt, dass Gott Glück und Macht nach seinen unergründlichen Rathschlägen austheilt, ohne auf Kenntnisse noch auf persönliches Verdienst einen Werth zu legen, hat der Muselmann die tiefste Verachtung vor der Bildung, der Wissenschaft, vor Allem, was wir das europäische Geistesleben nennen. Dieses durch den mahomedanischen Glauben ihm eingeprägte Vorurtheil ist so mächtig, dass alle Unterschiede der Rasse und der Nationalität durch die einzige Thatsache der Bekehrung zum Islam verschwinden.“ (ebd.)
\end{abstract}

Alle ,Völker“, ,Nationen“ oder ,Rassen“ würden so gleich gemacht: „Die Berbern, die Bewohner des Sudan, die Tscherkessen, die Afghanen, die Malaien, die Egypter, die Nubier, welche Muselmänner geworden, sind keine Berbern, keine Afghanen, keine Egypter u. s. w. mehr, es sind Muselmänner.“ (ebd.)

Dabei gibt es eine Ausnahme. Renan lernte im Jahr vor seiner Rede von 1883 den muslimischen und aus Persien stammenden Gelehrten Jamāl al-Dīn alAfghān̄i kennen und schätzen. Nicht zuletzt vor diesem Hintergrund erfand er eine Ausnahme der alles gleichmachenden Islamisierung: „Persien allein macht 
eine Ausnahme, es hat seinen eigenen Genius sich zu erhalten gewusst; denn Persien hat innerhalb des Islam sich seinen besondern Platz gewahrt, es ist im Grunde viel mehr schiitisch als muselmännisch.“ (ebd.) Al-Afghān̄̄ antwortete Renan öffentlich. Neben viel Zustimmung zu Renan hob er unter anderem die Verfolgung des freien Gebrauchs der Vernunft sowohl im Islam als auch im Christentum hervor und begründete so die Möglichkeit, dass es Hoffnung für die „muselmännische Gesellschaft“ gäbe, ,ihre Fesseln zu brechen und entschlossen auf der Bahn der Civilisation fortzuschreiten nach dem Beispiel der abendländischen Gesellschaft" (al-Afghānī 1883). Renan stellte in seiner Replik daraufhin noch mal seine Bewunderung für al-Afghānī heraus; und hier begründet er auch die vermeintliche Ausnahmestellung der persischen Muslime. Der Grund für die Ausnahmestellung al-Afghān̄̄s sei, dass er ,,jenen kräftigen Rassen des oberen, an Indien grenzenden Iran an[gehöre], in denen der arische Geist noch so energisch unter der dünnen Hülle des officiellen Islam fortlebt“ (Renan 1883b). Für Renan ist al-Afghān̄̄ ,selber der beste Beweis jenes großen Axioms, das wir so oft proklamirt haben - nämlich dass Religionen das werth sind, was die Rassen werth sind, die sich zu ihnen bekennen“ (ebd.). Birgit Schäbler meint in ihrer Analyse hier den Kern von Renans Denken gefunden zu haben. Letztlich, so Schäbler, basiert Renans Denken doch wieder auf der Kategorie der ,Rasse“. „Die ,Rasse“ kann Europa nicht erklären, aber sie erklärt den Orient. In Europa versucht Renan Religion und Wissenschaft miteinander zu verbinden, für den Orient schließt er dies kategorisch aus." (Schäbler 2007).

So sehr ich mich prinzipiell dieser Einschätzung anschließe, dass ,ethnisch', ,rassisch ' usw. in kolonialen und heute vorherrschenden neokolonialen Denkmustern immer nur die anderen sind, so wenig teile ich ihre Problemanalyse. In ihrer Analyse erscheint der Befund wie die Entdeckung eines Geheimnisses; in Wirklichkeit denke er doch in der Kategorie der ,Rasse', auch wenn er anderes behauptet. Damit wiederholt sie meiner Meinung nach eine Geste der liberalen Rassismuskritik, die Rassismus nur dann als problematisch oder überhaupt als solchen ansieht, wenn darin ein Bezug zu biologistisch verstandenen ,Rassen' enthalten ist. Ich sehe in diesen Ausführungen vielmehr ein Symptom von der Konstruktionsweise des Volkes, das immer als Assemblage, im Ensemble, mit Bezugnahmen, Adaptionen, Andeutungen und Querverweisen zu anderen Elementen der Konstruktion arbeitet. So gilt Renan beispielsweise auch als ,Erfinder' der binären Opposition von Semiten und Ariern; trotz vieler Bezüge dieser Kategorien zu biologischen Rassen, stellte er doch immer wieder klar, dass diese Unterscheidung rein philologische und keine physiognomischen Bezüge habe (Simon-Nahum 2008). 
Die Dominante in Renans Konstruktion der Nationen stellt jedoch aus meiner Sicht der Bezug zu Fortschritt und Freiheit vor dem Hintergrund des Widerspruchs von ,Abendland “ und ,Orient' dar. Für ihn ist die Wissenschaft die „die Seele einer Gesellschaft; denn die Wissenschaft ist die Vernunft“ (Renan 1883a). Der Islam repräsentiert für ihn die Anti-Wissenschaft. Das, was oft als arabische Wissenschaft bezeichnet worden sei, sei in Wirklichkeit von anderen Völkern innerhalb muslimisch beeinflussten Territorien hervorgebracht. Hier zeigt sich die orientalistische Bewegung, die ständig - in einer Art systematischen Unschärfe - zwischen Muslim_innen und Araber_innen flottiert. Am Ende seiner Rede proklamiert er das ihm zufolge notwendige und zu erhoffende Ende des Islams. Die Wissenschaftsfeindlichkeit des Islams wird nach Renan zur weiteren „,militärischen und gewerblichen Überlegenheit“ (ebd.) des ,Westens ‘ beitragen. Diese Entwicklung denkt er in Bildern der militärischer Eroberungen:

„Das Wissen stellt die Kraft in den Dienst der Vernunft. Es gibt in Asien Elemente der Barbarei, denjenigen ähnlich, welche die ersten muselmännischen Heere und jene grossen Völkerstürme eines Attila oder Dschingis-Khan erzeugten. Die Wissenschaft versperrt ihnen den Weg. Wenn Omar, wenn Dschingis-Khan auf eine gute Artillerie gestossen wären, so hätten sie den Saum ihrer Wüste gewiss nicht überschritten." (ebd.)

Dieses militärische Vorgehen gegen den Islam bzw. die Unvernunft oder die Barbarei stellt er in einen breiteren Kontext des kolonialen Projektes der zivilisatorischen Mission:

\begin{abstract}
„Man muss sich bei momentanen Verirrungen nicht aufhalten. Was ist nicht bei ihrem ersten Auftreten gegen die Schusswaffen gesagt worden? Und doch haben sie Vieles zum Siege der Civilisation beigetragen. Was mich betrifft, ich habe die Ueberzeugung, dass die Wissenschaft gut ist, dass sie allein Waffen gegen das Böse liefert, welches man mit ihnen vollbringen kann, dass die Wissenschaft nur dem Fortschritt dient, ich habe hier den wahren Fortschritt im Auge, denjenigen, der unzertrennlich ist von der Menschenliebe und der Freiheit.“ (ebd.)
\end{abstract}

Hier ließen sich Parallelen zu diskursiven Legitimationsfiguren aktueller Kriege ziehen. Mein Fokus liegt aber an dieser Stelle auf etwas anderem.

Laut Renan hat es im Islam niemals eine „schöne wissenschaftliche Bewegung gegeben“ (ebd.). Vielmehr habe der Islam ,in der That die exakte Wissenschaft, und die Philosophie stets verfolgt; er hat sie schliesslich erstickt" (ebd.). Aus dieser grundsätzlichen Unvereinbarkeit zwischen Islam und Wissenschaft - Wissenschaft kann hier als Platzhalter für eurozentrisch verstandene Begriffe wie 
Moderne, Freiheit, Humanität, Vernunft usw. gelesen werden - wird einerseits der Islam abgewertet und andererseits auch das ,Abendland' als Entität und Identität konstruiert. Edward Said hat in seiner Studie zum Orientalismus gezeigt, wie die Wissenschaftsdisziplin des Orientalismus seit dem 19. Jahrhundert im Allgemeinen und Ernest Renan als einer seiner entscheidenden Vertreter im Besonderen den ,Orient' erschaffen, ihn orientalisiert, haben (Said 1978). Said zeigt, wie die diskursive Struktur des Orientalismus eine Realität hervorbringt, die konstitutiver Bestandteil des kolonialen und imperialen Projekts Europas ist und weit über die Wissenschaft hinaus hegemonial geworden ist. Der ,Orient ' fungiert in diesem Dispositiv als das Andere ,Europas ', des ,Westens “ und - was hier gleichgesetzt wird - der ,Moderne'. Das Konstrukt des ,Orients“ wird so konstitutiv für die Identität der kolonisierenden Nationen. In politikwissenschaftlichen Diskurs findet dies wohl am augenscheinlichsten Ausdruck in Werken, wie Oswald Spenglers Der Untergang des Abendlandes (1918), Samuel Huntingtons Clash of Civilizations (1992/1996) oder Thilo Sarrazins Deutschland schafft sich ab (2010). Während in vielen ehemals kolonisierten Ländern andere Bezugspunkte gewählt werden oder Momente des Orientalismus auf eine andere Weise angeeignet werden - man denke beispielsweise an das Modernisierungsimperativ des nation-building-Prozesses in Indien - ist im sogenannten, Westen ' orientalistische Ideologie in zahllosen gesellschaftlichen Feldern virulent - und spielt eben auch eine zentrale Rolle für die Konstruktion nationaler Identitäten.

Auch wenn das Land des ,Abendlandes' nicht auf das Territorium eines Nationalstaates beschränkt ist, ist es doch konstitutiver Bestandteil nationaler Identitätskonstruktionen. Das Erbe, das für Renan die Grundlage der Nationsbildung darstellt, ist eng mit der binären Opposition des ,Orients" und des ,Okzidents “ verbunden. Dieses Erbe konstruiert Renan als ein eindeutig christliches (sprich: nicht-muslimisches). Allerdings stehen sich hier nicht einfach Christentum und Islam gegenüber. Das Erbe ist nicht einfach ein christliches, sondern es ist die ,Moderne" selbst, die sich ausgehend von christlichen Wurzeln säkularisiert habe. Diese Konstruktion des Prozesses der Säkularisierung vom Christentum - also eine christliche bzw. christlich-jüdische Säkularisierung - ist die Figur, auf die sich dieses Erbe bezieht. Heutzutage ist es in Deutschland en vogue nicht mehr nur von der christlichen Tradition, sondern immer wieder auch von der christlich-jüdischen Tradition zu sprechen. Zu Recht wurde die Vereinnahmung der jüdischen Tradition problematisiert, in deren Zuge die gewaltvolle und mörderische Geschichte des Antisemitismus dethematisiert und instrumentalisiert wurde (Czollek 2018). Doch unabhängig davon, ob das ideologische Konstrukt des ,Abendland" nun mit seinen christlichen oder christlich-jüdischen Wurzeln als „Grundlage unseres Zusammenlebens“ (Rößler 2016) charakterisiert wird, wie 
es exemplarisch in einem Strategiepapier der CDU/CSU von 2016 heißt, wird hier die okzidentalistische Figur der Wertegemeinschaft geschaffen. Diese Figur der - gleichzeitig transnationalen und nationalisierenden - Wertegemeinschaft ist konstitutiver Bestandteil der je spezifischen nationalen Identitätskonstruktion und fungiert als entscheidender Baustein auf dem Feld der Auseinandersetzungen um die Frage der (Nicht-)Zugehörigkeit.

Diese Wertegemeinschaft zeichnet sich durch etwas Doppeltes aus: Die beschworene Wertegemeinschaft ist säkular und (post-)christlich bzw. ,christlichjüdisch' zugleich. Mit dieser Wertgemeinschaft wird auf den Rechtsstaat, das Grundgesetz, die freiheitlichen Werte, die Meinungsfreiheit, die Gleichstellung der Geschlechter usw. rekurriert und gleichzeitig zu verstehen gegeben, wessen Erbe diese Merkmale der Demokratie zugehören. Es findet hier eine spezifische Aneignung des Erbes der Menschenrechte, der Demokratie etc. statt; im eurozentrischen Diskurs erscheint dieses Erbe als ein ,westliches' (4.2.2.4). Diese Aneignung ist aus zahlreichen Gründen problematisch. Sie ist nicht nur historisch falsch und unterschlägt die Verwobenheit mit transnationalen Prozessen und Kämpfen in der Geschichte der Entwicklung von Demokratie. Diese Aneignung ist zentraler Bestandteil des kolonialen und neokolonialen Gestus der ,zivilisatorischen Mission", die meint, dieses Erbe auf quasi pädagogische und paternalistische Weis exportieren zu müssen. Die vermeintlich christliche bzw. jüdisch-christliche Säkularität bringt die/den diese Perspektive Repräsentierende in die Position über den Dingen zu stehen, also vermeintlich objektiv zu sein, im Gegensatz zum Rest der Welt also keine Wurzeln zu haben bzw. nicht durch diese in der Perspektive eingeschränkt zu sein. Das Gegenbild der Wertegemeinschaft ist notwendiger Bestandteil dieser ideologischen Konstruktion, also der Vernunft vs. Unvernunft, Universalität vs. Partikularität usw. Schließlich basiert diese Konstruktion ja nicht darauf, dass es tatsächlich demokratische, menschenrechtlich angemessene, auf Gleichheit basierende, ,moderne' usw. gesellschaftliche Zustände und Ideen in den Nationen des Globalen Nordens gäbe. Dies wird wohl am deutlichsten - um es durch ein Bild unter vielen zu veranschaulichen - in dem Umstand, dass beispielsweise in Deutschland selbst die konservativsten gesellschaftlichen Gruppierungen bis über die CSU hinaus, die als Bewahrerinnen patriarchaler und heteronormativer und patriarchaler Ordnung bezeichnet werden können, plötzlich zu Vorkämpferinnen geschlechtlicher Gleichstellung werden zumindest wenn es dabei um die Beschwörung der nationalen Wertegemeinschaft und die Abwertung des Anderen, des Islam, geht.

In Gesellschaften des globalen Nordens bietet diese Konstruktion des Erbes und der dazugehörigen Wertegemeinschaft die Grundlage für die Konstruktion 
von Zugehörigkeit und Nicht-Zugehörigkeit. Vor diesem Hintergrund sind beispielsweise die Diskurse rund um die sogenannte ,Flüchtlingskrise" - richtiger wäre wohl von Rassismus- oder Nationenkrise zu sprechen - zu sehen. Die vielbeschworene Angst vor ,Überfremdung', vor einem Verlust der nationalen Identität oder vor der Unmöglichkeit der ,Integration“ der ,Fremden ' basiert auf dem Denken in ,Kulturkreisen“ - eingewanderte Spanier_innen wären mit gänzlich anderen Diskursen konfrontiert. Die Konstruktion der Wertegemeinschaft als Ursprung und Träger der ,Moderne ', der ,Demokratie', der ,Humanität‘ usw. basiert also auf dem orientalistischen und kolonialem Ideologem des ,Orients ‘. Wobei der ,Orient hier als Platzhalter fungiert - die Herstellung der , abendländischen ' Wertegemeinschaft funktioniert oft auch in der Gegenüberstellung $\mathrm{zu}$ anderen vermeintlichen ,Kulturkreisen', wie beispielsweise das subsaharische Afrika oder Südosteuropa. Allerdings nimmt der antimuslimische Rassismus (Attia 2009) in den letzten Jahren eine zentrale Stellung im Imaginären dieser Wertegemeinschaft ein, weswegen an dieser Stelle Renan und der Orientalismus als Zugang gewählt wurde.

\subsection{Sieyès: Nation als Leistungsgemeinschaft}

Emmanuel Joseph Sieyès (1748-1836) war eine entscheidende Figur im Vorlauf und Nachgang der Französischen Revolution. Im Januar 1789, ein halbes Jahr vor dem Sturm auf die Bastille, veröffentlicht Emmanuel Sieyès seine berühmte Flugschrift Qu'est-ce que le tiers-état? (Was ist der Dritte Stand?). Ausgehend von diesem Text werde ich sein Nationsverständnis rekonstruieren und in damit zusammenhängende konkurrierende oder daraus folgende Nationsverständnisse einbetten. Für die Kontextualisierung werde ich mich insbesondere auf In Verteidigung der Gesellschaft (1976) von Michel Foucault beziehen. Sieyès argumentiert in seiner Flugschrift für die Abschaffung der aristokratischen Privilegien und die Etablierung einer bürgerlichen Ordnung. Die Privilegien verurteilt er: „Wir sind nicht frei durch die Privilegien, sondern durch die Bürgerrechte, Rechte die allen gehören." ${ }^{16}$ (Sieyès 1789: 43).

Mit seinem Begriff von Freiheit und Gleichheit stellt er sich in die Tradition, die als die liberale, vertragstheoretische Tradition bezeichnet werden könnte. Diese entwickelt sich ausgehend vom Denken von Hobbes, dessen Kernelemente Naturrecht und Vertragstheorie sind. In dieser Tradition wird ein Naturzustand konstruiert, in dem der Wilde als koloniale Figur konstruiert wird und entweder schlechte (Hobbes) oder gute, im Sinne von unschuldig (Rousseau), Eigenschaften

\footnotetext{
${ }^{16}$ Übersetzung M. K., Original: « On n'est pas libre par des privileges, mais par les droits de citoyen, droits qui appartiennent à tous.» (Sieyès 1789: 43)
} 
verkörpert. Die koloniale Imagination des Wilden ist als Antipode zu den Subjekten der kolonisierenden Gesellschaften ein konstitutives Element zur Entwicklung der Begriffe Geschichte, Fortschritt, Vernunft etc., wie beispielsweise Gayatri Spivak anhand von Kant und Hegel nachweist (Spivak 1999: 6). Die Gesellschaft muss dann diesen Zustand des Chaos bändigen bzw. die Gesellschaft entsteht durch die Einhegung der Wildheit. Dies geschieht durch den Vertrag, durch die fiktive Zustimmung aller unter die Souveränität des Staates. Bei Hobbes wird die Souveränität durch den Leviathan und bei Rousseau durch den allgemeinen Willen (volonté générale) verkörpert. An der Imagination des, Wilden “ werden bereits die Eigenschaften herausgearbeitet, die der bürgerlichen Gesellschaft zugrunde liegen (sollen), wie nicht zuletzt Eigensinn statt Gemeinschaftlichkeit, Privateigentum statt Allmende und Tausch statt Kooperation. Sieyès nimmt durchaus Elemente dieser Tradition auf. Im Zentrum seines Nationsverständnis, das auf dieser Form der Gleichheit basiert, steht jedoch aus meiner Sicht etwas anderes. In Sieyès Diskurs zeichnet sich ein organischer Begriff von Gesellschaft ab, der die ,wahre Nation, ihre Substanz, in den gesellschaftlichen Leistungsträgern sieht, denen die der Gesellschaft unnützen Teile entgegenstehen.

Den ersten Teil seiner Flugschrift strukturiert er nach drei Fragen: „1. Was ist der Dritte Stand? ALLES. 2. Was ist der Dritte Stand bis jetzt in der politischen Ordnung gewesen? NICHTS. Was verlangt er? ETWAS ZU SEIN.““: ${ }^{7}$ (ebd.: 31 f.) Für Sieyès kann die französische Nation nur der Dritte Stand sein, denn nur er stellt eine „,vollständige Nation“18 (ebd.: 37) dar. Der Dritte Stand ist also die Nation, während er in der politischen Ordnung keine Repräsentation erfährt. Die Aufhebung dieses Missverhältnisses ist dann das Programm der bürgerlichen Revolution. Doch was ist diese Nation, die er hier heraufbeschwört eigentlich? Wie ist ihr Verhältnis zum Staat zu denken?

\section{Das Narrativ der Erzählung der Ursprünge}

Zur Beantwortung dieser Fragen möchte ich kurz im Anschluss an Foucault auf die verschiedenen zu jener Zeit kursierenden Nations- und Staatsverständnisse Bezug nehmen. Foucault zeichnet nach, wie seit der Renaissance ein Staatsbegriff und eine Form der Herrschaftslegitimation dominant war, die ich als monarchisches Narrativ bezeichnen will. Dieses zeichnete sich durch eine „Erzählung von den Ursprüngen“

\footnotetext{
${ }^{17}$ Übersetzung M. K., Original: « $1^{\circ}$ Qu'est-ce que le Tiers état ? - TOUT. $2^{\circ}$ Qu'a-t-il été jusqu'à présent dans l'ordre politique ? RIEN. $3^{\circ}$ Que demande-t-il ? - A ÊTRE QUELQUE CHOSE.» (Sieyès 1789: 31 f.)

${ }^{18}$ Übersetzung M. K., Original: « nation complète» (Sieyès 1789: 37).
} 
(Foucault 1976b: 139) und einer um den König zentrierten Form staatlicher Souveränität aus. Das monarchische Narrativ war keinesfalls einheitlich; die Machtkämpfe wurden innerhalb der Form der Erzählung der Ursprünge ausgetragen. Eine Erzählung war beispielsweise, Frankreich bzw. die Franken seien ein Nachfahre Roms, da beide Flüchtlinge aus Troja seien. Als Nachfahre Roms konnte die Monarchie im Frankreich der Renaissance das imperialen Erbe Roms für sich reklamieren. Das französische Königshaus begründete so den eigenen, universalen Machtanspruch, insbesondere gegenüber den Habsburger Monarchien und dem Heiligen Römischen Reich Deutscher Nationen. Gleichzeitig wird mit der Bezugnahme auf das römische Imperium die Position des Königs gegenüber seinen Untertanen gesichert und in Form der kaiserlichen Souveränität legitimiert. Das römische Gallien, das die Vorfahren Frankreichs als koloniale Untertanen eines Reichs erscheinen lassen würde, musste zur Sicherung des imperialen Anspruchs unbedingt aus der Geschichte ausgespart bleiben; ebenso wie die Invasionen der Franken. Dies führte zu der paradoxen Situation, dass die Geschichtsschreibung zwar das Erbe Roms konstituieren musste, das Verhältnis Frankreichs zum historischen Rom aber nicht vorkommen durfte. Vor diesem Hintergrund wurde das Verhältnis der legitimen Erbschaft Roms komplexer konstruiert als in der Form der Nachkommenschaft. Frankreich wurde nicht als Nachfahre konstruiert, sondern vielmehr hatten Frankreich und Rom als Flüchtlinge Trojas den gleichen Ursprung. Frankreich beerbte Rom also nicht als Kind, sondern hatte als „Schwester oder Cousine Roms“ (ebd.: 141) gleiche Rechte wie Rom selbst, stammte also nicht von der universellen Monarchie ab, sondern ist von jeher schon selber eine Monarchie mit dem Anspruch einer universellen Monarchie gewesen.

Es gab jedoch auch andere, konkurrierende Erzählungen der Ursprünge, die auf je spezifische Weise darauf zielen, ein Recht auf Macht zu fundieren. Ein Beispiel unter vielen wäre François Hotman. Mit seinem Werk Franco-Gallia von 1573 führte er Elemente der germanischen Erzählung in Frankreich ein. Er behauptete, dass die Franken, die seinerzeit in Gallien eingefallen sind und eine neue Monarchie gegründet haben, keine Trojaner, sondern Germanen gewesen seien, die die Römer besiegt und verjagt hätten. Der entscheidende Unterschied zur germanischen Erzählung ist aber, dass die Franken nicht die Gallier, sondern die Römer besiegt hätten. Hotman erklärte die Franken und die Gallier so historisch zu einem „Brudervolk“ (ebd.: 146). Das historische Rom steht in seinem Diskurs stellvertretend für den zeitgenössischen Absolutismus und das zeitgenössische päpstliche Rom mit seinem Klerus, deren erklärter Feind Hotman ist. Er verfolgt mit dieser spezifischen Erzählung der Ursprünge, die eine ,germanisch-französische, fränkisch-gallische Einheit“ (ebd.) begründen soll, mindestens zwei Ziele: (1) Er will die absolute Macht des Monarchen begrenzen, indem er ein Modell der Vergangenheit zeichnet, das bei den 
Germanen eine wechselseitige Verpflichtung zwischen König und Volk festgeschrieben habe. Der König sei in der germanischen Geschichte nicht durch Abstammung bestimmt, sondern gewählt worden. Wie viele protestantischen Zirkel zu jener Zeit fordert er eine konstitutionelle Monarchie. (2) Der Calvinist Hotman plädiert für Religionsfreiheit und das Ende der Protestant_innenverfolgung in Frankreich. Der aus Rom stammende Katholizismus sei aufoktroyiert und die „brüderlichen und befreienden Germanen“ stehen für die „reformierte Religion jenseits des Rheins“ (ebd.: 147). Diese germanische These wurde schnell auch in katholischen Kreisen übernommen und war bis ins 17. Jahrhundert sehr einflussreich.

Seit Ende des ersten Drittels des 17. Jahrhunderts versuchte die absolute Monarchie - verkörpert durch Ludwig XIV. und Kardinal Richelieu - die These des germanischen Ursprungs Frankreichs auszuschalten, da sie zum realen Problem für die Ausübung der innenpolitischen Macht und auch für die europäische Außenpolitik geworden war. Zum einen wurde der trojanische Mythos wieder verstärkt in Umlauf gebracht. Zum anderen kam aber hier ein grundlegend neues Muster auf, das Foucault als „Gallo-Zentrismus“ (ebd.: 148) bezeichnet. Hier nähern wir uns dem in unserer Gegenwart präsenten, ideologischen Bild des gallischen Dorfes von Asterix ${ }^{19}$. Die Gallier, die Hotman als wichtige Partner in der Vorgeschichte der französischen Monarchie erschienen ließ, waren passiv; sie waren besiegt, besetzt und von außen befreit worden. Ab dem 17. Jahrhundert wurden diese Gallier jedoch zum führenden Prinzip der Geschichte. In vielen historischen Diskursen jener Zeit wird das Verhältnis umgekehrt und die Gallier werden zum „Motor“ (ebd.) der Geschichte und Ursprung der europäischen Nationen. Ein Narrativ einiger Historiker besagte beispielsweise, dass die Gallier „die Väter aller Völker Europas“ (ebd.) waren.

Der gallische König Ambigate habe das Problem der Überbevölkerung so gelöst, dass er einen seiner Neffen nach Italien und einen anderen nach Germanien schickte. So seien auch die Franken, die im 4. und 5. Jahrhundert in Gallien einfielen, nur die Nachkommen jenes ,ursprünglichen Galliens“ (ebd.: 149) gewesen. Ihnen ging es allerdings keinesfalls darum, Gallien und ihre besiegten Brüder zu befreien, sondern die Sehnsucht in der eigentlichen Heimat von der ,einst blühenden gallorömischen Zivilisation zu profitieren“ (ebd.). Zwar mussten sich die Franken bei ihrer Rückkehr nach Gallien schlagen, allerdings nicht mit den Galliern und noch nicht mal mit den Römern, sondern mit den Burgunden und den Goten, die als Arianer ketzerisch gewesen seien, sowie mit den , ungläubigen`S Sarazenen. Das in

${ }^{19}$ „Wir befinden uns im Jahre 50 v. Chr. Ganz Gallien ist von den Römern besetzt... Ganz Gallien? Nein! Ein von unbeugsamen Galliern bevölkertes Dorf hört nicht auf, dem Eindringling Widerstand zu leisten.“ (aus der Einleitung der Asterix-Comics) 
Gallien eingepflanzte römische Recht wurde durch die (gallischen) Franken allerdings keineswegs ins Wanken gebracht, sondern vielmehr übernommen. Hier wurde der Mythos der autochthonen gallischen Bevölkerung geschaffen oder zumindest maßgeblich bestärkt. Dieser Mythos diente auch zur Bestärkung jener vermeintlich natürlichen, von Cäsar beschriebenen Grenzen Galliens, deren Legitimation wichtiger Teil der Außenpolitik Richelieus und Ludwigs XIV. waren. Es diente aber auch dazu, die Einheit Frankreichs und die absolute Macht des Königs zu bestärken. In dieser Erzählung hatten die Krieger, die gegen die Burgunden, Goten und Sarazenen gekämpft hatten, vom König Lehensherrschaften zugeschrieben bekommen. Das Vorrecht der Aristokratie konnte also nicht aus irgendwelchen ,fundamentalen und archaischen Rechten“ (ebd.: 150) des Adels hergeleitet werden, sondern entsprang bereits dem Willen des Königs, dessen Macht und Absolutismus der Organisation des Feudalismus selbst vorgängig erscheinen sollte - schließlich ging es in jener Zeit darum, dem Zentralstaat mehr Macht zu verleihen und den Absolutismus auszubauen.

\section{Das Narrativ der rassisch-nationalen Kräfte}

In dieser Zeit wird laut Foucault ein Diskurs entstehen, der mit anderen Operatoren verfährt. In meinen Worten: Das monarchische Narrativ wird vom Narrativ rassischnationaler Kräfte herausgefordert. Bislang war es ein Rekurs auf die Geschichte gewesen, in dem Fragen des Ursprungs und der Invasionen die Legitimität der absoluten Monarchie begründet haben oder aber eine andere Form der Monarchie erstritten werden sollte. Aus der Geschichte des Ursprungs und der Invasionen ergaben sich die Prinzipien des öffentlichen Rechts der absolutistischen Monarchie; aus ihnen wurden die Rechte und Grenzen der königlichen Macht, die Rolle der Versammlungen und Räte des Königs, die Rechte des Adels gegenüber dem König und das Verhältnis der Monarchie und der Aristokratie zum Volk abgeleitet. Als Reaktion auf die Einschränkungen der Macht der Aristokratie durch den Absolutismus und das Erstarken der bürgerlichen Klasse wehrte sich die Aristokratie und erschuf ein neues Denken der Nation. Als zentralen Text, der diese diskursive Formation prägte, sieht Foucault den Bericht über den Zustand Frankreichs von Boulainvilliers (1658-1722) an.

Die Entstehungsgeschichte dieses Textes ist interessant. Ludwig der XIV. wies seine Verwalter an, einen umfassenden Bericht über den Zustand Frankreichs anzufertigen, der seinem Nachfolger in spe, dem Herzog von Burgund, die gesamten Kenntnisse über den Staat, die Regierung und das Land vermitteln sollte, die nötig sein werden, um zu regieren. Nachdem die Verwaltung diese Berichte erstellt und vereinheitlicht hat, beauftragt das Umfeld des Herzogs von Burgund Boulainvilliers, den sehr umfangreichen Bericht zu kürzen, zu erläutern und ihn zu interpretieren. 
Dieses Umfeld setzte sich insbesondere aus Adligen zusammen, die der Regierung Ludwigs XIV. vorwarfen, ihre ökonomische Potenz und politische Macht beschnitten zu haben. Boulainvilliers führte dieses Unterfangen durch, redigierte, interpretierte, systematisierte; und er fügte auch einen Diskurs als notwendige Ergänzung zu dieser riesigen administrativen Arbeit der Beschreibung und Analyse des Staates hinzu (ebd.: 155). In diesem Diskurs schreibt Boulainvilliers die Geschichte der Regierungen Frankreichs, ausgehend von Hugo dem Karpetinger im 7. Jahrhundert. In dieser Geschichte werden Thesen stark gemacht, die für den Adel günstig sind. Kritisiert wird die Käuflichkeit der Ämter, die für den verarmten Adel nachteilig ist; Boulainvilliers protestiert gegen die Enthebung des Rechts des Adels auf die Rechtsprechung und dem damit verbundenen Verlust an Vorteilen; er reklamiert einen rechtlich gesicherten Platz des Adels im Rat des Königs; er kritisiert die Rolle der Verwalter in der Provinzverwaltung.

Nach Foucault geht es Boulainvilliers in seinem Text und seiner Rekodierung der Beziehungen des Königs aber vor allem darum, dass das dem König und später dem Prinzen verliehene Wissen ein von der Verwaltungsmaschinerie bereitgestelltes Wissen ist. Diese Wissensform kann als der Hauptgrund des Machtverlustes des Adels gesehen werden. Es ging darum, welche Rolle und welche Beziehungen der König hat. Das Verwaltungswissen ist ein Wissen des Staates über den Staat. Boulainvilliers stellt die Frage danach, ob das Wissen des Königs über sein Königreich und seine Untertanen identisch mit dem Wissen des Staates über den Staat sein sollte. Der König und der Staat würden so eine Einheit, ein Körper. Foucault fasst diese Einheit so zusammen: „Die Verwaltung erlaubt dem König, über sein Land in grenzenloser Willkür zu herrschen. Umgekehrt regiert die Verwaltung über den König dank der Qualität und Art des Wissens, welches sie ihm auferlegt.“ (ebd.: 157) Der juridische und der administrative Apparat des Absolutismus hatte die Verminderung des Reichtums und der politischen Macht des Adels hervorgebracht.

Die adlige Reaktion wollte diesen Macht-Wissen-Komplex brechen und ein Verhältnis des Königs zum Adel etablieren, das auf der wechselseitigen Verpflichtung zwischen König und Adel basierte. Dafür erfand die adlige Reaktion eine neue Art Geschichte zu erzählen. Bis dahin war die Geschichte nicht nur einfach die Geschichte gewesen, die sich die Macht über sich selbst erzählte bzw. erzählen ließ. „Es war die Geschichte der Macht durch die Macht.“ (ebd.: 162) Foucault zufolge löst sich in diesem neuen Diskurs das „Zusammenspiel der historischen Erzählung mit der Ausübung der Macht, ihrer rituellen Bestätigung und ihrer imaginierten Formulierung des öffentlichen Rechts auf" (ebd.). Es entsteht ein neues Subjekt, das spricht: 
„Jemand anderer übernimmt das Wort in der Geschichte und wird die Geschichte erzählen, jemand anders wird ,ich“ und ,wir' sagen, wenn er die Geschichte erzählt; jemand anderer wird die Erzählung seiner eigenen Geschichte liefern; jemand anderer wird die Vergangenheit, die Ereignisse, die rechte, Ungerechtigkeiten, Niederlagen und Siege um sich und sein eigenes Schicksal herum gruppieren.“ (ebd.: 163)

Dieses andere Subjekt ist das, ,was im Vokabular der Epoche mit dem Wort ,Nation “ bezeichnet wird“ (ebd.). Die Nation lässt sich zu jener Zeit nicht durch ein ,,abgestecktes Territorium, eine bestimmte politische Morphologie oder ein System der Unterwerfung unter ein beliebiges Imperium“ (ebd.) charakterisieren. Die Nation zu jener Zeit ist „,grenzenlos“, hat „,kein bestimmtes Machtsystem“. Die Nation ist für Boulainvilliers ,,staatenlos“(ebd.).

„Die Nation zirkuliert hinter den Grenzen und Institutionen oder vielmehr ,die“ Nationen, die Gesamtheiten, Gesellschaften, Gruppierungen der Leute, Personen, Individuen, die ein Statut, Sitten, Bräuche, ein bestimmtes Gesetz gemeinsam haben - Gesetz, verstanden freilich eher im Sinne von statutenhafter Regelhaftigkeit als von staatlichem Gesetz.“ (ebd.: 164)

Staatenlos bedeutet dabei nicht, keine Beziehung zum Staat zu haben. Allerdings macht sich eine Nation nicht durch den Staat aus, sondern ringt unterhalb des Staates um die Macht im selbigen. Die in der Geschichte ausgemachten Wendepunkte werden sich auf einer, Ebene weit unterhalb des Staates ereignen, das Recht durchziehen und zugleich älter und tiefer [...] als die Institutionen“ (ebd.: 163) erscheinen. Der Adel, das Volk, die Monarchie werden als Akteure in der Form von Kräften imaginiert, die Motor der Geschichte sind. „Der Adel ist eine Nation neben anderen Nationen, die alle im Staat zirkulieren und gegeneinander antreten." (ebd.: 164).

Boulainvilliers definierte dabei die Adligen als Français (Franken); als eine Nation, die den Galliern bzw. dem Dritten Stand gegenübersteht. Die Franken seien jedoch die zu Recht überlegenen, deren Entmachtung und Einschränkung ihrer Privilegien dementsprechend unrechtmäßig ist. Ihr Vorrecht gründet sich auf der Invasion Galliens und der Unterwerfung der Gallier_innen. Allerdings habe - und dieses Argument richtet sich auch insbesondere gegen den Absolutismus - auch vorher kein arkadisches Gallien bestanden, da die Römer die gallische Kriegerkaste ausgemerzt und durch einen falschen Verwaltungsadel und eine Söldnerarmee ersetzt hätten. Wenn sich nun der Absolutismus auf eine römische Tradition bezieht, erhebt er damit keinen ,grundlegenden und entscheidenden Anspruch auf das Land Gallien“ (ebd.: 175), sondern steht mit der Politik der römischen Gleichmacherei und despotischen Herrschaft in einer wenig ehrenwerten Tradition der Unterdrückung. Die 
Franken seien freiheitsliebende Barbaren, blonde, nordische Barbaren, die aufgrund ihres Willens zur Macht den anderen überlegen seien.

Mit dem neuen Subjekt der Nation, um das herum sich die Geschichte spinnt, einem ,in der Geschichte sprechenden und in der Geschichte besprochenen Subjekt“" (ebd.: 164), wird Geschichte nicht mehr als die „ruhmreiche Geschichte der Macht“ erzählt werden; es wird um die „Geschichte ihrer Untergründe, ihrer Boshaftigkeiten, ihrer Verrätereien“ (ebd.) gehen. Die Themen, die diese Geschichte bestimmen, sind die ,dunklen Prozesse auf der Ebene von Gruppen, die unterhalb des Staates quer durch die Gesetze hindurch aufeinandertreffen“ (ebd.). Boulainvilliers beschreibt die Machtphänomene in der Geschichte nicht in den rechtlichen Begriffen der Souveränität, sondern in den ,historischen Begriffen der Herrschaft und des Spiels zwischen Kräfteverhältnissen“ (ebd.: 201). Auch beispielsweise Machiavelli hatte Kräfteverhältnisse in seine Hinweise für den Fürsten beachtet. Boulainvilliers erhebt das Denken in Kräfteverhältnissen, ,was bis dahin Rationalitätsprinzip der Staatslenkung“, gewesen war, zum „Erkenntnisprinzip der Geschichte“ (ebd.: 203). Für Boulainvilliers wird das „Kräfteverhältnis und das Machtspiel die Substanz der Geschichte selbst“ (ebd.: 202). Indem er das Rationalitätsmodell der Staatsführung als spekulatives Erkenntnisraster der Geschichte konstituiert, erschafft er ein „historisch-politisches Kontinuum“ (ebd.: 203).

Boulainvilliers schafft damit ein Analyseraster für die Gegenwart, das den Krieg verfeindeter Gruppen als die geheime „Substruktur des Staates“ (ebd.: 154) zum Grundmuster macht. Der Krieg ist im Denken Boulainvilliers nicht mehr Ausnahme, sondern der grundlegende Zustand von Gesellschaft. Die politische Macht - die Besetzung der Staatsmacht - wird als „Werkzeug, als Gewinnler, als destabilisierendes und parteiisches Element" (ebd.) in diesem Krieg betrachtet. Damit wird die in den vorhergehenden Diskursen implizit immer vorhandene und als vollkommen selbstverständlich erscheinende These der Homogenität des Gesellschaftskörpers zerlegt. In den vorhergehenden Erzählungen der Macht durch die Macht, aber auch in oppositionellen Schriften, wie beispielsweise von Hotman, wurde zwar die Macht aufgrund der Geschichte von Erbfolge, Invasionen und ähnlichem legitimiert oder delegitimiert. Allerdings war es unvorstellbar, dass eine „Dualität - der Rasse, des Ursprungs, der Nation - die Monarchie spalten“ (ebd.: 144) könnte, das also der Gesellschaftskörper der Monarchie von historischen und versteckten Kräften durchzogen wird, die eigentlich über seine Zukunft entscheiden. Die Monarchie, die alle Untertanen in eine Beziehung zum König setzte und eine Einheitsreligion propagierte, funktionierte nach dem „Prinzip , ein Glaube, ein Gesetz, ein König ““ (ebd.); und selbst bei Hotman kratzt die Forderung nach der Existenz zweier Religionen im Körper eines einzigen Staates nicht die Vorstellung der Einheit des Staates an. 
„Weder die Bürgerkriege noch die gesellschaftlichen Kämpfe, weder die religiösen Kämpfe der Renaissance noch die Konflikte der Fronde haben das Thema des nationalen Dualismus zur Reflexionsform gehabt oder zum Ausdruck gebracht.“ (ebd.: 154).

Dieser Diskurs der in der Geschichte ringenden nationalen Kräfte und die Theorie der franko-gallischen Dualität wurden sehr schnell in den Kreisen des Adels aufgenommen, weitergesponnen und in Auseinandersetzungen in Stellung gebracht (Franche 2004: 18). Ohne auf die verschiedensten Spielarten dieser Auseinandersetzungen eingehen zu können, soll hier aber nicht unerwähnt bleiben, dass auch die königliche Macht versucht hat, sich diesen Diskurs anzueignen oder ihn zu kontrollieren. So wurden seit den 1760er Jahren Institutionen geschaffen, die dazu beitragen sollten, den historischen Diskurs zu bändigen und in den Dienst der Monarchie zu stellen. Foucault bezeichnet diese verschiedenen Institutionen als ,eine Art Ministerium der Geschichte“ (Foucault 1976b: 167). Es stellt den Versuch dar, den Keil des historischen Diskurses mit seinen unterhalb des Staates ringenden Kräfte, der sich in die Einheit von Staat und Macht treibt, wieder in das administrative Wissen einzufügen. Der Versuch der Rekuperation dieses Gegenwissens, der Eingliederung dieser Wissensmatrix in die Selbstlegitimierung des Staates, zeigt umso mehr, dass sich hier ein neuer Diskurstyp durchgesetzt hat, der nicht mehr nur die Geschichte der Macht, der ruhmreichen Eroberungen und Kämpfe verschiedener Königshäuser nachzeichnet, sondern den Kriegszustand der Nationen jenseits und unterhalb des Staates als Grundlage der Gesellschaft begreift.

\footnotetext{
„Aus dieser Vorstellung, aus diesem Begriff der Nation geht das berühmte revolutionäre Problem der Nation hervor, aus ihr gehen natürlich auch die fundamentalen Begriffe des Nationalismus des 19. Jahrhunderts hervor; aus ihr geht auch der Begriff der Rasse und schließlich der Begriff der Klasse hervor.“ (ebd.: 164)
}

Mit Boulainvilliers Begriffen der Nation und der Geschichte sind bereits wesentliche Kategorien eingeführt, die bis heute zu den wesentlichen Bestandteilen der rechten Ideologie gehören: Macht wird als eine Auseinandersetzung von Nationen bzw. ,Rassen' gedacht; es gibt einzelnen Nationen zugeschriebene Wesensmerkmale, die deren Über- oder Unterlegenheit begründen; die Differenz der Nationen ist unaufhebbar, ihre Eigenschaften sind Teil ihres Wesens (unabhängig davon, ob sich das Bild der überlegenen Nation stark wandelte); es geht um die Aufdeckung des verborgenen Wissens über den Verrat und den Verlust, mit dem Ziel die ursprüngliche ,Reinheit" und naturalisierte Hierarchie wieder herzustellen. 


\title{
Die Nation als die Organizität der Bevölkerung
}

In den Kontext dieser beiden konkurrierenden Logiken der Machtlegitimierung interveniert nun der bürgerliche Diskurs, hier am Beispiel von Sieyès. Sieyès nimmt explizit Bezug auf den reaktionären Diskurs der Aristokratie und wendet den Diskurs des Rassenkrieges polemisch gegen diese selbst: ,Warum schicken wir sie nicht zurück in die fränkischen Wälder, alle die Familien, die die wahnsinnige Anmaßung beibehalten, von der Rasse der Eroberer abzustammen und die Eroberungsrechte geerbt zu haben?“20 (Sieyès 1789: 44, Herv. i. O.) Auch in Abgrenzung gegenüber den aristokratischen Diskursen des Rassenkrieges macht er sich gleichzeitig auch über das monarchische Narrativ der Ursprünge lustig:

\begin{abstract}
„Aber wenn die Rassen durchmischt sind, wenn das Blut der Franken, die sich nicht länger separieren können, durchmischt mit dem der Gallier fließt, wenn die Vorfahren des Dritten Standes die Väter der ganzen Nation darstellen, können wir erwarten, eines Tages diesen langen Vatermord enden zu sehen, in dem eine Klasse sich mit dessen Ausführung gegenüber allen anderen täglich ehrte?“21 (Sieyès 1789: 44 f)
\end{abstract}

Weiterhin voller Polemik fährt er fort: „Die dann gereinigte Nation wird sich über den Verlust hinwegtrösten können, denke ich, nicht mehr in dem Glauben zu sein, sich ausschließlich aus den Nachkommen der Gallier und Römer zusammen zu setzen."22 (Sieyès 1789: 44) Explizit weist er in der Folge das Denken der nationalen Dualität bzw. Multipolarität zurück. Für ihn ist eine Trennung der Nationalitäten für die auf dem französischen Territorium wohnenden Menschen aufgrund der Bestimmung der Abstammung und der Ahnen empirisch überhaupt nicht möglich. Er brandmarkt die Ungerechtigkeit, die darin besteht, dass eine Gruppe sich selbst als solche von den anderen abzuheben meint und dann aufgrund eines Rechts durch Eroberung privilegiert zu sein meint. So geht es Sieyès nicht darum, dass nun der Dritte Stand zum Eroberer und also zur neuen Aristokratie werde - auch wenn die

\footnotetext{
${ }^{20}$ Übersetzung M. K., Original: «Pourquoi ne renverrait-il pas dans le forêts de la Franconie toutes ces familles qui conservent la folle prétention d'être issus de la race des conquérants et d'avoir succédé à des droits de conquête ?» (Sieyès 1789: 44).

${ }^{21}$ Übersetzung M. K., Original: « Mais, si tout est mêlé dans les races, si le sang des Francs, qui n'en vaudrait pas mieux séparé, coule confondu avec celui des Gaulois, si les ancêtre du Tiers état sont les pères de la nation entière, ne peut-on espérer de voir cesser un jour ce long parricide qu'une classe s'honore de commettre journellement contre toutes les autres ?» (Sieyès 1789: 44 f.)

${ }^{22}$ Übersetzung M. K., Original: «La Nation, alors épurée, pourra se consoler, je pense, d‘être réduite à ne se plus croire composée que des descendants des Gaulois et des Romains.» (ebd.)
} 
Idee einer von den Franken gereinigten Nation in jener Zeit eine durchaus verbreitete Idee darstellte (Franche 2004: 20). Die Ergreifung der Macht durch den Dritten Stand in Abgrenzung zu anderen Nationen, ist allein deswegen unmöglich, da sich der Dritte Stand nicht durch Abstammung oder Erbe definiert, sondern über ihre gesellschaftliche Rolle. So seien die Vorfahren des Dritten Standes die „Väter der ganzen Nation" (Sieyès 1789: 45).

Sieyès Begriff der Nation ist offensichtlich ein fundamental anderer als der der aristokratischen Reaktion. Unter der Monarchie bildete die Nation keinen Körper, der unabhängig vom König gedacht werden konnte. Die Aristokratie hatte demgegenüber angenommen, dass es mehrere Nationen gäbe, die sich gänzlich unabhängig vom König - und damit dem Staat - konstituieren. Die Nation war hier dem König logisch vorgängig; es war eine Gruppe von Individuen gleichen Blutes, Sitten und/oder gleichen Interessen, die sich einen König gab, um gegen andere Nationen Krieg zu führen bzw. die um die Vorherrschaft innerhalb eines Staates rangen. Bei Sieyès bestimmt sich die Nation wieder durch ein Verhältnis zum Staat bzw. zur Gesellschaft - allerdings auf eine gänzlich andere Weise als in der Monarchie. Sieyès sagt, dass es für eine Nation zwei Dinge braucht: Ein gemeinschaftliches Gesetz und eine gesetzgebende Versammlung, die für alle gelten. Allerdings bleibt er nicht bei dieser formalen Definition stehen; logisch geht diesem Argument die Feststellung der Substanz der Nation voraus. Für Sieyès kann die französische Nation nur der Dritte Stand sein, denn nur er stellt eine ,vollständige Nation“23 (ebd.: 37) dar.

Diese substanzielle Bestimmung der Nation nimmt Fragmente des historischpolitischen Diskurses Boulainvilliers auf, indem sie der Bestimmung der Nation durch den Bezug zum Staat (Monarchie) noch eine Ebene vorlagert. Sieyès unterteilt die substanzielle Bestimmung der Nation in zwei Gruppen: Zum einen basiert die Gesellschaft auf der Arbeit. Unter Arbeit versteht er erstens Landwirtschaft, zweitens Handwerk und Industrie, drittens Handel und viertens die freien Künste. Zum anderen basiert die Gesellschaft auf den Funktionen, womit er die Armee, die Justiz, die Kirche und die Verwaltung meint. Waren vorher die Arbeit und die Funktionen eine Folge der Existenz der Nation gewesen, kehrt er die Logik des Arguments um. Nach Sieyès wird eine Nation erst zu einer solchen, wenn sie zu Landwirtschaft, Handel, etc. in der Lage ist und über Individuen verfügt, die in der Lage sind, eine Arme, eine Kirche, eine Verwaltung, etc. ausbilden. Nicht der Vertrag oder das Gesetz sind Existenzbedingungen der Nation, sondern die historische Existenz macht in der Folge den rechtlichen Zusammenschluss möglich und bildet somit die Substanz der Nation.

${ }^{23}$ Übersetzung M. K., Original: « nation complète» (Sieyès 1789: 37). 
Während in der Monarchie das Volk durch seine Unterwerfung unter den König definiert wurde, behauptete der Adel ein partikulares Recht bzw. Vorrecht, das ,,von Blut getränkt“ (Foucault 1976b: 263) war. Mit Sieyès und der bürgerlichen Revolution wird der Dritte Stand, also diejenigen, die die Gesellschaft mit ihrer Arbeit und ihren Funktionen ausmachen, zur einzig legitimen Nation erklärt, die den Staat führen sollte. Damit ist Sieyès Diskurs zutiefst demokratisch. Er ist quasi eine der Geburtsstunden der , modernen', bürgerlichen Demokratie selbst. In diesem Sinne heißt es im Artikel 3 der Erklärung der Menschen- und Bürgerrecht von 1789, die bis heute gültiges Verfassungsrecht in Frankreich darstellt: „Der Ursprung jeder Souveränität ruht letztlich in der Nation. Keine Körperschaften, kein Individuum können eine Gewalt ausüben, die nicht ausdrücklich von ihr ausgeht."Dies ist genau der Gedanke von Sieyès, der dafür eintritt, das Missverhältnis aufzulösen, das zwischen der Nation als Leistungs- und Funktionsträger der Gesellschaft auf der einen Seite und dem Ausschluss von der politischen Macht dieser durch die Privilegierung einer bestimmten Gruppe besteht.

Der Begriff der Nation funktioniert dabei totalisierend und ausschließend zugleich: „Der Dritte Stand umfasst also alles, was zur Nation gehört; und alles, was nicht der Dritte Stand ist, kann sich nicht als Bestandteil der Nation ansehen. Was also ist der Dritte Stand? ALLES.“24 (ebd.: 41) Das konkrete Andere der Nation ist bei Sieyès die Aristokratie. Im Zuge der Konstruktion dieses konkreten Anderen erscheint jedoch strukturell das abstrakte Andere als alles, was der Nation im Sinne ihrer staatlichen und privatwirtschaftlichen Reproduktion unnütz erscheint. Dies werde ich im Folgenden anhand der Konstruktion des konkreten Anderen bei Sieyès zeigen.

„Es [der Adel] ist in Wahrheit ein Volk [peuple] für sich, aber ein unechtes Volk, das aufgrund des Mangels an nützlichen Organen nicht durch sich selbst bestehen kann und sich an eine reale Nation anhängt, wie diese pflanzlichen Tumore, die nur mit dem Lebenssaft der Pflanzen leben können, was diese ermüdet und verdörren lässt.“25 (ebd.: 39)

\footnotetext{
${ }^{24}$ Übersetzung M. K., Original: « Le Tiers embrasse donc tout ce qui appartient à la nation; et tout ce qui n'est pas le Tiers ne peut pas se regarder comme étant de la nation. Qu'est-ce que le Tiers ? TOUT.» (Sieyès 1789: 41) Hier und im Folgenden gebe ich in eckigen Klammern Kommentare in der Funktion des Übersetzers,

${ }^{25}$ Übersetzung M. K., Original: «C'est véritablement un peuple à part, mais un faux people qui, ne pouvant à défaut d'organes utiles exister par lui-même, s'attache à une nation réelle comme ces tumeurs végétale qui ne peuvent vivre que de la sève des plantes qu'elles fatiguent et dessèchent.» (Sieyès 1789: 39) In [eckigen] Klammern schreibe ich in diesem und einigen folgenden Zitaten Anmerkungen als Übersetzer, um mögliche relevante begriffliche Konnotationen aufzuzeigen.
} 
Hier bemüht Sieyès, wie mehrfach in seiner Flugschrift die biologische Metapher des Parasitentums zur Charakterisierung des Adels. Nützlichkeit scheint hier ein entscheidendes Kriterium für die Zugehörigkeit zu sein:

\begin{abstract}
„Es reicht nicht, gezeigt zu haben, dass die Privilegierten, weit davon entfernt der Nation nützlich zu sein, nichts anderes können als diese zu schwächen [oder auch zu verwässern] und sie zu schädigen ; man muss noch beweisen, dass die Adelsordnung [l'ordre noble] nicht Teil der sozialen Ordnung ist ; dass sie ebenso eine Belastung für die Nation sein kann, aber dass sie niemals Teil werden kann. Zunächst, es ist nicht möglich, die Adelskaste im Ausmaß aller elementaren Teile einer Nation zu finden oder sie dort zu platzieren. Ich weiß, dass es Individuen sind, die sich durch ihr Gebrechen [auch Behinderung oder Schwäche], ihre Unfähigkeit [auch Invalidität oder Behinderung], einer unheilbaren Faulheit oder des Flusses der schlechten Sitten [moralisch konnotiert] zum größten Teil zu Fremden [Ausländern] der Arbeit der Gesellschaft machen.“26 (ebd.: 38 f)
\end{abstract}

Die nicht-nützlichen Teile, die als Nicht-Teil der Nation definiert sind, werden hier nicht nur als nicht zugehörig definiert, sondern auch als Bedrohung der ,sozialen Ordnung“ - deutet sich in diesem Begriff die Überlagerung von Nation und Staatsbevölkerung an? -, da sie diese ,schwächen“, ,schädigen“ oder belasten könne. Auch wenn ich mir in der Konnotation der Begriffe, insbesondere angesichts der 230-jährigen kontextuellen Distanz unsicher bin, scheint in der Rhetorik des Ausschlusses durch die Darstellung ihrer Nicht-Nützlichkeit auf, dass aufgrund von Krankheit, Behinderung oder Einstellung als nicht leistungsfähig kategorisierte Menschen qua Zuschreibung von der Nation ausgeschlossen werden. Das von Sieyès am häufigsten genannte Distinktionsmerkmal ist hier Faulheit: „Eine solche Klasse ist aufgrund seiner Faulheit [auch Nichtstuerei] zweifellos der Nation fremd [Ausländer].“27 (ebd.: 40).

Ich möchte zusätzlich kurz darauf verweisen, dass die von Sieyès kritisierte aristokratische Ordnung, in der die Nation nicht deckungsgleich mit der Kontrolle über den Staat ist, sondern die Regierung vielmehr nur eigenen Interessen dient,

\footnotetext{
${ }^{26}$ Übersetzung M. K., Original: «Il ne suffit pas d'avoir montré que les privilégiés, loin d'être utiles à la nation, ne peuvent que l'affaiblir et lui nuire; il faut prouver encore que l'ordre noble n'entre point dans l'organisation sociale; qu'il peut bien être une charge pour la nation, mais qu'il n'en saurait faire un partie. D'abord, il n'est pas possible dans le nombre de toutes les parties élémentaires d'une nation de trouver où placer la caste des nobles. Je sais qu'il est des individus, en trop grand nombre, que les infirmités, l'incapacité, une paresse incurable ou le torrent des mauvaises mœurs rendent étrangers aux travaux de la société.» (Sieyès 1789: $38 \mathrm{f.})$

${ }^{27}$ Übersetzung M. K., Original: « Une telle classe est assurément étrangère à la nation par sa fainéantise.» (Sieyès 1789: 40)
} 
auch mit der Gleichsetzung und Abgrenzung von der im kolonialen Imaginären heute und damals virulenten Figur des orientalischen Despotismus unterfüttert wird. Die Legitimation der bürgerlichen Ordnung und die Inszenierung als überlegen wird hier auch in Abgrenzung zum kolonialen Anderen konstruiert:

„Ist darauf aufmerksam gemacht worden, dass diese Ordnung der Dinge, grundlegend, und ich wage es zu sagen, schlecht von uns angesehen wird, wir finden dies, wenn wir die Geschichte des antiken Ägyptens oder die Verhältnisse der Reisen ins Großindien studieren, verachtenswert, monströs, destruktiv für die ganze Industrie, Feind des sozialen Fortschritts, insbesondere erniedrigend für die menschliche Spezies im Allgemeinen und unerträglich im Besonderen für die Europäer, etc.?‘28 (ebd.: 36)

Im Folgenden greife ich die Argumentation Foucaults wieder auf und stelle dar, wie Foucault das Nationsverständnis von Sieyès mit dem Begriff der Bio-Macht verknüpft.

Die argumentative Wende in Sieyès Diskurs bezeichnet Foucault als eine „Auto-Dialektisierung“(Foucault 1976b: 256) des historisch-politischen Diskurses Boulainvilliers. Im Zuge der Verbürgerlichung des historischen Diskurses werden die Machtkämpfe von der Ebene unterhalb des Staates zur Aufgabe des Staates selbst gemacht. Mit Sieyès bezieht die Nation ihren Anspruch nicht mehr aus der Vergangenheit, es geht nicht mehr um vergangene Siege, Eroberungen oder erbliche Abstammung. Im Diskurs von Sieyès geht es vielmehr um die Zukunft, die in der Gegenwart insofern schon gegeben ist, als es bereits eine Nation gibt, die die staatliche Universalität zumindest virtuell schon repräsentiert, die die Institutionen und die Ökonomie faktisch am Laufen hält. Es geht also darum, die faktische Totalität der Nation in die Universalität des Staates zu überführen. Die eigentliche, komplette Nation steht also nicht horizontal anderen Nationen gegenüber, mit denen sie um die Macht im Staat ringt. Sie beherrscht nicht andere Nationen, sondern ihre Praxis besteht im Wesentlichen aus der Verwaltung der ,eigenen` Bevölkerung und dem Funktionieren der staatlichen Macht. Staat und Nation sollen kohärent werden. Dieser neue, zum Ende des 18. Jahrhunderts erscheinende Typus der Macht nennt Foucault Bio-Macht. Nationalstaatlichem Handeln wird es darum gehen, die Bevölkerung zu verwalten, zu zählen, zu klassifizieren, zu vermessen, zu regulieren. Objekt der Bio-Macht ist nicht mehr das zu unterwerfende Individuum der

\footnotetext{
${ }^{28}$ Übersetzung M. K., Original: « A-t-on fait attention que cet ordre de choses, basement, et j'ose le dire, bêtement respecté parmi nous, nous le trouvons en lisant l'histoire de l'ancienne Égypte et les relations de voyages aux grandes Indes, méprisable, monstrueux, destructive de tout industrie, ennemi des progress sociaux, surtout avilissant pour l'espèce humaine en general et intolerable en particulier pour des Européens, etc.?» (Sieyès 1789: 36)
} 
Monarchie oder der zu disziplinierende Körper der Disziplinarmacht, sondern die Bevölkerung. Die Souveränität wird von nun an nicht mehr darin bestehen, dass der König die Macht hat, Leben zu lassen und sterben zu machen, sondern es ist der Staat der Bio-Macht, der die Souveränität ausüben sollte, indem er die Macht hat, leben zu machen und sterben zu lassen.

Ein wichtiger Baustein zur Entwicklung der Bio-Macht als Regierungstechnologie stellt die Entwicklung der Institution der Polizei dar. Die Institution der Polizei ist dabei nicht etwa auf die uniformierten Ordnungshüter_innen oder Aufstandsbekämpfung zu reduzieren. Das Ziel der Polizei in diesem Sinne ist der staatliche Zugriff auf das Leben selbst. In der Auseinandersetzung mit Theoretikern seit dem 17. Jahrhundert arbeitet Foucault das Ziel der Polizei heraus. Dieses besteht in der „Kontrolle und [der] Übernahme der Verantwortung für die Tätigkeit der Menschen, insofern diese Tätigkeit ein ausschlaggebendes Element in der Entwicklung der Kräfte des Staates darstellt“ (Foucault 1978a: 464). Dabei geht es „um die Tätigkeit des Menschen als konstitutives Element der Kraft des Staates“" (ebd.). Die Tätigkeit der Polizei umfasst also alles von der Gesundheitsversorgung über die Gebäudepflege, die Wissenschaften, das Theater, der Bildung und der Gewährleistung des freien Warenverkehrs bis zur Disziplinierung und Kontrolle der Armen, wobei es bei letzterem darum geht, den Ausschlusses jener zu realisieren, ,die nicht arbeiten können, und die Verpflichtung zu arbeiten, für jene, die dazu wirklich in der Lage sind“" (ebd.: 480). Mit dem Liberalismus entwickelt sich eine - zumindest scheinbar konträre - Auffassung von Gesellschaft und Staat. Die hier entstehende Annahme einer „Naturalität“ (Foucault 1978a: 501) von Markt und Bevölkerung, die dann nicht durch Verordnungen und Maßnahmen neu gestaltet, sondern eher reguliert werden muss, wird zu einer bis heute virulenten Fluktuation zwischen den beiden Polen des Polizeistaates auf der einen und dem liberalen, marktfokussierten Staat auf der anderen Seite führen (Foucault 1979: 443). Diese beiden Pole und die ständigen Verschiebungen zwischen ihnen stellen jedoch genau den Rahmen dar, in dem die Regierungstechnologie der Bio-Macht gedacht wurde. Vom Standpunkt der Bio-Macht entsteht die Gesellschaft; die Gesellschaft als etwas Organisches und Biologisches, was es zu pflegen und zu reinigen gilt.

Dies wird besonders deutlich am Beispiel des nach den Funktionsweisen der Bio-Macht wirkenden Staatsrassismus. Diese Art des Rassismus übernimmt die Annahme Boulainvilliers von der Teilung der Menschheit in ,Rassen', die dem Staat vorgeordnet sind, sieht diese jedoch nicht in erster Linie als äußere oder äußerliche Feinde, sondern als Möglichkeit der Klassifikation von Bevölkerungsgruppen, die es so zu stimulieren, zu trennen, zu reinigen oder im Zweifelsfall zu eliminieren gilt, da sie eine Bedrohung für die, Volksgesundheit' darstellen (Foucault 1976b: 302). Dies kann für ganze als , Rassen ' klassifizierte Gruppen gelten, wie beispielsweise im 
Fall kolonialer, antiziganistischer oder antisemitischer Völkermorde, oder für Teile einer als ,Rasse ' bezeichneten Gruppe, die als ,Degenerierte' die ,Gesundheit" des gesellschaftlichen Körpers gefährdeten (ebd.: 302, 304). Die Bio-Macht, die auf die Verwaltung und Ausweitung des Lebens zielt, bedient sich den Mitteln des Tötens, um innerhalb dieser Beziehungen biologischen Typs das Leben des Staates oder der Rasse zu schützen und auszuweiten. Dabei ist diese Form des Rassismus, seine Spezifik, nicht in erster Linie an Mentalitäten, Ideologien und Lügen der Macht gebunden, sondern vielmehr als Technik der Macht zu verstehen. Ganz anders als die Logik des Rassenkrieges und der geschichtlichen Erkenntnis Boulainvilliers ist sie mit den Mechanismen der Bio-Macht verknüpft, wo sich der Staat ,zum Zweck der Ausübung seiner souveränen Macht der Rasse, der Eliminierung der Rassen und der Reinigung der Rasse zu bedienen gezwungen sieht" (ebd.: 305).

Das organizistische und biologistische Verständnis von Bevölkerung wird in diesen Fällen besonders deutlich, ist jedoch auch in anderen Kontexten virulent. Dies betrifft dabei keinesfalls nur Kontexte, die mit dem biologischen Begriff von ,Rasse “ operieren. Die Vorstellung eines totalitären Gesellschaftskörpers mit der dazugehörigen Bevölkerung als Objekt staatlicher Regulierung zur Verwaltung des Lebens und Vermehrung der Kräfte der Nation ist für Foucault die Voraussetzung für die Normalisierungsgesellschaft. Statt die „Grenzlinie zu ziehen, die die gehorsamen Untertanen von den Feinden des Souveräns scheidet" (Foucault 1976a: 162), richtet die Bio-Macht die Subjekte an einer Norm aus, um welche herum sie diese anordnet. Wenn - um ein paar ebenso plastische, wie willkürliche Beispiele zu geben - der Rassist Thilo Sarrazin sagt, Türk_innen und Araber_innen hätten „keine produktive Funktion, außer für den Obst- und Gemüsehandel“, wenn Panik vor der sogenannten ,Armutsmigration “ aus Südosteuropa oder juristisch das Aufenthaltsrecht oder der Zugang zu Sozialleistungen an den Arbeitnehmer_innenstatus geknüpft wird, scheint die biopolitische Vorstellung der Leistungsgesellschaft auf.

\subsubsection{Geteilte Episteme in einer zu dekolonisierenden Welt}

\subsubsection{Epistemischer Wandel}

Lara (Gym18; 3.3.3) problematisierte die Kolonialität der Gegenwart und fordert eine Veränderung des Denkens. In diesem Sinne werde ich im Folgenden mögliche Konturen eines dekolonial motivierten, „epistemischen Wandels“ (Castro Varela 2016) und seiner Implikationen für die politische Bildung diskutieren. Ich sehe in Laras Vorstellungen drei Punkte, an die ich mit diesem Programm anknüpfen möchte. Zum einen weist sie auf die Gegenwärtigkeit der Kolonialität hin. 
Sowohl in Bezug auf ihre eigene, zukünftige Biographie als auch in Bezug auf die globale soziale Ungleichheit führt sie die Kolonialität ein: „Weil alle denken: ,Heute ist alles wieder gut. Es gibt keine Sklaven. Es gibt keine Kolonien mehr. Es ist alles in Ordnung." Aber eigentlich stimmt das ja nicht." (Lara, Gym18) Dabei stellt sie ihre Perspektive als eine abweichende dar, denn es ist nicht das, was ,alle“ denken würden. An anderer Stelle bringt sie einen ähnlichen Gedanken vor: „Die meisten merken vielleicht nicht, dass Geschichte wirklich passiert ist." (Lara, Gym18) Dabei geht es ihr auch darum, ein fundierteres Wissen über die Geschichte von Versklavung und Kolonialismus einzufordern, aber auch hier verweist sie darauf, dass „die meisten“ die Geschichte als etwas abgeschlossenes sehen würden und Geschichte - zumindest diesen Teil davon, die „dunklen Seiten“ - nicht als die Gegenwart mitstrukturierend begreifen würden.

An anderer Stelle problematisiert sie das kolonial strukturierte Wissensarchiv: „Aber irgendwann habe ich halt gemerkt, dass in den Büchern die Autoren halt auch alle Europäer sind. Oder Weiße oder Engländer mehr so.“ (Lara, Gym18) Dies diskutiert sie in Bezug darauf, dass es die Realisierung ihres Wunsches erschwert, Autorin zu werden, da sie Schwarz ist. Lara führt weiterhin an, dass die „dunklen Seiten der Geschichte“ als Ressource dienen können, um zu lernen, anders zu denken.

„Im Bereich Geschichte zum Beispiel die Geschichte mit den Sklaven und so was in der Art halt. Die dunklen Seiten der Geschichte, sag' ich mal. Also natürlich möchte man nicht an das Schlechte aus der Vergangenheit irgendwie erinnert werden. Aber ich finde, man sollte vielleicht ein bisschen was lernen dazu, um vielleicht ein bisschen anders zu denken." (Lara, Gym18)

Der von Lara ausgehende Vorschlag für einen dekolonialen epistemischen Wandel beinhaltet also zunächst drei Punkte: die Anerkennung der Kolonialität der Gegenwart, die Infragestellung des kolonialen Wissenskanons und die kritische Sicht auf die Geschichte der dunklen Seite im Sinne der Anerkennung und Vertiefung (wirklich geschehen) und als Ressource für eine Dekolonisierung der Episteme. Gleichzeitig führt sie die Episteme als geteilte ein. Geteilt im Sinne von divided sind sie, da sie ihre dekoloniale Perspektive als abweichend von der von „alle[n]“ bzw. den „,meiste[n]“ ansieht. Geteilt im Sinne von shared sind sie, da sie die Hoffnung auf eine Zukunft formuliert, in der potenziell ,alle“ Teil an einem solchen epistemischen Wandel haben. Die Frage der Dekolonialität wird so als „Option“ (Mignolo 2011), als eine Frage des Politischen, gestellt.

Damit skizziert sie, meiner Lesart zufolge, die Umrisse eines Programms dekolonialer politischer Bildung. Ausgehend von einer anderen Perspektive auf 
die Vergangenheit - das Koloniale wird zu einem schwierigen Erbe (2.3.3.2) und dekoloniale Perspektiven werden einbezogen - kann sie als Ressource dienen, um die Gegenwart der Kolonialität zu erkennen und infrage zu stellen. Dabei problematisiert sie die Frage, welche Stimmen den Kanon bestimmen und welche ausgeblendet bleiben. $\mathrm{Zu}$ ihrem Imperativ anders denken zu lernen fügt sie noch hinzu: „Und dass man irgendwann Menschen nicht nach ihrem Stand oder gesellschaftlichen Ansehen irgendwie beurteilt. Oder Nationalität und so." (Lara, Gym18) Damit deutet sie die potenzielle Reichweite eines solchen Wandels des Denkens an. Der epistemische Wandel zielt dabei auf die Dekolonisierung des Wissens, der Subjektivierungen, der Zugehörigkeiten, der Narrative, der Geschichtsschreibung, des Sozialen und nicht zuletzt auf eine Ahnung eines dekolonisierten Imaginären am Horizont einer möglichen Zukunft. Damit ist dieser Abschnitt im Prinzip auf den Punkt gebracht. Ich werde die von Lara angeführten Punkte im Folgenden noch etwas ausführen und bestehende Überlegungen aus dekolonialen Theorien referieren, kritisch diskutieren und ihre Nutzung für politische Bildung abwägen.

Da ich meine Argumente stark auf Laras Vorstellungen aufbaue, möchte ich an dieser Stelle einen kurzen Einschub zum Verhältnis von mir als weißem, männlichem Wissenschaftler und den dekolonialen Vorstellungen der sich als Schwarz verortenden Schülerin Lara anführen. Ich beziehe mich auf die von mir in ihren Ausführungen ko-konstruierten Vorstellungen. Diese nehme ich als Ausgangspunkt meiner Argumentation, in der ich die von mir in ihren Aussagen kokonstruierten Vorstellungen in meinem Sinne und meiner Perspektive mit anderen dekolonialen Ansätzen in Beziehung setze. Dies ist eine Art Bewegung des Aneignens, Ergänzens, Ausführens und Belegens. Dies kann in dieser Konstellation aus einer dekolonialen Perspektive durchaus als problematisch erscheinen. Wünschenswert wäre es gewesen, meine Interpretationen und Verwendungsweisen mit Lara (und anderen Schüler_innen) im Sinne einer kommunikativen Validierung rückzubesprechen, um das Verhältnis weniger als einseitige Aneignung, sondern vielmehr als eine Form des auf Respekt und Dialogik gründenden Mitforschens zu gestalten. Dies war leider rein forschungsorganisatorisch nicht möglich, da zum Zeitpunkt der Analyse die Schüler_innen schon nicht mehr zur Schule gegangen sind und ich auch aus datenschutzrechtlichen Gründen keinen außerschulischen Kontakt aufnehmen durfte. Zukünftige Forschungen sollten solche Formen des Mitforschens miteinbeziehen. Vor diesem Hintergrund besteht die Gefahr der einseitigen Aneignung, der Unsichtbarmachung und des einseitigen Profits für mich als männlich und weiß verortetem Wissenschaftler. Diese Gefahren kann und will ich nicht durch Argumente kaschieren. 
Auf der anderen Seite steht meine Hoffnung, dass ich durch den hier vorliegenden Text in einem abstrakten Sinne dazu einen wie auch immer geringen Teil dazu beitrage, dass Positionen, wie die von Lara, in einer möglichen Zukunft, eine andere Wertschätzung erhalten und ich hier möglicherweise ihre Aussagen oder Haltungen stärke. Ebenso problematisch wäre es doch, wenn ich den Ursprung dieser Ansätze dethematisieren würde. Exemplarisch steht der Bezug zu Lara auch für meine Überzeugung, dass nicht zuletzt als weiß verortete Wissenschaftler_innen, Lehrende oder auch Schüler_innen lernen sollten, eigene inkorporierte Wahrheiten zu verlernen, zugunsten einer Offenheit gegenüber anderen Perspektiven, denen zuzuhören - die Fähigkeit des Zuhörens - selbst Teil und anzustrebendes Resultat von dekolonialen Lernprozessen sein sollte. Dieses Dilemma ist nicht auflösbar.

\subsection{Dekolonialität als epistemischer Ungehorsam}

Madina Tlostanova und Walter Mignolo formulieren die Perspektive der Dekolonialität ganz ähnlich wie Lara. Als Kolonialität bezeichnen sie die dunkle Seite der Modernität. Kolonialität wird als konstitutiv für die Moderne selbst angesehen: "By writing modernity/coloniality, we mean that coloniality is constitutive of modernity and there is no modernity without coloniality." (Tlostanova/Mignolo 2012: 8) Mit dem Ansatz der Dekolonialität geht es ihnen nicht darum, ein neues Meta-Narrativ zu schaffen, sondern vielmehr lokale Geschichten und partikulare Perspektiven zu schreiben, die sich der Kolonialität des Wissens entziehen oder es infrage stellen. Es geht hier nicht um den allgemeinen Umstand, dass Wissen als gesellschaftliches Phänomen in konkreten sozialen und historischen Kontexten betrachtet werden sollte, sondern darum, die koloniale und eurozentrische Matrix der Macht, die die dominanten Formen der Wissensproduktion bestimmen, zu unterlaufen. Dafür muss aus ihrer Sicht der moderne/koloniale Mythos des nicht-situierten und körperlosen Subjekts des Wissens hintergangen werden. Mit dem Konzept des Grenzdenkens (,,border thinking“ (ebd.: 6)) wird versucht diesem Mythos etwas entgegenzusetzen. Dekoloniale Perspektiven versuchen diesem Verständnis nach, die Modernität bzw. globale Kolonialität von ihrer Exteriorität her zu sehen. Exteriorität meint dabei nicht etwa ein außerhalb. Eine solche Position gibt es nicht: "Since there is no outside position from which the colonial matrix can be observed and described (we are all within it), border thinking emerges in the process of delinking from the colonial matrix and escaping from its control." (ebd.: 7) Grenzdenken wird so als vielfältige Antwort gegen die epistemische Gewalt der Kolonialität aufgefasst. Dabei muss die eigene Verstricktheit, das eigene Involviertsein mit thematisiert werden (ebd.; Andreotti 2011a). Andreotti schließt ihre Überlegungen zur Global Citizenship Education 
direkt an Mignolo an und weist auf die Notwendigkeit der Reflexion der Geopolitik und Räumlichkeit (spaciality) von Wissensproduktion hin (Andreotti 2011a). Sie plädiert für eine Auseinandersetzung mit den Mechanismen der Kolonialität der Macht, die Unterordnung und Unsichtbarkeit hervorbringen sowie unsere Komplizenschaft mit Herrschaftsstrukturen begründen. Hier kann an das Konzept der ,,involvierte[n] Bildungsprozesse“ von Astrid Messerschmidt angeknüpft werden, die aufzeigt wie sich der „Bezug zum jeweiligen Gegenstand“ sowie die „Beziehung aller am Bildungsprozess Beteiligten“ verändert, wenn Lernende und Lehrende die Einsicht teilen, ,,selbst drin zu stecken“ (Messerschmidt 2009: 10).

Ausgehend vom Grenzdenken formuliert Walter Mignolo das Konzept des „epistemischen Ungehorsam“ (Mignolo 2012; ,epistemic disobedience“ (Mignolo 2011)). Dieser begründet sich auf dekolonialen Bewegungen, die ihre Gemeinsamkeit darin begründeten, die Folgen der Kolonisierung erfahren zu haben:

„Epistemic disobedience leads us to decolonial options as a set of projects that have in common the effects experienced by all the inhabitants of the globe that were at the receiving end of global designs to colonize the economy (appropriation of land and natural resources), authority (management by the Monarch, the State, or the Church), and police and military enforcement (coloniality of power), to colonize knowledges (languages, categories of thoughts, belief systems, etc.) and beings (subjectivity)." (Mignolo 2011: 45, Herv. i. O.)

Dekolonialität konzipiert Mignolo dabei als Reaktion auf die Kolonialität, deren unterdrückerische Logik und imperiale Gewalt eine Energie der Unzufriedenheit, des Misstrauens und der Befreiung bei denen freisetzt, die sich dagegen wehren: "This energy is translated into decolonial projects that, as a last resort, are also constitutive of modernity." (Mignolo 2011: 45, Herv. i. O.) Dekolonialität versteht Mignolo dementsprechend als die Energie, die weder die Operation der Logik der Kolonialität zulässt, noch ihr Märchen der Rhetorik der Modernität glaubt (ebd.). G. T. Reyes plädiert in diesem Sinne für eine Pedagogy of and Towards Decoloniality (2019):

\footnotetext{
„Decoloniality is an ongoing, agentive process that happens alongside coloniality. As long as coloniality exists, so will decoloniality. In education, despite how coloniality manifests in how power, knowledge, and humans are controlled, movements and people still demonstrate the agency to refuse, reject, rethink, reimagine, and recreate. As such, a pedagogy that visibilizes, questions, and dismantles colonial processes paves the way to reassemble approaches that map decoloniality." (Reyes 2019)
} 
Ähnlich wie schon Paulo Freire sieht er Bildung vor die Alternative gestellt, sich aktiv mit der Kolonialität auseinanderzusetzen oder diese zu reproduzieren: „Without doing so, people remain unaware or complicit in the colonial project and therefore reproduce it." (ebd.)

Ein wesentlicher Teil des Konzepts des epistemischen Ungehorsams von Mignolo ist das „Delinking“ (ebd.) von der Modernität/Kolonialität, das wohl am ehesten mit Entkoppelung zu übersetzen ist. Delinking erscheint notwendig, da es aus Sicht von Mignolo keinen Weg aus der Kolonialität selbst heraus gibt: "'Delinking' is then necessary because there is no way out of the coloniality of power from within Western (Greek and Latin) categories of thought." (Mignolo 2011: 45) Für dieses Delinking plädiert Mignolo für ein dekoloniales Erbe. Vor diesem Hintergrund liest er die Texte von Waman Puma de Ayala aus dem Jahr 1616 (4.2.2.4) wieder, die er als eine der ersten überlieferten Ansätze der Dekolonialität ansieht: „Waman Puma de Ayala is the first case of the decolonial turn in the viceroyalty of Peru.“ (Mignolo 2011: 45) Die Exteriorität, die Waman Puma de Ayala repräsentiert bzw. durch seine Artikulation herstellt, verweist hier nicht auf etwas Vorkoloniales oder durch die Kolonialität unberührtes Denken. Ganz im Gegenteil sieht er hier die Position der Exteriorität als außerhalb und innerhalb zugleich: „That is, exteriority in the precise sense of the outside (barbaric, colonial) that is constructed by the inside (civilized, imperial)“ (ebd.: 48). Dekoloniales Denken setzt sich dementsprechend immer ins Spannungsfeld der kolonialen oder imperialen Differenz. Dieses Innen der Kolonialität erschafft eine Totalität, der alles ein- und untergeordnet wird (ebd.). Epistemischer Ungehorsam bedeutet in diesem Sinne, aus dieser Totalität auszubrechen.

In diesem Zusammenhang thematisiert er auch die Sprachen, die Teil des Ausschlusses anderen Wissens sind. Deren Hegemonie gilt es aus seiner Sicht infrage zu stellen, um eine andere, dekoloniale Genealogie, ein dekoloniales Erbe, zu erschaffen. Diese imperialen Sprachen sind nach Mignolo Alt-Griechisch und Latein in der Antike, Italienisch, Kastilianisch und Portugiesisch seit der Renaissance und Französisch, Englisch und Deutsch seit der Aufklärung (ebd.: 47). Kurz erinnert sei hier an Bilal (HS15), der im Kontext seiner Kritik der Monolingualität im Integrationsparadigma die Vielfalt der Sprachen hervorhob: „Bei uns sagt man: ,Wenn du eine Sprache mehr kannst, dann bist du ein Mensch mehr dazu. " (Bilal, HS15) Delinking bedeutet für Mignolo nicht eine andere Wahrheit zu präsentieren, sondern vielmehr andere Orte, anderes Wissen, an ihre Stelle treten zu lassen, als Orte der kolonialen Erinnerung und Spuren der kolonialen Wunden (Mignolo 2011: 48).

Dies verbindet er mit einem anderen (an-,other') Begriff von Universalität, das weder als Totalität noch als Pluralität verstanden werden kann. Er greift hier 
das Konzept der Pluriversalität von Enrique Dussel auf, in dem Universalität und Pluralität auf eine spezifische Weise verbunden werden (Maldonado-Torres 2012: 6). Mignolo kreiert eine lose Genealogie des dekolonialen Erbes, das von Waman Puma de Ayala bis zu den Zapatistas reicht. Die Zapatistas hätten - wie Waman Puma de Ayala's Nueva Crónica - eine neue Chronik von der Exteriorität der Kolonialität her geschaffen, dessen Form aber auch dessen Existenz alleine einen Bruch mit der Kolonialität impliziert (Mignolo 2007b: 461). In den zapatistischen Caracoles sei der Gedanke der Pluriversalität gelebte Praxis. Diese Form des Delinking schlage sich in einer der zentralen Forderungen der Zapatistas nach einer, Welt, in der viele Welten Platz haben' nieder (ebd.).

\subsection{Delinking oder affirmative Sabotage?}

Mignolo stellt den Ansatz der postcolonial studies infrage, an dem er zahlreiche Dinge kritisiert, von denen ich zumindest zwei aufgreifen will, um damit selbst ein problematisches Moment in Mignolos Denken zu thematisieren. (1) Zum einen wird den postkolonialen Studien abgesprochen, auf gesellschaftliche Veränderung abzuzielen, da sich auf literaturwissenschaftliche, auf den akademischen Kreis begrenzte Fragen beschränkt würde und es vor allem um die Selbstrepräsentation in der akademischen Sphäre ginge. Ähnliche Kritiken, die die Reduktion der postcolonial studies auf koloniale Diskursanalyse und die Ausblendung der ,materiellen' Dimension kritisierten, wurden auch von zahlreichen von Vertreter_innen der postcolonial studies selbst vorgebracht, wie etwa von Arif Dirlik, Neil Lazarus, Benita Parry, Robert Young, Aijaz Ahmad oder Ella Shohat, um hier nur die prominentesten zu nennen. Diesen geht es dabei nicht darum, eine reine ,materialistische " Analyse vorzunehmen, sondern die irreduzible Verknüpfung von Repräsentation und dem Sozialen zu denken; oder - um es mit Hannah Franzki und Joshua Kwesi Aikins zu sagen - es geht einer postkolonialen Perspektive darum, ,die Verbindung einer materialistischen Analyse von Ausbeutungsverhältnissen mit einer Kritik der wissensbasierten, diskursiven Normalisierung kolonialer Dominanz" (Franzki/Aikins 2010: 25) zu untersuchen. Vor diesem Hintergrund wirkt die Kritik von Mignolo zwar wichtig, allerdings wenig überzeugend, wenn es darum geht die postcolonial studies abzuwerten. Aus meiner Sicht erscheinen diese beiden Ansätze nicht als konkurrierend, sondern als verschiedene Perspektiven, die sich gegenseitig bestärken können.

(2) Zum zweiten kritisiert Mignolo den starken Bezug der postcolonial studies auf ,europäische' Denker, wie etwa Foucault, Lacan und Derrida. So sei die postcolonial theory in der Falle der (Post-)Modernität gefangen:"Post-coloniality (post-colonial theory or critique) was born in the trap of (post) modernity. It is from there that Michel Foucault, Jacques Lacan, and Jacques Derrida have been 
the points of support for post-colonial critique (Said, Bhabha, Spivak)." (Mignolo 2011: 52) Dekoloniales Denken würde hingegen nicht in der akademischen Falle sitzen, sich in die Genealogie der eurozentrischen Denker einzureihen, und würde stattdessen die Vielfalt der Ursprünge dekolonialen Denkens betonen. Der Impetus der Vervielfältigung der Quellen des Denkens und der dazugehörige Bruch mit dem eurozentrischen Kanon des Wissens erscheint mir wichtig. Problematisch erscheint mir aber das Verständnis des Delinking, das hier deutlich wird. Im Anschluss an Mignolo führt Grosfoguel ebenfalls unter anderem Foucault und Derrida auf (Grosfoguel 2011). Durch die Benennung ihrer Herkunft als ,europäische' Denker werden diese zu eurozentrischen Denkern. Es scheint hier ein Verständnis durch, in dem ein okzidentales Wissen einem nicht-okzidentalem entgegengesetzt wird und der Ursprung - okzidental - gleichbedeutend wird mit okzidentalistisch, eurozentrisch und kolonial. Mir geht es hier nicht um die ,Verteidigung ' der genannten Autoren, sondern vielmehr wird an dieser Frage die Bestimmung des Kolonialen und Dekolonialen insgesamt verhandelt. Der Eurozentrismus von Foucault (Stoler 1995; Spivak 1988a) sowie die Potenziale seiner Theorie für dekoloniales Denken (Said 1978) sind mehrfach und ausgiebig nachgewiesen worden. Bei Derrida stellt sich darüber hinaus die Frage, ob er als in Algerien geborener und aufgewachsener sephardischer Jude, dem zu Zeiten des Vichy-Regimes der Schulbesuch verweigert wurde, so einwandfrei als Repräsentant der dominanten, weißen und europäischen Position eingeordnet werden sollte. An diesem letzten Beispiel wird deutlich, dass die Dichotomie von okzidentalem und nicht-okzidentalem Wissen bzw. ihrer Autor_innenschaft oft gar nicht so leicht ist. Die ,Weißwaschung ' - also die Verschleierung der Herkunft aus kolonisierten Kontexten - von im Kanon angekommenen Autor_innen hat ebenfalls eine lange koloniale Tradition von Marie Curie über Rosa Luxemburg bis Freddy Mercury. Andersherum impliziert die Herkunft aus nicht-okzidentalen Kontexten nicht automatisch eine dekoloniale Perspektive.

Statt eines dichotomischen Verhältnisses zwischen okzidentalem und nichtokzidentalem Wissen bietet sich das Konzept der geteilten Geschichten (Conrad/Randeria 2002) an, in dem die Herkunft nicht ausgeblendet wird, aber dennoch das Entanglement verschiedener Kontexte und die Einschreibung der imperialen Dimension in den verschiedenen Kontexten deutlich gemacht wird. Spivak schlägt vor, die Aufklärung und die von ihr geprägten, hegemonialen Episteme gegen den Strich zu lesen. Mit Spivak kann das Erbe der Aufklärung und die von ihr geprägten Normen, wie die Menschenrechte, als „Pharmakon, als Gift und Arznei zugleich“ (Dhawan/Castro Varela 2020) verstanden werden. Die Aufklärung und die mit ihr verbundenen Normen und Strukturen müssen in ihrer kolonialen Verstrickung analysiert werden. Vor diesem Hintergrund teilt auch 
Spivak die Kritik Mignolos an der Vorstellung einer Vervollständigung des als unvollständig wahrgenommenen Projekts der Aufklärung im Sinne von Habermas. Aus der Sicht von Spivak ist das Verhältnis zur Aufklärung aber komplizierter als das einer simplen Ablehnung. Zur Beantwortung der Frage, was Aufklärung sei, führt sie an, dass diese Frage eher in geopolitischen als in kosmopolitischen Kategorien behandelt werden sollte (Ehrmann 2009: 94). Das Verhältnis der postkolonialen Theorie zur Aufklärung und ihr Erbe von Modernität, Säkularismus, Demokratie, Menschenrechte, Wissenschaft, Technologie und hegemoniale Sprachen konzipiert Spivak als einen double-bind. (Dhawan 2014a: 70) Sie argumentiert gegen ein kulturrelativistisches Vorgehen, das sich auf die Ablehnung der Aufklärung reduziert oder ihr eine ethnozentrische Suche nach einem ,reinen' nicht-, westlichen' Wissenssystem entgegenstellt. Stattdessen zielt Spivaks Vorgehen auf die Analyse des Entanglements 'westlicher" und nicht-,westlicher" Denkweisen (ebd.).

Sie bezieht sich auf ihre Vorlesung von 1992, wenn sie ihre Vorstellung beschreibt, zu lernen, die europäische Aufklärung von unten zu nutzen: "I suggested that we learn to use the European Enlightenment from below. I used the expression ,ab-use " because that latin prefix 'ab' says much more than below." (Spivak 2012b: 3) Mit ab-use meint sie keinesfalls abuse, sondern zielt auf die vielfältigen Bedeutungen des lateinischen Präfix $a b$ : "Indicating both ,motion away' and ,agency, point of origin', supporting as well as , the duties of slaves', it nicely captures the double bind of the postcolonial and the metropolitan migrant regarding the Enlightenment." (ebd.: 4) Da die Aufklärung sowohl zu den Kolonisierenden als auch zu den Kolonisierten durch den Kolonialismus kam - und zwar nicht als Ausnahme, sondern in der Regel als Herrschaftsinstrument und „top-down policy“ (ebd.), schlägt sie im Umgang mit der Aufklärung selbst einen epistemischen Wandel vor: "This distinguishes our efforts from the best in the modern European attempts to use the European Enlightenment critically, with which we are in sympathy, enough to subvert!“ (ebd.)

Aus ihrer Sicht sind auch die dekolonialen Kämpfe irreduzibel eng mit dem Erbe der Aufklärung verbunden. Spivaks Bezug zur Aufklärung stellt dabei nicht das Ziel des Delinking infrage, den ,westlichen ' Kanon grundlegend zu verändern. Aber aus ihrer Sicht ist das Erbe der Aufklärung - oder zumindest ein bestimmter Teil davon - etwas, das wir nicht nicht wollen können (Dhawan 2014a: 71). Um ihren strategischen Umgang mit dem Erbe der Aufklärung zu fassen, verwendet sie den Ausdruck der affirmativen Sabotage: „Affirmative Sabotage, nach der postkolonialen Feministin Gayatri Spivak, beruht auf einer Strategie, die die Instrumente des dominanten Diskurses in Werkzeuge für dessen Überschreitung verwandelt.“ (Dhawan 2014b) Die Nutzung von unten muss also das Gift in 
Medizin verwandeln (Dhawan 2014a: 71). Mit Bezug zu Audre Lorde fast Nikita Dhawan dies in folgendem Bild zusammen: "The challenge is to employ the master's tools to dismantle the master's house." (Dhawan 2014a: 71) Die Frage der Überschrift, also der Wahl zwischen Delinking und affirmativer Sabotage, sollte aus meiner Sicht mit einem eindeutigen Sowohl-als-auch beantwortet werden.

\title{
4.2.4.2 Überlegungen zu einem dekolonialen Lernen
}

\subsection{Dekolonialität in der Schule?}

María do Mar Castro Varela (2018) hebt in ihrer Diskussion einer postkolonial informierten Bildung darauf ab, dass die Reflexion über und die Transformation von der Institution des Lernens selbst Teil eines postkolonial motivierten epistemischen Wandel sein muss. In ihrem Text Imperiale Didaktiken. Unterrichten als Unterwerfungsmethode stellt sie ihre postkolonialen Überlegungen in den Kontext der Diskussionen um eine machtkritische Analyse von Schule und Unterricht. Ausgehend von Antonio Gramsci, Louis Althusser und Pierre Bourdieu diskutiert sie die Rolle von Schule, die sie als zentralen Teil der Herstellung von Hegemonie und hier insbesondere als Reproduktionsort der dominanten kulturellen und sozialen Verhältnisse ansieht. Mit Gramsci kann gesellschaftliche Herrschaft sich nicht nur und noch nicht mal hauptsächlich auf Zwang gründen, sondern braucht Hegemonie, was im berühmten Aphorismus Gramscis - Hegemonie, gepanzert mit Zwang - seinen bildhaften Ausdruck findet. In diesem Zusammenhang zitiert Castro Varela die Soziologen Pierre Bourdieu und Jean-Claude Passeron:

\begin{abstract}
„Jedes institutionalisierte Bildungssystem (IB) verdankt die spezifischen Merkmale seiner Struktur und Funktionsweise der Tatsache, dass es auf institutioneller Ebene die institutionellen Bedingungen mit der für die Institution üblichen Mittel (re)produzieren muss (Selbstreproduktion der Institution), die für deren Existenz und Fortbestehen notwendig sind. Dies gilt sowohl für die spezifische Form des Einhämmerns von Wissen (l'inculcation), die der Reproduktion einer kulturellen Willkür dient, dessen Produzent sie nicht ist (kulturelle Reproduktion) und die ebenso zur Reproduktion der Beziehungen zwischen Gruppen oder Klassen beiträgt (soziale Reproduktion).“ (Bourdieu/Passeron 1970: 70; übers. von und zitiert nach Castro Varela 2018: 59)
\end{abstract}

Eine Dekolonisierung der Schule als Ort des Lernens muss dementsprechend immer sowohl die kulturelle als auch die soziale Reproduktion in den Blick nehmen. Der Ausschluss von Wissen und Perspektiven trägt zur Naturalisierung von Ein- und Ausschlüssen, sozialen Hierarchien und Subjektivierungsprozessen bei. Und andersherum erlaubt die soziale Stratifikation die (Re-)Produktion der Hegemonie bestimmter Formen des Wissens, also der kulturellen Hegemonie. 
Als Beispiel führt sie an, dass in der Schule oft die Gewohnheit bestärkt würde, „Menschen als Dazugehörige und Nicht-Dazugehörige wahrzunehmen“, was einem „internalisierten Grenzregime“ entspräche, „,welches insbesondere Menschen, die im globalen Norden verortet sind, oft unbewusst regiert" (Castro Varela 2017). Dies gilt aber auch allgemeiner:

„In der Schule lernen wir nicht nur zu lesen und zu schreiben, sondern werden auch daran gewöhnt, den vorgesehenen Platz innerhalb der Gesellschaft als den wahren und mithin allein richtigen Platz wahrzunehmen und schließlich auch einzunehmen. Für einige bedeutet dies, die Unterwerfung zu akzeptieren und soziale Ungleichheit als natürlich gegeben zu akzeptieren. Schule erscheint wie eine feudale Enklave innerhalb eines demokratischen Systems, welches beständig verspricht, dass alle dieselben Chancen haben." (Castro Varela 2017)

So trügen viele selbstverständliche Praxen in der Schule dazu bei, dass gelernt würde, „Rassismus als selbstverständlich und wenig irritiert hinzunehmen“ (ebd.). Dabei wird Rassismus hier nicht als losgelöstes Phänomen verstanden, sondern in ein Verhältnis zu sozialen Ungleichheiten gesetzt. Castro Varela stellt heraus, dass die Subjekte, die Bildungsprozesse durchlaufen haben, am Ende „nicht einfach klüger sind, sondern in einer sehr klaren Art geformt worden sind“" (ebd.):

„Rassistisches Wissen wird gelernt. Und so werden nicht nur unterworfene Subjekte, sondern wird auch ein imperialistisches Subjekt hergestellt. Letzterem erscheint der Alltag nicht nur nicht als privilegiert, es hat auch gelernt, sich rassistisch abzugrenzen, ohne dies als gewaltvolle Praxis zu lesen.“ (Castro Varela 2017)

Karen Pashby (2016) formuliert in ihrer Kritik der Global Citizenship Education eine ähnliche Perspektive. Für sie sind die dominanten Formen und Inhalte der Beschulung (schooling) verstrickt mit der Produktion und Reproduktion von Kolonialismus. Für sie stellt Schule dabei ein widersprüchliches Feld dar. Einerseits sind die institutionalisierten Bildungsprozesse wesentlich daran beteiligt, dominante Differenzen herzustellen - wie beispielsweise zwischen ,zivilisiert ${ }^{*}$ und ,primitiv', ,West' und ,Ost', ,Erster' und ,Dritter" Welt. Diese Differenzen werden durch diese Bildungsprozesse naturalisiert. Andererseits war Bildung nie eine widerspruchsfreie Angelegenheit kultureller Übertragung. Wenn also Bildung koloniale Differenzen zwischen Menschen essenzialisieren kann, kann sie uns auch helfen, anzuerkennen, wie diese Differenz zum Nachteil so vieler Menschen konstruiert wurde. "Dominant ideologies are relayed through schooling at the same time that schools are a key institutionalized space for the potential deconstruction of colonial narratives." (Pashby 2016: 76). 
Diese Widersprüchlichkeit des Lernortes Schule stellt auch Castro Varela heraus. Aus ihrer Sicht kann Pädagogik und Bildung ,,sowohl ein Instrument der Hegemoniesicherung als auch eine Waffe der Gegenhegemonie sein" (Castro Varela 2017). Sie stellt in diesem Zusammenhang heraus, dass die (eingeschränkte) Handlungsmacht, die Bildungsprozesse eröffnen, dafür genutzt werden, ,gegen die eigene Subjektwerdung zu rebellieren.“ (Castro Varela 2017) Die Regeln einzuhalten würde allzu oft bedeuten, die ,hierarchischen gesellschaftlichen Verhältnisse unumwunden zu akzeptieren“ (Castro Varela 2017). Für politische Bildung kann dies im Sinne von Inclusive Citizenship (2.3.2) so verstanden werden, dass der Regelbruch die Frage des Politischen stellt, indem die Frage der (Nicht-)Zugehörigkeit aufgeworfen wird. Allerdings bleibt die Frage, wie ein Regelbruch zum Bildungsziel erklärt werden kann und wie das mit der Logik von Curriculum und Institutionalisierung von Didaktik einhergehen kann. Hier wird ein double bind sichtbar, der entsteht, wenn eine dekoloniale Perspektive institutionalisiert werden soll, wenn also das Politische im Sinne Rancières programmatisch für einen Bildungsansatz werden soll. Das Politische lässt sich nicht institutionalisieren. Es lassen sich aber Rahmenbedingungen und Ansätze schaffen, die den Raum für das Politische eher eröffnen als andere.

Ausgehend von Spivak beschreibt Castro Varela die Konturen eines auf einer postkolonialen Perspektive beruhenden Bildungsansatzes als ein Re-Arrangieren des Begehrens. In Spivaks Worten: „The world needs an epistemological change that will rearrange desires. Global contemporaneity requires it." (Spivak 2012b: 2) Es geht einer dekolonialen politischen Bildung nicht darum, eine neue Wahrheit an die Stelle der alten zu setzen. Ausgangspunkt müssen die Vorstellungen der Lernenden und - im Sinne von Castro Varela - Praxen des Regelbruchs sein. Zur Sichtbarmachung dieser und zur Reflexion über angemessene Strategien ihrer Stärkung kann ein Wissensarchiv gelten, das ich versucht habe als decolonial heritage zu beschreiben. Teil dieses Archives sind die Erfahrungen der sozialen Bewegungen und Intellektuellen ebenso, wie die Lernendenvorstellungen. Dieses Archiv ist chaotisch, vielfältig und widersprüchlich; dies muss es auch sein, denn seine Totalisierung würde den Subjekten vielmehr Gewalt antun, als zu ihrer Befreiung beizutragen. Wie ich gezeigt habe, besteht das vereinigende Element dieser Perspektive eher in einer Haltung, als einem geschlossenen Theoriegebäude (2.3.3.4). Ansätze einer dekolonialen politischen Bildung können kontextuell spezifische Vereindeutigungen vornehmen, jedoch niemals eine allgemeine Totalisierung von Wissen anstreben.

Eine dekoloniale politische Bildung muss auch die Dimension des Lernens und Lehrens reflektieren, um ihren Ansprüchen gerecht werden zu können. So schreibt Castro Varela: „Das Re-Arrangieren von Begehren ist mithin der 
bewusste Umgang mit der Gewalt, die von Erziehungsprozessen ausgeht bzw. ausgegangen ist.“ (Castro Varela 2016: 52) Sie stellt die Entwicklung didaktischer und pädagogischer Logik in einen Bezug zur Geschichte des Kolonialismus. Im 19. Jahrhundert entwickelte sich die Didaktik und Pädagogik zum einen durch die Logik einer Nationalisierung und zum anderen durch die koloniale Mission. Die Positionen der Wissenden und Unwissenden wurden vor diesem Hintergrund neu erschaffen, verhärtet und rassifiziert (ebd.).

\begin{abstract}
„Als Wissende wurden bekanntlich insbesondere weiße europäische Lehrmeister, in den Kolonien waren es häufig Missionare, imaginiert, während auf der anderen Seite die kolonisierten Schüler*innen als Träger*innen von ,dunklem Unwissen“ als die Anderen repräsentiert wurden. Die europäischen Kolonialmächte brachten, dem hegemonialen kolonialen Narrativ folgend, Wissen, Erleuchtung und Zivilisation in Territorien, die als in Unwissenheit getränkt beschrieben wurden.“ (Castro Varela 2018: 65)
\end{abstract}

Das pädagogische Verhältnis selbst erscheint so schon aus einer postkolonialen Perspektive als problematisch. Es gilt also nicht nur diejenigen Hierarchien und Differenzen zu problematisieren, die das in-der-Welt-Sein der Lernenden bestimmen, sondern auch diejenigen des Lernens und Lehrens selbst.

\title{
4.2.4.2.2 Das didaktische Verhältnis
}

Bereits der Befreiungstheologe Paulo Freire hatte - wie auch Castro Varela erwähnt - herausgestellt, dass eine befreiende Pädagogik bei der „Lösung des Lehrer-Schülerwiderspruchs“ einsetzen müsse, so dass ,,beide gleichzeitig Schüler und Lehrer" (2016: 52) werden. Die Spuren von Freires Denken finden sich auch in den Ansätzen des Bürgerbewusstseins (2.3.1) und Inclusive Citizenship (2.3.2). Freire kritisiert ein Verständnis von Bildung als Bankiers-Methode, nach der davon ausgegangen wird, dass die Lehrenden über das entscheidende Wissen verfügen, die Lernenden hingegen nicht und dann das zu übermittelnde Wissen quasi wie in einem vorher leeren Bankdepot anhäufen. Dieser Form setzt er das problemorientierte Lernen entgegen, in der die Lernenden als Subjekte gesehen werden, die sich gemeinsam mit dem Lehrenden, der dann selber zum Lernenden wird, mit der gesellschaftlich strukturierten Lebenswelt auseinandersetzen.

Linnemann, Mecheril und Nikolenko verstehen politische Bildung im Anschluss an Freire als ,Prozess einer kritischen Bewusstwerdung (conscientização) über gesellschaftliche Verhältnisse und die eigene Eingebundenheit darin mit der Perspektive der Veränderung hin zu weniger gewaltvollen Verhältnissen.“ (Linnemann/Mecheril/Nikolenko 2013: 10) Den Begriff des conscientização fasst 
Freire folgendermaßen: „Der Begriff conscientização bedeutet den Lernvorgang der nötig ist, um soziale, politische und wirtschaftliche Widersprüche zu begreifen und um Maßnahmen gegen die unterdrückerischen Verhältnisse der Wirklichkeit zu ergreifen." (Freire 1971: 29) Reflexion und Handlung werden bei Freire ebenso zusammengedacht wie der Zusammenhang von Sprache und Erfahrung. Die Versprachlichung von Erfahrung spielt eine große Rolle in Freires Denken, denn solange Erfahrung sprachlos bleibe, sei Sprache sinnlos und Erfahrung folgenlos. Ann Laura Stoler schlägt in diesem Kontext den Begriff der kolonialen Aphasie vor, der aus dem algriechischen in etwa mit Sprachlosigkeit zu übersetzen ist. Aus ihrer Sicht erscheint dieser Begriff treffender als die Begriffe Vergessen oder Amnesie und ist besser dazu geeignet ist, das problematische Verhältnis zur kolonialen Vergangenheit und der Kolonialität der Gegenwart zu fassen, da Aphasie sowohl die aktive Blockade als auch den fehlenden Zugang gleichzeitig thematisiert:

\footnotetext{
"Rather, calling the phenomenon colonial aphasia emphasizes both the loss of access and active dissociation. In aphasia, an occlusion of knowledge is the issue. It is not a matter of ignorance or absence. Aphasia is a dismembering, a difficulty in speaking, a difficulty in generating a vocabulary that associates appropriate words and concepts to appropriate things." (Stoler 2016: 128)
}

Eine dekoloniale politische Bildung müsste also darauf abzielen in kollektiven Lernprozessen zum einen die Sprachlosigkeit infrage zu stellen und zu problematisieren sowie zum anderen die Sprachlosigkeit zu überwinden und die Entwicklung eines Sprechens und einer Sprache über die Kolonialität und die eigene Einbindung in Herrschaftsverhältnisse zu befördern. Dies entspricht einem Bildungsbegriff, der Bildung als die subjektive „Aneignung und Transformation von Selbst- und Weltverhältnissen“ (Broden/Mecheril 2010: 11) versteht.

Sowohl Freire als auch Spivak machen deutlich, dass Bildung nie harmlos, unabhängig oder neutral sein kann. Die Nicht-Einbeziehung dekolonialer Perspektiven bedeutet de facto in der Regel die Übernahme kolonialer Muster (Castro Varela 2018: 69). Vor diesem Hintergrund erscheint die Forderung nach einer Neutralität der politischen Bildung als (herrschaftsstabilisierender) Mythos. Das von Spivak geforderte Lernen, von unten ' muss dabei mit einer aktiven Herausforderung der dominanten Episteme einhergehen, um auch alternative Perspektiven einen möglichen Platz in Bildungsräumen zu geben (Heinemann 2020: 207). Damit wird die Hierarchisierung innerhalb der „hegemonialen Wissensproduktion“ herausgefordert, die „bestimmtes Wissen als ,wissenschaftlich, legitim, wahr, notwendig, wissenswert" hervorhebt und andere als ,unwissenschaftlich, 
spekulativ, spirituell/Aberglaube, nice-to-have“" (ebd.) abwertet. Es geht auch um die Frage, welches Wissen als ideologisch abgetan - wie etwa rassismuskritische und dekoloniale Perspektiven (Dirim et al. 2016) - und welches Wissen als anerkannt und neutral - normalisiert und herrschaftsstabilisierend? - gilt; warum zum Beispiel diejenigen, ,die sich eine Welt ohne Grenzen vorzustellen wagen“, als „SpinnerInnen“ (Castro Varela 2015b) gelten, da die Grenzen und dazugehörige Konzepte wie etwa ,Kultur' und Zugehörigkeit unhinterfragt als natürlich, statisch und prinzipiell unveränderbar wahrgenommen werden. Damit einher geht die Frage der Curricula: „Welche Inhalte gelten als lehrens- und lernenswert, welche bleiben unberücksichtigt und wer bestimmt (nicht) darüber?" (Heinemann 2020: 207) Ebenso stellt sich die Frage danach, wer eigentlich die Lehrenden sind und warum sich hier so wenige ,aus marginalisierten gesellschaftlichen Gruppen“ (ebd.: 208) finden und was das für die Perspektivenvielfalt im Unterricht bedeutet.

Castro Varela stellt die Frage danach, wie nun aber eine dekoloniale Didaktik vorstellbar sei? Kann die von Comenius ausgehende Didactica Magna (1657) im Sinne einer affirmativen Sabotage für eine herrschaftskritische Unterrichtspraxis nutzbar gemacht werden? (Castro Varela 2018: 65) Didaktik stammt ethymologisch „,vom griechischen didáskein“ (ebd.). Dem Begriff Didaskein ( $\delta\llcorner\delta \alpha ́ \sigma \kappa \varepsilon \iota \nu)$ werden mehrere Bedeutungsebenen zugeschrieben, die möglicherweise helfen, verschiedene Formen des Lernens zu identifizieren. Im verbreitetsten Verständnis scheint hier das Lernen dem Lehren untergeordnet. Im Aktiv bedeutet es im Altgriechischen ,lehren, belehren, unterrichten ' und im Passiv ,lernen, unterrichtet werden, sich belehren lassen' (Meueler 2009: 976). Im dritten, dem medialen Genus bedeutet Didaskein ,aus sich selbst lernen, ersinnen, sich aneignen, sich selbst ein Lehrer sein“ (ebd.). Während die ersten beiden Ebenen eher eine Herstellungsperspektive bezüglich des Lernens verhaftet bleiben, schließt die dritte Ebene an die Überlegungen von Bildung als Aneignung von Selbst- und Weltverhältnissen und der Problematisierung des Verhältnisses von Lernenden und Lehrenden an.

Folgen wir nach diesem kurzen etymologischen Exkurs wieder dem Argument Castro Varelas, müssen wir uns die Frage stellen, wie ,die europäischen Unterrichtsdidaktiken zu dekolonisieren“ und wie ,ein hegemoniekritisches Unterrichten vorstellbar" ist, dass den Status quo nicht stabilisiert, sondern herausfordert? Eine dekoloniale politische Bildung zielt dabei nicht auf Indoktrination der Lernenden in eine neue , dekoloniale ' Wahrheit, sondern vielmehr auf die Ermöglichung einer Infragestellung der dominanten, kolonialen Episteme. Als einen Gedankenstrang verfolgt Castro Varela hier die Methode des Universalunterrichts, die von Jean Joseph Jacotot im 19. Jahrhundert erfunden und 1987 von Jacques Rancière in seinem Buch Der unwissende Lehrmeister wieder aufgegriffen wurde. 
Die ebenso simple wie radikale Ausgangsidee ist dabei, dass alle am Lernprozess beteiligten Subjekte gleich an Intelligenz sind. In dominanten Vorstellungen von Didaktik wird eine hierarchische Lücke zwischen den lehrenden Wissenden und den lernenden Unwissenden konstruiert. Das hieraus resultierende didaktische Verständnis ist das der Vermittlung und Erklärung. Jacotots Ansatz zielt dabei darauf $a b$, dass sich die Lernenden von den Lehrenden emanzipieren und ihre Wissensaneignung selbst in die Hand nehmen. Ein solches Verständnis von Lernen nimmt den Subjektstandpunkt der Lernenden ernst, was auch bedeutet, dass der didaktische Input nicht mit dem Output gleichgesetzt werden kann. Im Zentrum steht das Subjekt, dessen Lernprozess als ein begründetes Handeln verstanden werden kann. Lernräume haben in diesem Sinne die Funktion, Lernenden die Möglichkeiten zu geben, zu erkennen, inwiefern die Auseinandersetzung oder die Aneignung von bestimmten Lerninhalten die eigenen Handlungsspielräume erweitert, was beinhaltet, dass Lernräume einen Raum geben, eigene Lernziele für sich selbst zu entwickeln und zu reflektieren. Castro Varela fordert in diesem Sinne, das didaktische Wissen mit der Tatsache und den Konsequenzen der Kolonialität zu konfrontieren und didaktische Ansätze „affirmativ zu sabotieren, um das klassische Lernen zu verlernen und Raum zu schaffen, neue Lernvorstellungen zu generieren" (Castro Varela 2018: 12).

Hier stehen zwei Ansprüche einer dekolonial politischen Bildung in einem Spannungsverhältnis. Einerseits geht es dabei um eine radikale Demokratisierung im Sinne des unwissenden Lehrmeisters, andererseits zielt eine dekoloniale politische Bildung auf einen Bruch mit den Epistemen der Kolonialität, die sich tief in das Denken, auch das der Befreiung eingeschrieben hat. Diese Spannungsverhältnisse sind weder als Widerspruch anzusehen noch lassen sie sich einfach auflösen. Es führt uns zurück zu einem meiner Ausgangspunkte, nämlich, dass Ausgangspunkt für eine dekoloniale politische Bildung die Vorstellungen der Lernenden sein müssen und ihre Handlungsmacht im Zentrum stehen muss. In der Analyse der Lernendenvorstellungen habe ich zahlreiche dekoloniale Momente gefunden, die Ausgangspunkte einer solchen Praxis darstellen können. Ebenso oft habe ich aber koloniale Momente gefunden, deren Irritation durch didaktische Interventionen nötig sein könnten. Deutlich ist aber auch geworden, dass die Frage von der (Re-)Produktion kolonialer oder dekolonialer Momente in den Lernendenvorstellungen unabhängig ihres institutionell anerkannten Bildungsgrads erfolgte. Dekoloniale politische Bildung verläuft aus meiner Sicht quer zur Position in der schulischen Hierarchie. Dekoloniale politische Bildung ist dem Anspruch nach radikal demokratisch: „To educate as the practice of freedom is a way of teaching that anyone can learn.“ (bell hooks 1994: 13) Dekoloniale politische Bildung 
bedeutet nicht, Spivak zu lesen, sondern die Regeln zu brechen, die die kolonialen Episteme vorgeben.

Wenn Bildung Räume schaffen will, solche widerständigen Praxen zu ermöglichen, muss - im Anschluss an Spivak - die Komplizenschaft von Bildung mit der Herstellung der herrschenden Verhältnisse anerkannt werden: „In order to find a way out of this double bind, those who teach will have to develop [...] , an itinerary of agency in complicity “" (Dhawan/Castro Varela 2009). Eine dekoloniale Didaktik muss die Verstrickung von Bildungsprozesse mit dem (neo-)kolonialen Projekt reflexiv in den Blick nehmen. Das Re-Arrangieren von Begehrensstrukturen als ein Moment von Bildung zu denken zielt nicht zuletzt auch darauf, die subjektivierende Funktion von Bildungsprozessen mitzudenken. Begehren ist hier keine natürliche und auch keine per se sexualisierte Kategorie, sondern vielmehr eine soziale Kategorie, die mitdenkt, dass Diskurse und Bildungspraxen Subjekte mit bestimmten Begehren hervorbringt. „Bildung bringt die Subjekte der Bildung hervor, die durch eine spezifische Begehrensstruktur beschreibbar sind. Wenn wir Bildung als Subjektivierung lesen, dann ist diese ermächtigend und unterwerfend zugleich. Sie produziert und unterwirft die Subjekte." (Castro Varela/Heinemann 2016: 19) Die Perspektive auf das Re-Arrangement der Begehren zielt somit auch auf einen „,bewussten Umgang mit der Gewalt“, die von Bildungsprozessen ausgeht.

\subsection{Unlearning one's privilege as one's loss}

Die Episteme, die ich in den Vorstellungen der Schüler_innen ko-konstruiert habe, können als geteilte beschrieben werden. Sie beziehen sich alle auf einen verbindenden Raum der Schule, den sie als Schüler_innen teilen (share). Gleichzeitig sind sie insofern geteilt (divided), als dass einige Vorstellungen koloniale und andere dekoloniale Momente aufweisen. Diese Teilung in koloniale und dekoloniale Vorstellungen korrespondiert dabei nicht geradlinig mit der Subjektposition der Schüler_innen, also der Frage, ob sie innerhalb der kolonialen Matrix als relativ privilegiert oder deprivilegiert anzusehen sind. Gleichzeitig scheint immer wieder ein Zusammenhang zwischen der Position und der Positionierung (2.2.3.5) auf, insbesondere wenn es um die Perspektive von Migrations- und Rassismuserfahrung geht, beispielsweise bei der Kategorie der Farbe als Zugehörigkeitsmarker (3.3.3) oder der Agency von Geflüchteten (3.4.4). Regina Richter thematisiert zu Recht, wie unterschiedlich verschieden positionierte Schüler_innen von kolonial strukturierten Unterrichtsinhalten betroffen sind.

„Was macht das etwa mit (dem Geschichtslernen) einer Schwarzen Schülerin, wenn ihr überall rassistische (und sexistische) Geschichtspräsentationen begegnen, wenn 
Schwarze Menschen nicht oder nur einseitig und negativ dargestellt werden, wenn ihr immer wieder vermittelt wird, dass sie anders und nicht zugehörig ist, oder dass sie keine Geschichte hat? Oder wenn andersherum ein weißer Schüler meist Erfahrungen macht, die seine Besserstellung und sein Dazugehören im Vergleich zu anderen als normal bestätigt?"“ (Richter 2017: 23)

Um bei dem Beispiel zu bleiben: Als weiß gelesene Menschen passiert dies nicht. Die weiße Subjektposition wird derart naturalisiert, dass , wir' lernen, Weißsein als eine solche Selbstverständlichkeit zu internalisieren, dass es möglich - und eher die Regel als die Ausnahme - ist, nicht einmal wahrzunehmen, dass es ,in einer rassistischen Gesellschaft ein unglaubliches Privileg ist, weiß zu sein" (Castro Varela 2017). Dabei schützt die weiße Subjektposition vor unzähligen schmerzhaften Erfahrungen: ,ausgegrenzt zu werden; unhöflich befragt und ausgefragt zu werden; Angst zu haben in Räumen, die andere als neutral beschreiben würden; beschämt und verlacht zu werden; nicht bedient zu werden ..." (ebd.). Als quasi transparente Erfahrung wird die Privilegierung im Alltag zunächst nicht spürbar. Erst im aktiv hergestellten Kontrast zu den Alltagerfahrungen Schwarzer Menschen und People of Color wird deutlich, dass „Weißsein nicht die normale Position ist, sondern eben die privilegierte" (ebd., Herv. i. O.). Diese Haltung der Privilegierten gegenüber kolonialen Machtverhältnissen bezeichnet Spivak auch als sanktionierte - im Sinne von hegemonial gebilligte und Herrschaft legitimierende - Ignoranz (,sanctioned ignorance“, Spivak 2012: 175). Die Unsichtbarkeit der Privilegien geht dabei damit einher, sich rassistisch abzugrenzen, rassistische Unterscheidungspraxen zu vollführen - und das, „ohne dies als gewaltvolle Praxis zu lesen“ (Castro Varela 2017). Da rassistisches Wissen gelernt werden muss, können diese Subjektivierungen unterworfener Subjekte ebenso wie „imperialistischer Subjekt[e]“ (ebd.) als Ergebnisse von Lernprozessen angesehen werden.

Vor diesem Hintergrund wurde das Konzept des Verlernens entwickelt. Castro Varela sieht Bildung als einen Vorgang an, der „Lernen und Verlernen in einem Zusammenhang" (ebd.) sehen sollte. Dekoloniale Bildung schließt also nicht einfach eine Informations- oder Wissenslücke, sie adressiert auch die sanktionierte Ignoranz. Diese Ignoranz, die mitunter sozial belohnt wird, besteht in der Ausblendung der machtvollen Effekte der Kolonialität und dadurch entstehender Privilegien, wie etwa durch rassistische Zugehörigkeitsregime, die Selbstverständlichkeit der Ungleichwertigkeit des Lebens, die Ausblendung oder Naturalisierung der Ausbeutung der Menschen des Globalen Südens oder der migrantischen CareArbeiter_innen oder Gemüse- und Fleischproduzent_innen im Globalen Norden usw. In der Einleitung zum Spivak Reader paraphrasieren Donna Landry und 
Gerald Maclean eine Idee Spivaks mit folgendem Satz: „unlearning one's privilege as one's loss“ (1996: 4). Verlernen bestimmen sie als die kritisch-reflexive Aufarbeitung der eigenen Geschichte, der Vorurteile und der gelernten, aber nun als instinktiv erscheinende Denkformen (ebd.). „If we can learn racism, we can unlearn it, and unlearn it precisely because our assumptions about race represent a closing down of creative possibility, a loss of other options, other knowledge." (ebd.) Sie stellen heraus, dass anzunehmen ist, dass wir, wenn wir Spivak lesen, relativ gesehen, in Bezug auf Bildungschancen und unsere Verortung innerhalb der internationalen Arbeitsteilung privilegiert sind.

Spivak formuliert den Imperativ, sich mit ihren oder seinen Privilegien auseinanderzusetzen, durchaus auch als ethische oder politische Verantwortlichkeit, zum Beispiel als die "responsibility not to take advantage of the sanctioned ignorance of the West" (Spivak 2012c: 175). Oft wird das Verlernen von Privilegien als ein Verlust erlebt, eine Art mildtätigem Abgeben von Privilegien aufgrund von einer moralischen Verpflichtung. Spivak will mit ihrem Argument, die eigenen Privilegien als Verlust zu erleben, nicht die den Privilegien zugrunde liegende Ungleichheit und Ungerechtigkeit klein reden. Doch sie dreht die Perspektive einer Mildtätigkeit um, mit der die Privilegierten implizit auch als überlegen konstruiert werden. Sie stellt heraus, dass - worin auch immer unser Privileg gründet, „race, class, nationality, gender, and the like“ (Landry/Maclean 1996: 4), es immer auch eine epistemische Beschränkung impliziert, indem es uns anderes Wissen und andere Perspektiven verstellt: "not simply information that we have not yet received, but the knowledge that we are not equipped to understand by reason of our social positions." (ebd.) Gleichzeitig und damit verbunden verhindert die privilegierte Positionierung dialogische Beziehungen zu den anderen, nicht oder weniger privilegierte Positionen einnehmenden Subjekten.

So beschrieb Spivak die Option, dass sich ihre weißen, männlichen Studierenden - diese Fokussierung in meinem Text steht mit Sicherheit in einem Zusammenhang zu meiner eigenen Positionierung - ebenso die Frage stellen können, was ihr Sprechen verhindert, wenn sie beispielsweise durch einen begrenzten Aufstieg von Feminismus oder Rassismuskritik dieses Gefühl der Begrenztheit der eigenen Perspektive bekommen. Es klingt ein wenig ironisch und ist doch auch ernstgemeint, wenn Landry und Maclean schreiben: "I am only a bourgeois white male, I can't speak." (ebd.: 5) Dies kann ein Ausgangspunkt für eine selbstreflexive Praxis des Verlernens darstellen, die nicht - oder zumindest nicht in erster Linie - durch Scham bestimmt ist (vgl. Castro Varela/Heinemann 2017). Mit Bezug zu Spivak schreiben Landry und Maclean: "Why not develop a certain degree of rage against the history that has written such an abject script for you that you are silenced?" (Landry/Maclean 1996: 5) Die Arbeit des Verlernens der 
eigenen Privilegien sehen sie als möglichen Beginn einer ethischen Beziehung zum Anderen (ebd.; vgl. dazu 4.2.4.4). Das Beispiel verdeutlicht, die simple und doch weitreichende Einsicht, dass jede - und nicht nur die der Marginalisierten oder Veranderten - Subjektposition ,mit einer spezifischen, immer auch eingeschränkten Handlungsmacht" (ebd.) einhergeht. Das Ziel des Verlernens besteht dann darin, sich dieser Subjektposition bewusst zu werden, sich uns also als ,historisch gewordene Subjekte vorzustellen, die Teil gesellschaftlicher Verhältnisse sind und in diesen distinkte Positionen einnehmen" (ebd.). Gleichzeitig bedeutet aber die Einsicht in die historische Gewordenheit auch, die Veränderbarkeit dieser Machtstrukturen zu erkennen.

Alisha Heinemann hat jüngst darauf aufmerksam gemacht, dass sich Spivak später selbst vom Konzept oder zumindest dem Begriff des Verlernens wieder abgewandt hat, ,denn zu oft sei der Begriff missinterpretiert worden, nämlich so als wäre es tatsächlich möglich, Privilegien einfach durch einen (Ver-)Lernprozess abzulegen" (Heinemann 2020: 213). Heinemann weist darauf hin, dass der Ansatz des Verlernens nicht darauf abzielt, die Privilegien abzulegen, sondern sich mit der Geschichte der Privilegien zu beschäftigen, ,also zu wissen, woher diese stammen, auf wessen Kosten sie gehen und sie so einzusetzen, dass sie dazu beitragen, die gelebte Gegenwart gerechter zu machen, [...] für die Subalternen des globalen Südens, aber auch die Marginalisierten der westlichen Metropolen“ (ebd.). Darüber hinaus stellt eine - ständige und anstrengende - Praxis des Verlernens der eigenen Privilegien, die als Verlust erlebt werden, aus meiner Sicht aber eine Voraussetzung dafür dar, sich der Möglichkeit zu nähern, Beziehungen und Allianzen zu entwickeln, die sich nicht an die Platzzuweisungen der Kolonialität der Macht halten. „Die Praxis des Verlernens“, schreibt María do Mar Castro Varela in diesem Sinne, ist „aufs Engste mit der Praxis des Regelbrechens verwoben“ (2017).

\subsubsection{3 Überlegungen zu einer ethisch-epistemischen Dekolonialität}

\subsection{Verunsicherung, Politik, Utopie?}

Die koloniale Ordnung formt und platziert Subjekte, erschafft Trennlinien und Differenzen und erschafft die Fiktion einer natürlichen Ordnung der Welt. In den dargestellten Ansätzen klingt es manchmal, als würden die institutionalisierten Bildungsprozesse dies zustande bringen - und als würde dementsprechend eine dekoloniale Bildung die lernenden Subjekte befreien müssen. Damit wird aber die Wirkung von Bildungsprozessen maßlos überschätzt. Dies gilt auch für die Subjekte, deren Prozess der Anrufung eben nicht wie bei Althusser im Sinne der Herrschaft reibungslos vonstattengeht, in der also eine Entsprechung von 
Anrufung und Subjektivierung unterstellt wird, sondern - hier folge ich Butler (1997) - vielmehr immer schon als ein performativer Prozess der Verschiebungen, Umdeutungen, Transformationen und des Widerstands anzusehen ist. Unterricht ist ein wichtiger Faktor für die lernenden Subjekte, aber - wie auch Castro Varela schreibt, unterrichten ist ,machtdurchzogen, aber [...] nie als ein Feld ungebrochener Indoktrination zu sehen" (Castro Varela 2018: 69). Die zahlreichen dekolonialen Perspektiven, die ich in den Vorstellungen der Schüler_innen kokonstruiert habe, zeigen dies. Diese dekolonialen Vorstellungen scheinen jedoch größtenteils eher trotz als aufgrund der formalisierten Bildungsprozesse im Kontext Schule vorhanden zu sein. Die Handlungsmacht der Lernenden steht dabei im Zentrum dekolonialer Didaktiken. Spivak - und mit ihr auch viele anderen Ansätze in post- oder dekolonialen Theorien - bietet kein fertiges Rezept für die pädagogische Unterstützung zur Entwicklung von Handlungsfähigkeit. Ziel einer dekolonialen politischen Bildung ist es dabei jedenfalls nicht, literaturwissenschaftlich studierte Dekonstruktivist_innen zu schaffen, sondern die Aneignung von Selbst- und Weltverhältnissen der Lernenden zu unterstützen, die dazu beitragen, die Kolonialität zu untergraben, zu problematisieren oder gegen sie zu intervenieren - sowohl praktisch als auch theoretisch, auch wenn diese Trennung nicht weit trägt.

Spivak zufolge stellt sich die Frage für Bildung, wie es gelingen könne, ,einen schlafenden ethischen Imperativ [...] [zu] aktivieren“ (Spivak 2008b: 48). In den Lernendenvorstellungen hat sich gezeigt, dass dieser Imperativ gar nicht - zumindest nicht flächendeckend - so schlafend zu sein scheint. Einige Lernende artikulierten Vorstellungen, die offen für dekoloniale Perspektiven sind bzw. schon selber dekoloniale Ansätze darstellen. Die Aufgabe dekolonialer politischer Bildung besteht nun nicht darin, diese Ansätze dafür zu nutzen, die Lernenden zu guten Konvertit_innen dekolonialer Theorien zu machen; diese Ansätze also als Einfallstor für die Hegemonisierung einer neuen, dekolonialen Wahrheit anzusehen. Dekoloniale Bildung muss vielmehr einen Raum schaffen, in welchem eine gemeinsame Sprache entwickelt werden kann, ein kontextspezifisches dekoloniales Imaginäres zu erschaffen.

In Verbindung, aber keinesfalls deckungsgleich, mit der Frage des angedeuteten Spannungsverhältnisses von selbstreflexiver und interventionistischer Fokussierung sehe ich ein Spannungsfeld von zwei Momenten, die die post- und dekolonialen Ansätze durchziehen: Das Moment der Veruneindeutigung und der Vereindeutigung. Veruneindeutigung kann insofern als ein dekoloniales Bildungsziel verstanden werden, als es darum geht, eingeübte, normalisierte Narrative, Weltbezüge, ,kulturelle` Differenzen, (Nicht-)Zugehörigkeiten, Grenzen, Subjektpositionen, die neokoloniale Geburtsrechtslotterie oder andere Ungleichheiten 
ihrer Selbstverständlichkeit sowie den diesen Phänomenen zugrunde liegenden Ordnungen, Platzzuweisungen und Zuschreibungen ihrer Eindeutigkeiten zu berauben. Es geht um die radikale Infragestellung der kolonialen Ordnung der Dinge, des Wissens und der Subjektivierungen, ohne eine bereits bekannte, alternative , bessere' Ordnung an ihrer statt zu propagieren. Die didaktische Strategie der Veruneindeutigung kann oft mit dem Gefühl der Verunsicherung einhergehen, das dadurch hervorgerufen werden kann, dass bisher sicher geglaubte Weltund Selbstverhältnisse ihrem epistemischen Fundament beraubt werden und eine Neuorientierung notwendig wird. Dies trifft insbesondere auf relativ privilegierte Lernende zu, die der Partikularität ihrer eigenen Perspektive und der Komplizität mit kolonialen Strukturen gewahr werden. Verunsicherung kann vor diesem Hintergrund durchaus als Bildungsziel verstanden werden.

Demgegenüber - und gleichzeitig irreduzibel damit verstrickt - steht die Vereindeutigung als dekoloniales Bildungsziel. Eine Infragestellung der Kolonialität, also die Dekolonisierung des Wissen und Denkens, der Subjektivierungsweisen oder der gesellschaftlichen Machtverhältnisse erfolgt ja nicht im Einvernehmen, sondern stößt unweigerlich auf Widerstand, bei sich selbst, bei anderen oder der Institution. Mit meiner Lesart von Césaire (2.3.3.4) kann das dekoloniale Erbe weniger als eine geschlossene Tradition oder ein Wissenssystem verstanden werden, sondern entsteht im Kern durch eine Haltung, die sich beispielsweise durch Verweigerung oder Kritik auszeichnet. Dies verweist auf die irreduzible Dimension des Politischen in dekolonialer politischer Bildung. Mit Rancière gesprochen braucht es den Streit oder vielmehr seine Subjektivierung. Mignolo schreibt für die Dekolonialität: „Identität auf der Grundlage von Politik, aber keine Politik auf der Grundlage von Identität.“ (Mignolo 2006: 188) Ich wäre hier vorsichtig mit dem Begriff der Identität und schlage den Begriff der Subjektivierung vor, die sich durch die Zuspitzung des Streits, durch den Ruf nach Gleichheit herstellt, der die koloniale Matrix der Ungleichheit herausfordert. Während also die Strategie der Veruneindeutigung auf Ambivalenzen abzielt, schafft die Strategie der Vereindeutigung einen Antagonismus. Wenn beispielsweise eine Schulklasse gegen die Abschiebung einer Mitschülerin protestiert, dann kann dies die Form eines Antagonismus - als eine Form des Politischen der Dekolonialität - annehmen. Hier ist die Form des Antagonismus verhältnismäßig offensichtlich, die sich in der Solidarität mit der Mitschülerin gegen die koloniale Entrechtung wendet. Oft stellt sich der Antagonismus aber weniger eindeutig und fassbar dar. Aber auch ,abstraktere" dekoloniale Praxen, die sich mit dem epistemischen Wandel beschäftigen, brauchen dieses Moment des Widerständigen, in welchem Subjekte sich einen gemeinsamen Sprechort erarbeiten, um ,nein!' zu sagen und sich der Kolonialität zu widersetzen. 
Mit Spivak kann die Frage der Vereindeutigung mit dem Begriff des strategischen Essenzialismus diskutiert werden. In Anlehnung an ihre Texte kann das hier beschriebene Spannungsfeld zwischen Veruneindeutigung und Vereindeutigung als das Spannungsfeld zwischen Dekonstruktion und Praxis artikuliert werden, wobei auch hier wieder hervorzuheben ist, dass dieses Verhältnis keines des Widerspruchs ist. Politische Praxis braucht einen gewissen Grad an Essentialismus und ,Identität', um einen - zumindest vorübergehend - festen Grund zu haben, von dem aus die Kolonialität herausgefordert werden kann: "So long as the critique of essentialism is understood not as an exposure of error, our own or others', but as an acknowledgement of the dangerousness of something one cannot not use." (Spivak 1989: 5) Diese Art der Schließung (Essenzialismus) konzipiert sie also gleichzeitig als etwas, dass man sowohl nicht nicht nutzen kann als auch als Gefahr. Dabei plädiert sie immer wieder dafür, das strategische Moment nicht aus den Augen zu verlieren: „The strategic use of essentialism can turn into an alibi for proselytizing academic essentialism. The emphasis then inevitably falls on being able to speak from one's own ground, rather than matching the trick to the situation, that the word strategy implies." (ebd.: 4) Die Handlungsmöglichkeiten sind für Spivak immer durch einen double bind charakterisiert. In dem Moment aber, wo wir entscheiden, also handeln, - und aus ihrer Sicht müssen wir handeln - verwandeln wir den double bind in einen single bind: „When and as we decide, we know therefore that we have broken the double bind into a single bind, as it were, and we also know that change will have to be undertaken soon, or, things will change: task or event." (Spivak 2012b: 11) Handlung, Intervention, Entscheidung - wir können das nicht nicht wollen. Dabei unterscheidet sich aus Spivaks Sicht eine kritische, postkoloniale Perspektive von Perspektiven der globalisierungsbefürwortenden und -kritischen Akteure der globalen Elite. Während letztere durch eine unhinterfragte Hoffnung gesteuert werden, macht sich erstere der Kontingenz und Widersprüchlichkeit des eigenen Handelns bewusst und dieses dementsprechend mit einer selbstkritischen emotionalen Haltung, die diese Entscheidungen begleitet, ,decisions - ethical, political, legal, intellectual, aesthetic, and indeed decisions of the daily grind" (Spivak 2012b: 11).

Dabei spielt auch die Frage der geteilten Perspektiven eine Rolle. In der Analyse der Lernendenvorstellungen hat sich ergeben, dass die Perspektiven zu einem gewissen Grad als geteilte (divided) erscheinen, dass zum Beispiel oft - nicht immer - negativ von Rassismus Betroffene eine kritischere Haltung einnehmen, die als Ausgangspunkt dekolonialer Bildungsprozesse dienen können. Gleichzeitig haben oft relativ privilegierte Lernende diese Perspektiven dethematisiert, wie beispielsweise die Existenz von Rassismus in der eigenen Lebenswelt (3.3.3). Während die Strategie der Veruneindeutigung auf die Sichtbarmachung, 
die Besprechbarmachung, die Intelligibilität dieser Unterschiede der Subjektpositionen zielt, hebt die Strategie der Vereindeutigung potenziell diese Unterschiede temporär in der Subjektivierung des Streits auf. Anschließend an die Überlegungen zum Verlernen der eigenen Privilegien, die als Verlust erfahrbar werden, kann dies eine Teilung im Sinne von share erlauben. Dabei stehen die beiden Strategien nicht separat nebeneinander, sondern in einem Verhältnis, das ich zunächst als Spannungsverhältnis benannt habe, das aber gleichzeitig auch ein Verhältnis der gegenseitigen Bedingtheit darstellt. Eduardo Galeano fasste dies in folgende Worte: "Every promise is a threat, every loss a discovery. Courage is born of fear, certainty of doubt. Dreams announce the possibility of another reality, and out of delirium emerges another kind of reason." (Galeano 1989, zitiert nach Andreotti 2011a: 396).

Das Politische der Dekolonialität verweist dabei auf ein Universales. Die Strategie der Veruneindeutigung hält dieses Universale dabei davon ab, sich zu totalisieren, es in seiner strategischen Essenzialisierung zu denken, indem es auf die Kontextualität, also die Partikularität jedes politischen Universalen, verweist. Das Konzept der Pluriversalität (Mignolo 2007: 452 ff.), dieser spezifischen begrifflichen Verbindung von Pluralität und Universalität, kann hier als Konzept dienen, um das Universale in seiner Grenzenlosigkeit und Begrenzung gleichzeitig zu denken. Die temporäre Aufhebung des Spannungsverhältnisses des geteilten Wissens als shared und divided ist dabei nicht einfach in einem neuen Universalen aufzuheben, denn die in einem kollektiven Prozess hergestellte Provinzialisierung der privilegierten und universalisierten Perspektive und die damit einhergehende Reflexion der Teilung (divide) des Wissens stellt die Bedingung der Möglichkeit eines geteilten (shared) dekolonialen Imaginären dar. Was in dekolonialen Perspektiven immer mitschwingt, ist Etwas, das ich ein utopisches Moment nennen würde; ein imaginärer Horizont, der am Rande des Denkens, eine Art bewussten oder unbewussten Fluchtpunkt bildet. Gerade wenn wir dekoloniale Bildung im Anschluss an Spivak als das Re-Arrangieren von Begehren ansehen, braucht es diese Dimension des Utopischen. Die lernenden Subjekte, die auf die Dekolonisierung zielen, werden dabei nicht nur von Verunsicherung, Unzufriedenheit oder Wut angetrieben, sondern auch von Träumen und Hoffnung.

Nikita Dhawan und María do Mar Castro Varela heben hervor, dass allerdings jedes politische Ziel rekuperiert und dabei ihre Absicht pervertiert werden kann. Auch zunächst dekoloniale Lösungen können in die Herrschaft reintegriert werden. Oder um es mit Spivak zu sagen: "This particular solution, offered as liberal education as such, suits capitalism better." (Spivak 2012b: 10) Bildung muss vor diesem Hintergrund vorsichtig damit sein, festgeschriebene Lösungen zu präsentieren, sondern vielmehr das kritische, unabhängige und potenziell widerständige 
Denken zu stärken: "Education should not be about preaching to the converted, but about encouraging people to think independently, capable of disagreement." (Dhawan/Castro Varela 2009) In ihrem Ansatz der ästhetischen Bildung (aesthetic education) schlägt Spivak in diesem Sinne vor, dass Bildung auf die Erweiterung der Vorstellungskraft zielen sollte, die es dem Subjekt erlaubt, zu spielen und praktisch oder theoretisch die Prämissen der Haltung zu (ver)lernen, die es nötig erscheinen lässt, die Kolonialität zu transzendieren (Spivak 2012b: 10). Um einen Bruch oder einen grundlegenden Wandel der kolonialen Episteme zu erreichen, weist Spivak aber darauf hin, dass dies langwierige Prozesse sind, die nicht einfach durch didaktische Geschicklichkeit der Lehrenden zu erreichen sind: "If, however, this is only a 'rearrangement of desire' or the substitution of one habit for another through pedagogical sleight-of-hand, there will be no ability to recover that discovery for a continuity of epistemological effort." (Spivak 2012b: 10).

Vor dem Hintergrund der möglichen Rekuperation und der grundlegenden und langfristigen Bildungsprozesse, die für einen epistemischen Wandel nötig sind, erscheint es nötig, dass sich eine dekolonial ausgerichtete Fachwissenschaft der Didaktik der politischen Bildung selbst als Teil der dekolonialen Theoriebildung begreift. „My postcolonial lens would also like to see in this 'decolonial global citizenship' a commitment to ongoing critical engagement with decolonial theory itself." (Andreotti 2011a: 395) Andreotti problematisiert die Realisierung dekolonialer Bildungsprozesse angesichts der gegenwärtigen Ausrichtung der institutionalisierten Bildungspraxen. Ihre Einschätzung, die sich auf den kanadischen Kontext bezieht, gilt aus meiner Sicht auch für Deutschland:

\footnotetext{
„How to develop a teacher education programme around this is a different (and more problematic) matter as it will need to respond to institutions that more than often require fast, predictable and easily measurable outcomes that provide a sense of immediate reward and satisfaction to 'client-learners' (and the kind of education I am talking about does not fit such scripts very easily).“ (Andreotti 2011a: 395 f)
}

Mit Spivak formuliert sie diese Schwierigkeit, indem sie darauf hinweist, dass es nie Garantien gibt. „Although there are some safeguards in the ideas outlined here against absolute
relativism and identity politics, there is still a risk of territorialising difference and
homogenising modernity if educators adopt a half-baked, simplified version of it
(which is a serious possibility given the increasing instrumentalist drive in education).“
(ebd.: 395 ) 
Im gegenwärtigen Bildungssystem besteht immer die Gefahr, einer problematischen Umsetzung - und dieser müssen wir uns bewusst sein. Dafür gibt es kein Rezept, sondern vielmehr nur die Hoffnung und die endlose Auseinandersetzung mit den Widersprüchen in der Welt und in der Bildung. Eine dekoloniale politische Bildung zielt auf eine Erneuerung der Curricula. Mindestens ebenso entscheidend erscheint aber ein grundlegender Wandel in der Ausbildung angehender Lehrer_innen sowie der Weiterbildungsprogramme. Eine solche selbstreflexive und gleichzeitig interventionistische Praxis bedarf umfangreicher und zeitintensiver Bildungsprozesse.

\subsection{Imperative zur Neu-Erfindung des Planeten}

Im Folgenden werde ich den Konturen dekolonialer Überlegungen zur Ethik von Spivak nachspüren. Dies soll nicht als Grundlegung , der ' dekolonialen Ethik missverstanden werden. Es ist vielmehr eine mögliche Spur, ein Streifzug, der auch als eine Art Übung im Denken eines ethisch-politischen Imaginären zu verstehen ist. Es wären hier ganz andere Zugänge möglich. In ähnlicher Weise wäre es möglich, an dieser Stelle ein anderes Beispiel für eine mögliche ethischpolitische Überschreibung eines kolonialen Konzepts zu wählen. Ein anderes Beispiel wäre - ich will dies nur kurz andeuten - der Kulturbegriff von Homi Bhabha, der für eine dekoloniale Bildung eine entscheidende Rolle spielen könnte (Andreotti 2011b). Entgegen eines kolonialen Begriffsverständnisses von ,Kultur' definiert Bhabha Kultur ausgehend von der Erfahrung der Marginalisierung durch die Kolonialität als ,einer ungleichmäßigen, unvollendeten Produktion von Bedeutung und Wert [...], die sich oft aus miteinander unvereinbaren Forderungen und Praktiken zusammensetzt, wie sie aus dem Akt des sozialen Überlebens hervorgehen" (Bhabha 1994: 256). Vanessa Andreotti sieht hier mit Bezug auf de Souza einen Kulturbegriff, der nicht statisch oder essenzialistisch, sondern hybrid, dynamisch und produktiv ist, und der Kultur von einem Nomen zu einem Verb umschreibt. Dieses Verb verweist dabei auf eine Überlebensstrategie, die (a) transnational ist, dabei aber die Spuren der diversen Erfahrungen und Erinnerungen der Verwerfungen (dislocations) mit sich trägt, und die (b) translational ist und damit eine Umdeutung (re-signification) der hegemonialen ,kulturellen“ Repräsentationsformen verlangt, die die gängige, koloniale Überdeterminierung von ,Kultur' durch eine homogenisierendes und totalisierendes Imaginäres der ,Kultur` unterläuft (Andreotti 2011b). Im Folgenden werde ich aber der von Spivak vorgetragenen Spur des Planetarischen folgen.

Ethik wird hier nicht als moralisches Programm, sondern vielmehr als irreduzibel verwoben mit Politik und epistemischer Hegemonie verstanden. Spivaks 
epistemisch-ethischer Vorschlag zielt darauf, unser in-der-Welt-sein neu zu verstehen. „Im Zeitalter der galoppierenden Globalisierung schlage ich also vor, den Globus mit dem Planeten zu überschreiben“ (Spivak 1999b: 45) Der Globus steht für sie, für eine Welt, deren Sein sich durch fortschreitende kapitalistische Finanzialisierung der Beziehungen und die konstitutive Rolle des (kolonialen) Anderen auszeichnet. Dabei ist dies eben nicht die einzig denkbare Form, das in-der-Welt-Sein zu denken:

\begin{abstract}
„Der Globus ist auf unserem Computer. Doch niemand lebt auf ihm, und wir machen uns vor, daß wir diese Form der Globalität beherrschen. Der Planet hingegen steht im Zeichen der Alterität, er gehört einem anderen System an; und doch bewohnen wir den Planeten, sozusagen auf Kredit. Der Planet eignet sich nicht für einen genauen Gegensatz zum Globus. Man kann nicht sagen , andererseits ... ““(Spivak 1999b: 45)
\end{abstract}

Der Planet steht hier als die radikale Infragestellung, einer radikal anderen Sichtweise auf die Welt als der Globus. Gleichzeitig kann dies nicht als diametraler Gegensatz angesehen werden. Mir erscheint das Verhältnis von Globus zu Planet ähnlich wie das Verhältnis zwischen Kolonialität und Dekolonialität. Dekolonialität entsteht in der Unterwanderung von Kolonialität; es hat unabhängig von ihr kein feststehendes System, keine festgeschriebene Alternative. Gleichzeitig ist es auch nicht als dialektische Negation zu verstehen, in der das Andere nur aus dem Eigenen entsteht. Inspiriert von der Dekonstruktion Derridas und der Ethik des Anderen von Levinas steht im Zentrum von Spivaks Überlegungen der Begriff der Alterität. Spivak bezieht dies nun sowohl auf ein Anderes der Zukunft, auf eine andere Zukunft, die sich im Planetendenken andeutet, als auch in Bezug auf die Alterierten der Globalisierung:

„Bis vor kurzem war das markanteste Beispiel solch epistemischer Gewalt das von Ferne orchestrierte, weit gespannte und heterogene Projekt, das koloniale Subjekt als Anderen zu konstituieren. Dieses Projekt umfasst auch die asymmetrische Auslöschung der Spur jenes Anderen in dessen prekärer Subjektivität.“ (Spivak 1999a: 265)

Planetendenken besteht demgegenüber im unaufhörlichem Versuch, den Anderen ${ }^{29}$ als Anderen denken zu lernen.

\footnotetext{
${ }^{29}$ Es ist wohl meiner sprachlichen Unfähigkeit oder der Unmöglichkeit der Übersetzung geschuldet, dass ich hier eine gendergerechte Sprache nicht realisieren kann. ,The Other ist auf Englisch nicht gegendert. Eine Übersetzung in ,die Anderen“ oder ,die_der Andere“ würde die Mehrdeutigkeit des Wortes aufheben, das sowohl auf die konkreten Anderen als
} 
Sie bezieht dies konkret auf die Veranderten der Globalisierung: Um ,sowohl den Migrant als auch den Empfänger von Entwicklungshilfe“ denken zu können, müssen ,wir' den Anderen denken und auf ,den Anderen intendiert sein“ (Spivak 1999b: 45 f.).

\begin{abstract}
„Wenn wir uns als planetische Subjekte anstatt als globale Akteure imaginieren, als planetische Lebewesen anstatt globale Einheiten, so kann Alterität kein Derivat von uns selber darstellen oder als unsere dialektische Negation verstanden werden, sondern umfängt uns im selben Maße wie sie uns wegschleudert - und somit ist dieses Denken immer schon eine Übertretung." (ebd.: 47)
\end{abstract}

Ein solches Verständnis des Anderen sei die Voraussetzung, um ,uns“ in die Lage zu versetzen, ,sowohl Migranten als auch den Empfänger von Entwicklungshilfe im Zeichen der Alterität zu denken, und nicht nur als die Bürde des weißen Menschen, wie es Kipling tut" (ebd.).

Was bedeutet es nun im Sinne Spivaks, den Anderen als Anderen zu denken? Dieser Frage werde ich nachgehen, indem ich ausschließe, wie der Andere im Sinne der Kolonialität unsichtbar gemacht wird. Spivak führt Derridas Kritik an Sartre an, an dessen, also Sartres, ,persönlichem wie politischen guten Willen“ (Spivak 1999a: 177) kein Zweifel bestünde:

„,Alles geschieht als habe das Zeichen ,Mensch“ keinerlei Ursprung, keinerlei historische, kulturelle oder sprachliche Grenze.' Wenn man in ,keiner [der Entwürfe des Menschen] bleibt mir völlig fremd ' $[. .$.$] die rhetorische Spur Roms betrachtet, dann$ erkennt man in der Tat, dass die hier ausgelöschte Geschichte die der Arroganz des radikalen europäischen humanistischen Bewusstseins ist, das sich selbst konsolidieren wird, indem es den Anderen imaginiert bzw., mit Sartre gesprochen, durch das Sammeln von Informationen ,in sich den Entwurf des Anderen nachgestaltet'." (ebd.)

Obwohl Sartre sich gegen den Kolonialismus engagiert, erscheint seine Konzeption dem eurozentrischen Humanismus verhaftet, in der letztlich die ,Ethik der Alterität zur Politik der europäischen Identität“" (Spivak 1999b: 85) wird. Alterität wird zur „,bloßen Ergänzung“ (ebd.) des globalen, dem Eurozentrismus verhafteten Narrativs. In Bezug auf die migrationsgesellschaftlichen Verhältnisse in EUropa sei es unter diesen Voraussetzungen ,fast unmöglich vom Gedanken über die Geberfunktion Europas abzukommen“ (ebd.). „Die Gedanken kreisen immer um die Idee von kosmopoliteia. Diese Form des Überlegenheitsdenkens geht nicht

auch die Alterität als solche verweist. Diese Unstimmigkeit zieht sich leider auch durch die nächsten Absätze. 
mehr an." (ebd.) Dies ist auch als eine Kritik an Kants Begriff des Weltbürgertums zu lesen, in die der Andere erst durch die Auslöschung seiner Andersheit eintreten kann, durch welche er dann gleichzeitig zum Menschen wird. Vor diesem Hintergrund schlägt sie vor, der ,Alterität innerhalb eines planetischen Schreibsystems einen angemessenen Namen, anstatt eines kontinentalen Metonyms“ (ebd.: 87) zu geben.

Dieser Name kann nicht ,Kultur' sein:

"If those of us who direct dissertations and teach future teachers still peddle something called 'culture' on the model of national-origin validation (crucial to the undergraduate curriculum), we have failed to grasp the moment of the merging dominant, to rend time with the urgency of justice." (Spivak 2012d: $154 \mathrm{f}$ )

Das Wort ,Kultur ${ }^{6}$ - in all seinen zuschreibenden und homogenisierenden Funktionen - bezeichne in der kolonialen Rationalität ,"Verhaltensmuster jenseits der Vernunft“ und schließt damit von der ,Vernunft als solcher“ (Spivak 1999b: 51) aus. Nach Spivak wird die ,,multikulturelle Erziehung“ in den USA in zwei Kategorien aufgeteilt: ,Erziehung zur Tradition und Erziehung für die Moderne“ (ebd.: 77). Dies entspricht der falschen Alternative zwischen ,Moderne" und ,Tradition", ,Universalität' und ,Kultur'. Spivak beschreibt dies auch als ,Zwickmühle zwischen eurozentrischer Arroganz und unhinterfragtem Nativismus“ (Spivak 1999a: 179). Das Planetische kann sich weder durch das eine, noch durch das andere herstellen, sondern vielmehr genau durch die ungelöste Zwickmühle: „Eigentlich (und sehr praktisch) ist eine Zwickmühle in weit weniger gefährlicher Weise ermächtigend als die Unilateralität gelöster Dilemmata.“ (ebd.) Statt der kulturalisierenden Logik schlägt Spivak vor, sich ,,unsere eigene Heimat als auf dem Planeten eingeschrieben“ vorzustellen, „so wie wir es in den Schulstunden über Astronomie taten“ (ebd.: 87). „In einer solchen gebrochenen Sichtweise der Ethik könnte Raum das Merkmal der Alterität sein. Nicht Zeit, auch nicht Nation, Mutter, oder visage als Intentionalität.“ (ebd.) Dies lese ich als Kritiken an den ethischen Ansätzen von Levinas und Derrida. Spivak folgt ihnen hier darin, dass sie Ethik nicht als ,freiwillige und individuelle Entscheidung des autonomen, freien und vernünftigen Selbst“ (Ehrmann 2009: 93) konzipiert, sondern das Selbst als immer schon durch andere, durch den Anderen konstituierte. In diesem Sinne versteht sie Ethik als Beziehung des Ich zum Anderen nicht als „,selbstmotiviertes politisches Kalkül - , das Richtige tun““ - sondern als „Offenheit gegenüber der imaginierten Handlungsfähigkeit der Anderen“ (Spivak 2008b: 39). Die Kritik besteht hier darin, dass sie einfordert, die kosmopolitische durch eine geo-politische Dimension zu ersetzen. Um das Denken des Planetischen zu 
ermöglichen, um planetisches Verantwortungsdenken zu ermöglichen, bedarf es der Anerkennung, ,in globale Verflechtungen und Machtasymmetrien eingebunden zu sein, die die Komplizenschaft der von der Transnationalität Privilegierten beinhaltet" (Ehrmann 2009: 94). Mit Spivak ist es also notwendig, in die teilweise machtvergessenen Diskurse ,um kosmopolitische Demokratie oder Gerechtigkeit und transnationale Verantwortung und Solidarität“ (ebd.) zu intervenieren. „If there is one item on our agenda it is to think of geo-political rather than cosmopolitical answers to the question ,What is enlightenment?"“ (Spivak 1992, zit. nach Ehrmann 2009: 94).

Das Planetarische impliziert also eine Reflexion des Kolonialen und der geopolitischen Machtverhältnisse sowie die Transzendierung der nationalen und kapitalistischen Logik. Das Globale definiert Spivak demgegenüber als eine Form „sanktionierte[r] Ignoranz“, als hegemonial gebilligte und Herrschaft legitimierenden Dethematisierung dieser Herrschaftsdimensionen: „Was dort im Spiel ist, ist das Phänomen einer sanktionierten Ignoranz, die heutzutage mehr denn je sanktioniert wird durch die Beschwörung der ,Globalität' (die Funktion dieses Wortes besteht darin, die Finanzialisierung des Globus zu verdecken) [...].“ (Spivak 1999a: 171) Spivak sieht das Denken dieser Globalität auch in gesellschaftskritischen Diskursen: ,[...] ein großer Teil der sogenannten kulturübergreifenden disziplinären Praxis, [...] [reproduziert] koloniale Strukturen [...] (eine sanktionierte Ignoranz sowie die Verweigerung eines Subjekt-Status und damit von Mensch-lichkeit); [...]." (Spivak 1999a: 173) Dies sind zwei zentrale Elemente, die nach Spivak entscheidend für koloniale Macht sind: Die sanktionierte Ignoranz sowie die Verweigerung des Subjektstatus.

In Bezug auf den Subjetstatus der Anderen hebt sie sie hervor, dass es nötig ist, die kolonialen Episteme zu unterlaufen. In der Tradition der Dekonstruktion und in Bezug auf Bildung denkt sie dies beispielsweise als transnational literacy.

„Learning the praxis, that may produce interruptions to capitalism from within, requires us to make future educators in the humanities transnational literate, so they can distinguish between the varieties of decolonization on the agenda, rather than collapse them as 'postcoloniality'. I am speaking of transnational literacy.“ (Spivak 2012d: 152)

Transnational literacy meint dabei, den Anderen nicht nur als Stimme zu sehen, sondern ebenfalls als artikulierendes Subjekt, das selbst, genau wie ,wir', durch Texte geformt wird. Als Beispiel führt sie an, dass, wir ${ }^{\circ}$ lernen müssten, andere Episteme als solche lesen zu lernen, statt diese, wie im Fall von Literatur von native americans darin nur ein vormodernes, ethnisiertes Anderes des kolonialen Imaginären sehen zu können (ebd.). Dabei geht es ihr nicht darum, dass jetzt alle 
Expert_innen in Literaturwissenschaften werden müssen: „We must remember that to achieve literacy in a language is not to become expert in it. I am therefore not making an impossible demand upon graduate curriculum." (ebd.) Vielmehr geht es ihr darum, eine epistemische Haltung zu ändern und zu trainieren.

Dabei findet sich im Anschluss an den vorherigen Abschnitt die Idee, das Planetarische als eine Art Subjektivierung des Streits um die Episteme - im Sinne eines strategischen Essenzialismus - zu konzipieren:

„Ich schlage also vor, daß sich sowohl der dominante als auch der untergeordnete Teil der Menschheit gemeinsam als von einer planetischen Alterität intendiert und sich als von ihr gleichsam aufgerufen neu denkt, obwohl dieses Denken und Handeln sich von unterschiedlichen ,kulturellen' Perspektiven her artikuliert. Was hier neu ist, ist, daß dieser dominante Teil sich neu definiert, um von , unten “ her Lernen zu lernen. " (Spivak 1999b: 79)

Dieser dominante Teil - dies ist bei Spivak kein synonym für weiß und bezieht immer auch die internationale Arbeitsteilung im Kapitalismus mit ein - muss dabei nicht nur Vorstellungswelten verlernen, um andere Perspektiven erlernen zu können, sondern auch sein Verhältnis zum Anderen muss sich insofern ändern, als dass es den Anderen in seiner Subjektivität anerkennt und lernt, lernen zu wollen. Im Planetendenken erscheint die Freiheit der Anderen als die Bedingung der eigene Freiheit. Das Begehren der Dekolonialität zielt darauf, zu lernen, den Anderen in seiner radikalen Gleichheit und radikalen Alterität gleichermaßen denken zu lernen und Beziehungen aufbauen zu können, die nicht nur durch die Floskel der „nicht hierarchischen Gleichheit“ (ebd.) getragen sind. Kurz: „Ich spreche von einem Imperativ, das Subjekt als planetisch zu denken.“ (ebd.: 49) „Planetarisierung“ bestimmt Spivak dementsprechend als eine Strategie der „Eindämmung der Globalisierung" (ebd.: 83) und die Erfindung unterbrechender Praxis aus unserer sich entwickelnden Hoffnung. „Die Auswirkung davon wäre ein Ablenken des rationalen Imperativs einer kapitalistischen Globalisierung; die Dialogik in einer Auseinandersetzung mit diesen Widersprüchen zu verschieben.“ (ebd.)

Im Wiederlesen eines Konzept aus islamischen Schriften mit Bezug auf Mahmood Mamdani greift sie das Konzept des Haq auf, das sie als die ,paraindividuelle strukturelle Verantwortung, in die wir geboren werden" (ebd.: 55), versteht und von dem ausgehend sie ein Denken von Verantwortung und Recht oder vielmehr ein Verantwortung-als-Recht (er)findet. Mit diesem Ansatz will Spivak die in der kolonialen Aufklärung begründete Trennung zwischen Verantwortung und Recht aufheben. Durch die Kritik dieses Widerspruchs von Verantwortung und Recht kritisiert sie die Begrenzung einer Perspektive, die in 
der Sprache von Rechten die Einhegung des kolonialen Kapitalismus anstreben. Dabei zitiert sie Marx, wenn sie sagt, dass diese Rechte ,in der Lage sind, ein Gegengewicht zur Wirtschaft zu bilden, welches im Namen von individuellen Rechten die ganze soziale Realität ins gleißende Licht des Marktes und der Administration rückt“ (Marx, zit. nach Spivak 1999b: 61). Zur weiteren Darstellung des Aufgreifens, wie Spivak Haq aufgreift, möchte ich eine letzte Passage von Spivak zitieren und kommentieren. Dabei profitiere ich davon, dass ihre abgedruckte Rede Imperatives to Re-Imagine the Planet im Buch sowohl im englischen Original als auch in der deutschen Übersetzung abgedruckt ist. Anhand der letzten Passage kann ich auch auf die Unmöglichkeit von Übersetzung verweisen, da ich Spivaks englischen Text ganz anders verstehe, als es der Übersetzer getan hat. Hier das Zitat:

"I am simply suggesting that, without an education into an epistemic transformation whose most efficient description I happen to find in haq, capital - industrial and finance - cannot be persistently checked and turned around to the interest of the social as practically laid out in the Marxian passage, which has not grown old." (Spivak 1999b: 75)

In der Übersetzung wird education mit Erziehung übersetzt. Dies ist irreführend, da dekoloniale Bildung - auch im Verständnis von Spivak - nichts mit Indoktrination, Überzeugung oder Disziplinierung zu tun hat, sondern als ein Ort des freien Denkens über die Unfreiheit. Es gibt aber auf Englisch keinen Begriff für Bildung. Diese „Erziehung“ ziele dem Übersetzer zufolge auf eine „epistemische Änderung“" (ebd.: 76). Eine Änderung klingt nach einer leichten Korrektur, wie das Kürzen einer Hose in der Änderungsschneiderei. Spivak zielt aber auf eine radikale Transformation der Episteme, auf denen sich die Kolonialität der kapitalistischen Globalisierung aufbaut. Ihr geht es nicht darum, beispielsweise im Sinne von Attac eine Steuer auf Finanztransaktionen durchzusetzen, sondern die Hegemonie der Kapitalform infrage zu stellen. In diesem Sinne ist auch der Ausdruck „Finanzmarkt“ in Bezug auf meine Leseweise (reading) von Spivak irreführend, da es mit Marx um das Finanzkapital geht, was nicht das gleiche ist. Der Übersetzer schreibt, ,daß Kapital [...] ohne die Erziehung zu einer epistemischen Änderung [...] nicht ständig eingedämmt, sondern für das gesellschaftliche Interesse verwendet werden kann“ (ebd.). Ich lese Spivak als Marxistin aber vielmehr so, dass es ihr darum geht, das das planetarische Verantwortlichkeitsdenken, das sie hier mit Haq zu beschreiben versucht, die Voraussetzung dafür darstellt, das Kapital in das Interesse des Sozialen umzuwandeln, da sie vorher in ihrer Rede gezeigt hat, dass es dem Kapital strukturell eigen ist, nicht auf das Soziale, 
sondern auf die Kapitalakkumulation - und mit ihr globales Wirtschaftswachstum und die koloniale Globalisierung - zu zielen. Mit Haq wird es also denkbar, die auch von zivilgesellschaftlichen Organisationen unhinterfragten Rahmen des Kapitals zu transzendieren, statt eine Eindämmung der Effekte einer die koloniale Differenz reproduzierenden Struktur zu versuchen.

Im Anschluss führt Spivak ihr Verständnis von Haq weiter aus:

"I am further arguing that this social practice of responsibility based on an imperative imagined as intended from alterity cannot today be related to any named ground - as in Kant or Islam. This is where educating into the planetary imperative - assuming and thus effacing an absolute and discontinuous alterity and thus comfortable with an inexhaustible diversity of epistemes - takes its place." (Spivak 1999b: 75)

Der planetische Imperativ muss vom Anderen her gedacht werden. Alterität wird aber nicht im Sinne Kants als eine Vorform des Eigenen objektiviert, sondern in seiner potenziellen Subjektivität, die eben auch Willen und Handlungsmacht „,intended“ - umfasst. „Absolute und diskontinuierliche Alterität“ erscheint dabei als Voraussetzung einer auf den planetischen Imperativ zielenden Bildung nach Spivak, die gleichzeitig durch diesen Prozess ausgelöscht wird. Eine solche, auf den planetischen Imperativ zielende Bildung nach Spivak zielt dabei darauf, sich mit der unerschöpflichen Vielfalt von Epistemen wohl zu fühlen, statt Angst vor ihr zu haben. Es geht dabei weder um die Behauptung einer ,kulturellen Äquivalenz“, in der alle historischen Unterschiede in einer „Isomorphie von Sprachen und Kulturen" aufgehoben werden, noch um eine Essenzialisierung ,kultureller Unterschiede“, die „direkt ins Lala-Land des kulturellen Relativismus führen würde" (Spivak 2008a). Im Zuge einer (gelingenden) Bildung zum planetischen Imperativ erscheint vielmehr ein gemeinsames, verbindendes dekoloniales Imaginäres am Horizont, ohne dabei die Unterschiede in einem hegelianischen Sinne aufzuheben. Dabei geht es Spivak nicht um den Begriff des Planeten selbst. Eine solche Bildung und ein solcher Imperativ können viele Namen haben. Der Begriff Planet ist dabei nicht aus sich selbst heraus besser als der Begriff Globus. Diese dekonstruktive Praxis des Lesens kann vielmehr als eine mögliche Strategie, vielleicht auch ein Spielen oder ein Üben, eines dekolonialen, epistemischen Wandels und einer dekolonialen Ethik/Politik gesehen werden. 
Open Access Dieses Kapitel wird unter der Creative Commons Namensnennung 4.0 International Lizenz (http://creativecommons.org/licenses/by/4.0/deed.de) veröffentlicht, welche die Nutzung, Vervielfältigung, Bearbeitung, Verbreitung und Wiedergabe in jeglichem Medium und Format erlaubt, sofern Sie den/die ursprünglichen Autor(en) und die Quelle ordnungsgemäß nennen, einen Link zur Creative Commons Lizenz beifügen und angeben, ob Änderungen vorgenommen wurden.

Die in diesem Kapitel enthaltenen Bilder und sonstiges Drittmaterial unterliegen ebenfalls der genannten Creative Commons Lizenz, sofern sich aus der Abbildungslegende nichts anderes ergibt. Sofern das betreffende Material nicht unter der genannten Creative Commons Lizenz steht und die betreffende Handlung nicht nach gesetzlichen Vorschriften erlaubt ist, ist für die oben aufgeführten Weiterverwendungen des Materials die Einwilligung des jeweiligen Rechteinhabers einzuholen. 